
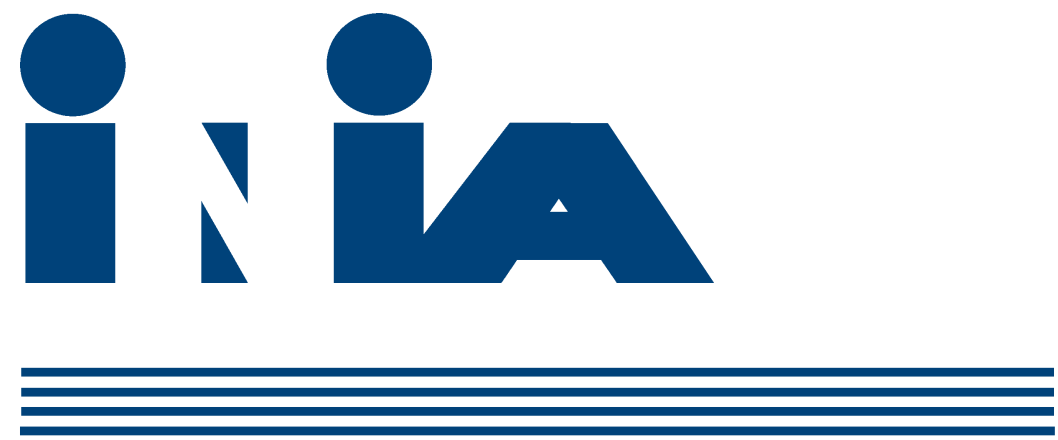

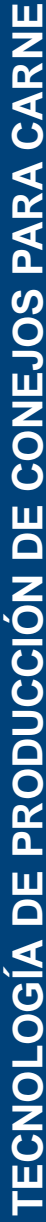

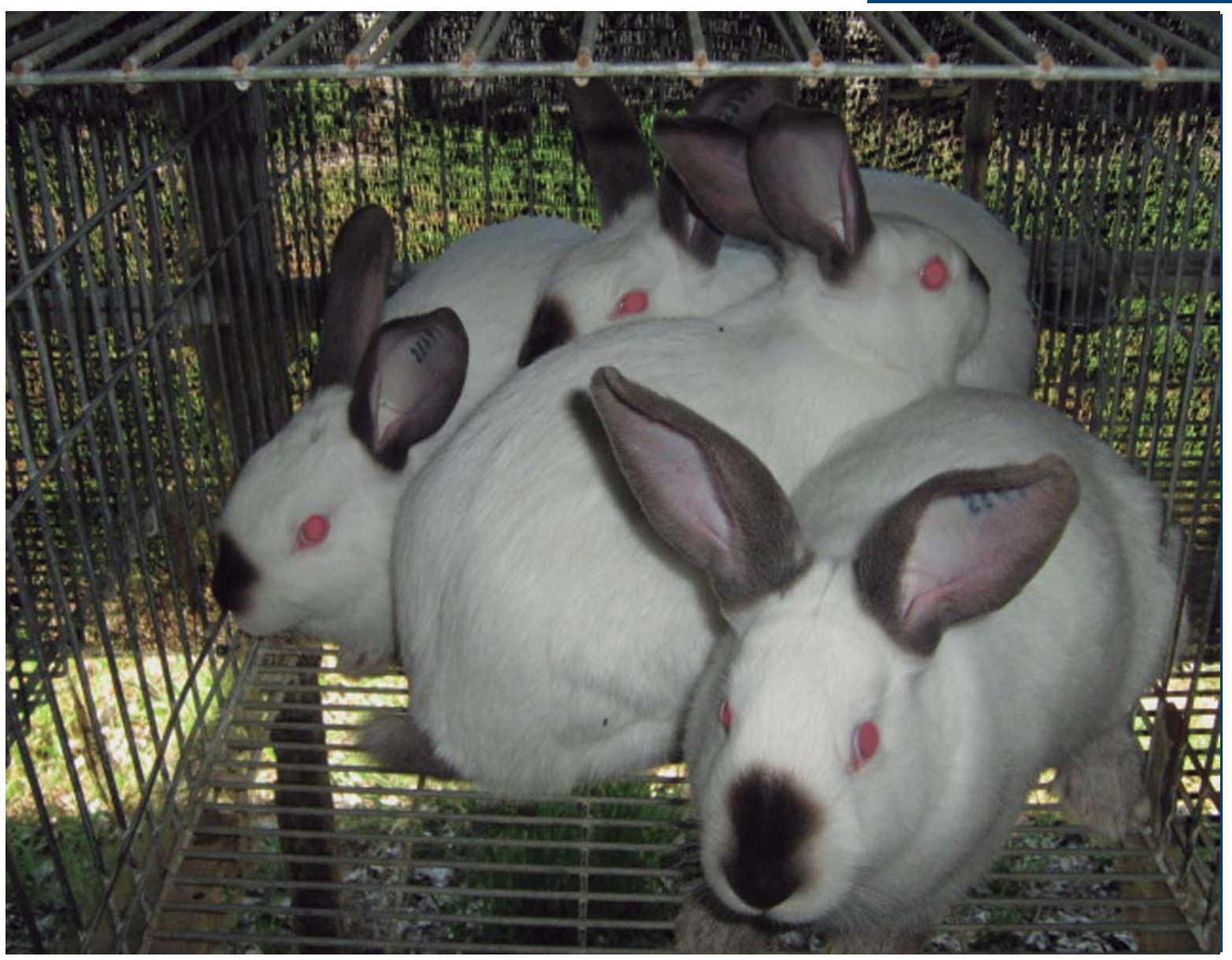

TECNOLOGÍA DE

PRODUCCIÓN

DE CONEJOS PARA CARNE

\begin{abstract}
INSTITUTO NACIONAL DE INVESTIGACIÓN AGROPECUARIA
\end{abstract}

URUGUAY

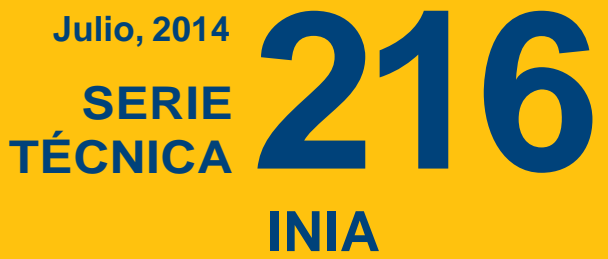




\title{
TECNOLOGÍA DE PRODUCCIÓN DE CONEJOS PARA CARNE
}

\author{
Editor: Gustavo Capra* \\ Oscar Blumetto**
}

Ing. Agr., Msc, Programa Nacional de Investigación Carne y Lana, Programa Nacional de Producción Familiar. INIA Las Brujas.

** Ing. Agr., PhD, Programa Nacional de Investigación Carne y Lana, Programa Nacional de Producción Familiar. INIA Las Brujas. 
Título: TECNOLOGÍA DE PRODUCCIÓN DE CONEJOS PARA CARNE

Editor: Gustavo Capra
Oscar Blumetto

Serie Técnica $N^{\circ} 216$

(C) 2014, INIA

Editado por la Unidad de Comunicación y Transferencia de Tecnología del INIA Andes 1365, Piso 12. Montevideo - Uruguay

http://www.inia.uy

Quedan reservados todos los derechos de la presente edición. Esta publicación no se podrá reproducir total o parcialmente sin expreso consentimiento del INIA. 


\section{I nstituto Nacional de I nvestigación Agropecuaria}

\section{Integración de la Junta Directiva}

Ing. Agr., MSc., PhD. Álvaro Roel - Presidente

D.M.T.V., PhD. J osé Luis Repetto - Vicepresidente

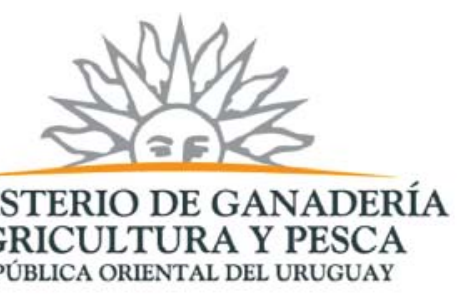

D.M.V. Álvaro Bentancur

D.M.V., MSc. Pablo Zerbino
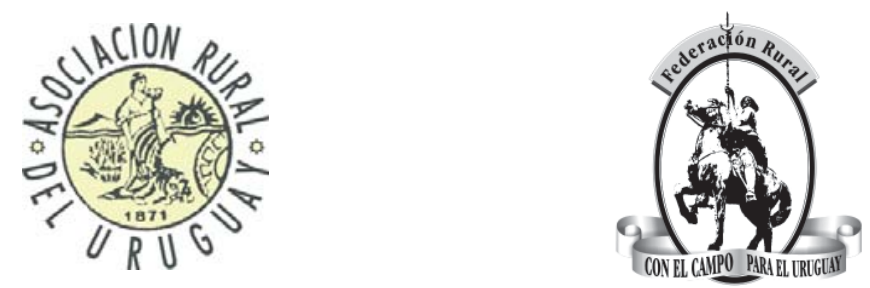

Ing. Agr. J oaquín Mangado

Ing. Agr. Pablo Gorriti
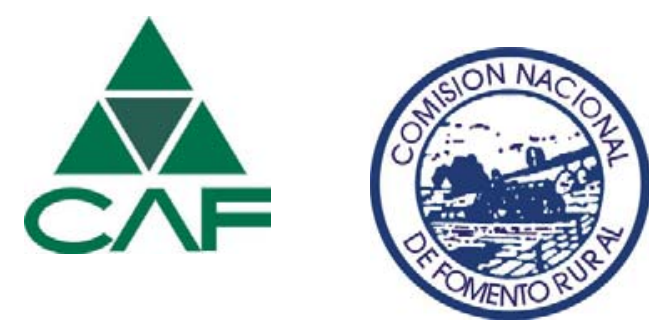


\section{CONTENIDO}

Página

Mejora genética del conejo de carne. La experiencia española

Manuel Baselga' Agustín Blasco, María A. Santacreu

Mejora genética del conejo de carne. La experiencia Uruguaya

Gabriel Ciappesoni, Oscar Blumetto, Gustavo Capra

Reproducción: aspectos fisiológicos y de manejo en la cunicultura

Claudio Scapinello

Técnicas y manejo reproductivo del conejo

José S. Vicente, Raquel Lavara, María P. Viudes de Castro, Francisco Marco Jiménez

Algunos conceptos sobre la nutrición del conejo para carne

María Elena Cossu

Utilización de forrajes frescos en la dieta de los conejos

Gustavo Capra

Efecto del número de conejos por jaula sobre el desempeño productivo

en la fase de crecimiento y terminación

Gustavo Capra

Valor nutritivo de la carne de conejo y su potencial como alimento funcional

María Elena Cossu, Gustavo Capra

Investigaciones en calidad de carne de conejo en INIA Uruguay

Gustavo Capra

Climatización y calidad ambiental en cunicultura.

Fernando Estellés y Salvador Calvet

El bienestar animal y sus bases etológicas en la cunicultura comercial

Arantxa Villagrá

Las instalaciones y equipos en cunicultura y su interacción con el esquema de manejo productivo

Oscar Blumetto 


\section{PRESENTACIÓN}

Esta publicación de la Serie Técnica de INIA reúne información científica y tecnológica para la producción de conejos para carne, como aporte al trabajo de los técnicos y los productores que procuran el desarrollo de la cunicultura en el Uruguay y en la región Sur del continente americano.

Intentamos resumir los principales elementos que configuran la propuesta tecnológica desarrollada por INIA para el sector cunícola uruguayo, basada en un proceso de generación, adaptación y validación, en el que el apoyo de la cooperación técnica internacional y el trabajo conjunto con otras instituciones permitieron importantes logros.

Si bien la mayor parte de la información tecnológica generada en estos años se encuentra disponible en diversas publicaciones y en el sitio web de INIA, esta Serie Técnica es el fruto de un esfuerzo por organizarla y sistematizarla, enriqueciéndola con aportes de especialistas. Está animada de una fuerte orientación práctica, tendiente a facilitar la interpretación por parte del técnico y la aplicación por parte del cunicultor.

Participan en esta obra colectiva, investigadores de diferentes centros académicos de España, Argentina y Brasil, que han sido referentes para nuestra tarea a lo largo de los años de funcionamiento de la Unidad Experimental de Cunicultura de INIA Las Brujas. El aporte de especialistas en disciplinas que constituyen pilares básicos de la cunicultura moderna (genética, nutrición, manejo reproductivo, control ambiental, comportamiento y bienestar animal, calidad de carne) permitió alcanzar un adecuado equilibrio entre los fundamentos teóricos en que se sustenta la moderna tecnología de producción de conejos para carne y los detalles prácticos que demanda su aplicación.

Confiamos que la publicación resultará útil en la tarea de quienes desempeñan su actividad profesional en la cunicultura de carne, contribuyendo de este modo al desarrollo de esta actividad productiva que, en nuestra región, aún procura consolidarse.

Gustavo Capra

Oscar Blumetto

(Editores) 


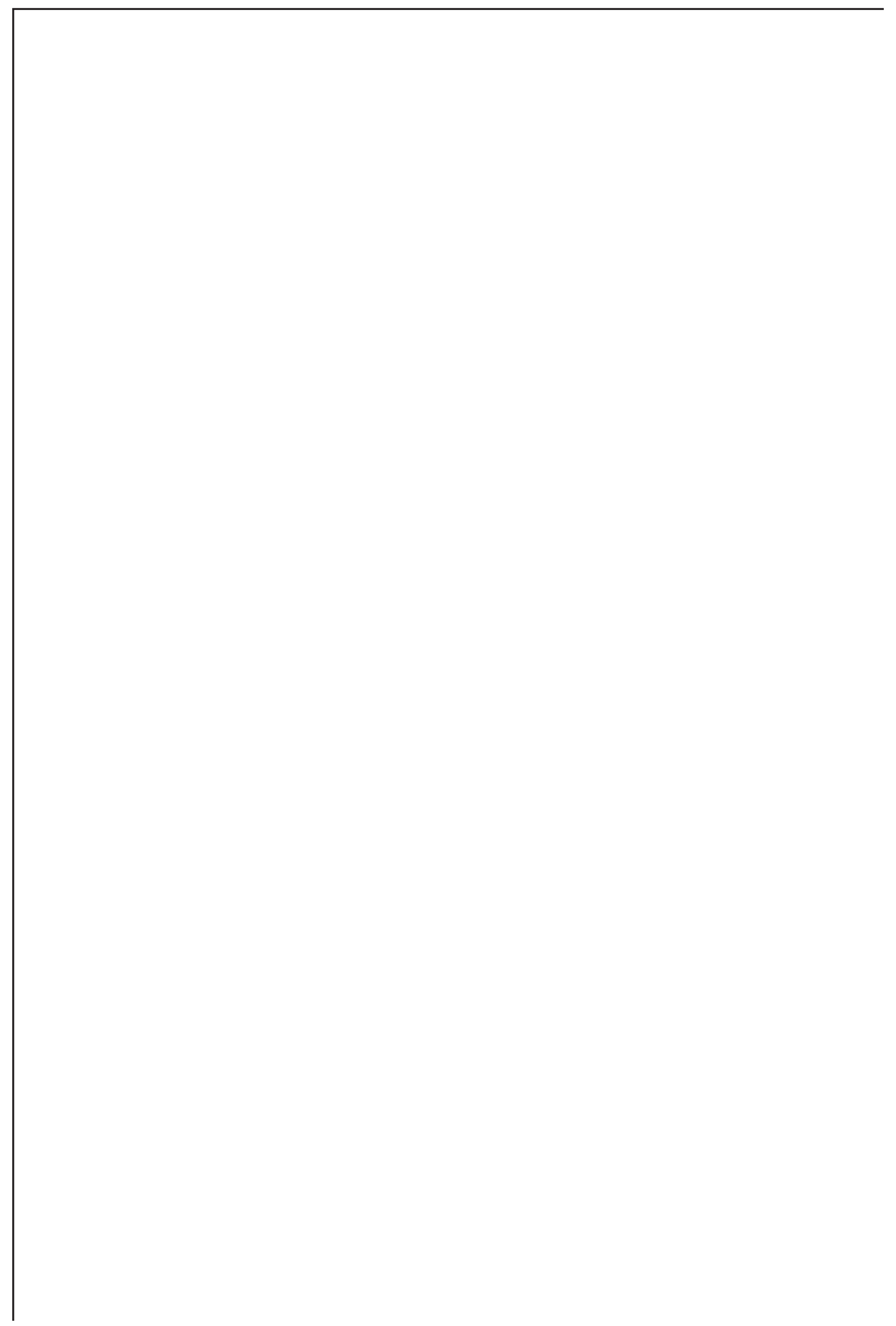




\section{PRÓLOGO}

El presente manual de la Serie Técnica de INIA de Uruguay tiene por objetivo exponer diversos trabajos científicos y experiencias de investigadores oriundos de países latinoamericanos y europeos, en referencia a la tecnología aplicada y los resultados físicos y económicos obtenidos en la producción de conejos para carne. Estos aportes ayudarán a consolidar la cadena agro-comercial cunícola y favorecer a la promoción del consumo de carne de conejo a nivel local, regional y de cada país.

El enfoque dado incluye la descripción detallada de las investigaciones sobre los pilares de la producción hasta las cualidades nutricionales de la carne de conejo, permitiendo a los usuarios de este libro ser aplicadores de los conocimientos obtenidos. Se presenta en este sentido, un aporte de los resultados de trabajos experimentales basados en la realidad latinoamericana, especialmente de URUGUAY, con especial énfasis en cumplir los estándares productivos y lograr óptimos resultados a nivel de la explotación. Debido al lenguaje claro y específico en el desarrollo de los temas, su lectura permite no solo destacar los aspectos técnicos a ser implementados por parte de los especialistas, sino también ser útil para todas aquellas personas involucradas en la actividad, especialmente los productores.

El manual abarca una extensa variedad de temas que deben ser considerados para la obtención de resultados económicos ligados a la sustentabilidad de la explotación y bienestar de los animales. Entre otros, se refiere a los avances en la mejora genética y su difusión, para que ésta llegue del núcleo de selección a los cunicultores, ejemplificándose con dos modelos muy diferentes: el francés y el español y sus aplicaciones prácticas. Se hace referencia a la reproducción como el pilar central para la obtención de índices productivos y económicos competitivos fortalecida por programas de manejo a través de la renovación del plantel reproductivo y la aplicación de la técnica de inseminación artificial como práctica recurrente en un establecimiento. Respecto al ambiente, se describen las instalaciones necesarias para la cría de conejos, el manejo del ambiente en búsqueda del confort ambiental y la densidad animal. Analiza aspectos sanitarios, de nutrición y alimentación por fases según los requerimientos de cada estado fisiológico y productivo del animal, con el fin de lograr la eficiencia económica ya sea mediante el índice global de conversión del criadero o de cada etapa. También hace referencia científica al manejo de la dieta sobre la modificación del perfil lipídico de la carne con la incorporación de aceites y semillas de oleaginosas así como el uso de forrajes frescos o secos como sustitutos parciales de los concentrados. Se destaca el esfuerzo por difundir y resaltar las cualidades técnicas y nutritivas de la carne como resultado del sistema de producción, siendo las propiedades sensoriales cruciales para la elección del consumidor, así como también la aplicación de las tecnologías de envasado para mantener dicha calidad y las estrategias llevadas a cabo para mejorar el valor 'funcional' de la carne de conejo.

La cunicultura y especialmente la de producción de carne es multifacética en cuanto a la oferta de productos; no solo aporta proteína animal de alto valor biológico, sino que genera subproductos, colabora en la mejora del ambiente y fortalece los valores del trabajo y de la práctica artesanal. 
Finalizando, agradezco a los científicos involucrados, el aporte realizado a través de su esfuerzo personal y en representación de las instituciones a las cuales pertenecen, de permitirme dar humilde opinión de tan relevante trabajo, que plasma la dinámica de intercambio de experiencias e información presente entre los científicos de esta actividad.

América aún está despertando al desarrollo cunícola y queda un largo camino por recorrer.....

A disfrutar de estos conocimientos!!

Ing. Agr. María Laura Cumini

Presidente de la American Branch de la WRSA 


\title{
MEJORA GENÉTICA DEL CONEJO DE CARNE. LAEXPERIENCIA ESPAÑOLA
}

\author{
Manuel Baselga ${ }^{1}$ \\ Agustín Blasco ${ }^{1}$ \\ María A. Santacreu ${ }^{1}$
}

\section{RESUMEN}

En el presente trabajo se discute, en función del tipo de cunicultura y las posibilidades de organización del entorno productivo al que se dirige la mejora, qué tipo de animales o líneas y cruces son convenientes desarrollar. La primera cuestión relacionada con ellas es la de su fundación, que va a determinar el punto inicial de su capacidad productiva y especialización. Se ejemplifican diversas alternativas para enfrentar el problema de la fundación. A continuación, se trata de la selección de las líneas disponibles en el programa de mejora, distinguiendo si se trata de líneas paternales, maternales o multipropósito y se presentan las respuestas obtenidas en los programas y experimentos analizados, tanto respuestas en las líneas, como las respuestas en el cruzamiento. De este modo se obtiene una idea de lo que puede ser razonable progresar, generación por generación, desde el momento inicial o de fundación de las líneas. Finalmente se discute cómo organizar la difusión de la mejora, para que ésta llegue del núcleo de selección a los cunicultores, ejemplificándose con dos modelos muy diferentes: el francés y el español. Respecto al aprovechamiento de la mejora genética por parte de los cunicultores se señalan algunos aspectos sobre los que el cunicultor debe tener un sentido especialmente crítico como son los relativos a la sanidad de los animales que va a introducir en su granja, a los problemas de adaptación, a su capacidad productiva y al programa genético que los desarrolla.

\section{INTRODUCCIÓN}

La mejora genética animal, independientemente de la especie a la que se refiera, exige una dedicación continua y permanente de recursos humanos y materiales, que debe plantearse con una perspectiva a medio y largo plazo. En este sentido, y en lo que concierne al conejo de carne, es importante saber qué tipo de animal va a ser el más conveniente a utilizar en el entorno productivo en el que se va difundir la mejora, es decir, si las características de dicho entorno exigen el uso de razas o líneas puras como tales, o si permiten el uso más o menos intenso de animales cruzados. En función de la respuesta a la cuestión anterior, quedarán definidas las características iniciales deseables y los objetivos de selección de las línea de animales que van a ser objeto de mejora. En relación con ello deben tratarse las alternativas posibles para fundar nuevas líneas, la metodología de selección, las mejoras esperables conforme la selección se va aplicando y formas sencillas de organizar la mejora y de hacerla llegar a los productores.

El presente trabajo va a tratar los puntos anteriores y, en lo que concierne a los aspectos aplicativos, va a ejemplificarlos con lo hecho en España desde 1976. En ese año, la Universidad Politécnica de Valencia (UPV) y el Institut de Recerca i Tecnologia Agroalimentàries (IRTA), iniciaron el desarrollo de líneas especializadas de conejos, con el objetivo de que fueran competitivas interna- 
cionalmente para la producción de carne, y formaron conjuntamente una red de difusión de las líneas que permitiese su uso a los productores de una forma sencilla, transparente, con mínimos riesgos sanitarios y económicamente aceptable. Un punto de interés de la experiencia española es que lo que se inició en 1976 sigue activo y potenciado en el momento actual. En el mundo, sólo el programa francés, iniciado por el INRA y actualmente también activo, se inició antes que el español. Fue en 1969 cuando iniciaron el desarrollo de sus líneas especializadas (Rouvier, 1981). Posteriormente, diversas instituciones públicas en el mundo se han implicado en el desarrollo de líneas de conejos con interés para la producción y detalles de las mismas pueden verse en Baselga (2004) y en Garreau et al. (2004).

\section{TIPOS DE ANIMALES: CRUZADOS O NO CRUZADOS}

Desde un punto de vista productivo los dos tipos de animales más importantes en una granja de producción son las hembras y los gazapos que, tras su cebo, son sacrificados para obtener carne. Es necesario que las hembras sean eficientes produciendo gazapos destetados y que estos gazapos crezcan rápidamente y aprovechen bien el pienso durante el cebo.

Un programa de mejora debe orientar sus objetivos fundamentales a conseguir eficiencia en los dos tipos de animales mencionados. Ello podría abordarse con animales pertenecientes a una sola raza o línea de conejos en cuyo caso, tanto las hembras como los gazapos no serían cruzados. En este caso la raza o línea elegida debiera tener rendimientos reproductivos y de crecimiento aceptables y concentrar en su programa de mejora ambos objetivos. Esta solución, de razas o líneas multipropósito, tendría ventajas organizativas en la difusión de la mejora a los cunicultores, en el sentido que bastaría ir introduciendo en la granjas comerciales machos o semen de las generaciones recientes del programa de selección. Por eso, esta solución puede ser la conveniente cuando el tipo de cunicultura predominante en el país o región sea de pequeña escala, haya dificultades para que los cunicultores sean capaces de comprar el reemplazamiento de machos y hembras del exterior, y el destino de la producción sea fundamentalmente el consumo familiar o la venta en pequeños mercados locales, no vislumbrándose una evolución de este tipo de producción a otro de mayor escala en un plazo breve (Khalil y Bolet, 2010).

Otra solución, intermedia entre la anterior y la que se adopta para cuniculturas más desarrolladas, es utilizar hembras de una línea o raza de tipo maternal, eficiente reproductivamente, que al aparearse con machos pertenecientes a una línea paternal, de buenas características de crecimiento, producen gazapos cruzados. Es lo que se denomina cruzamiento simple. Esta alternativa permite la difusión de la mejora, introduciendo machos o semen de la línea maternal, para obtener las hembras de reemplazo, y machos o semen de la línea paternal para producir los gazapos.

El modo habitualmente elegido, en especies prolíficas como el cerdo y el conejo, es desarrollar líneas de animales que permitan el cruzamiento doble o de tres vías. En éste, el primer cruce es el apareamiento de hembras de una línea maternal, con machos de otra línea maternal para obtener las hembras cruzadas. El segundo cruce consiste en aparear las hembras cruzadas obtenidas en el primero con machos de una tercera línea. Esta línea, de tipo paternal, generalmente se selecciona por velocidad de crecimiento posdestete o por el peso a una edad próxima a la edad de sacrificio. El resultado de este segundo cruce son los gazapos destinados al cebo para producir carne. El propósito del cruce entre las líneas maternales es abaratar las hembras usadas en las granjas como reproductoras, puesto que el coste de mantener el núcleo de selección se divide entre las hembras cruzadas producidas; aprovechar la heterosis positiva esperada en los caracteres reproductivos; aprovechar la eventual complementariedad entre ambas líneas; y finalmente hacer desaparecer la consanguinidad en las hembras cruzadas, puesto que la consanguinidad se va acumulando dentro de las líneas que se mantienen cerra- 
das reproductivamente. Se espera que la heterosis inicial expresada en el cruce se mantenga a lo largo de las generaciones de selección y se siga sumando a los progresos de la selección dentro de las líneas. En Francia, desde 1969, el INRA (SAGA, Toulouse) selecciona dos líneas maternales por caracteres de tamaño de camada, llamadas A2066 y A1077 y de su cruce se obtiene la hembra cruzada 1067. Brun y Saleil (1994) estimaron la heterosis en el cruce de estas líneas, en un experimento realizado en condiciones de granja comercial. Obtuvieron valores del $15,2 \%, 20,1 \%$ y $6,7 \%$ para nacidos totales, nacidos vivos y número de destetados por camada. Los autores explican el bajo valor de la heterosis estimada para el número de destetados como consecuencia de la práctica de los cunicultores de eliminar algún recién nacido en las camadas más numerosas. No obstante los valores anteriores son importantes, pues prueban que la heterosis se mantiene pese a que las líneas llevaban, en el momento de realizar este experimento, un elevado número de generaciones de selección. La heterosis entre la línea $\mathrm{V}$ (línea maternal, UPV, España) y la A2066 para los caracteres nacidos totales y nacidos vivos por camada fue estudiada por Brun et al. (1998), obteniéndose heterosis del $13,6 \%$ y $20,7 \%$ para dichos caracteres. Para estos mismos caracteres, Baselga et al. (2003), en los cruces simples entre las líneas maternales, $\mathrm{A}, \mathrm{V}$ y $\mathrm{H}$ de la UPV vieron que la heterosis estimada oscilaba entre 0,45 y 0,95 gazapos (4 y $10 \%$ ). Orengo et al. (2003) han estudiado los cruces entre las líneas $A, V$ y Prat (IRTA, España) encontrando heterosis para los caracteres de tamaño de camada entre el 7 y el $16 \%$. Igualmente se han encontrado heterosis positivas para caracteres reproductivos en los cruces de la línea $\mathrm{V}$ con razas de conejos egipcias y saudíes (Al-Saef et al., 2008; Iraqi et al, 2010) y para tamaño de camada (Ragab, 2012) y longevidad funcional en los cruces de cuatro líneas maternales españolas (Ragab et al., 2011).

En el cruce terminal, entre la hembra cruzada y el macho de la línea paternal, la complementariedad juega una importancia extrema, en el sentido de que la hembra cruzada debe tener un rendimiento reproductivo so- bresaliente, mientras que la línea paternal debe de tenerlo en crecimiento, eficiencia alimenticia y caracteres de la canal.

En la alternativa del cruzamiento doble la difusión de la mejora requiere, como ya hemos sugerido anteriormente, una organización mayor y será tratada más adelante.

\section{DESARROLLO DE LÍNEAS}

En el marco del cruzamiento simple o doble, el desarrollo de líneas maternales y paternales es una actividad central de un programa de mejora genético (Baselga, 2004; Garreau et al., 2004), mientras que si en la producción va a utilizarse una única línea, ésta debería ser multipropósito y en sus objetivos de selección deberían equilibrarse caracteres reproductivos y de crecimiento (Moura et al., 2001; Gacem et al., 2008).

Una visión más detallada del esfuerzo desarrollado en la selección de líneas maternales, puede verse en Garreau et al. (2004).

\section{Fundación}

La primera cuestión que se plantea respecto a las líneas que van a formar parte de un programa de selección es la de la disponibilidad de las mismas $y$, en caso de que no se disponga de ellas como tales, ¿qué procedimientos y criterios pueden seguirse para su constitución o fundación? Este punto es sumamente importante pues define el nivel de partida del programa, sobre el que se van a acumular las respuestas que obtengamos con la selección subsiguiente.

Antes de indicar las alternativas de fundación, es conveniente puntualizar qué se entiende por línea, a efectos de la mejora genética animal. Las líneas son poblaciones de animales que se reproducen en su núcleo de selección y que, en el caso de los conejos, suelen estar compuestas por un número de 20-25 machos y de al menos 80100 hembras. El tamaño máximo raramente excede de 250-300 hembras y 50 machos. Su aislamiento reproductivo, el tamaño reducido de la población y la aplicación repetida de un programa de selección tienen como consecuencia que, dentro de estas pobla- 
ciones, los animales sean mucho más uniformes que dentro de una raza. Por otra parte, a través de la fundación de estas poblaciones, como vamos a explicar, y de los objetivos del programa de selección se consigue su especialización productiva.

En el pasado, el modo más común utilizado para fundar una línea consistía en obtener muestras de animales de una o de varias de las razas existentes que se considerasen adecuadas para la producción de conejo de carne (Lukefahr et al., 1996). Estas muestras de animales se apareaban entre si durante dos o tres generaciones para dar oportunidad de recombinación entre el material genético de los distintos orígenes, obteniendo una nueva población de pequeño tamaño que se consideraba la población fundadora de la nueva línea (Khalil y Baselga, 2002). Este procedimiento, seguido para fundar la línea A de la UPV (Ragab y Baselga, 2011) no es difícil de realizar, pero está expuesto a algunos problemas importantes. Uno de ellos puede derivarse de la gran diversidad de animales y poblaciones que existen dentro de una raza. Esto significa que los animales fundadores pueden haberse muestreado de poblaciones de la raza que son genéticamente pobres para los caracteres de interés y, consecuentemente, el nivel de partida de la nueva línea será bajo y no competitivo. Otro problema que puede aparecer es de tipo sanitario, pues hay que reunir y aparear en una misma granja los animales fundadores, que proceden de un número relativamente elevado de granjas. Cada una de estas tiene un microbismo particular, que si bien puede ser aceptable aisladamente, al reunirse el de todos los orígenes pueden surgir importantes problemas sanitarios. Este último problema puede evitarse practicando histerectomías u otras técnicas como la congelación de embriones y su posterior transferencia (García-Ximénez et al., 1996).

Seguidamente comentamos dos alternativas al procedimiento anteriormente descrito para fundar nuevas líneas. En ambos casos, el primer aspecto es definir la especialización deseada para la línea. La primera alternativa intenta encontrar dos o tres poblaciones, sin importar su origen genético (raza pura, líneas sintéticas o cruzados), que sean claramente sobresalientes para los caracteres importantes en la especialización deseada de la línea (Baselga, 2002). El siguiente paso consiste en obtener animales de estas poblaciones y aparearlos entre ellos, sin hacer selección, durante dos o tres generaciones. Este es el procedimiento que se siguió para fundar la línea $V$ (UPV). La segunda alternativa se fundamenta en aplicar altas intensidades de selección para caracteres de interés en poblaciones muy grandes (por ejemplo, poblaciones comerciales). Ilustramos el procedimiento detallando la fundación de la línea H (UPV). Está basado en la detección de hembras llamadas hiperprolíficas, buscándolas en el conjunto de granjas comerciales de España. Una coneja se consideraba hiperprolífica si tenía un parto con 17 o más nacidos vivos, o si el número acumulado de nacidos vivos en el conjunto de todos sus partos permitía clasificar a esa hembra dentro del $1 \%$ mejor. El primer paso del procedimiento fue el obtener descendencia masculina de un primer grupo de hembras hiperprolíficas (20) montadas con machos normales (9 machos, pertenecientes a la línea $V$ ). En el segundo paso, los machos obtenidos en el primero, montaron a un segundo grupo, más numeroso, de hembras hiperprolíficas, con el fin de ir acumulando en su descendencia genes favorables para la prolificidad. Este proceso de acumulación puede continuarse con un tercer y sucesivos pasos, en los que la descendencia masculina del paso anterior, monta a nuevos grupos de hembras hiperprolíficas. Sin embargo, en la constitución de la línea $\mathrm{H}$ la descendencia del segundo paso se consideró la población fundadora (generación 0). En esta alternativa, en la que se utilizan animales procedentes de muchas granjas, los problemas sanitarios pueden ser graves y se evitaron realizando histerectomías en el primer paso y congelación de los embriones producidos en el segundo (García-Ximénez et al., 1996). Tras descongelar y transferir estos embriones se obtuvieron 474 conejos de la generación 0 . Estos se utilizaron para mantener la línea y para estudios de comparación de la nueva línea $(H)$ con la línea $V y$ con hembras cruzadas AxV. La comparación fue favorable para la línea $\mathrm{H}$ (Cifre et al., 1998a, 1998b) y después de tres generacio- 
nes sin selección, se inició su programa de selección por número de nacidos vivos por camada, criterio que se ha cambiado al número de destetados a partir de la séptima generación de selección. La misma alternativa se ha aplicado para fundar la línea LP (UPV), para la que el criterio de búsqueda de hembras sobresalientes en las granjas comerciales era la hiperlongevidad y una prolificidad por encima de un umbral (hembras con más de 28 partos y prolificidad por encima de 7.5 gazapos). En este caso, en lugar de dos pasos se hicieron tres. Sánchez et al. (2008) describen con detalle el proceso de fundación de la línea LP y su comparación con la $\mathrm{V}$, poniendo de manifiesto, de nuevo, la utilidad del procedimiento de las elevadas intensidades de selección para fundar líneas. En este caso, la línea LP se ha mostrado especialmente resistente frente a desafíos ambientales relacionados con el manejo, temperatura, alimentación o respuesta inmunitaria (Theilgaard et al., 2009; Savietto et al., 2012; Ferrian et al.; 2013).

Ragab y Baselga (2011) han analizado las diferencias en la fundación entre las líneas A, V, H y LP, evidenciándose diferencias importantes en prolificidad entre la línea A y las restantes, a favor de éstas, que se explicaron por las diferencias en el procedimiento de fundación. En el caso de la línea A, se siguió el primero de los procedimientos indicados, basado en aceptar la raza, en su caso Neozelandés Blanco, como un indicador útil de capacidad productiva.

\section{Selección}

Una vez que se han fundado las líneas de un programa de mejora, o se dispone de ellas, el paso siguiente es iniciar su programa de selección. Es necesario distinguir la selección de las líneas paternales, de la de las maternales. Las paternales son comúnmente seleccionadas por ganancia diaria de peso posdestete (Rochambeau et al., 1989; Estany et al., 1992; Gómez et al., 2002) o por un peso a un tiempo próximo a la edad del sacrificio para carne (Lukefahr et al., 1996; Larzul et al., 2003a). Estos caracteres son muy fáciles de medir y tienen una correlación genética negativa y favorable con el índice de conversión (Moura et al., 1997; Piles et al., 2004) lo que es muy importante para una producción eficiente. El índice de conversión no se utiliza directamente, pese a la importancia de los costes de alimentación (Cartuche et al, 2013) porque es caro de medir individualmente. Si se utilizan las jaulas colectivas, en las que comúnmente se realiza el cebo, se requerirían dispositivos electrónicos automáticos de identificación y control individual del consumo, que serían caros y actualmente no disponibles para conejos. Si los conejos se alojan en jaulas individuales, el control del consumo puede hacerse manualmente, lo que también es caro y además podrían existir interacciones genotipo-tipo de jaula. Es decir, Ios conejos con mejor índice de conversión en las jaulas individuales, podrían no serlo en jaulas colectivas. La metodología utilizada para seleccionar estos caracteres de peso o ganancia de peso ha sido, en general, la selección individual, en la que el criterio de selección es directamente el valor del carácter medido en el individuo. Es el procedimiento más sencillo y es razonable y posible, porque estos caracteres se expresan en los dos sexos y tienen una heredabilidad media. De este modo se ahorra tiempo, trabajo y otros recursos. El intervalo generacional puede ser alrededor de seis meses. Gyovai et al. (2012) están seleccionando la raza Pannon Blanco por ganancia diaria y calidad de la canal, evaluada utilizando técnicas de tomografía computarizada. Larzul y Rochambeau (2005) han considerado experimentalmente el interés de seleccionar por consumo residual en alimentación ad libitum.

Por lo que se refiere a la selección de las líneas maternales la cuestión es más compleja. Aquí, el criterio más común para su selección está relacionado con el tamaño de camada al nacimiento o al destete (Estany et al., 1989; Rochambeau et al., 1994; Gómez et al., 1996). En un caso del programa francés, el criterio de selección por tamaño de camada al nacimiento, se amplió con el peso a las nueve semanas, a efectos de evitar respuestas negativas en el peso adulto (Bolet y Saleil, 2002). Por otra parte existen propuestas y programas que incluyen caracteres relacionados con la capaci- 
dad de la hembra para satisfacer las exigencias de lactación de su camada, como son el peso al destete (Garreau y Rochambeau, 2003), el peso de la camada al destete o la producción total de leche. El que los machos no expresan ellos mismos los caracteres de tamaño de camada, que las hembras pueden tener varios registros de estos caracteres y que la heredabilidad de ellos es baja, hace que sea necesario considerar tantos datos propios o de parientes como sea posible para la evaluación de las hembras y de los machos. Como consecuencia, el intervalo generacional es más largo que en la selección de las líneas paternales y, además, es conveniente o necesario considerar algunos efectos ambientales y fisiológicos en los modelos de evaluación. Inicialmente se propusieron índices familiares que integraban la información propia y la de los parientes más próximos para realizar la evaluación genética (Matheron y Rouvier, 1977; Baselga et al., 1984). Esta metodología todavía se sigue aplicando en la selección de la línea $A$, que actualmente ha alcanzado la generación 43 de selección. Actualmente, el BLUP, basado en la metodología de los modelos mixtos, es el procedimiento más utilizado en la evaluación. Una de sus principales diferencias con el índice de selección es que en el BLUP se consideran algunos efectos fisiológicos y ambientales (Estany et al., 1989; Gómez et al., 1996; Rochambeau et al., 1998). Estudios de simulación con datos reales han mostrado eficiencias similares de ambas metodologías para seleccionar por tamaño de camada en conejos cuando las generaciones son discretas. En este caso la pérdida de eficiencia por seleccionar con un índice familiar en lugar de con un BLUP es alrededor del $8 \%$ (Armero et al., 1995). Se han realizado o están en curso experimentos que estudian métodos alternativos para la mejora del tamaño de camada. Entre ellos se ha estudiado la selección por capacidad uterina (Santacreu et al., 2005), por tasa de ovulación (Laborda et al., 2012) o por tamaño de camada y tasa de ovulación conjuntamente (Badawy et al., 2013). Este último experimento ha alcanzado su novena generación de selección y sus resultados son prometedores.

\section{Respuesta dentro de línea}

Al aplicar los métodos de selección que acabamos de exponer, las líneas van modificando sus valores medios en los caracteres de selección y en caracteres relacionados. Las respuestas estimadas en experimentos de selección para incrementar el peso a los 63-70 d, oscilan entre 18 y $35 \mathrm{~g}$ por generación y hay una buena concordancia entre las estimas obtenidas utilizando línea control y las que usan BLUP-REML ( Lukefahr et al., 1996; Garreau et al., 2000; Larzul et al., 2003a). Cuando la selección era por velocidad de crecimiento pos-destete se estimaron respuestas entre 0,45 y $1,23 \mathrm{~g} / \mathrm{d}$ (Rochambeau et al., 1989; Estany et al., 1992; Piles y Blasco, 2003). En el experimento de Piles y Blasco (2003), la respuesta se estimó, utilizando embriones congelados y mediante inferencia bayesiana, obteniendo con ambos métodos las mismas estimas. La selección por crecimiento origina respuestas correlacionadas en otros caracteres, como en el peso adulto que se incrementa (Blasco et al., 2003). A un peso fijo de sacrificio, con el transcurso de las generaciones, el índice de conversión disminuye y el consumo aumenta (Feki et al., 1996); se incrementa el contenido intestinal y se reduce el rendimiento a la canal (Gómez et al., 1998; Pla et al, 1998) en razón, entre otras causas, de la menor madurez. Consecuencias de esta menor madurez son, también, una reducción de los depósitos grasos y una menor capacidad de retención de agua de su carne (Piles et al., 2000), así como un pH último del músculo, más bajo (Gondret et al., 2003). Algunas de estas consecuencias negativas de la selección por crecimiento no son cuantitativamente importantes y pueden reducirse o eliminarse aumentando el peso de sacrificio y con un ligero ayuno de los animales antes de ser sacrificados. En un análisis a edad constante puede desaparecer la mejora del índice de conversión, así como los efectos negativos sobre el rendimiento a la canal y la madurez (Garreau et al., 2000; Larzul et al., 2003b; Hernández et al., 2004). 
En relación con la respuesta a la selección de las líneas maternales, vamos a dar los resultados correspondientes a las líneas directamente implicadas en programas largos de selección que incluían población control (Rochambeau et al., 1998; Tudela et al., 2003) o congelación de embriones. (García y Baselga, 2002a, 2002b). Las respuestas estimadas oscilaban entre 0,08 y 0,09 gazapos nacidos totales, nacidos vivos o destetados por camada y generación. En las mismas líneas, las tendencias genéticas estimadas por BLUP-REML, concordaban completamente en los tres primeros experimentos (Rochambeau et al., 1998; García y Baselga, 2002a; Tudela et al., 2003), pero la tendencia genética estimada en el cuarto es de 0,175 gazapos destetados por camada y generación, aproximadamente el doble de la respuesta obtenida utilizando embriones congelados. Hay, también, estudios en que las respuestas se han estimado, exclusivamente por BLUP-REML, oscilando los valores obtenidos entre 0,05 y 0,13 nacidos vivos 0 destetados por camada y generación (Estany et al., 1989; Rochambeau et al., 1994; Gómez et al., 1996). Haciendo selección conjunta por tasa de ovulación y tamaño de camada, Badawy et al. (2013) han estimado con una metodología bayesiana respuestas en la tasa de ovulación de 0,17 óvulos/generación y en el tamaño de camada de 0,17 gazapos nacidos totales/generación, a lo largo de 9 generaciones.

En alguna de estas líneas, con respuestas significativas en el tamaño de la camada, se ha analizado si alguno de sus componentes se ha modificado. Así, García y Baselga (2002a) encontraron que la explicación principal de la respuesta en el tamaño de camada fue en una línea la mejora en la tasa de ovulación, mientras que en otra, probablemente lo fue por la mejora de la supervivencia fetal (García y Baselga, 2002b). También se han investigado las respuestas correlacionadas en caracteres de crecimiento, cuando se selecciona por tamaño de camada. A este respecto, García y Baselga (2002c) no encontraron respuestas significativas para el peso al destete, peso al sacrificio, ganancia diaria posdestete, consumo de alimento e índice de conversión, cuando las comparaciones se hacían a tamaño de camada al nacimiento constante. Sin embargo, Rochambeau et al. (1994) informaron que la selección para aumentar el tamaño de camada resultaba en una disminución del peso individual al destete, si bien el peso total de la camada en ese momento se incrementaba en sus dos líneas maternales. Esta constatación fue la que motivó la modificación del objetivo de selección, incluyendo en una de las líneas el peso a los 63 días, además del tamaño de camada al nacimiento (Rochambeau, 1998), a efectos de intentar incrementar, al mismo tiempo, el tamaño de camada y el peso individual.

\section{Respuesta en el cruzamiento}

Como se ha indicado al principio, el objetivo final de la mejora genética de las líneas especializadas es la mejora de los rendimientos de las hembras cruzadas y de los gazapos cruzados. Sin embargo, con independencia de que las líneas vayan a ser utilizadas en los cruzamientos, su selección, tal como la hemos presentado se hace intralínea, esperando, que las respuestas conseguidas en ellas se expresen en los cruces. En este sentido es importante evaluar la respuesta en las hembras y gazapos cruzados. Para ello es necesario hacer comparaciones contemporáneas entre animales representantes de diferentes generaciones del programa de selección. Tales comparaciones han sido hechas por Tudela et al. (2003), por Costa et al. (2004) y por Quevedo et al. (2005, 2006a, 2006b). Las líneas implicadas en el primer experimento fueron la A1077 en la generación 30 de selección y la A9077, que era una línea control, ambas apareadas con otra línea maternal francesa en su generación actual para producir dos tipos de hembras cruzadas. La diferencia en el tamaño total de la camada entre ambos tipos de hembras cruzadas fue de 1,43 , ligeramente superior al esperado de la selección de la línea $A 1077(1,12)$. En el segundo experimento (Costa et al., 2004) las líneas maternales fueron la $\mathrm{A}$ y la $\mathrm{V}$, disponiendo de animales de la $A$ de dos generaciones diferentes. Las hembras cruzadas se obtenían apareando hembras $V$ con machos de la lí- 
nea A. Así, pudieron compararse dos tipos de hembras cruzadas, que llamaremos $\mathrm{H} 1$ y $\mathrm{H} 2$. Las hembras $\mathrm{H} 1(\mathrm{H} 2)$ procedían del apareamiento de hembras $\mathrm{V}$ de la generación 26 con machos A de la generación 16 (29). Se obtuvieron gazapos cruzados de estas hembras, apareando las hembras $\mathrm{H} 1(\mathrm{H} 2)$ con machos de la línea paternal $R$ de la generación 6 (18). Las generaciones antiguas se habían conservado como embriones congelados, que se descongelaron, transfirieron y reprodujeron para obtener adultos contemporáneos de las generaciones recientes. Todas las respuestas en tamaño de camada y ganancia diaria fueron en favor de los cruzados actuales. En lo que se refiere al tamaño de camada las diferencias fueron de 0,83 , 1,16 y 0,74 gazapos para el número de nacidos totales, nacidos vivos y destetados por camada. Estas respuestas fueron mayores que las esperadas a partir de las respuestas que se habían conseguido en las líneas. Por ejemplo, la respuesta esperada en el tamaño de camada al destete era de 0,55 gazapos, siendo la eliminación de la consanguinidad en las cruzadas la explicación más plausible de la mayor respuesta. Por el contrario, la respuesta en el crecimiento de los gazapos cruzados fue inferior a la esperada. En ganancia diaria posdestete fue de 0,6 g/d, mientras la esperada era de $2,4 \mathrm{~g} / \mathrm{d}$. No se obtuvieron respuestas para el consumo diario, y el índice de conversión. Los autores no encontraron explicación para estos resultados en los caracteres de crecimiento y sugerían que la causa podía ser el tipo de alimento utilizado entonces para controlar la enterocolitis epizoótica, que se estaba extendiendo por Europa. El alimento podía tener efectos diferentes en el crecimiento de los animales dependiendo de su nivel genético respecto al consumo de alimento. En el tercer experimento (Quevedo et al., 2005, 2006a y b) se vuelven a comparar hembras $\mathrm{H} 1$ y $\mathrm{H} 2$, como en el segundo, con la diferencia de que las madres de las hembras $\mathrm{H} 1$ son hembras $V$ de la generación 15 y las de las H2 hembras $\mathrm{V}$ de la generación 26 . Es decir, las hembras $\mathrm{H} 1$ eran cruzadas antiguas por las generaciones de sus dos padres y las $\mathrm{H} 2$ cruzadas actuales. En hembras primíparas,
Quevedo et al. (2005), vieron que las hembras $\mathrm{H} 2$ tenían un número significativamente mayor de nacidos vivos (2.06) que las $\mathrm{H} 1$, número también mayor que el esperado por las respuestas intralínea (1.06). También observaron un mayor crecimiento fetal en las $\mathrm{H} 2$, con un mismo consumo de energía, lo que significaba un incremento de la eficiencia en el uso de la energía como consecuencia de la selección. En hembras multíparas, las hembras $\mathrm{H} 2$ volvieron a mostrar su superioridad en número de gazapos nacidos vivos (1.1) (Quevedo et al., 2006 a) y mostraron durante los primeros 21 días de lactación (Quevedo et al., 2006 b) un mayor consumo de alimento (3\%) y una mayor producción de leche (6\%). Al igual que en el experimento segundo $y$, aparentemente por las mismas razones, el crecimiento de los gazapos cruzados actuales sólo fue un tercio superior al esperado, respecto a los gazapos antiguos.

Recientemente se ha terminado el análisis de un experimento de cruzamiento que comparaba los parámetros reproductivos actuales de las cuatro líneas maternales de la UPV (A, V, H, LP) con los doce tipos de hembras cruzadas resultantes de los cruces simples entre ellas (Ragab, 2012). Resultados medios de todo el experimento para los dieciséis tipos genéticos, realizado en cuatro granjas con un total de 34.546 camadas fueron: 10,54 nacidos totales/camada, 9,79 nacidos vivos/camada, 7,97 destetados/ camada y 49,91 días de intervalo entre partos. Las hembras cruzadas tuvieron mejores resultados, superando a la línea $V$ en 0,46 gazapos nacidos totales/camada, 0,56 nacidos vivos/camada, 0,75 destetados/camada y -2,21 días de intervalo entre partos. También se estudiaron las características de crecimiento de los gazapos cruzados, resultantes del apareamiento de los dieciséis tipos de hembras anteriores con machos actuales de la línea paternal R. Los valores medios (datos todavía no publicados) fueron: $615 \mathrm{~g}$ de peso al destete, 28 días, 45,6 g/d de crecimiento diario entre el destete y el final del engorde a 63 días y un índice de conversión de 2,79 para el todo el periodo de engorde. 


\section{ORGANIZACIÓN Y DIFUSIÓN DE LA MEJORA}

El paso final de un programa de mejora es difundir los logros conseguidos desde el núcleo a las granjas. El modo estándar sigue una organización piramidal, incluyendo la multiplicación de los animales del núcleo, como un paso intermedio, anterior a la difusión en las granjas comerciales. En la fase de multiplicación se hace el cruce entre las líneas maternas, obteniéndose las hembras cruzadas que se suministran a los granjeros. Según las necesidades, este paso puede estar precedido por un paso de multiplicación de las líneas puras. De este modo los costes del programa de selección son distribuidos entre un número mucho más elevado de animales. El retraso genético entre el núcleo y los granjeros se incrementa conforme los pasos de multiplicación aumentan. Con el objeto de reducir dicho retraso, los programas francés y español han modificado el paso de multiplicar las líneas puras en un paso que incluye selección propiamente dicha. El programa francés lo hace a través de lo que se llama «demultiplicación», que consiste en contratar con algunas compañías la selección de las líneas maternales. En una granja de «demultiplicación» las hembras de reemplazo de una línea son seleccionadas entre la progenie de dicha granja con la misma metodología de evaluación que en el núcleo, pero los machos de reemplazo proceden del núcleo original que los va suministrando periódicamente a la granja. Las compañías que «demultiplican» pueden ser grandes compañías que pretenden vender animales puros y cruzados en Francia y en otros países (Rochambeau, 1998). Además de las compañías que se han adherido al esquema de «demultiplicación», en Francia existen otras compañías privadas, con programas de mejora genética del conejo de carne, que disponen de sus propias líneas paternales y maternales. El programa español es muy diferente e integra completamente la multiplicación de las líneas puras maternales en el estadio de selección. El modo elegido consiste en crear lo que podríamos llamar núcleos secundarios de selección, que son propiedad de granjeros elegidos, cooperativas o pequeñas compañías. Una línea maternal se replica en cada núcleo secundario que se selecciona, bajo la responsabilidad de los genetistas del núcleo primario, del mismo modo que en éste. La línea que se selecciona en el núcleo secundario es utilizada como la hembra madre para producir hembras cruzadas que son distribuidas a, o producidas por, los granjeros de la región próxima al núcleo secundario. Los machos padre de las hembras cruzadas, pertenecientes a otra línea maternal, son proporcionados por el núcleo primario. La principal característica de este esquema es su sencillez, que permite producir animales de línea pura y cruzados a un coste bajo, con un retraso mínimo entre las organizaciones de mejora y los productores. Este procedimiento reduce los problemas sanitarios y de adaptación derivados de la introducción de animales en las granjas. Así mismo contribuye a la comunicación entre las organizaciones de mejora y los granjeros. Su principal desventaja es su dificultad para operar a gran escala.

La difusión de los machos de las líneas paternales para el cruce terminal puede tener modalidades diferentes. Las líneas paternales pueden ser propiedad y ser seleccionadas por las compañías «demultiplicadoras», por los núcleos secundarios, por el núcleo primario o por mejoradores no adscritos al programa, asociados o no a centros de inseminación artificial. En el programa español es muy común que los núcleos secundarios tengan su propio centro de inseminación artificial, facilitando de este modo la difusión completa de los animales que están implicados en el cruzamiento doble. En Francia, las compañías de mejora tienen, también, sus centros de inseminación artificial.

\section{Recomendaciones a los cunicultores}

El aprovechamiento de un programa de mejora por parte de los cunicultores exige la introducción de animales o semen en sus explotaciones, tal como se ha explicado anteriormente, pudiendo encontrarse con diversas ofertas en el mercado. Es necesario que 
el cunicultor sea crítico con lo que se le ofrece $y$, al respecto, hay un conjunto de cuestiones a tener en cuenta, que vamos a comentar a continuación y que, a su vez, representan importantes exigencias para cualquier programa de mejora genética. Pretendemos referirnos a: la sanidad de los animales; los problemas de adaptación; la capacidad productiva de los animales y al programa genético que los desarrolla (Baselga y Blasco, 1989).

La sanidad de los animales es uno de los problemas importantes. Este ha sido un factor, junto con el coste de los animales, que ha frenado la difusión de algunas organizaciones importantes de mejora del conejo. El estancamiento e incluso retroceso de la utilización de conejos híbridos que se constató en Francia en la década de los ochenta, así como en Italia y España se ha explicado por los problemas sanitarios de los animales que suministraban (Rochambeau, 1988). En algunos casos, las empresas de venta de reproductores han sido responsables de la difusión de pasterelas, tiñas, estafilococias o salmonelas. La solución del problema anterior exige normas de higiene y manejo estrictas, así como unas instalaciones adecuadas en los núcleos de selección y en las granjas de multiplicación. Las empresas que venden reproductores, que tienen una visión de su actividad a largo plazo, tienen programas sanitarios muy cuidadosos y algunas de ellas prevén, en algunos casos, el cierre de sus granjas por un período limitado cuando se presenta en ellas problemas patológicos que por su carácter o su intensidad hacen desaconsejable la salida de animales. En cualquier caso resulta necesario que los cunicultores mantengan en cuarentena a los animales que compran, antes de introducirlos en sus explotaciones.

Los problemas de adaptación surgen inevitablemente cuando los animales de una explotación se trasladan a otra. La confrontación entre los microbismos de ambas explotaciones puede originar situaciones de desequilibrio que afecten a unos y otros animales. Esto significa que, salvo cuando se inicia la producción en una explotación, bien porque se inicie realmente la actividad, bien porque se haya hecho un vaciado sanitario, hay que procurar disminuir cuanto sea posi- ble el número de animales a introducir. De esta manera se reducen también los riesgos sanitarios que acabamos de comentar. Sin embargo, la solución que se adopte deberá ser un compromiso entre la minimización de los riesgos sanitarios y de adaptación, la productividad de la granja (ocupación de las jaulas y calidad genética de los animales), y coste de la solución.

La introducción de animales del exterior se fundamenta, supuesta una sanidad correcta, en la capacidad productiva de los mismos. Las empresas que venden reproductores, en sus catálogos informan sobre la productividad numérica (tamaños de camada al nacimiento y al destete), productividad ponderal (velocidad de crecimiento, rendimiento a la canal, aprovechamiento del pienso) y otros aspectos de interés, como precocidad sexual, fertilidad o rusticidad. El cunicultor debe de ser crítico con esta información, siendo necesario que la complete. Lo ideal sería que instituciones públicas o privadas, independientes de las empresas suministradoras de los animales, hiciesen una evaluación objetiva de la capacidad productiva de las distintas fuentes de reproductores. Desgraciadamente dichas pruebas no se realizan, prácticamente en ningún país, en el campo de la cunicultura. En esta situación resulta razonable ampliar la información de los animales a adquirir a través de otros cunicultores que lleven tiempo utilizándolos, información que será tanto más valiosa cuanto mayor sea el número de ganaderos que podamos consultar.

Cuando el cunicultor se plantea la cuestión de la reposición externa de sus animales como un proceso continuo, al que va a recurrir mientras mantenga su explotación, adquieren importancia cuestiones como lo que realmente son y hacen las empresas concretas que suministran los reproductores. ¿Son éstas, meramente, multiplicadoras accidentales de una determinada línea o raza de conejos, o están integradas en organizaciones que tienen un programa genético propio? El conocimiento del programa genético es conveniente pues es una indicación de la seriedad de la organización y de su capacidad para ir mejorando paulatinamente la productividad de sus líneas. 


\section{BIBLIOGRAFÍA}

AL-SAEF, A.M.; KHALIL, M.H.; AL-HOMIDAN, A.H.; AL-DOBAIB, S.N.; AL-SOBAYIL, K.A.; GARCÍA, M.L.; BASELGA, M. 2008. Crossbreeding effects for litter and lactation traits in a Saudi project to develop new lines of rabbits suitable for hot climates. Live Science: 118: 238-246

ARMERO, E.; BASELGA, M.; CIFRE, J. 1995. Selecting litter size in rabbits. Analysis of different strategies. World Rabbit Science. 3(4):179-186.

BADAWY, A.Y.; PEIRÓ, R. ; MOCÉ, M.L.; BLASCO, A.; SANTACREU, M.A. 2013. Selección por tasa de ovulación y tamaño de camada en conejo. Estimación de la respuesta a la selección. En: JORNADAS DE PRODUCCION ANIMAL (XV; 2013, Zaragoza, ES, 14-15 mayo). AIDA II: 457-459.

BASELGA, M. 2002. Line V (Spain). En: KHALIL, M.H.; BASELGA, M. (ed.). Rabbit genetic resources in Mediterranean countries. Zaragoza: CIHEAM: 231-241.

BASELGA, M. 2004. Genetic improvement of meat rabbits. Programmes and diffusion. En: Proceedings WORLD RABBIT CONGRESS $\left(8^{\circ} ; 2004\right.$, Puebla, MX, September 7-10): 1-13

BASELGA, M.; BLASCO, A. 1989. Mejora genética del conejo de producción de carne. Agroguías. Madrid: Mundi-Prensa, $110 \mathrm{p}$.

BASELGA, M.; BLASCO, A.; ESTANY, J. 1984. Índice de selección de caracteres reproductivos con información variable. En: Proceedings WORLD RABBIT CONGRESS $\left(3^{\circ} ; 1984\right.$, Roma, IT, April 48). $\mathrm{p} 1: 62-65$

BASELGA, M.; GARCÍA, M.L.; SÁNCHEZ, J.P.; VICENTE, J.S.; LAVARA, R. 2003. Analysis of reproductive traits in crosses among maternal lines of rabbits. Animal Research, 52: 473-479.

BLASCO, A.; PILES, M.; VARONA, L. 2003. A Bayesian analysis of the effect of selection for growth rate on growth curves in rabbits. Genetics Selection Evolution, 35: 21-41.

BOLET, G.; SALEIL, G. 2002. Strain INRA1077 (France). En: KHALIL, M.H.; BASELGA,
M. (ed.). Rabbit genetic resources in Mediterranean countries. Zaragoza: CIHEAM, p. 109-116.

BRUN, J.M.; SALEIL, G. 1994. Une estimation, en fermes, de I'heterosis sur les performances de reproduction entre les souches de lapin INRA A2066 et A1077. En: Actes JOURNEES DE LA RECHERCHE CUNICOLE (6émes; 1994 , La Rochelle, FR, 6-7 décembre), 1: 203210.

BRUN, J.M. ; BOLET, G. ; BASELGA, M. ; ESPARBIE, J. ; FALIERES, J. 1998. Comparison de deux souches européennes de lapins sélectionées sur la taille de porté : intérêt de leur croisement. En: Actes JOURNEES DE LA RECHERCHE CUNICOLE (7 ${ }^{\text {émes; }} 1998$, Lyon, FR, 13-14 mai). p1:21-23.

CARTUCHE, L. ; PASCUAL, M. ; GOMEZ, E.A. ; BLASCO, A. 2013. Modelización del Beneficio de producción en cunicultura. En: JORNADAS DE PRODUCCION ANIMAL (XV; 2013, Zaragoza, ES, 1415 mayo). AIDA I: 64-66.

CIFRE, P.; BASELGA, M.; GARCÍA-XIMÉNEZ, F.; VICENTE, J.S. 1998. Performance of a hyperprolific rabbit line I. Litter size traits. Journal of Animal Breeding and Genetics, 115(2): 131-138.

CIFRE, P.; BASELGA, M.; GARCÍA-XIMÉNEZ, F.; VICENTE, J.S. 1998b. Performance of a hyperprolific rabbit line II. Maternal and growth performances. Journal of Animal and Breeding and Genetics, 115(2): 139-147.

COSTA, C.; BASELGA, M.; LOBERA, J.; CERVERA, C.; PASCUAL, J.J. 2004 Evaluating Response to Selection and Nutritional Needs in a Three-Way Cross of Rabbits. Journal of Animal Breeding and Genetics, 121:1-11.

ESTANY, J.; BASELGA, M.; BLASCO, A.; CAMACHO, J. 1989. Mixed model methodology for the estimation of genetic response to selection in litter size of rabbits. Livestock Production Science, 21: $67-76$.

ESTANY, J.; CAMACHO, J.; BASELGA, M.; BLASCO, A. 1992. Selection response of growth rate in rabbits for meat production. Genetics Selection Evolution, 24: $527-537$ 
FEKI, S.; BASELGA, M.; BLAS, E.; CERVERA, C.; GÓMEZ E.A. 1996. Comparison of growth and feed efficiency among rabbit lines selected for different objectives. Livestock Production Science, 45:87-92.

FERRIAN, S.; BLAS, E.; LARSEN, T.; SÁNCHEZ, J.P.; FRIGGENS; N.C.; CORPA, J.M.; BASELGA, M.; PASCUAL, J.J. 2013. Comparison of immune response to lipopolysaccharide of rabbit does selected for litter size at weaning or founded for reproductive longevity. Research in Veterinary Science, 94: 518-525.

GACEM, M.; ZERROUKI, N.; LEBAS, F., BOLET, G. 2008. Strategy for developing rabbit meat production in Algeria: Creation and selection of a synthetic strain. En: Proceedings WORLD RABBIT CONGRESS (9o; 2008, Verona, IT, June 10-13). p. 85-89.

GARCÍA, M.L.; BASELGA, M. 2002a. Estimation of genetic response to selection in litter size of rabbits using a cryopreserved control population. Livestock Production Science, 74: 45-53.

GARCÍA, M.L.; BASELGA, M. 2002b. Genetic response to selection for reproductive performance in a maternal line of rabbits. World Rabbit Science, 10(2): 71-76.

GARCÍA, M.L.; BASELGA, M. 2002c. Estimation of correlated response on growth traits to selection in litter size of rabbits using a cryopreserved control population and genetic trends. Livestock Production Science, 78(2):91-98.

GARCIA-XIMENEZ, F.; VICENTE, J.S. ; CIFRE, P. ; BASELGA, M. 1996. Foundation of a maternal rabbit line using hysterectomy and embryo cryopreservation. En: Proceedings WORLD RABBIT CONGRESS (60; 1996, Toulouse, FR, July 9-12).p 285-288.

GARREAU, H. ; PILES, M. ; LARZUL, C. ; BASELGA, M. ; ROCHAMBEAU, H. DE. 2004. Selection of maternal lines: last results and prospects En: Proceedings WORLD RABBIT CONGRESS (80; 2004, Puebla, MX, September 7-10). P. 14-25.

GARREAU, H.; SZENDRO, Z.S.; LARZUL, C.; ROCHAMBEAU H. DE. 2000. Genetic parameters and genetic trends of growth and litter size traits in the White Pannon breed. En: Proceedings WORLD RABBIT CONGRESS $\left(7^{\circ} ; 2000\right.$, Valencia, ES, July 4-7). A: 403-408.

GARREAU, H.; ROCHAMBEAU, H. DE. 2003. La sélection des qualités maternelles pour la croissance du laperau. En: Actes JOURNEES DE LA RECHERCHE CUNICOLE (10 émes. Paris, FR, 19-20 novembre). p 61-64.

GÓMEZ, E.A.; BASELGA, M.; RAFEL, O.; RAMON, J. 1998 Comparison of carcass caracteristics in five strains of meat rabbit selected on different traits. Livestock Production Science, 55: 53-64.

GÓMEZ, E. A.; RAFEL, O.; RAMÓN, J. 2002. The Caldes strain. In: Rabbit genetic resources in Mediterranean countries. En: KHALIL, M.H.; BASELGA, M. (ed.). Rabbit genetic resources in Mediterranean countries. Zaragoza: CIHEAM, p187-198

GÓMEZ, E. A.; RAFEL, O.; RAMÓN, J.; BASELGA, M. 1996. A genetic study of a line selected on litter size at weaning. EN: Proceedings WORLD RABBIT CONGRESS (6; 1996, Toulouse, FR, July 9-12). p. 2: 289-292.

GONDRET, F.; COMBES, S.; LARZUL, C. 2003. Sélection divergente sur le poids a 63 jours: conséquences sur les caractéristiques musculaires à même âge ou à même poids. En: Actes JOURNEES DE LA RECHERCHE CUNICOLE (10émes; 2003, Paris, FR, 1920 novembre). p153-156.

GYOVAI, P.; NAGY, I.; GERENCSÉR, ZS.; MATICS, ZS.; RADNAI, I.; DONKÓ, T.; BOKOR, A.; FARKAS, J.; SZENDRÕ, ZS. 2012. Genetic parameters for litter weight, average daily gain and thigh muscle volume measured by in vivo Computer Tomography technique in Pannon White rabbits. Livestock Science, 144(1-2):119-123.

HERNANDEZ, P; ALIAGA, S.; PLA, M.; BLASCO, A. 2004. The effect of selection for growth rate and slaughter age on carcass composition and meat quality traits in rabbits. Journal of Animal Science, 82: 3138-3143.

IRAQI, M.M.; GARCIA, M.L.; KHALIL, M.H.; BASELGA, M. 2010. Evaluation of milk yield and some related maternal traits in a crossbreeding project of Egyptian Gabali breed with Spanish V-line rabbits. 
Journal of Animal Breeding and Genetics, 127: $242-248$

KHALIL M.H., BASELGA M.(Ed). 2002. Rabbit genetic resources in Mediterranean countries. Zaragoza: CIHEAM, 262p.

KHALIL, M.H; BOLET, G. 2010. Sustainable Rabbit breeding and genetic improvement programs achieved in developing countries. En: Proceedings WORLD CONGRESS ON GENETICS APPLIED TO LIVESTOCK PRODUCTION (9o; 2010, Leipzig, GE, August 1-6) paper 962.

LABORDA, P.; MOCÉ, M. L.; SANTACREU, M. A.; BLASCO, A. 2012. Selection for ovulation rate in rabbits: I. Genetic parameters, direct response and correlated response on litter size. Journal of Animal Science, 90: $439-446$

LARZUL, C.; GONDRET, F.; COMBES, S.; GARREAU, H.; ROCHAMBEAU, H. DE. 2003a. Analyse d'une expérience de sélection sur le poids à 63 jours. IDéterminisme génétique de la croissance. En: JOURNEES DE LA RECHERCHE CUNICOLE (10 émes. Paris, FR, 19-20 novembre). p149-152.

LARZUL C., GONDRET F., COMBES S., GARREAU H., ROCHAMBEAU H. DE. 2003b. Analyse d'une expérience de sélection sur le poids à 63 jours :Il-Déterminisme génétique de la composition corporelle. En: JOURNEES DE LA RECHERCHE CUNICOLE (10 émes. Paris, FR, 19-20 novembre). p145-148.

LARZUL, C.; ROCHAMBEAU H DE. 2005. Selection for residual feed consumption in the rabbit. Livestrong Production Science, 95: 67-72.

LUKEFAHR, S.D.; ODI, H.B.; ATAKORA, J.K.A. 1996. Mass selection for 70-day body weight in rabbits. Journal of Animal Science, 74 : 1481-1489.

MATHERON, G. ; ROUVIER, R. 1977. Optimisation du progrés génétique sur la prolificité chez le lapin. Annales de genetique et de selection animale, 9(3): 393-405.

MOURA, A. S. A. M. T.; COSTA, A. R. C.; POLASTRE, R. 2001. Variance components and response to selection for reproductive, litter and growth traits through a multi-purpose index. World Rabbit Science, 9: 77-86.
MOURA, A.S.A.M.T.M.; KAPS, M.; VOGT, D.W.; LAMBERSON, M. 1997. Two-way selection for daily gain and feed conversion in a composite rabbit population. Journal of Animal Science, 75: $2344-2349$

ORENGO, J.; GÓMEZ, E.A.; PILES, M.; RAFEL, O.; RAMON, J. 2003. Ëtude des caractères de reproduction en croisement entre trois lignées femelles espagnoles. En : Actes JOURNEES DE LA RECHERCHE CUNICOLE (10 èmes ; 2003, Paris, FR, 19-20 novembre). p 57-60.

PILES, M.; BLASCO, A. 2003. Response to selection for growth rate in rabbits estimated by using a control cryopreserved population. World Rabbit Science, 11: 53-62.

PILES, M.; BLASCO, A.; PLA, M. 2000. The effect of selection for growth rate on carcass composition and meat characteristics of rabbits. Meat Science, 54: 347-355.

PILES, M.; GÓMEZ, E.A.; RAFEL, O.; RAMON, J.; BLASCO, A. 2004. Elliptical selection experiment for the estimation of genetic parameters of the growth rate and feed conversion ratio in rabbits. Journal of Animal Science, 82: 654-660.

PLA, M.; GUERRERO, L.; GUARDIA, D.; OLIVER, M.A.; BLASCO, A. 1998. Carcass characteristics and meat quality of rabbit lines selected for different objectives. I. Between lines comparison. Livestock Production Science, 54:115-123.

QUEVEDO, F.; CERVERA, C.; BLAS, E.; BASELGA, M.; COSTA, C.; PASCUAL, J.J. 2005. Effect of selection for litter size and feeding programme on the performance of young rabbit females during rearing and first pregnancy. Animal Science, 80:161-168.

QUEVEDO, F.; CERVERA, C.; BLAS, E.; BASELGA, M.; PASCUAL, J.J. 2006 a. Long-term effect of selection for litter size and feeding programme on the performance of reproductive rabbit does 1 . Pregnancy of multiparous does. Animal Science, 82: 739-750.

QUEVEDO, F.; CERVERA, C.; BLAS, E.; BASELGA, M.; PASCUAL, J.J. 2006 b. Long-term effect of selection for litter size and feeding programme on the performance of reproductive rabbit does 2 . Lactation 
and growing period. Animal Science, 82: 751-762.

RAGAB, M. 2012. Genetic analyses of reproductive traits in maternal lines of rabbits and in their diallel cross. 2012. Ph.D. Thesis. Valencia: Universidad Politécnica de Valencia, $144 \mathrm{p}$.

RAGAB, M.; BASELGA, M. 2011. A comparison of reproductive traits of four maternal lines of rabbits selected for litter size at weaning and founded on different criteria. Live Science, 136: 201-206.

RAGAB, M.; SÁNCHEZ, J.P.; MÍNGUEZ, C.; EL NAGAR, A.G.; BASELGA, M. 2011. Longevidad funcional en un cruce dialélico entre cuatro líneas maternales de conejos. En: Proceedings JORNADAS SOBRE PRODUCCIÓN ANIMAL (XIV; 2011, Zaragoza, ES, 17-18 Mayo) AIDA II: 73-475.

ROCHAMBEAU H. DE. 1998. La femelle parentale issue des souches expérimentales de I'INRA: évolutions génétiques et perspectives. En: JOURNEES DE LA RECHERCHE CUNICOLE (7émes; 1998, Lyon, FR, 1314 mai). p1:3-14.

ROCHAMBEAU, H. DE; BOLET, G. ; TUDELA, F. 1994. Long term selection. Comparison of two rabbit strains. En: Proceedings WORLD CONGRESS ON GENETICS APPLIED TO LIVESTOCK PRODUCTION (5\%; 1994, Guelph, August 7-12). 19: 257-260.

ROCHAMBEAU, H. DE; DUZERT, R.; TUDELA, F. 1998. Long term selection experiments in rabbit. Estimation of genetic progress on litter size at weaning. En: Proceedings WORLD CONGRESS ON GENETICS APPLIED TO LIVESTOCK PRODUCTION (60; 1998, Armidale, NSW, AU, January 11-16). p 26: 112-115.
ROCHAMBEAU, H. DE ; FUENTE, L.F. DE LA ; ROUVIER, R. 1989. Sélection sur la vitesse de croissance post-sevrage chez le lapin. Annales de genetique et de selection animale, 21:527-546.

ROUVIER, R. 1981. Les travaux de recherche français sur la sélection du lapin au cours des 10 dernières années (19701980). Comptes Rendus des Séances de l'Academie d'Agriculture de France., 61: 151-159.

SANCHEZ, J.P. ; THEILGAARD, P. ; MINGUEZ, C. ; BASELGA, M. 2008. Constitution and evaluation of a long-lived productive rabbit line. Journal of Animal Science, 86: 515-525.

SANTACREU, M.A.; MOCÉ, M. L.; CLIMENT, A.; BLASCO, A. 2005. Divergent selection for uterine capacity in rabbits. II. Correlated response on litter size and its components estimated with a cryopreserved control population. Journal of Animal Science, 83: 2303-2307.

SAVIETTO, D.; BLAS, E.; CERVERA, C.; BASELGA, M.; FRIGGENS, NC.; LARSEN, T.; PASCUAL, JJ. 2012. Digestive efficiency in rabbit does according to environment and genetic type. World Rabbit Science, 20: 131-140.

THEILGAARD, P.; BASELGA, M.; BLAS, E.; FRIGGENS, N.C.; CERVERA, C.; PASCUAL, J.J. 2009. Differences in productive robustness in rabbits selected for reproductive longevity or litter size. Animal, 3: 637-646.

TUDELA, F.; HURTAUD, J. ; GARREAU, H.; ROCHAMBEAU, H. DE. 2003. Comparaison des performances zootechniques des femelles parentales issues d'une souche témoin et d'une souche sélectionnée pour la productivité numérique En: JOURNEES DE LA RECHERCHE CUNICOLE (10 $10^{\text {mes; }}$ 2003, Paris, FR, 19-20 novembre). p53-56. 


\section{MEJORA GENÉTICA DEL CONEJO DE CARNE. LA EXPERIENCIA URUGUAYA}

\section{INCORPORACIÓN DE GENÉTICA AL URUGUAY}

Si bien durante décadas se sucedieron varios eventos de importación de conejos a Uruguay, la mayoría de las importaciones fueron de una cantidad pequeña de ejemplares de diferentes razas que poseían estándares determinados. La mayoría fueron realizadas por la principal agrupación de cunicultores del país, que actualmente se denomina SUDEC (Sociedad Uruguaya de Cunicultores). Estas importaciones tenían como principal objetivo incorporar nuevas razas y en ocasiones reforzar poblaciones de razas existentes, para luego mantener los estándares originales.

Quizás el primer antecedente de una importación de líneas con especialización productiva fue el realizado por la empresa Proinco en la década de los 80. Esta importación incluyó líneas maternas y terminales de origen alemán, que fueron mantenidas en un núcleo de multiplicación centralizado. Luego de la desaparición de ese emprendimiento comercial en los 90, el entonces encargado del manejo de los núcleos, Sr. Carlos Amaral procuró la conservación de dichas líneas distribuyendo los animales entre varios criaderos de los alrededores de la ciudad de Minas (departamento de Lavalleja). Casi una década después parte de estos animales se convertirían en la base de la Línea Celeste de INIA.

En 1999 la consultoría realizada en Uruguay por el Dr. Manuel Baselga, genetista Catedrático de la Universidad Politécnica de Valencia (UPV), inició una relación de intercambio técnico científico con España que además incluyó la donación del material fundador de núcleos de selección de líneas de alto potencial productivo. Mediante la técnica de transferencia de embriones vitrificados, se logró la constitución de núcleos de selección de dos líneas especializadas de conejos para carne, la línea Verde y la línea Rosa en el año 2000.

Paralelamente desde el año 2001, en el marco de un convenio con la Comisión Nacional de Fomento Rural y la Sociedad de Fomento Rural de Ortiz en Lavalleja, se realizaron trabajos de selección en la población de conejos procedente de Proinco, conservada en criaderos de productores asociados, con el fin de establecer una segunda línea materna de origen nacional (Línea Celeste). Esta población se destacaba sustancialmente en los aspectos reproductivos sobre la media nacional de las razas tradicionales en ese momento: Californiana, Neozelandesa y Chinchilla americana.

Es así, que se realizó un proceso de selección del material original importado desde Valencia en la Unidad Experimental de Cunicultura de INIA y en establecimientos de productores sobre la línea Celeste, que posteriormente también sería trasladada a la Unidad de Cunicultura de INIA. Con este trabajo se constituyó una base con diferentes líneas especializadas que permiten la aplicación de esquemas productivos eficientes tanto en los aspectos reproductivos como de crecimiento.

La pobre performance reproductiva de la línea Rosa amenazó la continuidad del núcleo de selección respectivo, por lo que en el año 2008 se realizó una nueva introducción de embriones vitrificados de esta línea 
y se incorporó la línea Amarilla. Como se logró una escasa supervivencia de embriones de la línea Rosa, finalmente se realizó una fusión de las líneas Rosa y Celeste, manteniéndose el nombre de la primera y el criterio de selección original de la misma.

\section{Línea Verde (UPV)}

Esta es una línea sintética maternal especializada, seleccionada por el criterio único del tamaño de camada al destete $\left(\mathrm{N}^{\circ}\right.$ de gazapo /hembra/parto).

Se caracteriza por ser una línea de tamaño medio (4,5 kg de peso vivo) y una alta prolificidad (Figura 1). Entre sus características reproductivas, además de la prolificidad, se destacan la precocidad sexual, la alta frecuencia de celo, alta tasa de concepción, la adaptación a ritmos reproductivos intensos y la gran habilidad materna.

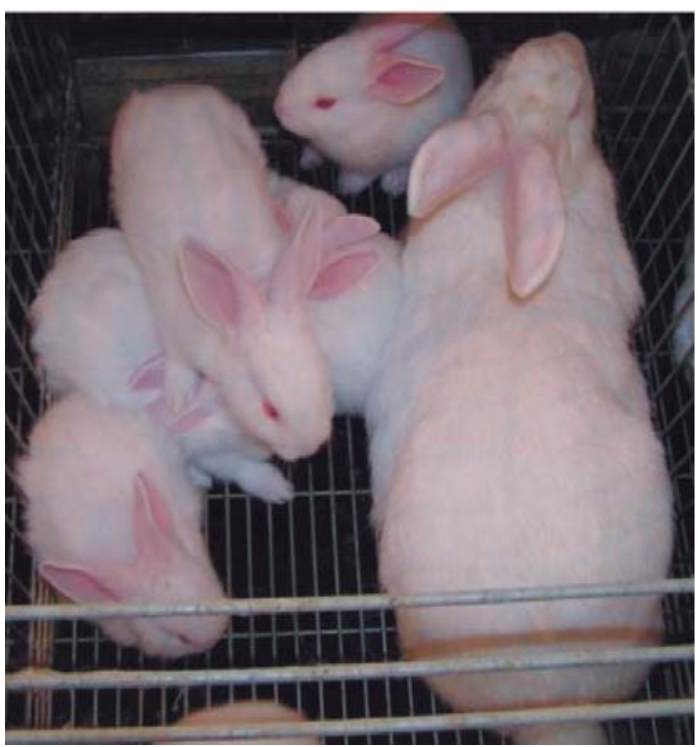

Figura 1. Linea Verde (UPV).

\section{Línea Rosa (UPV)}

Esta es una línea utilizada como terminal; el criterio único de selección es la velocidad de crecimiento, medida como la ganancia de peso entre los 32 y 70 días de edad. El programa de selección en este caso utiliza la selección masal, dada la alta heredabilidad de los caracteres asociados a la ganancia de peso. Los individuos de esta línea poseen un alto peso, pudiendo alcanzar los $7 \mathrm{~kg}$ en hembras adultas y $6 \mathrm{~kg}$ en machos (Figura 2). Su característica más sobresaliente es la velocidad de crecimiento, que oscila entre los 45 y 53 gramos por día según la estación del año y la etapa fisiológica de los animales. Son animales muy compactos, alcanzando pesos muy superiores a ejemplares de las razas tradicionales o líneas reproductivas de similar edad.

En condiciones de producción comercial, los machos son utilizados en el cruzamiento final para dar velocidad de crecimiento y eficiencia de conversión a los gazapos destinados a faena.

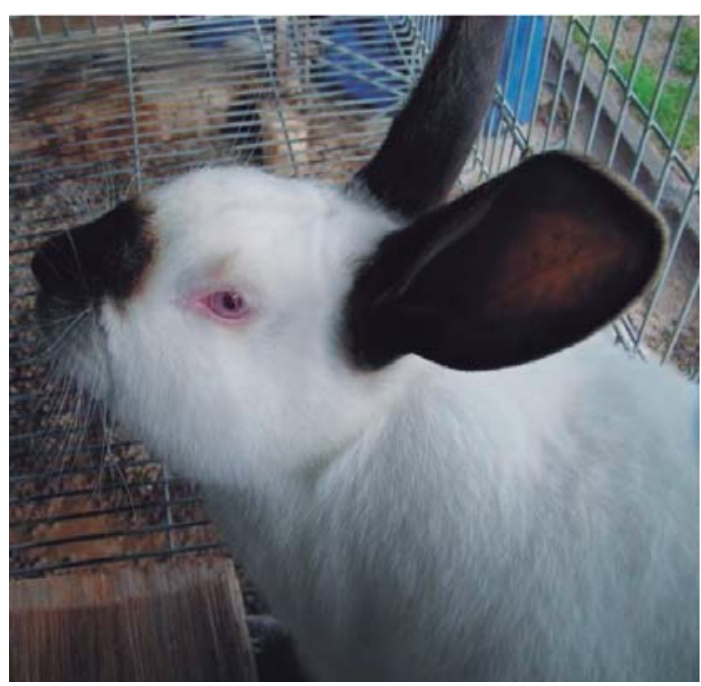

Figura 2. Linea Rosa (UPV).

\section{Línea Amarilla (UPV)}

Se trata de la línea maternal más antigua de la Universidad Politécnica de Valencia y una de las más extendidas en Europa a nivel comercial en cruzamientos maternales con la línea Verde. También ha sido seleccionada por tamaño de camada al destete y su objetivo es la producción de madres híbridas, en cruzamiento con la línea Verde (Figura 3). 


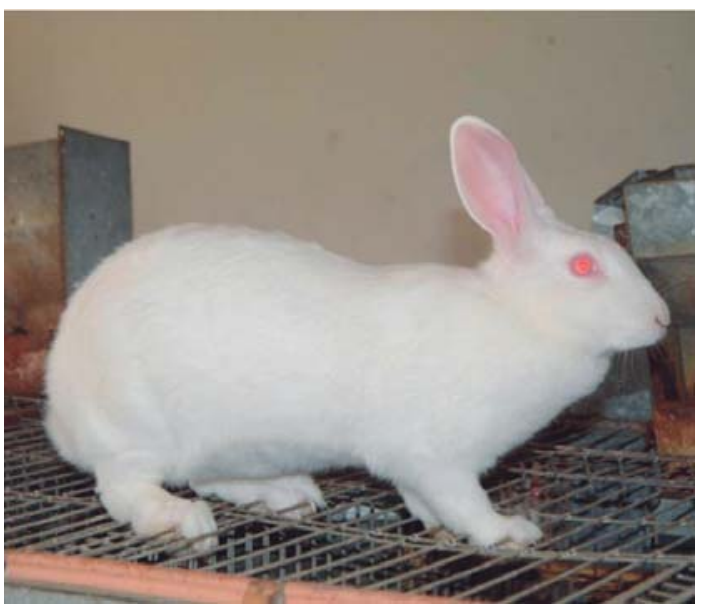

Fig. 3. Línea Amarilla UPV.

\section{Línea Celeste (INIA-CNFR)}

Originalmente la población fundadora proviene de un programa de producción desarrollado sobre la base de la raza Neozelandesa con diferentes grupos de especialización productiva. El programa de selección aplicado en la formación de esta línea, utilizó como criterio único el tamaño de camada al destete y metodología similar a la línea Verde.

Se caracteriza por ser una línea de tamaño medio (4,5 kg de peso vivo) y una prolificidad elevada. También se destaca por su adaptación al medio, ya que ha tenido un gran número de generaciones en nuestras condiciones de producción.

Su finalidad era utilizarla como línea abuela en la producción de madres híbridas (Celeste $x$ Verde) que serían empleadas en el futuro para la producción comercial con el esquema de cruzamientos de tres vías. Luego de seis generaciones de selección y tras la importación de la línea Amarilla, se discontinuó el proceso de selección en esta línea.

\section{PROGRAMA DE SELECCIÓN DE LA LÍNEA VERDE EN URUGUAY}

El núcleo desarrollado en Uruguay mantuvo como único criterio de selección el tamaño de camada al destete. Se realizó una evaluación genética anual por medio de la utilización de un modelo animal (BLUP), apuntando a que las conejas tuvieran 3 partos para aumentar la precisión de la estimación. Luego de cada evaluación genética en base a la Diferencia Esperada en la Progenie (DEP) para número de gazapos destetados por hembra y parto (DEP NGD), se seleccionaban las hijas e hijos de las mejores madres que serían los padres de la nueva generación. Asimismo, con el fin de no incrementar la consanguinidad se combinaban las diferentes líneas de origen de los padres.

En la última evaluación (año 2011, décima generación), se evaluaron en total 1.353 animales, 886 madres, con un promedio de 2,89 destetes. El modelo utilizado y los parámetros genéticos fueron los recomendados por el equipo técnico de la UPV. Se corrigió por los efectos fijos del grupo contemporáneo año-estación (26 niveles en el último año), estado de la lactancia (4 niveles), y por los efectos aleatorios: permanente de la coneja y del animal. Se descartaron los datos con destetes igual a cero debido a que se consideraban «desastres naturales» debidos a problemas de manejo o sanitarios y no a causas genéticas. De esta forma, el número de gazapos destetado promedio fue de $7,7 \pm 2,5$. En la Figura 4, se presentan los animales evaluados por generación. El promedio fue de 123 animales evaluados por generación, notándose un aumento en las primeras generaciones (hasta la cuarta), donde el número de animales tiende a estabilizarse con oscilaciones debidas principalmente a razones de manejo.

\section{Desempeño reproductivo: resultados fenotípicos}

En la Figura 5, se observa la evolución desde el año 2002 hasta el 2011 del desempeño reproductivo de las conejas en el núcleo de selección (NLV). El promedio a través de los años fue de 7,51 $\pm 2,77$ gazapos destetados por coneja por parto, sin embargo se observa una gran variación del desempeño reproductivo en los diferentes años-trimestre. El descenso registrado en el año 2010 se debió principalmente a factores de manejo, que pudieron ser corregidos al año siguiente. 


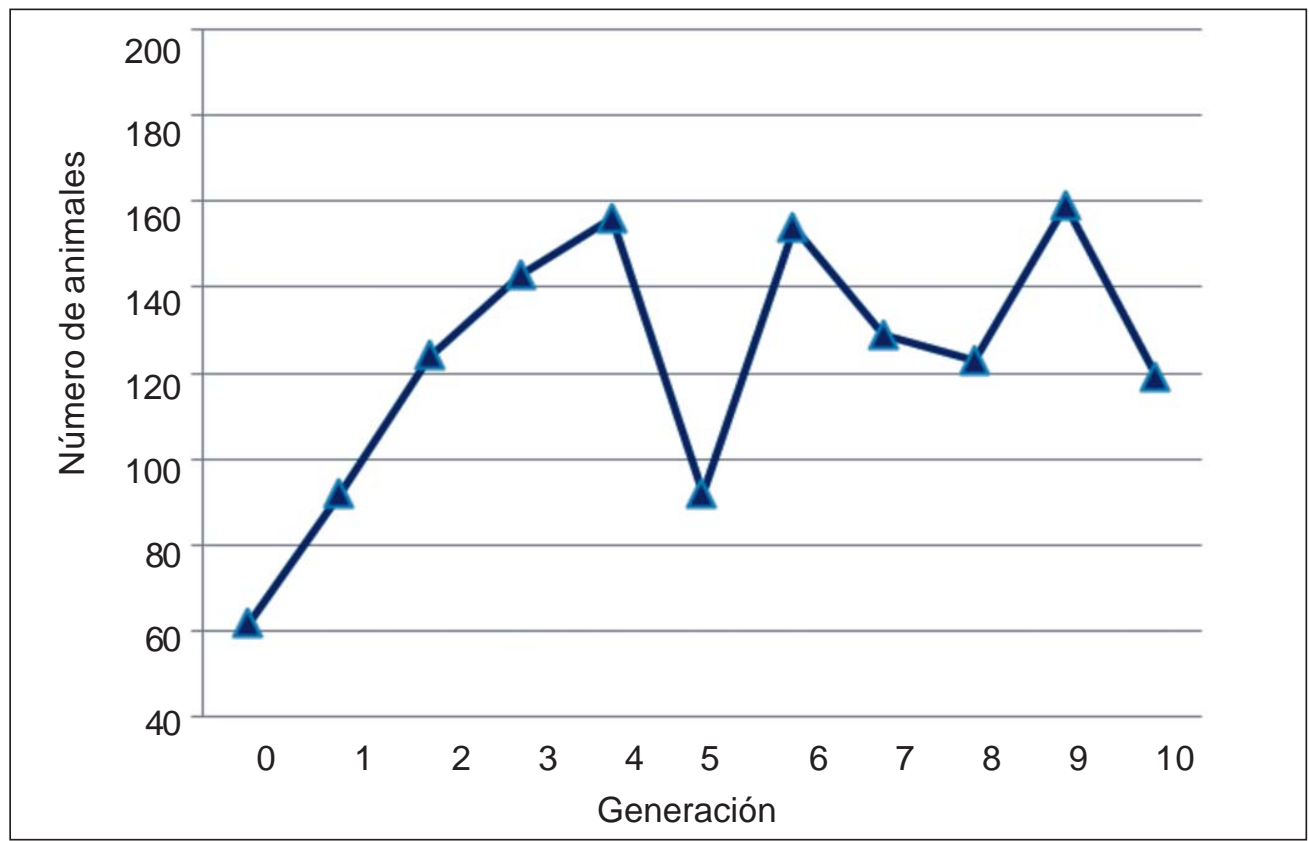

Figura 4. Animales evaluados por generación.

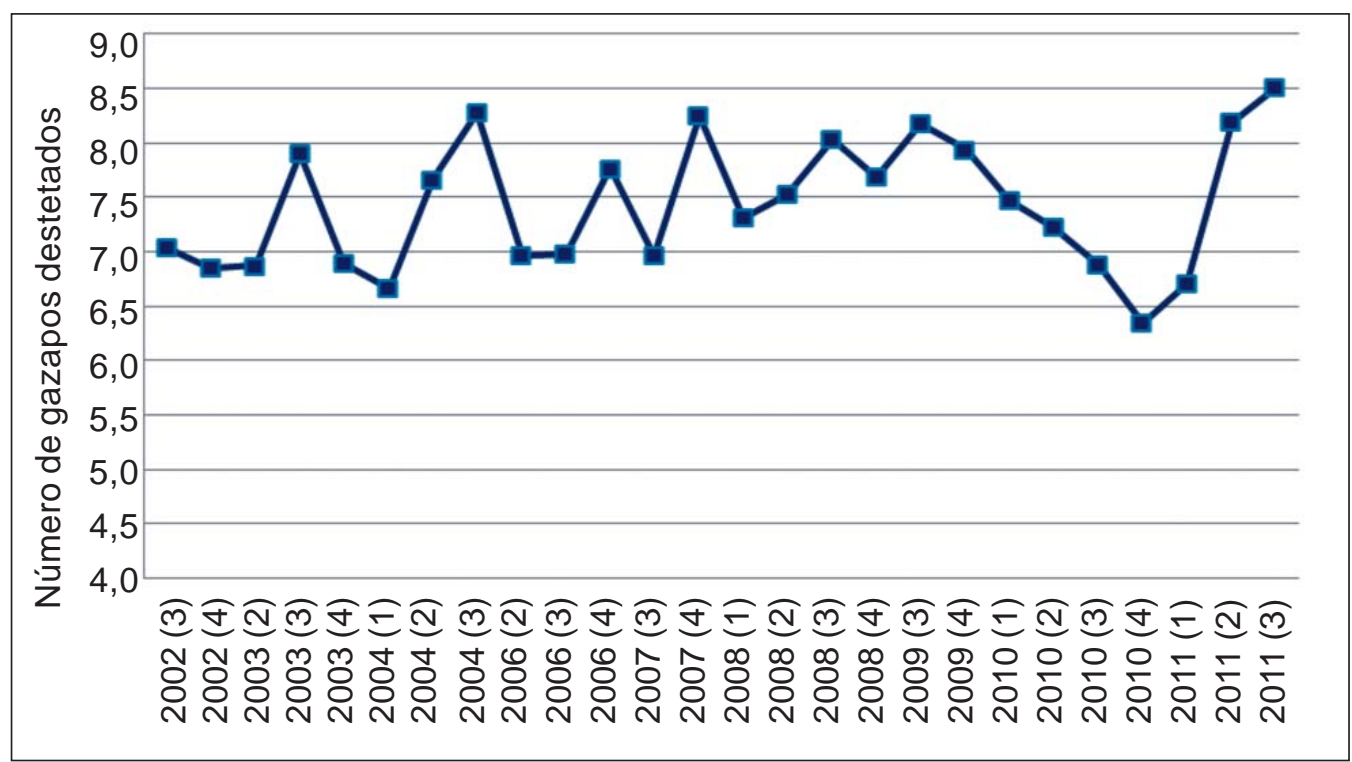

Figura 5. Número de gazapos destetados por Año-Trimestre.

\section{Resultados de la mejora genética}

En la Figura 6, se presenta la tendencia genética lograda desde la generación 0 a la 10 (correspondiente aproximadamente a los años 1999 a 2010). La respuesta genética lograda fue de 0,062 gazapos destetados por camada y por generación.
Esta respuesta estimada por BLUP-REML, se encuentra entre los valores citados por Baselga et al. (en esta publicación) obtenidos por varios estudios (Estany et al., 1989; Rochambeau et al., 1994; Gómez et al., 1996). Estas tendencias reflejan el correcto trabajo realizado en estos años, demostrando que se pueden lograr progresos interesantes incluso en poblaciones reducidas. 


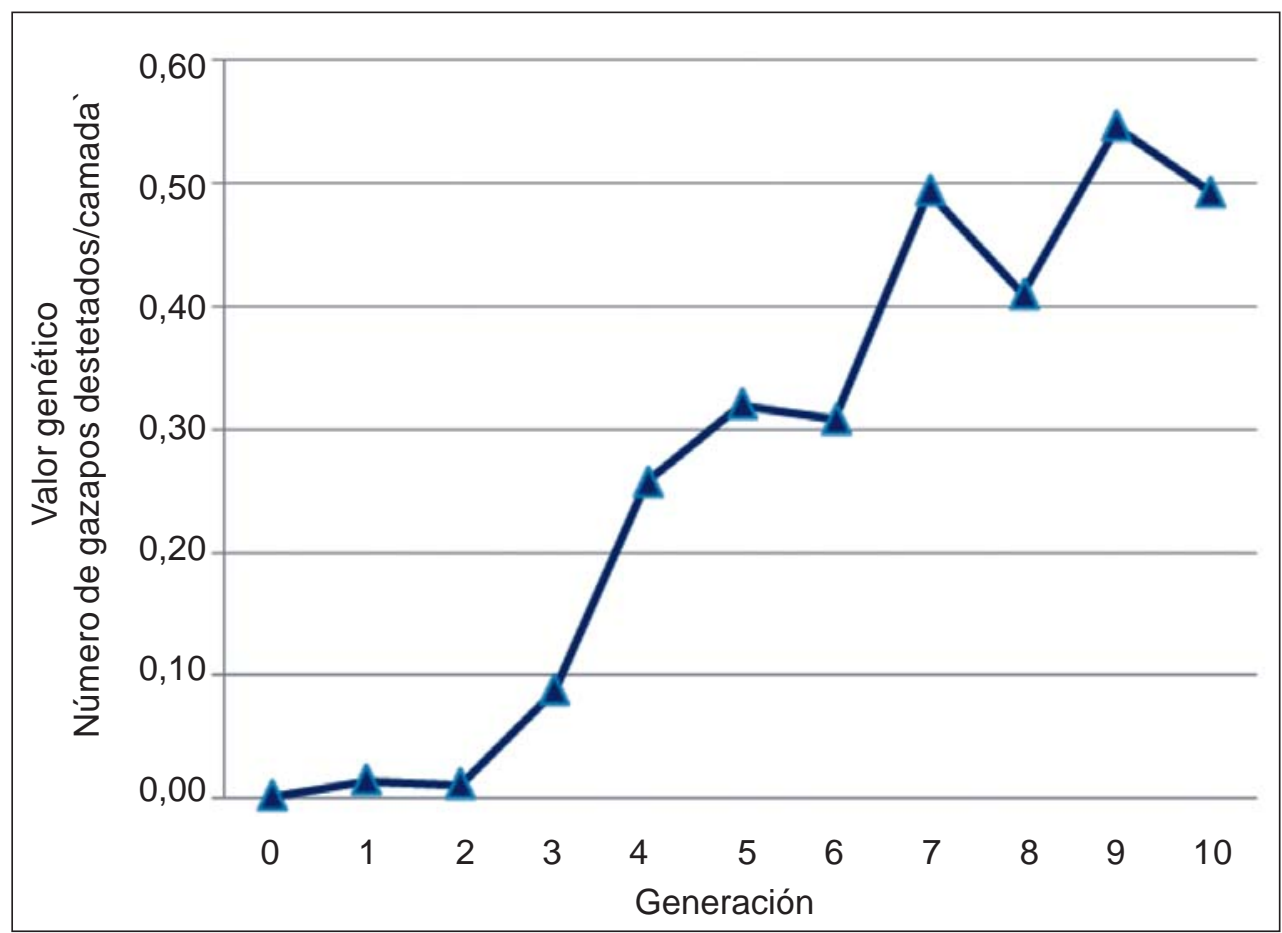

Figura 6. Tendencia genética para el número de gazapos destetados por camada.

\section{Consanguinidad y número efectivo}

Como se mencionó anteriormente, se realizó un esfuerzo adicional con el fin de controlar los apareamientos consanguíneos dentro del núcleo. Originalmente se manejaron 25 líneas de padres. Estas se mantuvieron hasta la generación 10 con al menos una coneja por línea. En esta última generación $(n=119)$, el promedio fue de 4.8 hembras por línea de padre (4\%), con un mínimo de una y un máximo de 10 hembras $(0,8$ y $8,4 \%$, respectivamente). La disminución de la cantidad de hembras por línea en general se debió a problemas de manejo y posibles errores en la correcta identificación de la línea de origen.
En la Figura 7, se presenta la variación de los coeficiente de consanguinidad $(F)$ y parentesco (f) promedio a través de las diferentes generaciones. Las tasas de consanguinidad $(\Delta \mathrm{F})$ y de parentesco $(\Delta \mathrm{f})$ por generación fueron de 0.00507 y 0.00424 , respectivamente. Basándose en estos coeficientes el número efectivo $(\mathrm{Ne})$ de la población de acuerdo con Falconer y Mackay (1996) sería de 118 y 99, respectivamente. De acuerdo con lo propuesto por Pérez-Enciso (1995), basándose en la regresión del Logaritmo natural de (1-F) con la generación (pendiente $b=-0.00515)$ el Ne sería de sería de 97. Si bien se ha incrementado la consanguinidad y el parentesco con el correr de las generaciones, estos son tolerables y no han redundado en un descenso marcado del $\mathrm{Ne}$. 


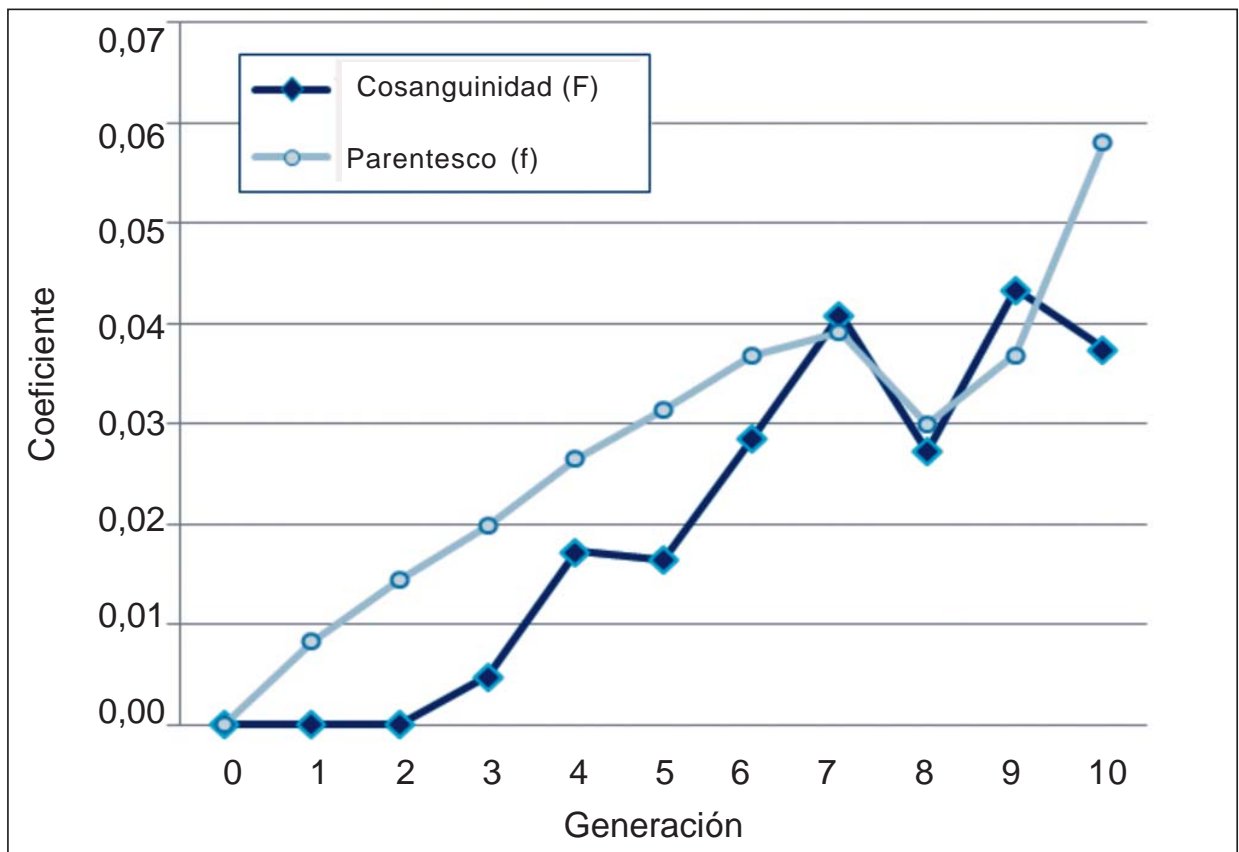

Figura 7. Coeficientes de consanguinidad (F) y parentesco (f) promedio por generación.

\section{Organización y difusión de la mejora}

\section{Bases de la propuesta}

Cuando se introdujeron por primera vez las líneas sintéticas procedentes de la Universidad Politécnica de Valencia se concibió una estrategia de corto plazo, basada en la utilización de las líneas Verde y Rosa en cruzamiento simple, combinada con una meta de largo plazo consistente en la utilización de cruces a tres vías con el uso de las líneas españolas más la incipiente línea Celeste de origen nacional.

La posterior introducción de la línea Amarilla permitió acortar el camino y ofrecer dos posibilidades al productor, en función de su experiencia y escala de producción: la cruza simple Rosa x Verde y la triple cruza Rosa $x$ (Amarillo $x$ Verde).

La propuesta de la cruza simple se consideró especialmente recomendable para productores que se inician en la cunicultura y que poseen una plantel de pequeño tamaño. Consiste en el cruzamiento simple, utilizando madres de la línea Verde y padres de la línea Rosa (Figura 8). Todos los gaza- pos producidos se destinan, en este caso, a la faena; el productor no produce sus propios reproductores para la reposición o crecimiento de su plantel, sino que se abastece de hembras Verde y machos Rosa.

En el mediano plazo o en el caso de productores experientes y con planteles de un tamaño que lo justificara, se procuró explotar las ventajas del cruzamiento a tres vías, es decir aprovechar la heterosis de las características reproductivas, con madres híbridas producto del cruzamiento de dos líneas maternales (Amarilla $x$ Verde), y la velocidad de crecimiento de la línea Rosa, utilizada como macho para el cruzamiento terminal (Figura 9).

Para proveerse de reposición se recomienda la adquisición de hembras de la línea Verde y al menos un macho de la línea Amarilla para producir hembras cruza para el plantel. Estas hembras cruza o «híbridas» serán servidas por un macho terminal de la línea Rosa para obtener los gazapos destinados a faena. En esta situación el productor debe abastecerse solamente de una parte de sus reproductores, ya que él mismo produce la mayor proporción de las hembras que necesita para su plantel. 

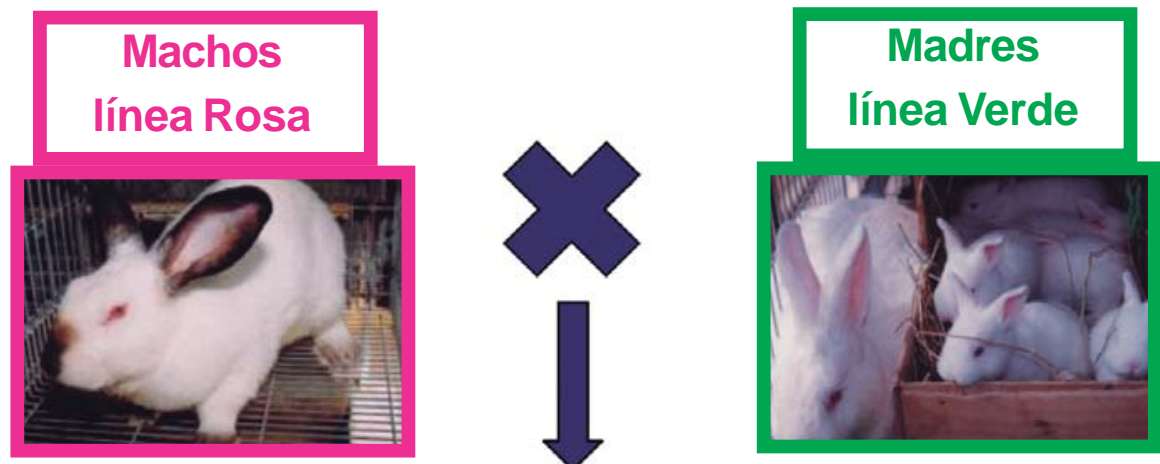

F1

gazapos híbridos para faena

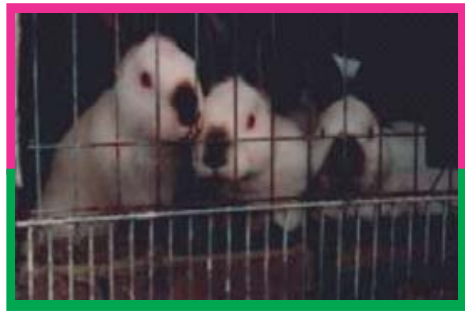

Figura 8. Cruza simple entre dos líneas.

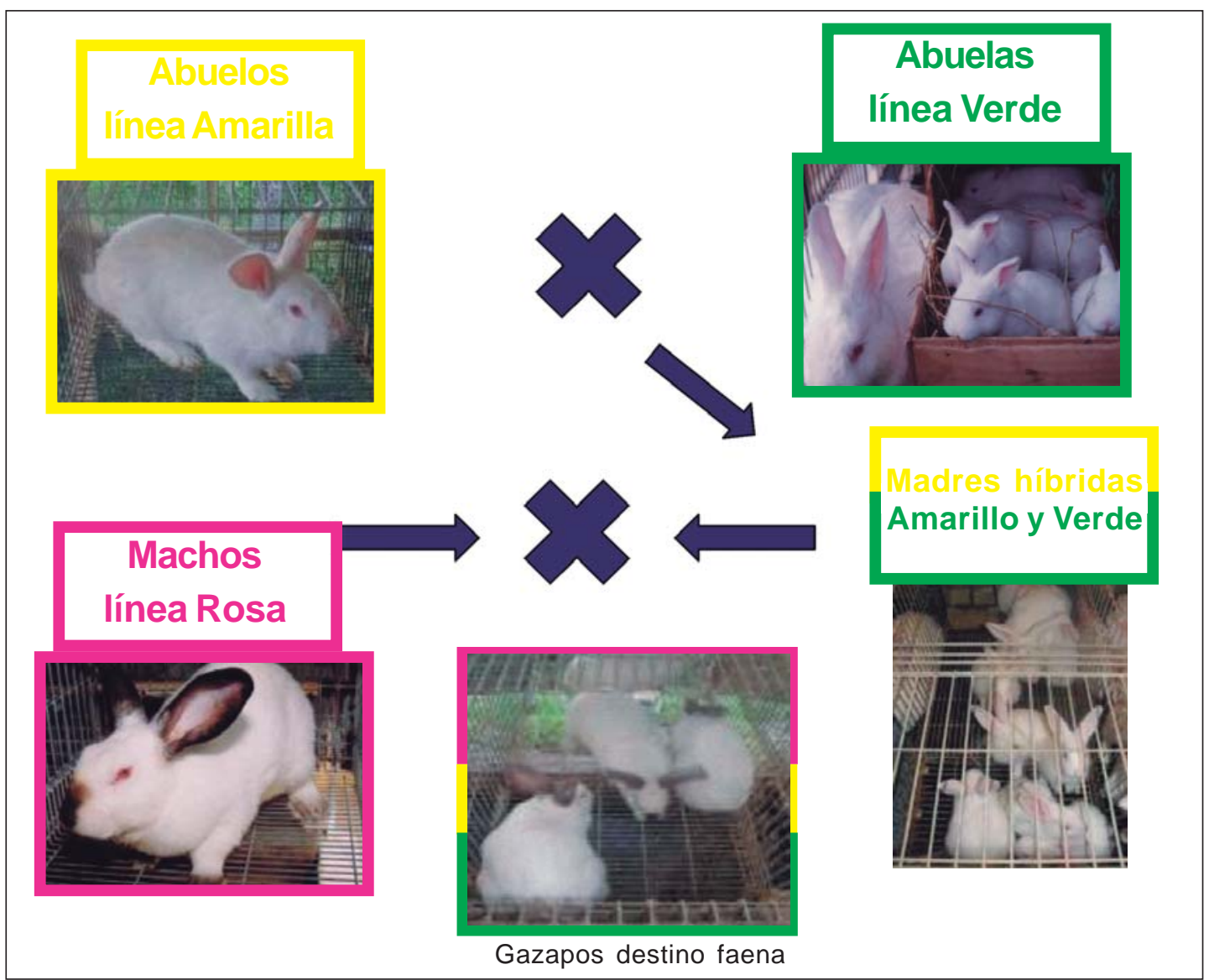

Figura 9. Esquema basado en la triple cruza. 


\section{Adopción de la mejora genética}

El proceso de difusión de la propuesta tecnológica relacionada a la disponibilidad de una base genética de alto potencial productivo y la consiguiente respuesta de adopción (o rechazo) por parte de los cunicultores uruguayos no tuvo una trayectoria lineal, sino que mostró facetas diferentes, condicionadas por la evolución de la cunicultura nacional y las expectativas con respecto a su consolidación como medio de vida para los productores. Si bien en su momento no se valoró la necesidad de documentar los avances o de someter el proceso a una evaluación basada en datos objetivos, parece oportuno relatar algunos acontecimientos para que la experiencia uruguaya pueda ser aprovechada.

La primera introducción de las líneas genéticas originarias de la Universidad Politécnica de Valencia fue acogida con dudas por parte de los productores, en relación a su adaptación a las condiciones de producción prevalecientes en el país. Con el acompañamiento de técnicos de una agencia de extensión gubernamental, la Junta Nacional de la Granja (JUNAGRA) se programó una instancia de validación en predios de cunicultores, donde se evaluó el comportamiento reproductivo de la línea Verde y el desempeño productivo de individuos cruza Rosa $x$ Verde en comparación con los tipos genéticos que utilizaban los productores, mayoritariamente cruzamientos asistemáticos entre individuos de las razas Neozelandés, Californiano y Chinchilla. Los primeros resultados no fueron auspiciosos, en contraste con los que se obtenían en la Unidad Experimental de Cunicultura de INIA. En particular el desempeño de la línea Verde no mostraba ventajas con respecto a la genética tradicional, aunque los productores rápidamente quedaron impresionados por el desempeño de la descendencia de la línea Rosa en cuanto a velocidad de crecimiento y eficiencia de conversión del alimento. Ya a partir de ese momento quedó establecida una fuerte demanda por reproductores machos de la línea Rosa.

Analizando las posibles causas del desempeño sub-óptimo de las hembras de la línea Verde, se estableció que el error había sido introducir los animales a las granjas a una edad demasiado próxima al inicio de la vida reproductiva, sin que tuvieran posibilidades de adaptación al nuevo ambiente y a su particular carga de potenciales patógenos. En coordinación con los técnicos de la UPV se promovió, a partir de esa experiencia, la entrega de reproductores a una edad máxima de 90 días y con un peso vivo máximo en el entorno de los $2,5 \mathrm{~kg}$.

Entre las pautas de manejo recomendadas para las líneas genéticas se hizo especial énfasis en este aspecto (García et al., 1999), que fue ratificado posteriormente en una actualización de las recomendaciones para el mejor manejo de los reproductores, publicada en 2011:

«Las medidas que el cunicultor debe tomar comienzan desde la adquisición misma de los reproductores. Es común que la ansiedad por un rápido retorno de la inversión realizada lleve a preferir la compra de reproductores que ya se encuentren en edad de servicio, lo cual en ocasiones puede generar dificultades. La experiencia indica que cuando los animales son trasladados requieren un tiempo para su adaptación al nuevo ambiente. En este aspecto, la adaptación no es únicamente un proceso de acostumbramiento a nuevos locales, jaulas, ruidos, olores, alimentación y manejo, sino también un proceso fisiológico que implica la adquisición de inmunidad contra cepas de patógenos locales, en especial cuando estos animales integrarán una unidad productiva que ya está en funcionamiento y por lo tanto con animales preexistentes.» (Blumetto y Capra, 2011)

Corregida esta importante clave del manejo y ajustadas las recomendaciones para sacar provecho del potencial productivo de las líneas introducidas, se inició una etapa de activa difusión de la genética, que acompañó un momento de expansión de la cunicultura y de incremento en el número de cunicultores. Para inicios del año 2004 la demanda de reproductores superaba las posibilidades de producción de la Unidad Experimental de Cunicultura, por lo que se instrumentó un convenio con productores que asumirían el rol de multiplicadores. Se sumó el 
interés de productores argentinos por introducir las líneas a su país y actuar también como multiplicadores de la genética INIA.

Lamentablemente en diciembre de 2004 se produjo en Uruguay un brote de Enfermedad Hemorrágica Viral del Conejo (EHVC), enfermedad de la que no se registraba ningún antecedente en el país, circunstancia que afectó profundamente la trayectoria ascendente de la cunicultura uruguaya. También determinó el cierre del mercado argentino para reproductores y todo producto derivado del conejo de origen uruguayo. Si bien las medidas de control de la enfermedad adoptadas por la Dirección de Sanidad Animal del MGAP (basadas en la aplicación de rifle sanitario en los criaderos afectados y la vacunación obligatoria), resultaron rápidamente efectivas, la cadena productiva y comercial cunícola no logró restablecer por completo las condiciones necesarias para su consolidación. Hubo un generalizado abandono de la actividad por parte de los cunicultores, lo que determinó una reducción en la demanda por reproductores.

A pesar de estas circunstancias desfavorables, se logró mantener un flujo razonable de venta de reproductores, que permitió una relativamente amplia difusión de la genética puesta por INIA a disposición de los productores. Un trabajo de investigación orientado a caracterizar las condiciones de producción de conejos para carne en Uruguay, permitió establecer que un $68 \%$ de los productores cunícolas disponían de reproductores de la línea Verde procedentes de INIA (Amoza et al., 2008).

A partir de la introducción de la línea Amarilla definitivamente se consolidó una estabilidad en la demanda de reproductores, ante la posibilidad de generar la reposición en el propio criadero que definió bases sólidas para la utilización más generalizada de la nueva propuesta. Entre 2008 y 2010 la venta de reproductores se multiplicó por 2,4 y la de machos de las dos líneas (Amarilla y Rosa) por 3,3.
En el año 2012, INIA tomó la decisión de ofrecer los núcleos de selección, derivados de las líneas genéticas introducidas desde España, a instituciones académicas u organizaciones sin fines de lucro que estuvieran interesadas en dar continuidad a los trabajos de mejoramiento genético. Se consideró que se había cumplido la meta de poner a disposición de la cadena cunícola uruguaya un producto tecnológico (las líneas genéticas) con alto potencial productivo, una metodología de selección validada y con pruebas fehacientes del progreso genético logrado, así como un conjunto de tecnologías de manejo reproductivo, nutricional y sanitario capaces de permitir la expresión de las capacidades potenciales de las líneas en un esquema definido de cruzamientos. En diciembre de 2013 se concretó la adjudicación de los núcleos (en una cesión en comodato) a una ONG, a la que se continúa apoyando técnicamente para propiciar la consolidación del emprendimiento y contribuir al cumplimiento de sus fines sociales.

\section{BIBLIOGRAFÍA}

AMOZA, C.; LUSARDO, R.; OLIVER, L. 2008. La explotación de la cunicultura y su fomento en el Uruguay. Montevideo: Facultad de Ciencias Económicas y Administración, Universidad de la República, $170 \mathrm{p}$.

BLUMETTO, O.; CAPRA, G. 2011. Recomendaciones para el manejo de líneas genéticas de alto potencial en conejos para carne. Actualización 2011. Canelones: INIA: Jornada Anual de Cunicultura, 1 de octubre de 2011. (Serie Actividades de Divulgación, 656).

GARCÍA, M.L; VICENTE, J.S.; TORRES, C. 1999. Difusión del material genético en cunicultura. Hoja de Divulgación de Producción Animal. Cunicultura, 26: 5 p.

PEREZ-ENCISO, M. 1995. Use of the uncertain relationship matrix to compute effective population size. Journal of Animal Breeding and Genetics, 112: 333-340.

FALCONER, D.S.; MACKAY, T.F.C. 1996. Introduction to quantitative genetics. New York: Longman, 463 p. 


\section{REPRODUCCIÓN: ASPECTOS FISIOLÓGICOS Y DE MANEJO EN LA CUNICULTURA}

Claudio Scapinello ${ }^{1}$

\section{INTRODUCCIÓN}

La rentabilidad de las explotaciones de conejos para producción de carne depende, entre otros factores, de la productividad, o sea del número promedio de gazapos producidos y vendidos por madre alojada en el criadero. Esta meta exige, primeramente, la disponibilidad de madres con elevada prolificidad y alta habilidad materna, capaces no solo de parir sino de destetar camadas pesadas y numerosas.

Estudios realizados en Francia en el año 2009, mostraron que las diferencias entre granjas de mayor y menor productividad son debidas, principalmente a tres factores:

- nacidos vivos/parto;

- fertilidad;

- mortalidad en el período de destete a faena.

Es evidente que todos los factores considerados pilares de la producción (genética, nutrición, sanidad, instalaciones y manejo), deben ser considerados en una misma medida para la obtención de resultados económicos de una explotación de conejos, sin contar con otros conceptos ligados a la sustentabilidad y bienestar de los animales. Del conjunto de todos estos factores observados y su aplicación diariamente es que resulta la viabilidad de la crianza de conejos, obteniéndose la máxima eficiencia de producción dentro de las condiciones de crianza y potencial genético del animal.

Se ha de considerar que todos los parámetros zootécnicos y económicos de una crianza de conejos son determinados por los parámetros reproductivos. Como ejemplo, el índice de conversión alimenticia global de una granja y el margen económico promedio sobre la alimentación de cada coneja difieren de acuerdo con el número de conejos destetados/madre/año.

Aspectos relacionados a la fisiología de reproducción de la coneja deben ser dominio del cunicultor para que pueda conducir el manejo reproductivo, buscando la máxima eficiencia de producción dentro de las condiciones presentes en el criadero.

\section{FISIOLOGÍA DE LA REPRODUCCIÓN}

La coneja presenta características reproductivas diferentes de otras especies zootécnicas, teniendo en cuenta que su ovulación no es espontánea y su ciclo estral solamente se completa con la liberación de óvulos por el ovario si hubiera estímulo con la monta o la aplicación de hormonas luteinizantes (LH).

En los casos en que la monta o la aplicación de LH no ocurren, los folículos maduros inician un estado de degeneración (atresia), siendo reabsorbidos en el ovario.

El aparato reproductor de la coneja comprende los siguientes órganos: dos ovarios, dos infundíbulos, dos oviductos, dos úteros, vagina y vulva.

Los ovarios presentan forma alargada y elíptica, con una superficie irregular y de coloración ligeramente amarilla el peso oscila entre 200 y 800 mg. Estos órganos poseen estructuras en su zona cortical denominados folículos ováricos, en distintas fases de desarrollo, responsables tanto de la síntesis de hormonas sexuales (estrógenos y progesterona), como del desarrollo y ma- 
duración de gametos femeninos, llamados ovocitos. También son encontrados los folículos atrésicos (degenerados) y los cuerpos lúteos, estos últimos en la medida que ha habido ovulación.

Los infundíbulos son una membrana conjuntiva encargada de capturar óvulos, liberados a partir del rompimiento folicular por causa de la ovulación estando situados junto al ovario.

Los oviductos son conductos finos y sinuosos, con aproximadamente $2 \mathrm{~cm}$ de largo, donde, en su tercio superior, se procesa la fecundación.

La coneja presenta úteros dobles, completamente separados entre sí, midiendo 5 a $7 \mathrm{~cm}$ de largo, con cuerpo diminuto, con dos cuernos uterinos de grandes dimensiones, donde son fijados y desarrollados los fetos que serán expulsados al final de la gestación, a través de los cuerpos uterinos y cérvix que se abre a la vagina.

La vagina es un conducto que mide de 6 a $10 \mathrm{~cm}$, que en su tercio final y en su porción ventral se encuentra una abertura de la uretra. El conocimiento de la posición de la abertura de la uretra es importante para evitarla durante las prácticas de inseminación artificial.

La vulva representa la porción final y externa del aparato reproductor de la coneja. Sus labios cambian de color y turgencia dependiendo del estado de receptividad sexual del animal. Los colores de la vulva varían de blanco, rosado, rojo y púrpura de acuerdo con las fases en que la coneja se encuentra en su ciclo estral, aspecto este importante para ser utilizado en el manejo reproductivo y que será abordado más adelante.

\section{DESARROLLO DEL APARATO GENITAL DE LA CONEJA}

La diferenciación sexual de los gazapos ocurre a los 14 a 15 días de gestación o sea, en la mitad de la gestación.

A partir del epitelio germinativo primitivo ocurre la formación de tres elementos sucesivos:

1- Aparición de cordones medulares: a los 23 días de gestación;

2- Formación de epitelio germinativo primordial: un día y medio después del nacimiento y que darán origen a la primeras células germinativas que madurarán en el futuro.

3- Producción de los primeros ovocitos: entre la $3^{\circ}$ y $4^{\circ}$ semanas de edad. Estas células serán los primeros óvulos que madurarán más adelante.

Del punto de vista fisiológico, las primeras maduraciones foliculares, ocurren entre los 65 a 90 días. A partir de los 80 a 90 días de edad se producen maduraciones foliculares cíclicas de forma continua. La pubertad se presenta entorno a la $17^{\circ}$ a $20^{\circ}$ semana con variaciones de acuerdo con las razas, alimentación, estación del año, peso corpo-

Figura 1. Aparato reproductor de la coneja.

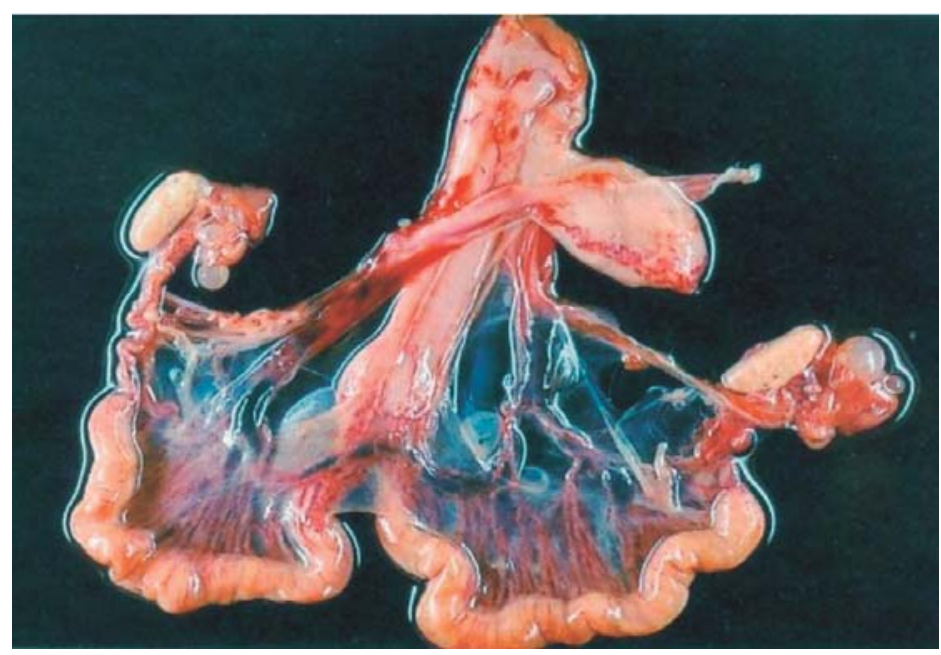


ral, entre otros factores. Las razas de porte medio para producción de carne presentan la pubertad entre 4 a 4,5 meses.

\section{CICLO ESTRAL DE LA CONEJA}

El estudio de la fisiología de la reproducción de la coneja permite comprender los mecanismos fisiológicos, que pueden ser modificados, en una u otra forma, al aplicar técnicas para el control de la reproducción, implicando mejoras en los resultados económicos de una explotación de conejos.

La coneja presenta características reproductivas diferentes de otras especies zootécnicas, debido a la ausencia de un ciclo estral definido y regular, además de la existencia de mecanismos reflejos que permiten la ovulación inducida por estímulos del coito.

Algunos autores mencionan la ausencia de un ciclo estral y afirman que la coneja se presentaría constantemente apta para ser fecundada. Sin embargo, la mayoría de los investigadores afirman que la coneja presenta ciclos, con duración de 16 días, siendo los dos días iniciales y los dos días finales infértiles o de remota fertilidad y en los 12 días restantes posibles de concebir. Todos los autores, partidarios de la teoría cíclica, consideran que se trata de un ciclo incompleto, donde la ovulación solamente se produce si hubo estímulos externos (monta, estímulos hormonales o procesos de bioestímulación).

Las dos fases iniciales del ciclo (pro estro y estro) ocurren de forma semejante a las demás especies. Durante la fase de proestro ocurre el crecimiento folicular y consecuentemente el aumento de los niveles de producción de estrógeno por los folículos, responsables por el comportamiento de celo y la receptividad para ser cubierta la hembra cada vez es mayor a medida que la coneja se aproxima al estro. El avance en este periodo del ciclo debe ser acompañado por el productor de conejos, observando los cambios en el color y aspecto de la vulva de la hembra que pasa de color más claro a rosada, cada vez más intensa, hasta roja, conjuntamente con el aumento de su tamaño y humedad. El conocimiento de este comportamiento fisiológico de la coneja tiene gran importancia en la definición del ritmo reproductivo a ser implementado en los planteles de conejos, con la intención de reducir, al máximo, las cubriciones forzadas en todos los casos en que la hembra no acepta al macho.

En la medida que haya un estímulo de monta mencionado anteriormente (presencia y lo saltos de un macho, hembras que saltan o se dejan saltar si son mantenidas en grupo en una misma jaula, o la aplicación de hormonas u otro estímulo que pueda inducir la ovulación), los folículos maduros, que aumentan en número con la proximidad de la fase de estro o celo, se rompen y liberan los óvulos, un proceso conocido como «ovulación». Este aspecto fisiológico exige que las madres sean mantenidas en jaulas separadas para evitar falsas gestaciones.

En el caso de que no haya cualquiera de estos estímulos, los folículos maduros pasaran por una fase de degeneración folicular durante el ciclo estral formando los «folículos atrésicos», al final se iniciará un nuevo ciclo con una nueva onda de crecimiento folicular.

En realidad, durante el período fértil del ciclo, la coneja puede presentar folículos viables para ser liberados, independientemente de las fases del ciclo, variando sin embargo en cuanto a su número.

Las diferentes fases del ciclo estral de la coneja pueden ser resumidas en la Figura 2.

Las diferentes fases del ciclo de la coneja podrían ser fácilmente identificadas a través de la coloración de la vulva, como puede ser observado en el Cuadro 1.

Este ciclo, es extremadamente sensible a factores como la luz, la temperatura, la alimentación, el manejo, la presencia del macho y diferencias individuales que se presentan, como estímulos que llegan al hipotálamo que pasa a producir hormonas liberadoras de Gonadotropina $(\mathrm{GnRH})$, que estimulan a la Hipófisis a producir hormona folículo estimulante (FSH) y en mayor escala la hormona Luteinizante (LH) que desencadenan la ruptura de los folículos maduros en el ovario, liberando óvulos (Ovulación). El folículo roto, en el ovario, se convierte en una nueva estructura endocrina denominada «cuerpo Lúteo», que pasa a producir la hormona Progesterona. 


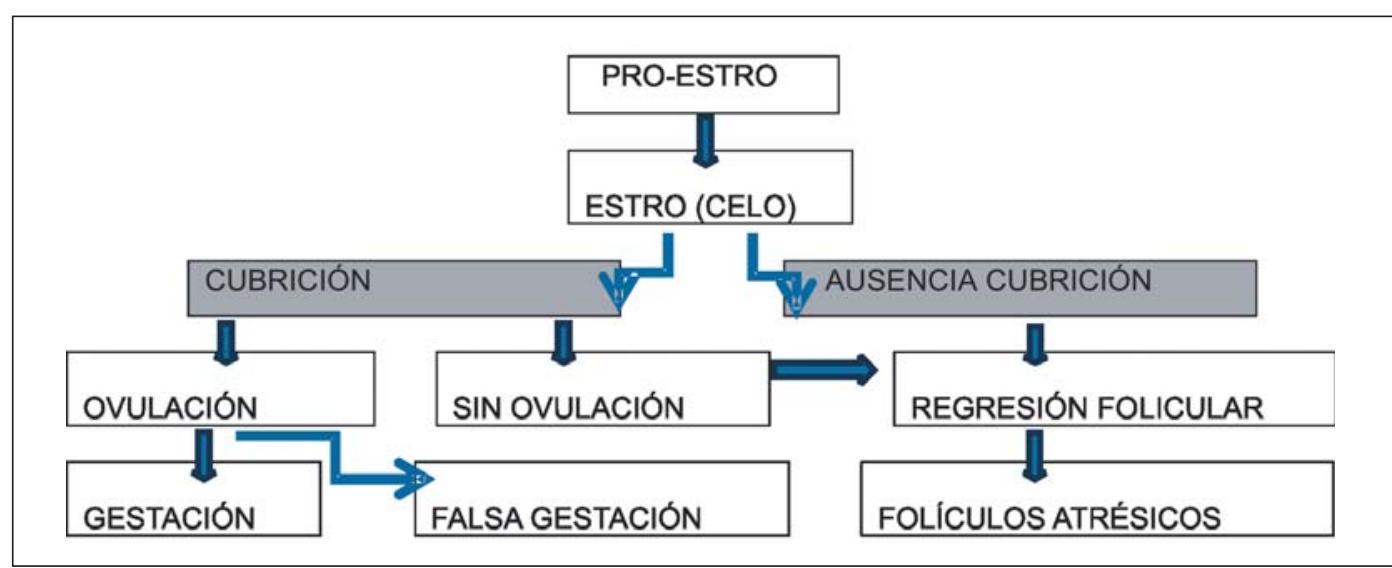

Figura 2. Fases del ciclo estral de la coneja.

Cuadro 1. Coloración de la vulva de la coneja en diferentes fases del ciclo.

\begin{tabular}{|l|c|c|c|c|c|}
\hline Color de la vulva & Blanca & Rosada & Roja & Violácea & Blanca \\
\hline Días de ciclo & $0-2^{0} \mathrm{~d}$ & $3^{0}-7^{0} \mathrm{~d}$ & $8^{0}-9^{0} \mathrm{~d}$ & $10^{0}-14^{0} \mathrm{~d}$ & $15^{0}-16^{0} \mathrm{~d}$ \\
\hline Fertilidad & Baja & Alta & & & Baja \\
\hline Fases de ciclo & Pro-estro & & Estro & Atresia folicular & \\
\hline
\end{tabular}

En cuanto a la hormona Estrógeno, producida por los folículos en el ovario, es responsable por el celo en la coneja, altos niveles plasmáticos de hormona Progesterona producidos por el cuerpo lúteo, inhiben todo este proceso. Con la ovulación e instalación del cuerpo lúteo, los niveles sanguíneos de progesterona permanecen altos, tanto en la situación en la que los óvulos hayan sido fecundados (siendo responsable en este caso del mantenimiento de la gestación), como si los óvulos liberados no hubieran sido fecundados; en este caso se instala un período denominado «seudogestación» 0 «falsa gestación» que dura aproximadamente 16 a 18 días después del coito. En la Figura 3 se

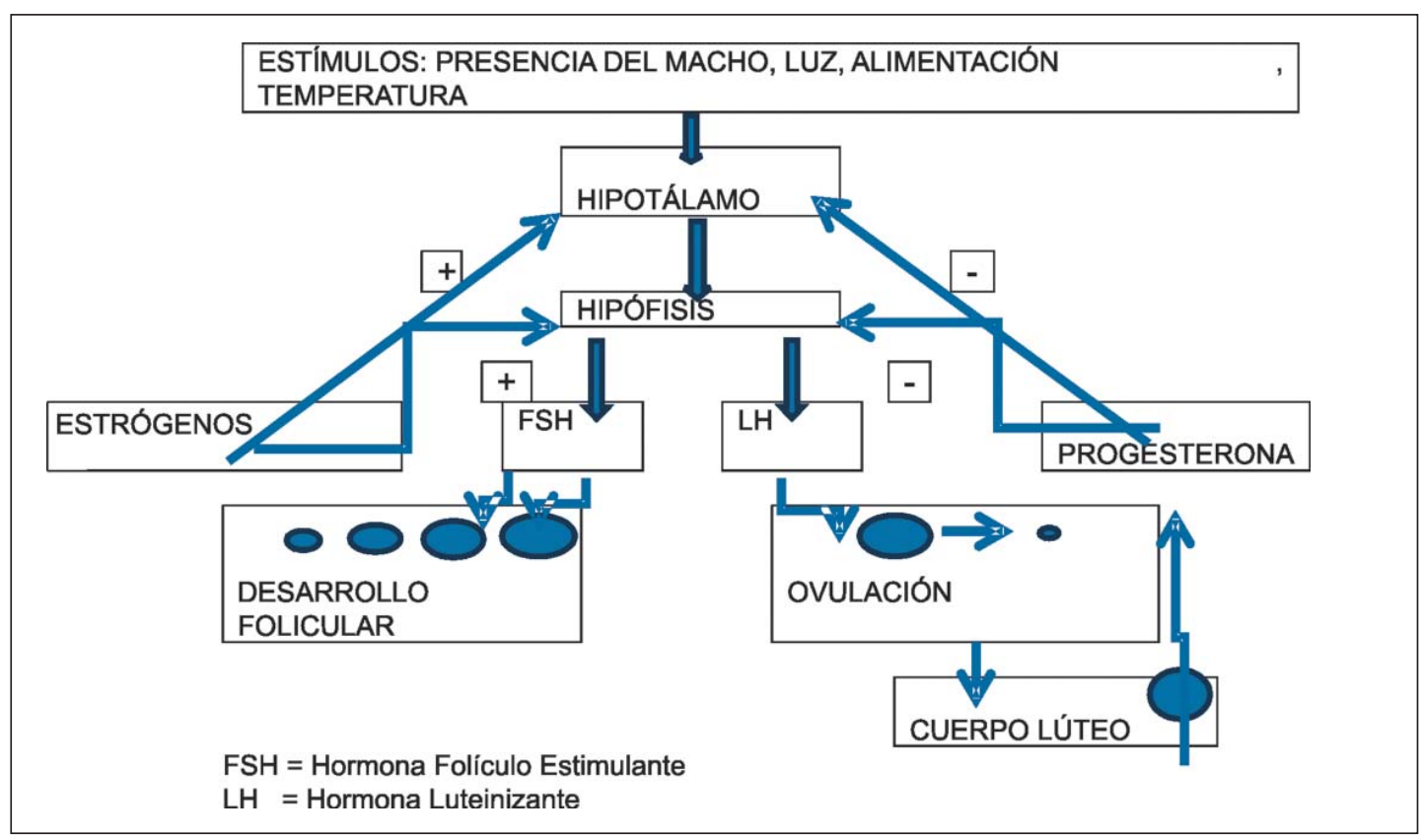

Figura 3. Control hormonal del ciclo estral de la coneja. 
presenta estructuras y hormonas que interfieren en el ciclo reproductivo de la coneja.

Al ser la coneja presentada al macho, podrá rechazar o aceptar la monta. En caso de rechazar, la coneja permanecerá inmóvil, con el vientre al ras del piso de la jaula y la cola protegiendo la región genital o intentando escapar del macho o aún agredirlo.

En caso de aceptar el macho, la hembra se presentará voluntariamente, inmóvil, adoptando una posición adecuada para posibilitar la penetración. Esta posición, denominada de lordosis, se caracteriza por la elevación de la parte posterior y la cola, exponiendo la vulva. Se asume que en esta condición la hembra se encuentra en celo y por lo tanto es el momento más adecuado para ser cubierta. Se debe considerar, en tanto, que aunque con pequeñas posibilidades, algunas hembras pueden aceptar el macho, en fase de ciclo estral no propicias a la reproducción o incluso estando en gestación, en caso de la hembra estar en contacto con el macho.

Por lo tanto el momento ideal para presentar a la hembra con el macho y realización de la cubrición será cuando la vulva se presenta de color rojo vivo.

El Cuadro 2 muestra resultados de comportamiento sexual de conejas en un criadero de acuerdo a la coloración de la vulva.

El Cuadro 3, relaciona también la coloración de la vulva con la fecundidad de la monta.

\section{ESTRATEGIAS NUTRICIONALES PARA LA FUTURA MADRE}

El aumento de investigaciones relacionadas a la selección y mejoramiento genético de conejos, tanto para características de desempeño productivo como reproductivo, unido a los sistemas de producción intensivo de conejos, que permiten, teóricamente, nueve o más partos por año, resultaron en grandes avances en la producción de conejos, particularmente en las dos últimas décadas.

Al mismo tiempo, está la necesidad de mejorías en los demás pilares responsables por la producción, como el manejo, instalaciones, ambiente y adecuación de los niveles nutricionales y estrategias de alimentación en las diferentes fases fisiológicas, tanto en conejos destinados a faena como para los animales destinados al plantel reproductivo.

Particularmente relacionado a las madres, tanto los niveles nutricionales de las dietas, como los programas o estrategias de alimentación, así como para otras especies, también para las conejas deben ser motivo de preocupación por parte de los nutricionistas y cunicultores, no solo durante la fase de la reproducción, sino desde las fases de crecimiento y recría de las futuras reproductoras, buscando adecuar la condición corporal y estimular la alta capacidad digestiva que permita alto consumo de ración durante la

Cuadro 2. Relación entre el color de la vulva y el comportamiento sexual de las hembras en la monta.

\begin{tabular}{|l|c|c|c|c|}
\hline \multirow{2}{*}{ Color de la vulva } & \multirow{2}{*}{$\begin{array}{c}\text { No de hembras } \\
\text { evaluadas }\end{array}$} & \multicolumn{3}{|c|}{ Comportamiento sexual en la cubrición } \\
\cline { 3 - 5 } & 62 & Rechaza & Acepta & Acepta c/lordosis \\
\hline Blanca & 154 & $57(37,5 \%)$ & $11(17,7 \%)$ & $1(1,6 \%)$ \\
\hline Rosada & 116 & $3(2,5 \%)$ & $69(44,8 \%)$ & $28(18,2 \%)$ \\
\hline Roja & 59 & $40(67,8 \%)$ & $17(28,8 \%)$ & $2(3,4 \%)$ \\
\hline Violácea & &
\end{tabular}

Cuadro 3. Porcentaje de saltos fecundos según la coloración de la vulva.

\begin{tabular}{|c|c|c|c|c|}
\hline Color de la vulva & Blanca & Rosada & Roja & Violácea \\
\hline Tasa de fecundación & $0 \%$ & $20 \%$ & $80-90 \%$ & $50 \%$ \\
\hline
\end{tabular}


vida reproductiva, especialmente durante la lactación, fase esta que demanda gran volumen de nutrientes para soportar la producción de leche.

Los programas de mejoramiento genético para las líneas maternas hasta ahora realizados, consideran en el modelo, especialmente, un aumento de número de gazapos nacidos y destetados, sin considerar, de forma más efectiva, el aumento de capacidad de consumo de ración para las futuras madres. Como resultado de estos trabajos, hay un aumento significativo del tamaño de las camadas al nacer y, consecuentemente, un aumento de las necesidades de nutrientes para soportar, tanto al desarrollo de los fetos, particularmente en el tercio final de gestación, como para la mayor producción de leche, a partir del parto.

Se debe considerar también que las exigencias nutricionales de conejas en reproducción, en comparación con las otras especies de mamíferos, son muy altas, teniendo en cuenta la elevada producción de leche, y los niveles elevados de materia seca, de proteína y de grasa en la leche, aproximadamente tres veces mayor que la leche de vaca, más allá de la sobreposición de fases fisiológicas, teniendo en cuenta que las conejas presentan un ritmo intensivo de reproducción siendo cubiertas o inseminadas 10 a 12 días después del parto. Se debes destacar en las hembras primíparas en lactación, además de las exigencias nutricionales para que mantenga producción de leche, se suman las necesidades de nutrientes para el crecimiento corporal de las madres.

Todos estos aspectos, que caracterizan una alta exigencia nutricional para estos animales, unido a la capacidad de consumo voluntario que no aumentó en la misma proporción que el aumento de la productividad, resultan en déficits nutricionales, exigiendo que la madre utilice reservas corporales en niveles elevados, para soportar la alta producción; esto puede llevar a fallas reproductivas en los ciclos subsecuentes o colocar en riesgo la propia vida de la madre, hecho observado en líneas de alta producción, especialmente entre el primer y el segundo ciclo reproductivo.
La estrategia para por lo menos disminuir los problemas relacionados a los déficits nutricionales debe considerar que las madres sean preparadas adecuadamente durante las fases de crecimiento y recría, estimulando las condiciones de «alta capacidad de consumo de materia seca», aspecto importante para soportar la alta producción de leche y minimizar los desbalances nutricionales negativos de las madres, especialmente durante la fase de lactación.

Por lo tanto, desde el destete hasta la $10^{\text {a }}$ semana de edad, las hembras son alimentadas a voluntad, con dietas normales de crecimiento, con 2500 a $2600 \mathrm{Kcal}$ ED $/ \mathrm{kg}$. A partir de la $10^{\mathrm{a}}$ semana de edad hasta la edad del primer servicio (aproximadamente $18 \mathrm{se}$ manas) o 3,2 a 3,5 kg de peso vivo, los cuidados en el manejo de alimentación deben considerar el control para que las hembras no depositen grasa excesiva y al mismo tiempo, que sean estimuladas a un alto consumo de materia seca diaria, con el objetivo de estimular el desarrollo del tracto digestivo. Esto es posible con el uso de dietas balanceadas con tenores más elevados de fibra y menores concentraciones de energía, exigiendo un consumo elevado para la obtención de los nutrientes necesarios para un adecuado crecimiento de la futura madre. A partir del $1^{\circ}$ servicio, las madres pasan a recibir dietas con tenores más elevados en energía (2600 Kcal ED/kg), así como de los demás nutrientes, de acuerdo con las exigencias nutricionales para madres en reproducción.

Como resultado, las madres pasaran a presentar una condición de alto consumo de materia seca durante la vida reproductiva, disminuyendo las condiciones de déficit nutricionales, particularmente, en las fases de mayor exigencia nutricional, durante la lactación y en la fase final de gestación. Esta condición permitirá a la madre buen desempeño reproductivo, con camadas más numerosas, mayor peso vivo de los gazapos en el destete y mayor tasa de fertilidad, reduciendo las fallas reproductivas.

La viabilidad económica de un criadero de conejos exige, por lo tanto, madres capaces de generar un número elevado de hijos, destetar camadas numerosas, con elevado 
peso vivo, y soportar ritmos de reproducción intensivos, con bajas fallas reproductivas. Obviamente que más allá de los índices de producción, responsables por la viabilidad económica de una explotación, deben estar presentes también las preocupaciones sobre el bienestar de los animales y aspectos que permitan una producción sustentable.

\section{RITMOS DE REPRODUCCIÓN Y DISTRIBUCIÓN DE LAS MADRES EN BANDAS}

A partir de los conocimientos de la fisiología reproductiva de la coneja y de las condiciones nutricionales, de manejo, instalaciones, ambientales (particularmente de temperatura de la región) y objetivos del cunicultor, se puede definir los programas reproductivos, con ritmos o ciclos más o menos intensivos. La elección y definición de un ritmo de reproducción correcto, que permita el máximo de productividad de las madres, dentro de las condiciones que la propiedad presenta, es una decisión muy importante para la viabilidad económica del criadero. Esto significa que no siempre los ritmos reproductivos más intensivos, con cortos intervalos entre el parto y la nueva cubrición de la madre, son responsables por un mayor número de conejos producidos/madre/año; esto se logrará con aquel ritmo que mejor se adapte a las condiciones propias del criadero.

En la gran mayoría de los países, los criaderos intensivos de conejos para la producción de carne utilizan ritmos de reproducción de 40 a 42 días, con cubriciones de madres de 10 a 11 días posparto, siendo adecuadamente analizadas las condiciones arriba presentadas.

A partir de la definición del ritmo reproductivo a ser aplicado en el criadero de conejos, las madres podrán ser divididas en grupos o bandas, que permitan al cunicultor organizar y agrupar actividades relacionadas al manejo reproductivo en determinados días de la semana y al mismo tiempo, programar la disponibilidad de conejos para la faena, de acuerdo con el número de bandas de madres dentro del ritmo de reproducción en el criadero.
La utilización de la monta natural, como sucede en prácticamente la totalidad de los criadores de conejos de América del Sur, exige que las madres sean divididas en por lo menos cuatro grupos o bandas, con intervalos de cubrición entre los grupos que permita fijar el ritmo de reproducción elegido en el criadero. Por ejemplo si utilizáramos un ritmo de reproducción de 40 días, la división de madres del criadero en cuatro grupos o bandas, cubiertos con intervalos de 10 días cada grupo, fijará el período de ritmo elegido de 40 días y el cunicultor tendrá las actividades relacionadas al manejo reproductivo agrupadas cada 10 días (cubrición, palpación, introducción del nido a la jaula de la madre, destete, faena y venta de animales). Si el cunicultor opta por cubriciones semanales, el plantel de madres debe ser dividido en seis grupos o bandas, donde las cubriciones de cada grupo o banda serán realizadas con diferencias de siete días, fijando el ritmo de reproducción en este caso de 42 días (seis bandas por siete días de intervalo entre cubriciones o inseminaciones de cada banda es igual a 42 días).

En este caso, todas las actividades de manejo, arriba citadas, serían agrupadas y agendadas cada siete días. Como ventaja de este último sistema reproductivo, si las cubriciones semanales fueran ejecutadas los viernes no ocurrirán partos los fines de semana y así, el cunicultor no tendrá actividades que demanden más tiempo de atención los sábados y domingos.

En los países con la posibilidad de realizar inseminación artificial, normalmente el manejo de reproducción es conducido en banda única, donde todas las madres son inseminadas cada 42 días. En este caso el cunicultor agenda, para que cada 42 días los técnicos de la empresa responsable por la inseminación de las madres estén presentes en la propiedad. Estudios demostraron que cuanto menor número de bandas, menor será el costo medio de mano de obral madre instalada. En tanto se observa que estas propiedades que utilizan manejo reproductivo en Banda Única deben presentar índices de fertilidad elevados, pues las madres con fallas reproductivas solamente serán cubiertas nuevamente 42 días después de la 
última inseminación, influenciando negativamente los índices de conversión alimenticia global del criadero.

\section{ALTO NIVEL GENÉTICO DEL PLANTEL: UNA NECESIDAD}

Un análisis técnico de las condiciones encontradas junto a la gran mayoría de cunicultores de los países de América del Sur muestra la posibilidad de mejorías casi que inmediatas y sin costos significativos en aspectos ligados a nutrición, sanidad, instalaciones y manejo, con resultados positivos sobre la productividad media del plantel. En tanto, resta todavía un importantísimo factor, que presenta un costo muy elevado y que no puede ser soportado por el cunicultor: «La disponibilidad de madres y reproductores de alto potencial genético, tanto para formación, como para la reposición y mantenimiento del plantel».

Necesariamente este aspecto solamente puede ser solucionado con la creación de Centros de Selección y Mejoramiento, conducidos por Organismos o Instituciones Públicas, Empresas Privadas o Instituciones de capital mixto.

En este aspecto, se ha de considerar las experiencias de programas de selección y mejoramiento, conducidos en los principales países productores y consumidores de carne de conejo como España, Francia e Italia.

La utilización de animales de poblaciones nacionales en programas de mejoramien- to y selección es una posibilidad que permite utilizar las ventajas de adaptabilidad de los animales a las condiciones de cada país. Sin embargo, la importación e introducción de material genético mejorado de otros países debe ser considerada, después de un análisis muy criterioso, para evitar riesgos de introducción de enfermedades que hasta entonces no están presentes y que podrían causar perjuicios incalculables. Existen los más diversos modelos de mejoramiento de selección, entre ellos, las posibilidades de trabajo con tres líneas, dos con habilidad materna y una línea paterna, conforme es presentado a continuación en un sistema de cruzamiento en tres vías.

\section{Cruzamiento en tres vías}

El cruzamiento de líneas en tres vías puede ser una posibilidad muy importante para obtención de elevados resultados de producción en criaderos intensivos de conejos.

La Figura 4 es conducida en tres fases. En una primera fase, empresas privadas o centros de mejoramiento genético realizan un trabajo de mejoramiento genético sobre tres poblaciones, dos de las cuales, consideran en el modelo matemático, con una o más características ligadas a habilidad materna como tamaño de camada al nacer, tamaño y peso de camadas a los 21 días o en el destete, generando hembras Línea 1 maternal y machos Línea 2 maternal. Una tercera empresa o Centro de mejoramiento genético trabaja una tercera población, considerando, en el modelo, una o más caracte-

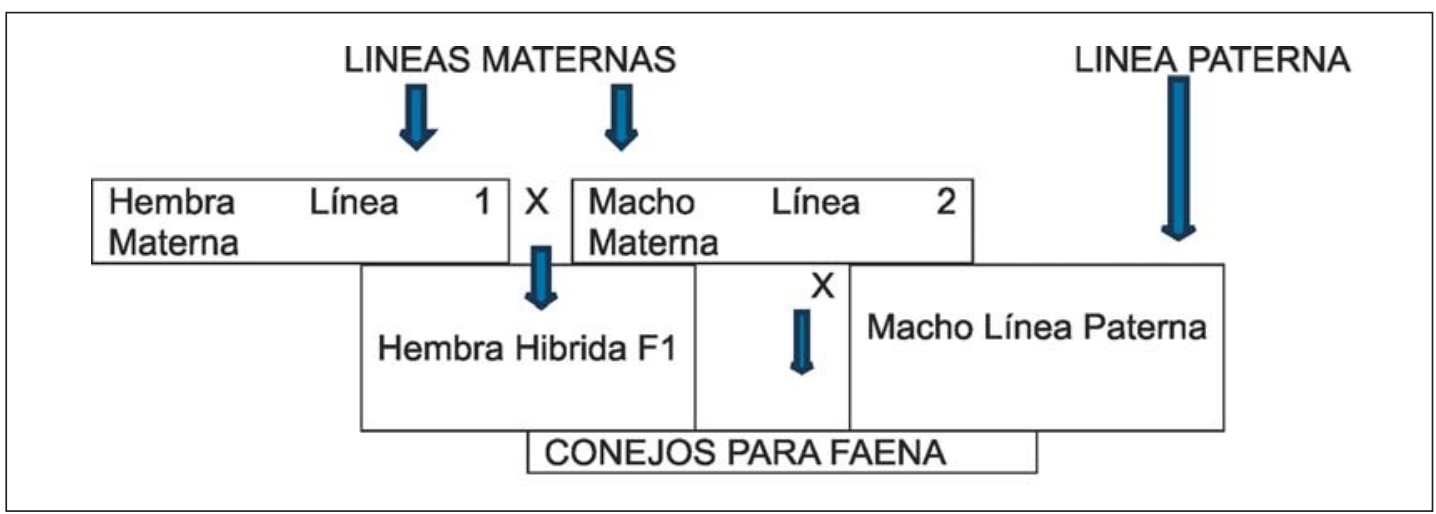

Figura 4. Cruzamiento en tres vías. 
rísticas productivas como: ganancia de peso, conversión alimenticia y características de carcasas, con el objetivo de generar un macho de Línea Paterna.

En una segunda fase, granja(s) de referencia(s) podrán recibir hembras y machos de las líneas maternales 1 y 2 para ser cruzados, generando la MADRE HIBRIDA F1 a ser comercializada a productores de conejos. De la misma forma, animales machos y hembras, seleccionados en la línea paterna, serian llevados a criaderos multiplicadores para generar REPRODUCTORES (machos) para ser comercializados a criadores de conejos.

En la tercera y última fase los criadores de conejos recibirían las Hembras Híbridas F1 y machos de la línea paterna para ser utilizados en el plantel reproductivo para producir animales exclusivamente para faena. Este modelo permitiría a los productores de conejos trabajar con hembras híbridas capaces de concebir y destetar un gran número de gazapos y con machos terminales que impriman en sus hijos elevada velocidad de crecimiento, garantizando alta productividad y rentabilidad.

Al cruzar dos líneas maternas distintas para generar la MADRE F1, se produce el efecto denominado HETEROSIS o VIGOR HIBRIDO, que permite una superioridad, tanto en la capacidad de producción, con camadas más numerosas al destete, como un menor riesgo de eliminación de madres por causas involuntarias como enfermedades o baja fertilidad.

Estudios realizados en España demostraron que madres cruzadas o híbridas presentaron mayor productividad en relación a madres de líneas puras: en promedio 0,8 gazapos nacidos más y 0,6 gazapos más destetados por camada.

Programas de esta naturaleza, normalmente, son organizados en una estructura piramidal o estratificada teniendo en el tope de la pirámide, unidades que representan el núcleo de selección, en la parte intermedia de la pirámide las unidades denominadas multiplicadores, que reciben los animales de los núcleos de la pirámide y son los responsables por la multiplicación y distribución del material genético a los productores, estos últimos formando parte de la base de la pirámide.

\section{Reposición de madres}

Para mantener a lo largo del tiempo, un plantel con altos niveles de producción en cuanto al número de gazapos nacidos vivos y destetados, es necesario organizar correctamente la reposición de las Madres Híbridas F1 para poder disfrutar al máximo las ventajas de heterosis: mayor tamaño de camadas y menor riesgo de eliminación de madres.

Datos de granjas de conejos de alta producción en España, que utilizan ritmos de reproducción con ciclos de 42 días, esto es con cubriciones realizadas 11 días después del parto, efectúan reposición anual de $120 \%$ de las madres, o sea entorno de $14,0 \%$ de reposición en cada ciclo reproductivo, índices muy superiores, prácticamente el doble, a los realizados por la mayoría de los cunicultores de diferentes países de América del Sur.

La no realización de la reposición o su realización de forma incorrecta supone un envejecimiento del plantel reproductivo y/o una caída de la productividad debido a la perdida de heterosis en casos en que se practique la autoreposición.

Existen dos posibilidades para reposición de Madres Híbridas F1 del plantel de criadores de conejos.

La primera, la adquisición de madres F1, de acuerdo con la programación e índices de reposición aplicados en las granjas comerciales de conejos, de una Granja Multiplicadora del material genético recibido de los Centros o Empresas de Mejoramiento Genético de Conejos (Hembras Líneas 1 materna y Macho Línea 2 materna). La otra posibilidad en la propia granja comercial de conejos es producir las Madres híbridas F1 necesarias para la reposición, manteniendo en producción, un grupo de madres y reproductores de las dos líneas puras (1 y 2). Esta última posibilidad permite al productor comercial de conejos disponer de las Madres hibridas F1 mejor adaptadas a las condicio- 
nes ambientales de su propiedad y reducir al mínimo los problemas asociados a entrada de animales de otras propiedades. La elección de esta posibilidad exige al criador comercial de conejos la disponibilidad de instalaciones y un pequeño plantel con las líneas maternas puras.

La opción por una de estas posibilidades debe considerar los factores con la distancia y logística entre multiplicadores y criadores comerciales, la infraestructura y condición técnica de estos últimos y aspectos relacionados a riesgo sanitario.

En el Cuadro 4, son presentados los resultados técnicos y económicos, durante el año 2012, de dos propiedades con 1000 madres en España, de acuerdo con el sistema de reposición de las Madres (auto-reposición de nuevas madres a partir de la selección de hijas de las madres F1 (1) o la introducción de nuevas Madres Híbridas F1 (2).

\section{ACTIVIDADES DE MANEJO CON EL PLANTEL REPRODUCTIVO}

\section{Manejo de la monta}

Es interesante considerar que para la realización de la monta, la hembra siempre debe ser conducida a la jaula del macho. Colocamos juntos los dos animales y en caso de la hembra estar en celo, en pocos segundos se realiza la cubrición. Durante la monta, podrán ser observadas cuatro fases en secuencia, tales como:

- aproximación del macho y olfateo general,

- lordosis de la hembra, donde ésta se colo-

ca en posición para recibir al macho, le-

vantando la grupa y exponiendo la vulva,
- monta

- eyaculación - una señal característica de que hubo eyaculación es que el macho cae para atrás o para uno de los lados.

Después de algunos instantes, retirar la hembra de la jaula del macho y observar si la eyaculación ocurrió correctamente a través de la verificación de la vulva bastante húmeda y con la presencia de semen. Enseguida, con cuidado, la hembra debe ser retirada de la jaula del reproductor, retornándola a su jaula de origen, donde son anotados, en su ficha, la fecha de cubrición y el número de macho utilizado.

Dependiendo del manejo implantado en cada criadero podrá ser realizada apenas una cubrición o una repetición de cubrición en una misma hembra, con un mismo macho, con un intervalo de 10 a 12 horas.

Algunas hembras en seguida del apareamiento podrán orinar y en este caso el semen que tiene contacto con la orina será inviabilizado.

La repetición de cubrición, 12 horas después de la primera, en este caso, sería recomendable, pues podría reducir situaciones de falsa gestación y fallas reproductivas. Es importante destacar que las coberturas deben ser asistidas y de preferencia realizadas en las primeras horas de la mañana o de tardecita.

Las primeras cubriciones realizadas por machos jóvenes, cuando es posible, deberían ocurrir con hembras adultas y en pleno celo. Esto facilita mucho el inicio de vida reproductiva y evita una posible inhibición del macho. Esta observación es válida también para hembras jóvenes, que deberán tener sus primeras cubriciones, preferentemente realizadas por macho experientes.

Cuadro 4. Productividad y costo de producción de conejos de acuerdo con el sistema de reposición de madres.

\begin{tabular}{|l|c|c|c|}
\hline \multicolumn{1}{|c|}{ Parámetros } & $\begin{array}{c}\text { Auto-reposición } \\
\text { de nuevas Madres } \\
\mathbf{( 1 )}\end{array}$ & $\begin{array}{c}\text { Introducción de } \\
\text { nuevas Madres } \\
\text { F1 (2) }\end{array}$ & Diferencias \\
\hline Gazapos producidos/año & 52.313 & 60.688 & 8.375 \\
\hline Peso vivo producido/año $(\mathrm{kg})$ & 117,704 & 136,548 & 18,444 \\
\hline $\begin{array}{l}\text { Índice de costo de } \\
\text { producción (\%) }\end{array}$ & 100 & 92,72 & 7,28 \\
\hline
\end{tabular}




\section{Cubrición forzada}

Muchas hembras, por no estar en celo, pueden rechazar la monta cuando son colocadas en la jaula del macho. En este caso, dependiendo del estado físico del animal, o sea, si no está debilitado, podrá ser realizada una monta forzada, donde la hembra es puesta en posición para que el macho realice la cubrición.

Se debe destacar que, en el caso que haya necesidad de un número muy elevado de cubriciones forzadas, esto podrá ser una señal de algún error de manejo, particularmente en relación al ritmo de reproducción, alimentación, sanidad y/o condiciones ambientales.

Como recomendación práctica, sería importante que el cunicultor, al realizar el manejo de montas, más allá de las anotaciones de arriba citadas en fichas de madres, también registre, en una ficha aparte, de las condiciones en que se realizaron las cubriciones:

- identificación de la madres = número de madre o jaula

- color de vulva= blanco (1), rosada (2), roja (3) y violeta (4)

- comportamiento de la madre = acepta con lordosis (1), o rechaza y cubrición forzada (2)

La introducción de estas informaciones numéricas que caracterizan cada condición de la madre, en computadora y uso de programas Excel podrán mostrar la frecuencia y el porcentaje de madres con los diferentes colores en vulva y por lo tanto las fases fisiológicas del ciclo estral en que las madres se encuentran en momento de la cubrición. El análisis de esta respuestas podrá ser importante para una toma de decisiones, al respecto de alteraciones en el ritmo reproductivo impuesto en el criadero y/o de mejoras en las condiciones de manejo, que deben ser implementadas, como alimentación, sanidad, instalaciones, temperatura, iluminación u otro factor que esté perjudicando la eficiencia reproductiva de las madres.

\section{Ritmo de utilización del macho}

La relación de machos en un plantel de reproducción, en situación de monta natural, será de uno cada 8 a 10 madres. En tanto, en los criaderos en que se realiza inseminación artificial, un reproductor podrá servir aproximadamente 50 madres.

Durante los primeros tres meses de actividad reproductiva, se aconseja una utilización moderada de machos con una media de dos o tres cubriciones por semana, y a partir de entonces el ritmo de utilización podrá aumentar a cuatro o cinco cubriciones semanales, siempre intercalando días de monta con los de descanso. En los casos en que el manejo reproductivo considera la repetición de la cubrición de la madre, en los días en que el macho es utilizado, podrá dar dos saltos, uno por la mañana y otro en la tarde. En este caso es recomendable utilizar la relación de un macho cada 8 hembras. La utilización muy intensa del reproductor puede provocarle un agotamiento, más allá de una baja en la concentración de espermatozoides en el semen, así como una disminución en el volumen de eyaculado, lo que puede causar un aumento de las fallas reproductivas.

\section{Manejo en la gestación}

Transcurridas 10 a 13 horas después de la cubrición, ocurre la ovulación y luego enseguida, la fecundación del óvulo en el tercio superior del oviducto. De esta forma la coneja entra en fase de gestación, cuya duración promedio es de 31 días, variando entre 29 y 33 días.

Estudios estadísticos indican que el $85,5 \%$ de las conejas paren después de 31 días de cubrición. Por otro lado, los gazapos nacidos antes de 29 días de gestación, difícilmente sobreviven, teniendo en cuenta la importancia del período final de gestación para el desarrollo de los fetos.

En los criaderos comerciales, las conejas pasan la mayor parte de vida reproducti- 
va, simultáneamente en gestación y lactación, o sea, la coneja es cubierta nuevamente por el macho antes del destete de los gazapos de la camada anterior. Es aconsejable que el criador dé la máxima atención a las madres, alimentándolas adecuadamente, ya que están continuamente exigidas por el intenso ritmo reproductivo.

En caso de hembras con fallas reproductivas es necesario también un ajuste en la alimentación para evitar situaciones de sobrepeso, que podrán comprometer los resultados reproductivos y económicos del plantel.

Esporádicamente, y particularmente en épocas o regiones con temperatura elevada, pueden ocurrir abortos, en este caso, no debe ser motivo de preocupación, pero si la incidencia aumentara es necesario tomar decisiones de acuerdo con las causas, que pueden ser debidas a:

- Enfermedades del aparato reproductor

- Medicamentos

- Animales extraños o predadores en el criadero (estrés)

- Hembras excesivamente gordas;

- Sustancias tóxicas presentes en los alimentos

- Frecuentes entradas de personas extrañas en el criadero (estrés)

- Elevadas temperaturas

\section{Diagnóstico de gestación}

Es una práctica muy importante a ser adoptada en la fase de gestación pues permite verificar si la coneja está o no gestando. El método más seguro y simple es la PALPACION VENTRAL, realizada entre el décimo y décimo quinto día de gestación, de la siguiente manera: la contención de la hembra se hace, sujetándola con una mano, por las orejas y un pliegue de la piel de la región torácico-cervical, manteniéndola en la jaula o sobre una mesa, con la cabeza dirigida hacia el operador. Con la otra mano se hace la palpación en la región inguinal, buscando localizar los embriones en el útero, los cuales, cuando presentes, dan la sensación de pequeñas bolitas. Esta práctica no es difícil de ser realizada, requiere cierto en- trenamiento para evitar posibles abortos, o bien tener confusiones de los embriones con los excrementos que se encuentran en el recto.

Los principiantes deben iniciar esta práctica, palpando hembras en 14 o 15 día de gestación, ocasión en que los embriones se destacan más, presentando un tamaño próximo a $1 \mathrm{~cm}$. Posteriormente con mejor entrenamiento y práctica, la persona debe ir anticipando los días de palpación, hasta llegar al décimo día de gestación, momento más recomendable para ejecutar esta práctica. La importancia de esta práctica es que permite anticipar las fallas y disminuir el intervalo entre partos.

\section{Seudogestación}

Este fenómeno puede ocurrir cuando los óvulos liberados en la ovulación no son fertilizados. Las posibles causas de no fecundación de los óvulos son:

- Esterilidad permanente o temporaria de los machos

- Presencia de orina junto con el semen

- Eliminación de semen del tracto reproductivo de la hembra al orinar enseguida de la monta

- Eyaculación fuera de la vagina

- Montas entre hembras con edad de reproducción

Las tres primeras son las causas más frecuentes. En regiones o épocas con temperatura encima de los $30^{\circ} \mathrm{C}$, puede ocurrir disminución drástica de la concentración de espermatozoides y calidad del semen, inclusive llevando a la esterilidad temporaria.

Tanto el macho podrá orinar en momento de eyacular, como la hembra luego de ser cubierta. En ambos casos podrán reducir o hasta eliminar por completo la viabilidad de los espermatozoides.

También cubriciones mal ejecutadas con eyaculación precoz, o fuera de la vagina son causas de hembras en seudogestación.

La coneja seudo-gestante se comporta fisiológicamente como si estuviese en gestación, con duración de 16 a 18 días. En este período, la coneja cesa toda actividad del 
ovario, no entrando en celo y no aceptando al macho, produciendo progesterona como consecuencia de la actividad del cuerpo lúteo. Al final del período de 16 a 18 días, las conejas presentan un vientre y mamas inflamadas y se arrancan pelo del abdomen, como si fuesen a construir el nido, manifestando el comportamiento semejante al del momento del parto.

Se puede evitar este fenómeno y aumentar la productividad de las hembras con uso de buenos machos, hacer que las montas se realicen de forma correcta y en presencia del cunicultor o persona responsable para el manejo reproductivo, además del análisis de la presencia de semen en la vagina después de la cubrición.

\section{Colocación del nido en la jaula}

Transcurridos 28 días de gestación debe ser colocado el nido en la jaula de la hembra, conteniendo viruta o hierba seca (sin tallos duros que puedan herir las mamas de la coneja) o aún paja de cereales como material de cama.

A partir del día anterior al parto o, a veces, después del parto, la coneja deposita también dentro del nido los pelos que ella misma arranca de su región ventral y de la papada. Conejas que arrancan gran cantidad de pelos, depositando dentro del nido para proteger a los recién nacidos, son hembras que presentan un instinto maternal muy desarrollado. En los casos de hembras, particularmente de primer parto, que no realicen este trabajo, el cunicultor deberá hacerlo, arrancando pelos de la madre para protección de los recién nacidos, o recoger material de otros nidos que tengan cama grande, y que no tengan problemas sanitarios.

Si esto no fue realizado y los gazapos no tuvieron condiciones adecuadas de temperatura, fatalmente aumentará la mortalidad durante esta fase.

Uno o dos días antes del parto, las hembras disminuyen el consumo de alimentos y desde ese momento en adelante no debe ser molestada, asegurando que tenga agua a disposición. En este sentido, el cunicultor deberá observar, diariamente, el funciona- miento de las válvulas y también la posibilidad de que el desplazamiento del nido en la jaula estuviera obstaculizando el acceso al bebedero.

\section{Manejo al parto}

Llegado el momento del parto, la coneja se presenta inquieta, entrando y saliendo, frecuentemente del nido, pudiendo ocurrir el parto, la mayoría de las veces, durante la noche.

El mecanismo que desencadena el parto es bastante complejo e involucra diversas etapas, coordinadas por el sistema endocrino, asociadas a maduración fetal, dilatación del canal cervical, inicio de las contracciones uterinas y síntesis y eyección de leche.

La gestación en la coneja es mantenida, fundamentalmente, por la secreción de progesterona por el cuerpo lúteo, siendo indispensable que su producción cese para que ocurra el parto.

Inicialmente ocurre la liberación, por el hipotálamo de la madre, de un factor liberador de corticoides (CRF) y por vía sanguínea estimula la secreción de la hormona Adrenocorticotropa (ACTH) por la adenohipófisis del feto.

La ACTH, a su vez, estimula el desarrollo de las glándulas adrenales y la producción de la hormona cortisol. El cortisol estimula la producción placentaria de estrógenos (estradiol), responsable de la formación de receptores de oxitocina en los miocitos y la producción de la prostaglandina F2 $\alpha$ (PGF2 $\alpha$ ) por el endometrio, a partir del ácido araquidónico. Mientras haya producción de progesterona en niveles suficientes, se inhiben los efectos estimulados por el estradiol.

La PGF2 $\alpha$ posee actividad luteolítica, tanto en la coneja gestante como en la seudo gestante provocando regresión del cuerpo lúteo.

La caída de la progesterona en el plasma produce aumento de la distensión uterina, para estimular la colagenólisis del tejido conectivo miometrial, así como la distención y la relajación del cuello del útero. La relaxina también estaría involucrada en este proceso. 
Finalmente, la neurohipófisis pasa a producir oxitocina, que en conjunto con la prostaglandinas $\mathrm{F}$ y $\mathrm{E}$ son responsables por las contracciones de las fibras musculares lisas uterinas y abdominales.

El comportamiento maternal de la coneja que se encuentra próxima al parto incluye la preparación del nido, arrancando pelos para la protección de la camada y después de ocurrido el parto, agrupa, lame los gazapos y se postra sobre ellos para amamantarlos. Este comportamiento es regulado por las hormonas prolactina, oxitocina y prostaglandina $\mathrm{F} 2 \alpha$.

El tiempo de trabajo de parto se extiende, en promedio, por 10 a 30 minutos. Muy raramente los partos tienen duración mayor de 40 a 50 minutos, lo que demandaría especial atención para estas madres que podrían estar con alguna dificultad de expulsión de los gazapos. Las posibles causas serían temperatura elevada, problemas físicos de la madre o gestaciones poco numerosas con gazapos muy grandes. Se debe destacar, en tanto, que son muy raros los problemas de partos en conejas.

En la medida que los gazapos van naciendo, la propia coneja los libera de la placenta, limpiándolos y ordenándolos en el nido. Algunas hembras pueden parir fuera del nido y es común, en estos casos, principalmente en épocas de baja temperatura, que ocurra la muerte de estos recién nacidos. En el caso de que no lleguen a morir, la caída de temperatura corporal en este momento, podría implicar una disminución de la capacidad de crecimiento con perjuicios en el desempeño durante toda la vida del animal.

Cuando la incidencia de partos fuera del nido es muy grande se debe sospechar de algún error en el manejo, entre ellos olores anormales o exceso de humedad en el nido, exceso de calor, material muy grosero colocado en la cama, siendo, por lo tanto importante las buenas condiciones del nido para que la hembra tenga acceso al mismo con naturalidad.

El número de gazapos nacidos por parto varía de 1 a 15, teniendo como promedio 8 a 10 gazapos/parto, con un peso vivo de $40 \mathrm{a}$
$60 \mathrm{~g}$ por gazapo, siendo ideal que nazcan con un peso promedio de $50 \mathrm{~g}$.

Cuanto más bajo sea el peso al nacer, mayor es la posibilidad de muerte de los gazapos.

Después del parto, la hembra se mostrará aún agitada y la respiración acelerada, demorando algún tiempo para volver a la normalidad. Por esta razón, solamente después de transcurridas algunas horas, en las situaciones de parto normal y natural, es que procedemos al primer examen del nido, que comprendería:

- contar los gazapos y retirar los muertos,

- anotar en la ficha de la madre, la fecha de parto y el número de nacidos vivos y muertos,

- retirar los restos de placenta y cama húmeda del nido, pudiendo, inclusive, ser cambiado cuando las condiciones de higiene no son las adecuadas, procurando mantener una cama abundante y seca (pelos, viruta o heno bien suave y rico en hojas),

- hacer trasferencia de gazapos de una hembra a otra que tenga parición del mismo día o del día anterior, en el caso de que el número de nacidos fuera muy grande (más de 8 a 10 gazapos)

La transferencia de gazapos, usualmente, es realizada con el objetivo de uniformizar las camadas, dejándolas con 8 a 10 gazapos, número éste que las conejas, con raras excepciones, consiguen criar en condiciones satisfactorias.

Las precauciones a ser tomadas en esta práctica serían en relación a la selección de animales para reproducción debido a los animales con diferentes filiaciones en una misma camada, lo que puede ser resuelto en la marcación de los gazapos transferidos a la nueva madre. Esta preocupación no existe, en tanto, con los animales que son destinados para el abasto.

Cuando la transferencia no puede ser realizada por la falta de otras camadas con edades semejantes, los gazapos excedentes podrán ser sacrificados escogiéndose los de más bajo peso. Las conejas amamantan sus camadas generalmente una vez al día, preferentemente en horarios nocturnos. 


\section{Aspectos fisiológicos de la lactancia}

Dentro de los factores que participan en el complejo lactogénico, la prolactina (PRL) es la hormona esencial para el mantenimiento de la lactación. Esta hormona regula directamente el inicio de la lactación y en conjunto con los glucocorticoides, la síntesis de caseína y lactosa, activando la PGF2 $\alpha$ como el mediador de este efecto sobre las células responsables por la síntesis de la leche.

La lactación se inicia con un aumento significativo de PRL y una disminución paralela de la PGF2 $\alpha$, que produce un aumento de receptores de la $P R L$ en el parénquima mamario a partir del vigésimo día de lactación, aumentando hasta $500 \%$ después del parto. El amamantamiento provoca una liberación inmediata y prolongada de $\mathrm{PRL}$ con una duración de tres a cuatro horas. Este efecto es fundamental para el mantenimiento de la lactación, alcanzando concentraciones máximas de PRL en el plasma entre el segundo y el vigésimo día de lactación y disminuyendo paulatinamente en seguida hasta el final, entre el vigésimo octavo y trigésimo día posparto.

El amamantamiento también estimula la producción de la hormona oxitocina por la neurohipófisis, indispensable para la eyección de la leche. La oxitocina se une a los receptores de las células mioepiteliales dispuestas longitudinalmente en los conductos lactíferos y alrededor de los alvéolos de la mama, provocando su contracción y el pasaje de leche en dirección a los conductos mamarios y su consecuente eyección.

Otras hormonas lactogénicas indirectas son la STH (somatotrofina), insulina, estrógenos y triyodotironina que participan en el metabolismo general del organismo.

La progesterona, a su vez, posee un efecto marcadamente inhibitorio de la lactogénesis.

\section{Manejo durante la lactación}

La fase de crianza de los gazapos, comprendida del nacimiento al destete, es bas- tante importante porque, en gran parte, el éxito de la explotación de los conejos depende del desempeño de los animales en este período.

Las principales metas dirigidas en la fase de lactación son la baja mortalidad y el gran desarrollo de los gazapos, teniendo la madre la mayor responsabilidad para que los objetivos sean alcanzados, en tanto que el cunicultor provea todas las condiciones exigidas por los animales.

La revisación de los nidos deberá ser hecha diariamente o como máximo, día por medio, tomando siempre el cuidado de ser rápidas, evitándose, sin embargo, movimientos bruscos, molestar a la hembra o pasar olor extraño a los gazapos a través de las manos sucias. Se debe observar la cantidad de pelo, para que los gazapos, al menos en la primera semana de vida, tengan condiciones de temperatura del nido, de 30 a $34{ }^{\circ} \mathrm{C}$.

Durante la lactación los gazapos son amamantados una o dos veces por día. A partir de décimo quinto al décimo octavo día de edad los gazapos comienzan a salir del nido y frecuentar el comedero de la madre y gradualmente, la ración sustituirá la leche. A medida que se aproxima el destete que ocurrirá entre el 28 a 35 días de edad. Durante este período ocurre un cambio importante en el hábito de consumo, con un aumento gradual de la frecuencia de ingestión de alimentos secos. En el destete los gazapos ya frecuentan el comedero más de 40 veces por día, ingiriendo pequeñas cantidades de ración cada vez. Esta frecuencia de ingestión diaria disminuye a aproximadamente 35 veces a partir de los dos a tres meses y en animales adultos 25 a 30 veces por día.

Durante las primeras semanas de vida de los gazapos ocurren cambios morfológicos y de sus hábitos:

- al nacer los gazapos se presentan con el cuerpo totalmente desprovisto de pelos,

- en el cuarto a quinto día de vida ya están completamente cubiertos de pelo,

- en el sexto día presentan el doble de peso que al nacer,

- entre los diez y doce días abren los ojos, - a los 15 días ya andan con desenvoltura y 
- entre los 15 a 20 días salen del nido e inician el consumo de ración.

Cuando los gazapos salen del nido antes de esta edad es porque sienten mucho calor o porque la disponibilidad de leche es insuficiente.

Hasta los 21 días de edad, aproximadamente, la alimentación de los gazapos es básicamente LECHE MATERNA. Por lo tanto, el peso de los animales a esta edad es una medida importante para la evaluación de la capacidad de la madre en criar sus gazapos.

Las anomalías de comportamiento maternal, o los casos más comunes de accidentes en el parto en conejas son:

- canibalismo,

- falta de cuidado con los recién nacidos,

- abandono de la camada,

- falta de leche

El canibalismo, a pesar de no ser tan frecuente, es un problema serio, donde la coneja devora, total o parcialmente, sus crías recién nacidas. Normalmente, está relacionada con deficiencia nutricional, especialmente en proteína. También puede estar relacionado con errores en el manejo tales como:

- nidos mal desinfectados,

- exceso de humedad,

- instalaciones inadecuadas,

- enfermedades,

- parasitismos (sarna),

- personas extrañas en las instalaciones,

- falta de agua

A veces ocurren casos de conejas que abandonan a los gazapos, los cuales mueren de frío o inanición. Esta actitud de las hembras podrá estar ligada a problemas patológicos o como consecuencia de un manejo inadecuado.

Entre las causas patológicas, son causas de abandono todas las enfermedades que se producen durante el período de recuperación después del parto tales como:

- metritis

- mastitis
- fiebre de la leche

- otras enfermedades que provocan fiebre o que causan inapetencia, hasta el corte definitivo de la producción de leche (agalactia).

Otras causas de abandono de la camada están relacionadas con la falta de instinto maternal. Normalmente en este caso las conejas se presentan:

- agresivas

- no construyen el nido adecuadamente

- entran y salen del nido sin cuidado, hiriendo a los gazapos

- los gazapos se encuentran dispersos dentro del nido.

Madres con este comportamiento deben ser descartadas.

Los abandonos de camadas pueden estar relacionados con un manejo, pudiendo ser enumerados varios factores, entre ellos:

- gazapos muy pequeños, nacidos de madres mal alimentadas, presentan dificultades de succión de la leche, siendo incapaces de desencadenar el proceso de lactogénesis y eyección de la leche,

- todas las alteraciones ambientales que provocan estrés,

- nidos mal construidos que favorecen el aplastamiento de los gazapos o su dispersión dentro del nido,

- la presencia de gazapos muertos en el interior del nido,

- exceso de humedad, nidos sucios y mal desinfectados,

- hierba muy gruesa, dura y que hiere las mamas de la coneja cuando entra al nido,

- falta de agua

Para evitar los problemas de abandono de la camada, canibalismo y disminuir la mortalidad de los gazapos en esta fase, es imprescindible que el cunicultor observe todos los ítems citados, causantes de trastornos para las hembras y los gazapos.

El Cuadro 5 muestra la evaluación en la producción de leche durante la lactación.

Como puede ser observado la coneja produce entorno de $55 \%$ de la cantidad de le- 
Cuadro 5. Producción media de leche por coneja.

\begin{tabular}{|c|c|c|}
\hline Semana de lactación & Producción semanal (g) & $\begin{array}{c}\text { Porcentaje de producción } \\
\text { acumulada }\end{array}$ \\
\hline 1 & 842 & 11,9 \\
\hline 2 & 1291 & 31,5 \\
\hline 3 & 1690 & 55,3 \\
\hline 4 & 1460 & 75,9 \\
\hline 5 & 1030 & 90,4 \\
\hline 6 & 680 & 100 \\
\hline
\end{tabular}

che del período total de lactación hasta los 21días posparto. A los 30 a 35 días de lactación la coneja ya produjo entorno del $90 \%$ de leche del período total de lactación. Esto muestra que a partir de los 28 a 35 días de edad de los gazapos, la cantidad de leche disponible para la camada contribuye poco en su alimentación, pudiendo, a partir de esta edad, ser fecha de destete de conejos.

Tanto la producción, como el consumo individual de leche varían de acuerdo con el tamaño de camada.

\section{Crecimiento de los gazapos lactantes}

Los gazapos se caracterizan por presentar un desarrollo muy rápido, pudiendo do- blar su peso al nacer en apenas seis días, un período muy corto si consideramos el tiempo necesario para que esto ocurra en otras especies, como se puede observar a continuación:

- Humano 183 días

- Caballo 60 días

- Ternero 47 días

- Lechón 14 días

- Conejo 6 días

Con relación a la velocidad de crecimiento, los conejos pueden multiplicar su peso al nacer por 20 veces a los 42 días de vida.

El Cuadro 7 muestra el incremento de peso medio de los gazapos lactantes, en sus primeros 35 días de edad.

Cuadro 6. Tamaño de camada y producción láctea de la coneja.

\begin{tabular}{|c|c|c|c|c|}
\hline $\begin{array}{l}\mathbf{N}^{\circ} \text { gazapos/ } \\
\text { camada }\end{array}$ & $\begin{array}{c}\text { g leche } \\
\text { producido } \\
\text { en 42 días }\end{array}$ & $\begin{array}{c}\text { g de leche ingerida } \\
\text { Igazapo en } \\
\mathbf{4 2} \text { días }\end{array}$ & $\begin{array}{c}\text { g de leche } \\
\text { ingerida/gazapo } \\
\text { en 21 días }\end{array}$ & $\begin{array}{c}\text { Peso Vivo } \\
\text { a los 21 días } \\
\text { (g) }\end{array}$ \\
\hline 3 & 3150 & 1050 & 588 & 345 \\
\hline 4 & 4000 & 1000 & 560 & 329 \\
\hline 5 & 4875 & 975 & 546 & 321 \\
\hline 6 & 5700 & 950 & 532 & 312 \\
\hline 7 & 6300 & 900 & 504 & 296 \\
\hline 8 & 6960 & 870 & 487 & 286 \\
\hline 9 & 7650 & 850 & 476 & 280 \\
\hline 10 & 8100 & 810 & 453 & 266 \\
\hline 11 & 8470 & 770 & 431 & 252 \\
\hline 12 & 8880 & 740 & 414 & 243 \\
\hline
\end{tabular}


Cuadro 7. Pesos promedios de gazapos lactantes en distintas edades.

\begin{tabular}{|c|c|c|}
\hline Edad (días) & Peso (g) & $\begin{array}{c}\text { Aumento de peso } \\
\text { diario (g) }\end{array}$ \\
\hline 1 & 50 & \\
2 & 60 & 10 \\
3 & 70 & \\
4 & 80 & \\
5 & 90 & \\
6 & 100 & 15 \\
\hline 7 & 115 & \\
14 & 220 & \\
21 & 335 & 23,5 \\
\hline 28 & 500 & 38,5 \\
\hline 35 & 770 & \\
\hline
\end{tabular}

\section{Destete y recría de los gazapos}

El destete es una operación que consiste, básicamente, en la separación de los gazapos de la madre. Esta separación podrá ocurrir de dos formas:

1- Manteniendo a la madre en su jaula y retirando la camada que deberá ser alojada en otra jaula hasta de la edad de faena o

2- Retirando a la hembra que deberá ser alojada en otra jaula, en la misma o en otra instalación y los gazapos mantenidos en la jaula donde nacieron hasta la faena.

La opción por uno u otro sistema dependerá del manejo adoptado en el criadero y la organización de los lotes de las madres en bandas o no. El sistema más común, aún hoy, es la retirada de los gazapos, manteniendo la hembra en su jaula durante toda la vida reproductiva.

Con los nuevos sistemas de organización de las madres en bandas, particularmente, cuando es una banda única, donde todas las hembras son inseminadas en una misma época, el destete podrá ser hecho, retirando la hembra de su jaula, conjuntamente con su ficha de identificación, y alojándola en otra jaula, normalmente en otro galpón. Esta opción permite el vacío sanitario, además que el estrés para los animales jóvenes es menor.
De cualquier forma el destete es un factor de estrés de los conejos, teniendo en cuenta la finalización del amamantamiento, cambios en la alimentación, necesitando por lo tanto de algunos cuidados para reducir al máximo posible, los perjuicios a los animales, particularmente, en relación al trastorno digestivo responsable de una mortalidad elevada en la fase peri destete.

El primer ítem a ser observado es la edad de destete. Del punto de vista nutricional y considerando la producción de leche de la madre, la edad de destete recomendada para los criaderos comerciales, sería alrededor de 30 a 35 días de edad, no habiendo ventajas mayores si se prolonga la fase de lactación. La cantidad de nutrientes proporcionados por la leche después de 32 a 35 días de lactación es pequeña en relación a las exigencias de los gazapos, las cuales pueden ser satisfechas por dietas adecuadamente balanceadas.

La edad de destete también está directamente relacionada con el programa o ritmo de reproducción implantado en el criadero y la edad de faena de los conejos. El período entre el destete y la faena nunca debe ser superior al ritmo de reproducción implementado en el criadero, de lo contrario será necesario mayor número de jaulas para el alojamiento del las camadas en este período. 
Destetes más precoces, anteriores a los 28 días de edad, exigen raciones especiales y aumentan los riesgos de pérdida de gazapos, no siendo, por lo tanto, recomendado.

Es frecuente, en pequeños criaderos de conejos con objetivos no comerciales, realizar destetes más tardíos, entre 35 a 40 días de edad. Normalmente en estos criaderos las hembras son mantenidas en ritmos reproductivos más largos, siendo cubiertas a los 30 días o más, después del parto. En criaderos intensivos no es recomendable seguir este programa por presentar una productividad muy baja.

Al destete, puede realizarse la marcación o tatuaje de los gazapos, dependiendo del manejo realizado. En muchos criaderos, la identificación (colocación de la caravana o tatuaje) es hecha solamente para los animales seleccionados y que podrán componer el plantel reproductivo. Esta práctica puede llevarse a cabo a la edad de faena de los animales, solamente en aquellos machos y hembras escogidos en esta primera selección. Después del destete es interesante mantener la camada agrupada en una jaula de recría. En el caso de camadas muy numerosas al destete, los conejos deberán ser distribuidos en dos jaulas para evitar sobrepoblación. En este caso, los conejos deberán ser clasificados de acuerdo a su desarrollo, procurando mantener lotes homogéneos.

Cuando la faena fuera realizada entorno a los 70 días, se puede alojar siete u ocho conejos por jaula.

A partir del destete hasta la faena, el cunicultor deberá estar atento a los posibles trastornos digestivos, como incidencia de diarreas, particularmente enseguida al destete hasta los 50 días de edad. La ausencia de leche materna en la alimentación solo con ración seca, exige que la formulación de estas dietas presente niveles moderados de almidón, teniendo en cuenta las limitaciones de los conejos en digerir este nutriente, por la insuficiente producción de enzima amilasa en esta edad. Entre las estrategias para minimizar este problema, que puede ser responsable por índices elevados de mortalidad en esta fase de crecimiento, se recomienda formulaciones de dietas con la inclusión de probióticos, prebióticos, ácidos orgánicos, adición de 1 a $2 \%$ de aceite, u otra fuente de energía como la glicerina (subproducto de la industria del biodiesel) que permitirá reducción de la cantidad de cereal, particularmente, maíz en la dieta y/o el aumento de niveles de fibra, con una adecuada relación entre los componentes más o menos solubles de la fibra (FDN/FDA). Estas estrategias permitirán la presencia de una población de microorganismos benéficos en el tracto digestivo, evitando la proliferación de patógenos y el mantenimiento de condiciones adecuadas en relación al tránsito de la digesta y a los procesos vinculados a la digestión y absorción.

Otros aspectos a tener cuenta son disponibilidad de espacio adecuado de comedero, de acuerdo con el número de animales alojados por la jaula, uso de equipamientos que minimicen el desperdicio de ración, disponibilidad de agua de buena calidad, estado sanitario de los animales, condiciones de temperatura lo más próximo posible a la zona de confort del animal y adecuada renovación del aire, evitando, la acumulación de amoniaco en el ambiente. El conjunto de estas acciones y cuidados, sumados a la condición genética de los animales, permitirá alto desempeño de los animales y bajos índices de mortalidad, aspecto indispensable para la viabilidad de un criadero.

El cuadro 8 presenta una estimación de consumo y desempeño de los conejos desde el nacimiento hasta la edad de faena. Sin embargo, no deben ser tomados como valores absolutos, teniendo en cuenta la multiciplicidad de factores que determinan variaciones de estas características. 
Cuadro 8. Consumo de alimentos y ganancia de peso según edad.

\begin{tabular}{|c|c|c|c|}
\hline Edad (días) & $\begin{array}{c}\text { Consumo de leche } \\
\text { (g/día) }\end{array}$ & $\begin{array}{c}\text { Consumo de ración } \\
\text { (g/día) }\end{array}$ & $\begin{array}{c}\text { Ganancia de peso } \\
\text { (g/día) }\end{array}$ \\
\hline $0-15$ & $3-15$ & - & $8-10$ \\
\hline $15-21$ & $15-30$ & $0-20$ & $10-20$ \\
\hline $21-35$ & $10-20$ & $15-50$ & $20-30$ \\
\hline $35-40$ & - & $45-80$ & $30-37$ \\
\hline $40-45$ & - & $70-100$ & $30-40$ \\
\hline $45-50$ & - & $90-125$ & $30-40$ \\
\hline $50-55$ & - & $110-140$ & $30-45$ \\
\hline $55-60$ & - & $120-155$ & $35-45$ \\
\hline $60-65$ & - & $130-160$ & $35-40$ \\
\hline $65-70$ & - & $150-175$ & $35-40$ \\
\hline
\end{tabular}

El Cuadro 9 también presenta datos semanales de crecimiento, consumo de ración e índice de conversión alimenticia. Como puede ser observado, los conejos presentan un deterioro acentuado en la eficiencia de utilización de los alimentos y también en el desempeño a partir de los 60 a 70 días de edad, cuando los animales pasan a depositar más grasa en la canal. De esta forma, la edad adecuada para la faena de los conejos debe fijarse entre 60 a 70 días de edad, con un peso vivo entorno a los 2,0 a $2,5 \mathrm{~kg}$.

Cuadro 9. Evolución semanal de peso vivo, ganancia, consumo y conversión.

\begin{tabular}{|c|c|c|c|c|c|c|}
\hline \multirow{2}{*}{$\begin{array}{l}\text { Período } \\
\text { (días) }\end{array}$} & \multirow{2}{*}{$\begin{array}{l}\text { Peso vivo } \\
\text { al final } \\
\text { del período } \\
\text { (g) }\end{array}$} & \multirow{2}{*}{$\begin{array}{l}\text { Ganancia de } \\
\text { peso diario } \\
\text { (g) }\end{array}$} & \multicolumn{2}{|c|}{ Consumo de ración } & \multicolumn{2}{|c|}{ Conversión Alimenticia } \\
\hline & & & $\begin{array}{c}\text { En el período } \\
\text { (g) }\end{array}$ & $\begin{array}{l}\text { Diario } \\
(\mathrm{g})\end{array}$ & En el período & Acumulada \\
\hline $29-35$ & 700 & 27,5 & 420 & 60 & 2,18 & 2,18 \\
\hline $36-42$ & 920 & 36,5 & 592 & 85 & 2,32 & 2,26 \\
\hline $43-49$ & 1200 & 43,0 & 791 & 113 & 2,63 & 2,41 \\
\hline $50-56$ & 1500 & 46,0 & 980 & 140 & 3,08 & 2,61 \\
\hline $57-63$ & 1800 & 41,0 & 1071 & 153 & 3,77 & 2,85 \\
\hline $64-70$ & 2100 & 35,0 & 1130 & 161 & 4,61 & 3,12 \\
\hline $71-77$ & 2300 & 31,0 & 1155 & 165 & 5,32 & 3,39 \\
\hline $78-84$ & 2500 & 28,0 & 1180 & 169 & 6,02 & 3,64 \\
\hline
\end{tabular}




\section{CONCLUSIÓN}

La reproducción representa el pilar central para la obtención de índices productivos y económicos competitivos en la cunicultura.

La renovación del plantel reproductivo debe ser realizada sistemáticamente en cada banda ocupando jaulas de madres descartadas por baja productividad, problemas sanitarios o mortalidad.

La creación de Centros, Instituciones o Empresas de mejoramiento genético es una necesidad preeminente para el desarrollo de la cunicultura brasileña.

\section{BIBLIOGRAFÍA}

ALVARIÑO, M.R. 1998. Inseminação artificial como base de la cunicultura industrial. Leon: Laboratório Ovejero, 78p.

CHICO, A.M. 2010. Cuidemos la reposición. Cunicultura, 35 (204): 7-9.

GONZALEZ-MARISCAL, G. 2005. La conducta maternal de la coneja: su regulación por hormonas y factores externos. Cunicultura, 30 (177): 299-308.

MAERTENS, L.; COUDERT, P. 2006. Recent advances in rabbit sciences. Bélgica: ILVO, 300p.

MARTíN, M. 2002. Problemas reproductivos en el conejo doméstico. Cunicultura, 27(157): 157-162.

MARTíN, M. 2002. Reproducción en la coneja: I- Anatomía y Fisiología. Cunicultura, 27(160): 381-392.
MOURA, A.S.A.M.T.; FERNANDES, S. 2003. Características reprodutivas e peso corporal em coelhos: efeito da idade à primeira apresentação ao macho e do intervalo de reacasalamento. Acta Scientiarum, 25 (1): 115-120.

MOURA, A.S.A.M.T.; FERNANDES, S.; VASCONCELOS, J.L.M.; BIANOSPINO,E. 2003. Bioestimulação da atividade reprodutiva de coelhas lactantes em regime de monta natural. Revista Brasileira de Zootecnia, 32 (2): 315-324.

RAFEL, O.; RAMON, J.; PILES, M. 2012. ¿ES rentable comprar reposición en tiempo de crisis? Cunicultura, 37 (220): 7-10.

REBOLLAR, P.G. 2000. El aparato reproductor de la coneja y su ciclo hormonal. Sincronización y bioestimulaçión. Cunicultura, 25 (145): 117-123.

REDONDO, P.G. 2006. Parto, manejo perinatal y colocacción del nidal. Cunicultura, 31(179): 41-49.

RIGAU, T.; RIVERA, M.M.; MORA, F.X. 2009. Bases para reducir los problemas reproductivos en cunicultura. Cunicultura, 34 (201): 7-10.

ROCA, T. 2008. Efectos de la temperatura en cunicultura. Cunicultura, 33(193): 23-26.

ROCA, T. 2007. La reposición en la cunicultura industrial. Cunicultura, 32 (187): 135-144.

ROMMERS, J.M. 2002. Cría de conejas de reposición. Cunicultura, 31(184): 373-378.

URDIALES, R.G. 2005. Bioestimulación en la coneja reproductora: ¿Alternativa a los tratamientos hormonales? Cunicultura, 30 (173): 7-17. 


\title{
RESUMEN
}

\begin{abstract}
En la actualidad, las granjas de conejo se deben de gestionar con criterios empresariales para incrementar tanto la productividad como la competitividad. Una parte importante de este desafío es la utilización correcta del manejo y de las técnicas reproductivas en una explotación cunícola. En la presente revisión se pretende por un lado presentar las características reproductivas de la especie y por otro lado mostrar las diferentes tecnologías reproductivas disponibles y su posible aplicación en las granjas comerciales.

En relación con la fisiología reproductiva, se enumeran las características más representativas de la especie así como la influencia que ejercen los diferentes factores sobre las mismas (genéticos, ambientales y de manejo). En el apartado de tecnología reproductiva se exponen las diferentes técnicas utilizadas en la actualidad tanto para el manejo en granja como para la difusión y conservación de recursos genéticos.
\end{abstract}

\section{FISIOLOGÍA REPRODUCTIVA EN EL CONEJO}

\section{Fisiología de la reproducción en el macho}

Las pautas de comportamiento sexual pueden observarse ocasionalmente a partir de los tres meses de edad, siendo probable obtener las primeras eyaculaciones en torno a los cuatro meses. A partir de esta edad, la proporción de machos que manifiestan comportamiento de monta y eyaculan dependerá de las condiciones ambientales y de la estirpe genética.

En general, la mejor edad para la primera cubrición fértil en estirpes o líneas de formato medio $(3,5$ a $4,5 \mathrm{~kg})$ se sitúa en torno a los cinco meses, alcanzando la plena producción espermática a los siete u ocho me- ses de edad, pudiendo mantener su actividad sexual hasta los cuatro años, según la estirpe genética, condiciones ambientales y manejo.

Las líneas o razas de gran formato (5 a 7 $\mathrm{kg}$ ) presentan un inicio reproductivo más tardío, habiéndose observado que los comportamientos de monta no se manifiestan hasta los cinco e incluso los seis meses de edad.

La duración de la espermatogénesis es de unos 49 días. La producción testicular diaria de espermatozoides se sitúa en torno a 150-250 millones con notables variaciones genéticas y estacionales. La capacidad epididimaria de almacenamiento es limitada (1.300-1.900 millones), encontrándose el 15$20 \%$ de los espermatozoides en la cabeza y cuerpo del epididímo y el $80-85 \%$ en la cola del epidídimo El conducto deferente contiene menos del $10 \%$ de los espermatozoides producidos (Theau-Clement et al., 1995). 
El eyaculado presenta un color blanco nacarado en el que pueden observarse pequeñas partículas microscópicas de gel o por el contrario una fracción gelatinosa fácilmente extraíble del eyaculado. El número de espermatozoides que contiene un eyaculado (200-600 millones en 0,2 a 1 ml, Figura 1) disminuye sustancialmente tras el tercer eyaculado si éstos se obtienen en el mismo día. El plasma seminal de conejo contiene numerosas vesículas de origen prostático que parecen conferir estabilidad a las membranas espermáticas reduciendo el estrés oxidativo y la capacitación post-eyaculación (Mouraki et al., 2010). El plasma seminal presenta un contenido proteico que se sitúa entre 15 y $36 \mathrm{~g} / \mathrm{L}$, en torno a unos $5 \mathrm{~g} / \mathrm{L}$ de lípidos totales, de los que el colesterol representa un $30 \% \mathrm{y}$, alrededor de 1,9 g/L de fructosa (Yousef et al., 2005).

En general, el conejo manifiesta un elevado ardor sexual que, a diferencia de otras especies, no se corresponde con sus posibilidades de fecundar a un hembra. La mayor parte de los machos de conejo de estirpes de formato medio son capaces de realizar 10-12 montas en un breve lapso de tiem- po (30 a 60 minutos, Ambriz et al., 2002). Este comportamiento provoca en algunos cunicultores un manejo reproductivo inadecuado. De un lado suele existir una proporción insuficiente de machos frente a hembras (menor de1:15) y de otro, se suele dar una utilización abusiva y poco eficaz de los machos que presentan mayor ardor sexual.

La cubrición de una coneja más de una vez puede mejorar ligeramente las posibilidades de desencadenar la ovulación, puesto que esta especie es de ovulación inducida. Sin embargo, si se establece como práctica cubrir una coneja más de dos veces con el mismo macho, no debe olvidarse que el macho no produce una gran cantidad de espermatozoides y que no dispone de unas grandes reservas seminales, por lo que un intento, claramente innecesario, de asegurar la inducción de la ovulación puede desencadenar la falta de fertilidad de ese macho en una cubrición posterior sobre otra hembra. Estos problemas se acentúan durante el verano y el otoño, en primer lugar, por una pérdida de ardor sexual debido a las altas temperaturas y, en segundo lugar, por una disminución de la producción espermática (Nizza et al., 2003; Safaa et al., 2008).

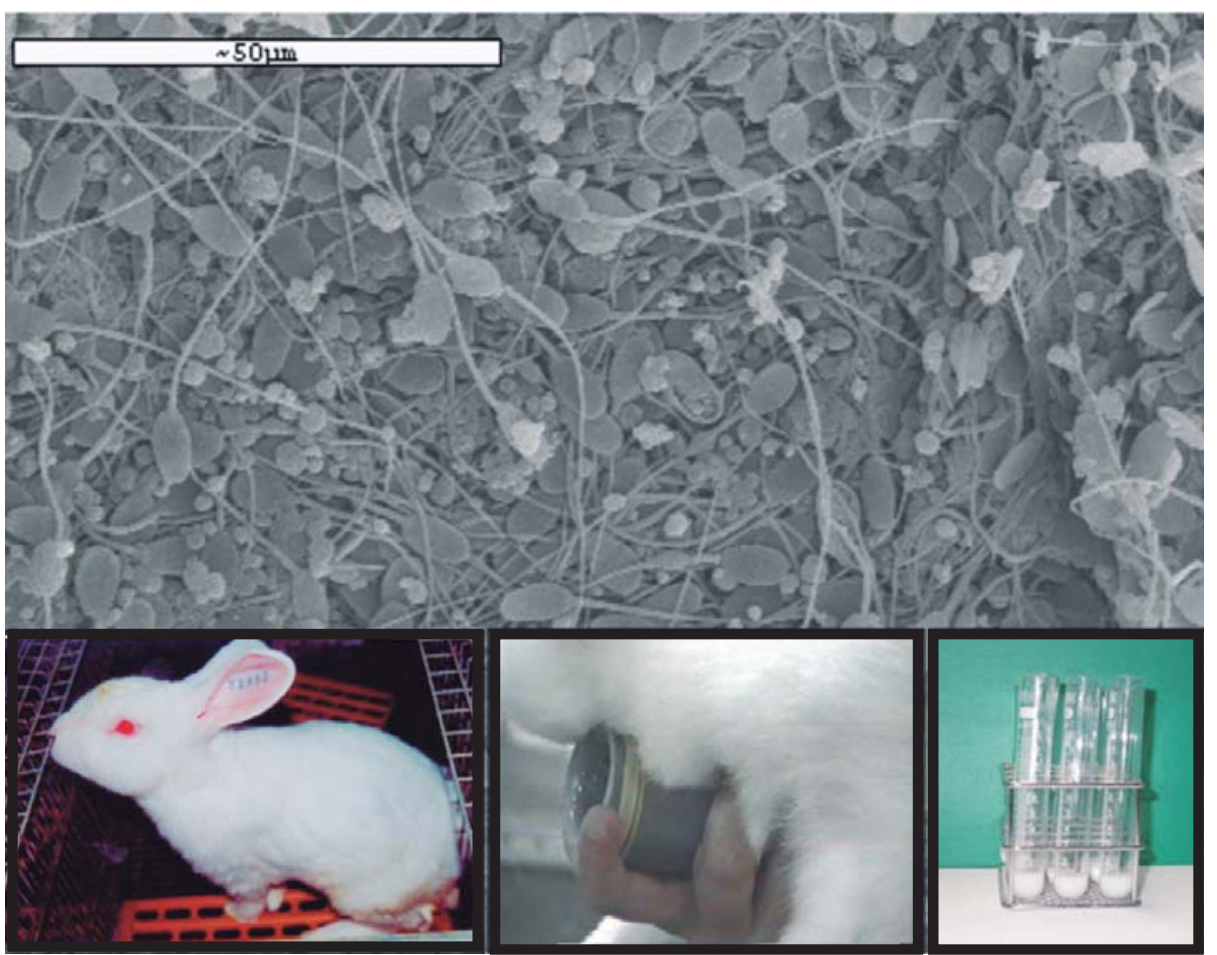

Figura 1. Espermatozoides de conejo tras su recuperación mediante vagina artificial. 
En general, desde el punto de vista de la utilización de machos para inseminación artificial, una frecuencia de dos eyaculados por semana, un fotoperiodo 16:8 y una alimentación rica en ácidos grasos de la serie omega 3 y 6 , así como en Zn, Se y/o vitamina $E$ permite obtener mejora en la producción espermática o en los parámetros espermáticos indicadores de calidad (Pascual et al., 2004; Castellini et al., 2007).

\section{Fisiología de la reproducción en la hembra}

En la coneja la pubertad se alcanza, en general, cuando alcanzan el $70-75 \%$ del peso adulto (de tres meses y medio a cuatro meses en líneas de formato medio), si bien es preferible esperar a que hayan alcanzado los cuatro meses y medio de edad (en líneas de formato medio) para iniciar la reproducción.

Las manifestaciones externas que indican el celo en la coneja se limitan al reflejo lordósico y al aumento de la turgencia y coloración de los labios vulvares.

La coneja es un mamífero polítoco de ciclo reproductivo corto. Sus cuernos uterinos están completamente separados entre sí, desembocando en la vagina de forma independiente a través de sendos canales cervicales, por lo que no se producen migraciones de embriones de un cuerno al otro.

La coneja no presenta ciclo estral, ya que la ovulación en esta especie no es una con- secuencia directa de la culminación del desarrollo folicular. Sin embargo, presenta una alternancia entre fases de aceptación y no aceptación de la monta, que está relacionada con el desarrollo y la atresia de folículos pre-ovulatorios responsables del aumento de los niveles de estradiol y del reflejo lordósico. La coneja requerirá, además, de la estimulación coital para desencadenar la descarga de GnRH que conducirá a la ovulación unas 9-10 horas post-coito. Si la ovulación no es seguida por una gestación, la coneja presenta un estado de pseudogestación que durará unos 17 días (Figura 2).

En el conejo, el esperma se deposita en la zona superior de la vagina. Al igual que en otros mamíferos, la fecundación se producirá en el ámpula unas 14 horas después de la monta o inseminación. Los estadios de desarrollo embrionario previos a la implantación se caracterizan por la influencia que sobre su desarrollo ejercen los ambientes oviductal y uterino. En las primeras 68-72 horas, a su paso por el oviducto, se produce la segmentación de los embriones y se inicia la formación del blastocisto. En este período se deposita la cubierta de mucina alrededor de la zona pélucida. La secuencia del proceso de segmentación, en función del tiempo postcoito, es la siguiente: a las 1416 horas, expulsión del segundo corpúsculo polar; a las 21-24 horas postcoito (h.p.c.), primera división embrionaria; a las 48 h.p.c., 8-16 células; a las 60 h.p.c., mórula y a las72 h.p.c., blastocisto temprano (Figura 3).

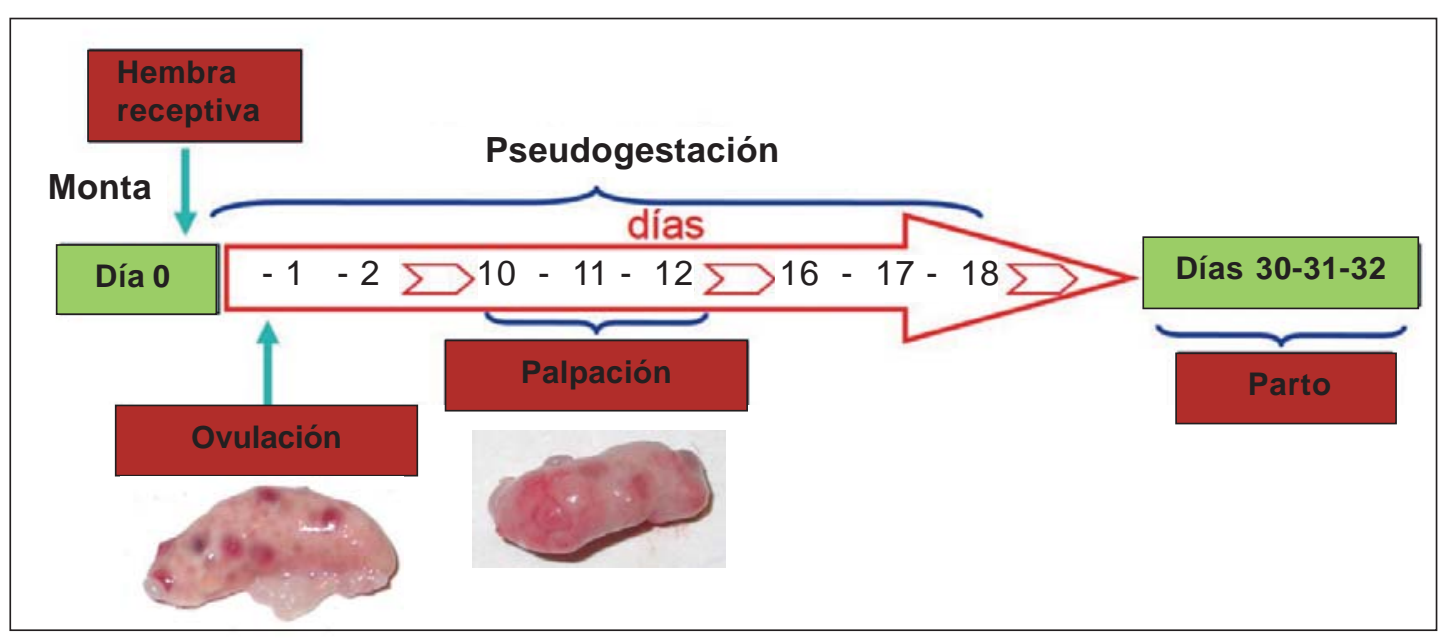

Figura 2. Ciclo reproductivo y pseudogestación en conejas. 

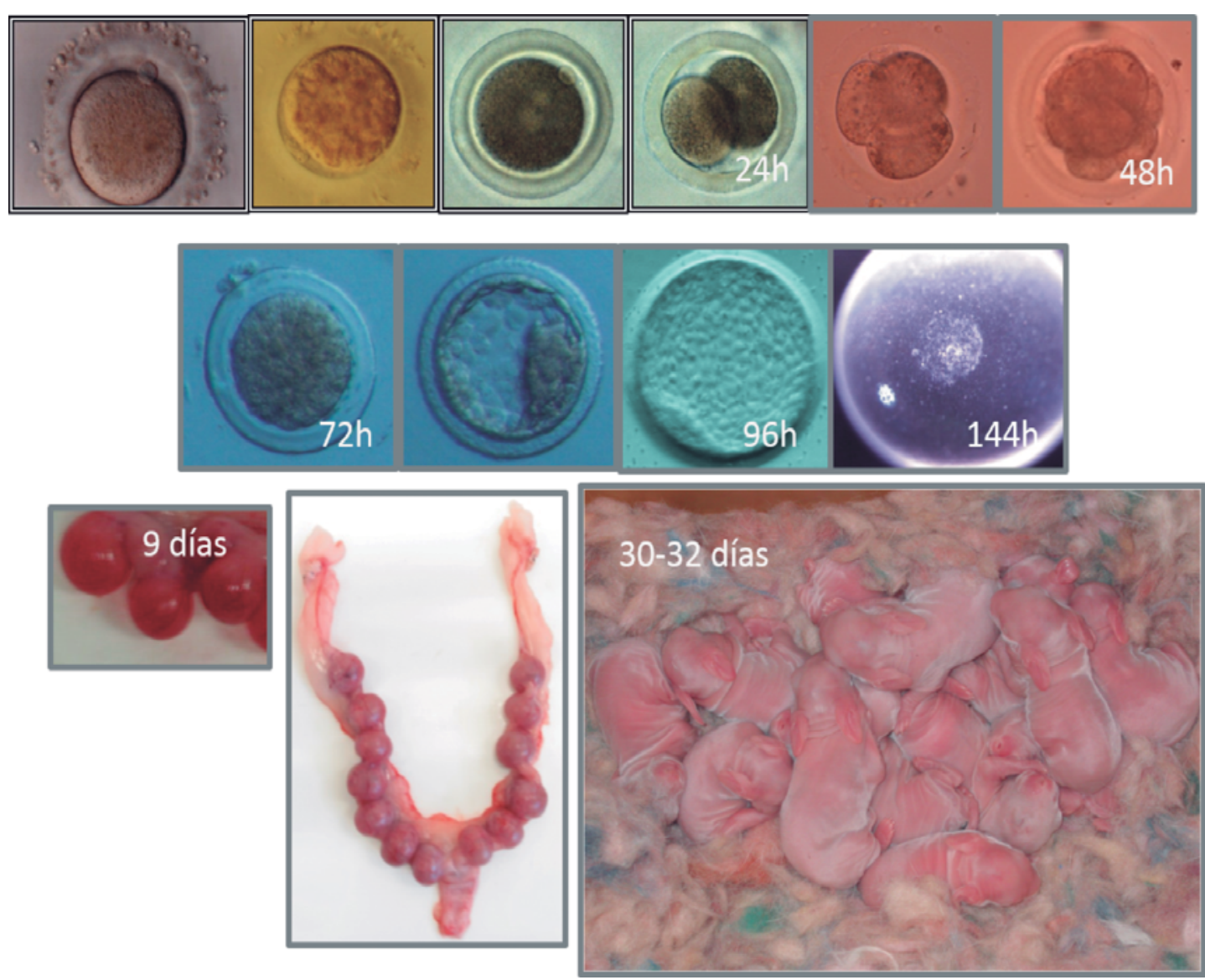

Figura 3. Desarrollo embrionario y fetal en el conejo.

Una vez el blastocisto ha alcanzado el útero, inicia una etapa de intensa proliferación y diferenciación del embrioblastema y el trofoblasto. En este período, las cubiertas embrionarias sufren importantes alteraciones como consecuencia tanto del proceso de expansión del blastocisto como de la actividad enzimática a la que se ven sometidas. La zona pelúcida y la cubierta de mucina son progresivamente transformadas y reemplazadas. De esta forma, el blastocisto presenta finalmente tres capas con diferente origen. La más externa, el gliolema, que parece derivar de las secreciones uterinas; la capa situada en el medio, que parece representar restos de la capa de mucina; y la última capa, la neozona, que podría estar formada por secreciones del trofoblasto, o bien, por secreciones uterinas que han difundido a través de las otras capas, situándose en la zona más interna. Las principales funciones que se han postulado para estas capas son facilitar el espaciamiento de los blastocistos en el cuerno uterino en el momento de la implantación e inmovilizar y orientar a éstos en los lugares de implantación (Denker, 2000).

Una vez en el útero y hasta el quinto día, los embriones colonizan progresivamente los cuernos uterinos, entre los días seis y siete se observa ya una distribución equidistante de los mismos a lo largo del cuerno uterino que los contiene. En esta etapa los blastocistos incrementan su diámetro desde 1 a $5 \mathrm{~mm}$. La expansión del blastocisto no sólo provoca dicho espaciamiento sino que además, determina finalmente su inmovilización, quedando ya establecida la posición definitiva que ocupará cada embrión en el cuerno uterino durante la gestación. Siete días post coito se observan dilataciones antimesometriales, a modo de pequeñas hinchazones traslúcidas 
(decidualización), en las que se encuentran cada uno de los embriones. Entre los días 10 y 17 se constituirá y desarrollará una placenta corioalantoidea y hemicorial (Hoffman et al., 1998). El parto tiene lugar 30-32 días post-coito, en función del número de fetos gestados y de la estirpe genética (Figura 3).

La coneja es capaz de iniciar una nueva gestación con éxito desde el mismo momento del parto y durante toda la etapa de lactación, no siendo por ello necesario esperar al destete de los gazapos. Por ello es posible definir varios regímenes reproductivos (intensivo, semi-intensivo o extensivo) en los que los intervalos entre partos teóricos serán de 35, 42 y 60 días. En condiciones de explotación semi-intensiva (el más habitual hoy en día), las conejas son montadas o inseminadas 10-12 días post-parto, dando lugar a un solape parcial de gestación y lactación (de 19 a 21 días). En el sistema de explotación intensivo las conejas serán montadas o inseminadas de 3 a 5 días post-parto. Es necesario reseñar que las necesidades nutritivas de los animales y los procedimientos de sincronización para alcanzar una productividad óptima deben adaptarse al régimen reproductivo elegido.

En general, a menos que se utilicen métodos de bioestimulación basados en el control del fotoperiodo, se recomienda seguir un fotoperiodo de 16 horas de luz y 8 de oscuridad para evitar o reducir las fluctuaciones estacionales.

El grado de receptividad de las conejas, caracterizado esencialmente por el color y turgencia de los labios vulvares, determina en gran medida los resultados de fertilidad. La probabilidad de que una coneja con una coloración blanquecina (pálidos) acepte la monta es prácticamente nula (<10\%), con un color rosado se situaría entre el $40 \%$ y el $60 \%$, con un color rojizo entre el 80 y el $100 \%$ y con un color violáceo entre un 60 y un $80 \%$. A su vez la probabilidad de que las hembras montadas queden gestantes sigue una proporcionalidad semejante. En los nuevos sistemas en los que la explotación cunícola se organiza en bandas, los tratamientos para la sincronización de celos en un conejar son imprescindibles (una revisión más extensa sobre los procedimientos y fac- tores a tener cuenta puede encontrarse en Theau-Clement, 2007).

Los tratamientos hormonales de inducción del celo más generalizados consisten en promover el crecimiento de una población de folículos ováricos, utilizando hormonas de acción folículo estimulante, la más utilizada es la PMSG o eCG, que tiene como ventaja su bajo precio y la fácil aplicación (dosis única subcutánea o intramuscular). El inconveniente que presenta es la variación de la respuesta individual, la formación de anticuerpos (25 U.I., tras 10-12 aplicaciones) y, en ocasiones, una posible inducción anticipada de la ovulación con dosis superiores debido a su actividad secundaria LH. Tanto en monta natural como en inseminación artificial, la PMSG se inyecta dos días antes de la monta o inseminación. La dosis recomendada actualmente es de 8 a 12 U.I. de PMSG. En general, alrededor del $95 \%$ de las hembras tratadas con PMSG muestran evidentes signos de receptividad a las 48 horas del tratamiento.

La prostaglandina $F 2 \alpha$ y sus análogos inducen la luteolisis y por consiguiente la receptividad. Deben ser utilizadas tras una palpación negativa (a los 12 días de la cubrición), en inyección intramuscular y las hembras se cubrirán de nuevo a los dos días. También es posible su utilización combinada para provocar el parto y favorecer la cubrición de las conejas cuando se utiliza el régimen intensivo.

Otra posibilidad de inducir la receptividad sobre conejas en fase de lactación es el cierre del nidal 24-36 horas antes de la monta o inseminación (práctica cada vez mas común). Este bloqueo del amamantamiento no tiene efectos negativos sobre la viabilidad de los gazapos o sobre la incidencia de mamitis. El efecto positivo que se obtiene sobre la receptividad o celo de la coneja es consecuencia de la disminución de la secreción de prolactina y el aumento consecuente de gonadotropinas. En el caso de hembras primíparas lactantes, Arias-Álvarez et al. (2010), observaron que la calidad ovocitaria dependía del tipo de método de inducción de receptividad empleado, presentando la bioestimulación (cierre de nidales durante $24 \mathrm{~h}$ ) mejores resultados frente al tratamien- 
to convencional de eCG (25 UI). Las hembras tratadas con eCG mostraron un mayor número de folículos atrésicos y una menor maduración citoplasmática de los oocitos (medida como tasa de migración de los gránulos corticales).

Por último, también se puede sincronizar a las hembras mediante la modificación del fotoperiodo. Las hembras son sometidas a un fotoperiodo 8 :16 antes del parto y tras éste se incrementa progresivamente hasta las 16:8 en la semana en la que se producirá la cubrición (Theau-Clement et al., 2000).

\section{TECNOLOGÍA REPRODUCTIVA PARA LA PRODUCCIÓN, DIFUSIÓN Y CONSERVACIÓN DE RECURSOS GENÉTICOS DEL CONEJO}

El desarrollo alcanzado en la tecnología reproductiva permite hoy, de un lado incrementar las posibilidades de mejora y difusión genética de las líneas comerciales, y de otro conservar y caracterizar los recursos genéticos de esta especie. Así, la inseminación artificial ha contribuido notablemente al desarrollo de la cunicultura industrial, mientras que técnicas como la crioconservación de espermatozoides o embriones han contribuido a generar bancos de germoplasma, tanto de líneas comerciales como de algunas razas, favoreciendo en ocasiones la difusión y el conocimiento genético así como la conservación frente a posibles epizootias o pérdidas de patrimonio genético.

\section{Inseminación Artificial}

La utilización de la inseminación artificial persigue un único objetivo en granjas comerciales: incrementar la productividad. Esta mejora de la productividad debe lograrse por:

- la reducción del número de machos en granja (con el aumento consiguiente del número de hembras)

- la introducción de nuevos sistemas de organización (dos bandas o banda única)
- la utilización del semen de machos de características deseadas, como por ejemplo de elevada velocidad de crecimiento

En los últimos años se ha producido una rápida expansión de la inseminación artificial en el conejo asociada a una mejora organizativa del manejo en las explotaciones y a un incremento en el tamaño de las explotaciones. Esta expansión no ha conllevado en España, al igual que en otros países como Italia o Francia, sustanciales avances en las técnicas de inseminación que todavía se encuentra limitada por la variabilidad de resultados de la aplicación del semen conservado y por una deficiente relación coste-beneficio del proceso. La mayor parte de los estudios realizados se han centrado sobre el control de la receptividad de la hembra y de la inducción de la ovulación. Unos pocos trabajos han dedicado su atención al comportamiento, manejo y optimización del macho de inseminación. Y en muy pocos casos se ha utilizado la inseminación artificial en cunicultura para mejorar la difusión de animales seleccionados a las explotaciones y consecuentemente la productividad de las mismas. Se ha perdido así una de las principales ventajas de la inseminación artificial, la difusión de los mejores machos.

\section{Tecnología de la inseminación artificial}

El semen de conejo puede utilizarse refrigerado, los resultados obtenidos mediante inseminación artificial (I.A.) con semen refrigerado son de un 60-80 \% de fertilidad, con una prolificidad similar a la de monta natural (8-10 gazapos vivos por parto). Sin embargo, la inseminación artificial en cunicultura se encuentra limitada por la baja relación eyaculado:hembras inseminadas (1:10) y por el tiempo de refrigeración recomendado para el semen (24-48 horas a 15$18^{\circ} \mathrm{C}$ ) así como por la tecnología de congelación de semen, que en esta especie, por el momento, no ofrece resultados competitivos a nivel de explotación, ya que la motilidad y normalidad acrosómica post-descongelación desciende un $50 \%$, resultando un porcentaje de gestación en torno al 40 \% y 
una pérdida de prolificidad alrededor de 2 gazapos. En determinadas líneas y con fines de conservación genética se han obtenido buenos resultados de fertilidad (80 \%) y prolificidad con semen congelado.

La técnica a aplicar se resume en:

- extracción del semen del macho utilizando una vagina artificial

- dilución del semen (1:5 a 1:25)

- conservación del semen hasta 48 horas después de su recolección

- inducción de la ovulación en el momento de la inseminación

\section{Recogida de eyaculados}

El uso de vagina artificial es el método más utilizado para la recogida del semen en conejo, ya que permite utilizar temperaturas (en torno a $50^{\circ} \mathrm{C}$ ) y presiones adecuadas para estimular la eyaculación de los machos.

La extracción del semen, al igual que la monta natural, se realiza en la jaula del macho. En general, son pocos los machos que presentan rechazo al uso de la vagina artificial, bien sea utilizando como engaño una coneja, una piel de coneja u otras dispositivos de simulación. En torno a un 10-30 \% de los machos no son útiles por diversas circunstancias entre las más importantes se encuentran la inadaptación a la vagina (frecuentes eyaculaciones con orina) y una baja producción y calidad del semen (suficiente para monta, insuficiente para rentabilizar un macho para inseminación).

El macho realiza la eyaculación de la misma forma que en la monta natural, empujando hacia adelante y posteriormente cayendo de costado o de espaldas.

La frecuencia de recogida más extendida es la de dos eyaculaciones con un lapso de tiempo de 15-30 minutos entre ellas, una o dos veces por semana.

\section{Análisis y contrastación seminal}

La fertilidad del macho está relacionada directamente con la calidad del semen. Por ello, el objetivo es evaluar la calidad del semen y predecir, a través de la misma, la capacidad fecundante de los espermatozoides. Son muchos los test de valoración, pero po- cos los que han sido correlacionados con la fertilidad y menos los que habitualmente se utilizan en la valoración rutinaria del semen. El color del eyaculado es blanco nacarado. La primera operación sobre un eyaculado es retirar cualquier partícula visible de gel para evitar la aglutinación posterior de los espermatozoides sobre éste.

Las técnicas o test de análisis son similares a los descritos en otras especies en cuanto a evaluación de la movilidad, concentración, viabilidad, morfoanomalías o estado del acrosoma. Tan sólo debe tenerse en cuenta que el semen de conejo presenta numerosas partículas seminales que suelen dificultar la evaluación de la movilidad con los sistemas de evaluación automáticos (CASA) y que las diluciones para su evaluación no deberían superan la relación 1:20, dado que algunos autores han observado modificaciones de los parámetros de movilidad probablemente debidas a un incremento de los daños por lipoperoxidación en eyaculados diluidos 1:30 (Castellini et al., 2000).

A diferencia de otras especies, en general, la inseminación artificial en conejo se lleva a cabo con mezclas heteroespérmicas, quizás por el tradicional bajo número de dosis obtenidas a partir de la producción espermática de un sólo macho o por la no utilización de machos de alto valor genético. No obstante, los eyaculados deben evaluarse individualmente antes de su mezcla y dilución definitiva. Los estudios sobre las ventajas o desventajas de la utilización de las mezclas heteroespérmicas frente a la utilización de machos individualizados sean escasos y por lo tanto difícilmente se procede a la valoración individual de machos, lo que permitiría localizar machos subfértiles que podrían estar afectando al conjunto de la mezcla y reduciendo en algunos puntos la fertilidad de las granjas.

Una práctica recomendable es la dilución 1:3-1:5 del eyaculado inmediatamente después de la recolección. Procediendo tras su evaluación, al menos en términos de movilidad y porcentaje de espermatozoides anormales (Lavara et al., 2005), a su mezcla y dilución definitiva en función de la dosis espermática a utilizar $(6,16,40$ millones de espermatozoides por 
dosis) y del periodo de conservación (8, 24,48-72 h, respectivamente).

\section{Características de los diluyentes}

Los diluyentes más utilizados actualmente están constituidos por tampones orgánicos como el Tris-Cítrico (Roca et al., 2000). Este podría formularse para tener un $\mathrm{pH}$ en torno a 6,9 y una osmolaridad de 300 $340 \mathrm{mOsm} / \mathrm{K}$ con $250 \mathrm{mM}$ de Tris-hidrimetilaminometano, $82,7 \mathrm{mM}$ de ácido cítrico, $50 \mathrm{mM}$ de glucosa y antibióticos para controlar el crecimiento bacteriano (500 a $1000 \mathrm{UI}$ de penicilina y 500 a $1000 \mu \mathrm{g}$ de estreptomicina por mililitro de diluyente). Con la finalidad de mejorar la distribución y facilitar la aplicación de la técnica de inseminación se han desarrollado sistemas de envasado de semen de conejo monodosis basados en la gelificación del diluyente. Esta gelificación se puede obtener, por ejemplo añadiendo $1,4 \%$ de gelatina ( $\mathrm{g} / \mathrm{v})$ al diluyente y conservando la dosis seminal refrigerada hasta su aplicación (López-Gatius et al., 2005).

Recientemente, se ha evaluado, utilizado y comercializado un diluyente al que se le adiciona un análogo sintético de $\mathrm{GnRH}$ con la finalidad de inducir la ovulación mediante la absorción de ésta vía mucosa vaginal. La utilización de este diluyente evita que tras la inseminación sea necesario inyectar intramuscularmente o subcutáneamente el análogo.

\section{Conservación}

\section{Refrigeración}

El semen que ha de ser conservado por refrigeración es diluido en un medio convencional y enfriado lentamente hasta $15-18^{\circ} \mathrm{C}$ (método habitual) o utilizando un medio de dilución modificado por la adición de yema de huevo enfriado hasta $5^{\circ} \mathrm{C}$ (no es habitual).

El semen refrigerado permanecerá a la temperatura de refrigeración hasta su utilización. La perdurabilidad del mismo es función del genotipo, medio utilizado y calidad del eyaculado, oscilando entre las 24-72 horas en conejo. Recientemente, se han obtenido buenos resultados en la utilización de semen de conejo después de 72 horas asociado a su inmovilización en gel (LópezGatius et al., 2005). Las condiciones experimentales en las que se desarrolló implican la utilización del diluyente con gelatina, una dosis en torno a los 40 millones de espermatozoides, una temperatura de conservación de $15-18^{\circ} \mathrm{C}$ e inseminación de hembras receptivas.

\section{Congelación de semen}

El desarrollo de los métodos de congelación de semen en el conejo se inició en los años 60 , quedando tempranamente descartado el glicerol, habitual en otras especies, como crioprotector (revisar Mocé y Vicente, 2009). Actualmente, los medios utilizados para congelar semen de conejo incluyen, además de los diluyentes tradicionales (Triscítrico-glucosa), un crioprotector como la acetamida o el dimetil sulfóxido y en ocasiones se suplementan con yema de huevo.

El semen debe ser envasado en pajuelas de inseminación $(0,25$ ó $0,50 \mathrm{ml})$ y sufrir un proceso de enfriamiento (entre $45 \mathrm{~min}$. y 4 horas a $5^{\circ} \mathrm{C}$ ), para posteriormente permanecer durante 15 minutos a $-110^{\circ} \mathrm{C}$ y por último ser almacenado a $-196^{\circ} \mathrm{C}$.

La posibilidad de inseminar con semen congelado con fines productivos hay que descartarla actualmente, fundamentalmente por sus resultados. Los menores porcentajes de motilidad espermática post-descongelación (32-50 \% con dimetilsulfóxido y glicerol como crioprotector, y $43 \%$ con acetamida como crioprotector), obligan a practicar diluciones menores que con semen fresco, esto junto con la obtención de una tasa de fertilidad y prolificidad generalmente menor que con semen refrigerado cuando se ha aplicado para producción (40-50\% de fertili$\mathrm{dad}$ ), hacen que este método no sea, hasta ahora, comercializable. Existen muy pocas experiencias en las que el semen congelado haya dado resultados de fertilidad y prolificidad comparables al semen fresco. En general estos buenos resultados se asocian a líneas genéticas o a la utilización de un elevado número de espermatozoides por dosis (90-100 millones). 
En otras especies han sido localizadas proteínas seminales correlacionadas tanto con la fertilidad del semen no congelado como congelado (Maxwell et al., 1999; Killian et al., 1999). No sólo es necesario desarrollar una metodología de valoración que proporcione información sobre las probabilidades de uso con éxito de un semen congelado y que permita estudiar y evaluar con rapidez modificaciones en los métodos de conservación, sino además conocer si en conejo es posible localizar estas proteínas y su modo de actuación para favorecer la utilización rutinaria del procedimiento de congelación.

\section{Dosis de inseminación}

En general la mayor parte de los centros de inseminación utilizan dosis en torno a 3040 millones de espermatozoides. Desde 1995, en la Universidad Politécnica de Valencia (UPV) hemos llevado a cabo varias experiencias para determinar el número mínimo de espermatozoides requeridos en inseminación artificial con los machos de la línea R. Los resultados demostraron que con 4 millones de espermatozoides podían obtenerse tasas de fertilidad y prolificidad comparables a los observados por otros autores con un número de espermatozoides sensiblemente superior ( $74 \%$ de fertilidad al parto y 9,4 nacidos vivos, Vicente y Viudes-deCastro, 1997). Esto ha permitido multiplicar, al menos por cuatro, las posibilidades de difusión del semen de estos machos. Si bien es cierto que todos aquellos técnicos y cunicultores formados por nuestro laboratorio tienen como norma utilizar un mínimo de 6 millones de espermatozoides por dosis en las primeras 12 horas, siendo los resultados medios obtenidos en más de un millón inseminaciones realizadas muy satisfactorios, lo que proporciona un margen de garantía para los cunicultores. Por supuesto, al igual que otras metodologías de trabajo de otros grupos o centros de inseminación, la interacción con determinadas prácticas de manejo, ambiente o tipo de animal puede provocar que los resultados, en un porcentaje bajo de explotaciones, no sea el deseado ni por los centros ni por el cunicultor. En ocasiones tan sólo es necesario analizar si se han esta- blecido las condiciones necesarias que han de cumplirse en una granja que vaya a utilizar la inseminación para corregir progresivamente los problemas.

El número de hembras inseminadas por macho y semana oscila entre las 10 y 20 de la técnica tradicional, siendo posible alcanzar las 50 ó 100 con la técnica anteriormente citada, aunque reduciendo el tiempo de conservación.

El volumen de semen diluido que se utiliza en inseminación artificial en coneja es de 0,5 a 1 mililitro por dosis.

\section{Posición del animal e inseminación}

Es posible inseminar con la coneja en posición dorsal o ventral con la ayuda de una segunda persona que inmoviliza la coneja (generalmente cabeza y lomo) mientras el inseminador utiliza una mano para separar los labios vulvares y favorecer la introducción de la cánula. En otras ocasiones, bien mediante un dispositivo tipo cañón o simplemente inmovilizando la coneja dorsalmente con la mano (lomo y cola) y codo (cabeza y nuca) sobre su jaula, la inseminación puede ser realizada por una sola persona.

Una vez escogido y preparado el material para inseminar, se introduce por la vagina de la hembra el catéter o pistola de inseminación (si tiene acodadura, deberemos introducir ésta hacia la parte dorsal), evitando su introducción en la uretra, situada en la parte ventral de la vagina. Pasada la pelvis, si el catéter de inseminación es curvado, se gira unos $180^{\circ}$ y se prosigue su introducción hasta que se alcanza el fondo de la vagina. Entonces se presiona el émbolo para depositar el semen.

La hembra ha de ser inducida a ovular inmediatamente después de la inseminación con un análogo sintético de $\mathrm{GnRH}(20 \mu \mathrm{g}$ de Gonadorelina, 0,8 a $1 \mu \mathrm{g}$ de Acetato de Buserilina, triptorelina o deslorelina ). Tradicionalmente estos análogos se suministran vía intramuscular, sin embargo, es conocido que estos péptidos sintéticos pueden ser absorbidos vía mucosa y por ello en los últimos años se ha añadido a la dosis de inseminación (Quintela et al., 2004 y 2009, Viudes de Castro et al., 2007; Vicente et al., 2008 y 2011). La absorción vía mucosa vaginal de 
los análogos estudiados hasta el momento parece ser menos eficiente que la intramuscular, siendo necesario incrementar notablemente la cantidad de análogo sintético añadido a la dosis de inseminación (por ej.: de 5 a $16 \mu \mathrm{g}$ de acetato de buserilina, $30 \mu \mathrm{g}$ para la deslorelina) para obtener una elevada tasa de inducción de la ovulación y buenos resultados de fertilidad y prolificidad (74$80 \%$, 9,6-10,0 gazapos respectivamente).

\section{Producción y crioconservación de embriones. Restauración de poblaciones}

\section{Métodos de superovulación y obtención de embriones}

La recuperación o producción de embriones en el marco de un programa de conservación pretende no sólo obtener un elevado número de embriones, sino además que éstos provengan del mayor número de orígenes macho y hembra, con el fin de obtener una adecuada representación de la población original.

La obtención de óvulos es una etapa imprescindible tanto para los programas de conservación ex situ de recursos genéticos, como para su aplicación en diferentes técnicas reproductivas como ICSI, FIV o transferencia nuclear. En conejo, es habitual que las recuperaciones de ovocitos tengan lugar post-mortem. Para la obtención de ovocitos inmaduros se suelen utilizar tanto las técnicas de cortes foliculares -por el reducido tamaño de los folículos antrales- como la punción folicular (en torno a 0,6-2 mm de diámetro por folículo). En cambio, si se desean recuperar óvulos maduros la técnica utilizada con más frecuencia es la recuperación post-mortem, mediante lavado oviductal, realizado a las 14-16 horas tras la inducción de la ovulación. La recuperación de óvulos in vivo por laparotomía o laparoscopia es técnicamente posible pero inusual, a diferencia de la recuperación de embriones.

La obtención de embriones in vivo por laparoscopia ofrece la posibilidad de realizar varias veces el procedimiento para incrementar u optimizar el número de embriones re- cuperados por hembra, en especial cuando se utilizan poblaciones con escaso número de individuos o animales de gran valor genético (Besenfelder et al., 1998; Mehaisen et al., 2005; Cortell et al., 2010, Figura 4). En general, la obtención de óvulos y embriones se realiza tras un tratamiento de superovulación, ya que las técnicas a las que pueden destinarse posteriormente (FIV-Crioconservación, Clonación o Transgénesis) presentan bajas eficiencias, además del elevado coste económico cuando la técnica de recuperación se realiza in vivo. Sin embargo, la calidad de los embriones y/o óvulos se ve alterada por los tratamientos de superovulación, ya que, en muchas ocasiones, aumentan los casos de óvulos no fecundados, se incrementa el número de embriones que presentan anomalías en su desarrollo y, entre los morfológicamente normales, se observa una disminución de su viabilidad.

Los resultados de los tratamientos de superovulación son muy variables. Como ya se ha descrito en otras especies, la eCG se administra 48 a 72 horas antes de inducir la ovulación en una única dosis de unas $20 U . I$. Los tratamientos de FSH siguen una pauta típica de dos dosis diarias cada 12 horas durante 72 horas llegando a suministrar a lo largo del tratamiento en torno a 2 mg de extractos hipofisarios (Kennelly y Foote, 1965 Kauffman et al., 1998, Mehaisen et al., 2006). No obstante, para disminuir el número de dosis en los tratamientos con FSH, se han utilizado, tanto en conejo como en otras especies, diferentes protocolos introduciendo pilivinilpirrolidona (PVP) para aumentar el periodo de estimulación efectivo. En el conejo ha sido posible utilizar con éxito una dosis única de FSH al día de 0,6 mg durante tres días (Viudes de Castro et al., 2009; Cortell et al., 2010). Los tratamientos con eCG y FSH consiguen duplicar y en ocasiones triplicar la tasa de ovulación media de la población que es tratada ( 20 a 40 frente a 12-14 de los controles; Kennelly y Foote, 1965; López-Béjar y López-Gatius, 2002; Mehaisen et al., 2006).

Por otra parte, si la FSH es de origen animal, el tratamiento de superovulación tendría otro factor de variación, ya que al provenir de extracto de tejido hipofisario, la rela- 

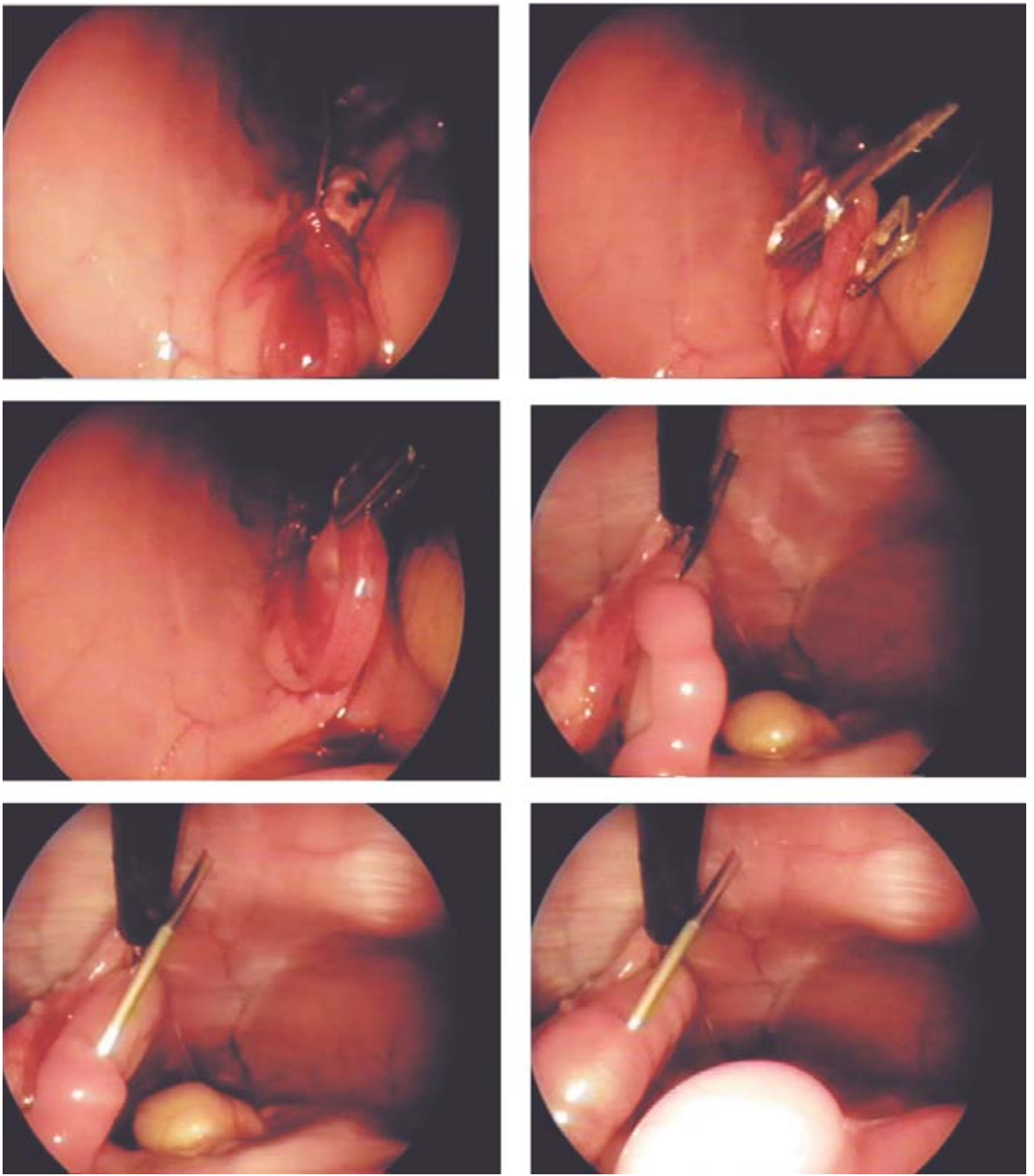

Figura 4. Procedimiento de recuperación y/o transferencia oviductal y uterina en conejo por laparoscopía.

ción FSH/LH de los preparados comerciales puede variar según el lote de fabricación; lo cual podría influir en la respuesta de las hembras sobre las que se aplique. Existen también en el mercado FSH ultrapuras, en las que la relación $\mathrm{FSH} / \mathrm{LH}$ es prácticamente constante, e incluso FSH y $\mathrm{LH}$ recombinantes, con las que la relación FSH/LH puede ser controlada, si bien los ensayos en conejo con FSH/LH ultrapura de porcino o FSH/ LH recombinante humana no aportan mejoras en relación con el número y la viabilidad de embriones.

La recuperación de óvulos y embriones tanto postmortem como in vivo alcanzan entre un 70 y un $90 \%$ respecto a la tasa de ovulación en las conejas de las que se obtienen óvulos y embriones. En un $30 \%$ de las conejas superovuladas no es posible encontrar óvulos o embriones.

Se ha podido observar una pérdida total de respuesta superovulatoria tras el segundo tratamiento tanto con eCG como con FSH de origen animal, no obstante, con FSH recombinante, un número variable de conejas permite realizar tres o cuatro tratamientos superovulatorios con éxito (de un 15 a un $25 \%$ de las conejas, llegando a recuperar entre 60 y 80 embriones por coneja). 


\section{Crioconservación de embriones}

Desde los años 70 es posible congelar con éxito embriones de conejo (Banks y Maurer, 1974) y en los años 90 se establecieron los primeros procedimientos de vitrificación para esta especie (Smorag et al., 1989; Kasai et al. 1992). Posiblemente junto con el ratón, el conejo y el vacuno sean las especies en las que más estudios se han realizado de crioconservación en cuanto a protocolos de adición-dilución, tipos de crioprotectores, congelación-descongelación, estadios embrionarios e incluso origen genético de los embriones dentro de una misma especie.

Entre los factores que pueden afectar al éxito de la crioconservación en conejo se encuentran la sincronización y el origen genético de la hembra receptora. En general los embriones congelados y vitrificados son transferidos a hembras con una asincronía de 12 a 17 horas (-12-17 horas) en relación con la edad de los embriones.

Los programas de crioconservación asociados a los grupos INRA y UPV que han constituido bancos de conservación de recursos genéticos se han desarrollado con diferentes objetivos. En el INRA, la finalidad ha sido la de preservar tanto líneas comerciales como razas de conejo no competitivas desde el punto de vista productivo y que habían quedado en manos de asociaciones y grupos de ganaderos para su exposición en concursos y ferias (Argentado de Campaña, Belier, Gigante de Flandes, Mariposa, Turingia, Blanco de Viena, Chinchilla, Pequeño Ruso). En la UPV, el banco establecido responde a las necesidades científicas de evaluación y difusión de líneas sintéticas seleccionadas para mejorar la productividad de este sector.

Ambos programas utilizan embriones de conejo en estadio de mórula pero se diferencian en la técnica de crioconservación. El grupo del INRA utiliza la congelación lenta, en la que los embriones son expuestos en tres etapas (de 5 minutos cada una) a un medio de congelación de concentración creciente de un crioprotector $(0,5 ; 1$ y $1,5 \mathrm{M}$ de dimetilsulfóxido, DMSO) en PBS suplementado con un 0,4\% (peso/volumen) de BSA.
Tras su envasado en pajuelas de 0,125 mL, se inicia el descenso de la temperatura a $-1^{\circ} \mathrm{C} / \mathrm{min}$ hasta $-7^{\circ} \mathrm{C}$ en el que se induce la congelación del medio que contiene los embriones. Posteriormente, la temperatura desciende a $-0,5^{\circ} \mathrm{C} / \mathrm{min}$ hasta $-35^{\circ} \mathrm{C}$, momento en el que son sumergidos en nitrógeno líquido (Renard et al., 1982, Salvetti et al., 2007). La descongelación se realiza exponiendo las pajuelas a temperatura ambiente durante 30 segundos y posteriormente finaliza la descongelación en un baño de agua a $20^{\circ} \mathrm{C}$, eliminado el medio de congelación en tres etapas de concentración decreciente del crioprotector en PBS suplementado con BSA (1; $0,5 \mathrm{M}$ DMSO y PBS). Mientras que el grupo de la UPV utiliza la vitrificación como técnica de crioconservación (Vicente y GarcíaXiménez, 1994, Vicente et al., 1999, Lavara et al., 2011). En este caso, los embriones son expuestos en dos etapas a la solución de vitrificación compuesta por un $20 \%$ (V/V) de DMSO y un $20 \%$ (V/V) de etilengicol en PBS suplementado con 0,2\% (peso/volumen) de BSA. En la primera etapa los embriones permanecen dos minutos en una solución al $50 \%$ de la concentración final de crioprotectores, en la segunda, los embriones son expuestos a la solución de vitrificación menos de 1 minuto, durante el cual son cargados en pajuelas de $0,125 \mathrm{~mL}$ y sumergidos en nitrógeno líquido. La desvitrificación se realiza en primer lugar en vapor de nitrógeno durante 30 segundos y posteriormente en baño de agua a $20^{\circ} \mathrm{C}$. La eliminación de la solución crioprotectora se realiza en dos etapas, en la primera los embriones en la solución de vitrificación son vertidos en un medio $0,33 \mathrm{M}$ de sacarosa en PBS suplementado con BSA, en la que permanecen 5 minutos, tras lo cual se lavan otros 5 minutos con PBS suplementado con BSA antes de ser transferidos.

Los embriones congelados y transferidos sobre la línea francesa 2066 alcanzan un porcentaje medio de supervivencia en torno al $50 \%$ (40-60 \%) en los diferentes trabajos realizados en el INRA. En los trabajos realizados en la UPV, en los que se han transferido más de 2500 embriones vitrificados sobre las líneas maternales $\mathrm{V}$ y $\mathrm{A}$, la supervivencia se sitúa en torno al $40 \%$ (25-57 \%). 
La supervivencia post-crioconservación, en uno y otro grupo, está influenciada tanto por el origen genético de los embriones como por el de las hembras receptoras.

Actualmente el banco de embriones establecido inicialmente por el INRA se ha incorporado a su banco nacional de conservación de recursos genéticos, contabilizando en torno a 11.500 embriones de 35 razas o estirpes genéticas clasificadas en tres grupos: razas catalogadas, estirpes o líneas de interés genético por su especificidad genómica y por último, líneas comerciales.

El banco de embriones y semen de la UPV contiene unos 7.200 embriones de 7 líneas seleccionadas de conejo.

\section{BIBLIOGRAFÍA}

ARIAS-ÁLVAREZ, M.; GARCÍA-GARCÍA, R.M.; TORRES-ROVIRA, L.; GONZÁLEZBULNES, A.; REBOLLAR, P.G.; LORENZO, P.L. 2010. Influence of hormonal and non hormonal estrus synchronization methods on follicular and oocyte quality in primiparous lactating does at early postpartum period. Theriogenology, 73: 26-35.

AMBRIZ, D.; ROSALES, A.M.; SOTELO, R.; MORA, J.A.; ROSADO, A.; GARCÍA, A.R. 2002. Changes in the quality of rabbit semen in 14 consecutive ejaculates obtained every 15 minutes. Archives of Andrology, 48:389-395.

BANK, H.; MAURER, R.R. 1974. Survival of frozen rabbit embryos. Experimental Cell Research, 89:188-196.

BESENFELDER, U.; STROUHAL, C.; BREM, G. 1998. A method for endoscopic embryo collection and transfer in the rabbit. Journal of Veterinary Medicine, 45: 577-579.

CASTELLINI, C.; LATTAIOLI, P.; MORONI, M.; MINELLI, A. 2000. Effect of seminal plasma on the characteristics and fertility of rabbit spermatozoa. Animal Reproduction Science, 63: 275-282.

CASTELLINI, C.; MOURVAKI, E.; DAL BOSCO, A.; GALLI, F. 2007. Vitamin E Biochemistry and Function: A Case Study in Male Rabbit. Reproduction in Domestic Animals, 42(3): 248-56.
CERVERA, R.; GARCIA-XIMENEZ, F. 2003. Oocyte age and nuclear donor cell type affect the technical efficiency of somatic cloning in rabbits. Zygote, 11: 151-158.

CORTELL, C.; VICENTE, J.S.; MOCÉ, E.; MARCOJIMÉNEZ, F.; VIUDES DE CASTRO, M.P. 2010. Efficiency of repeated in vivo oocyte and embryo recovery after rhFSH treatment in rabbits. Reproduction in Domestic Animals, 45 (1): 155-159.

FORTUN-LAMOTHE, L. 2006. Energy balance and reproductive performance in rabbit does. Animal Reproduction Science, 93: 1-15.

HOFFMAN, L.H.; OLSON, G.E.; CARSON, D.D.; CHILTON, B.S. 1998. P4 and implanting blastocysts regulate Muc1 expression in rabbit uterine epithelium. Endocrinology, 139: 266-271.

KASAI, M.; HAMAGUCHI, Y.; ZHU, S.E.; MIYAKE, T.; SAKURAI, T.; MACHIDA, T. 1992. High survival of rabbit morulae after vitrification in an Ethylene Glycol-Based solution by a simple method. Journal of Reproduction and Fertility, 89: 91-97.

KAUFFMAN, R.D.; SCHMIDT, P.M.; RALL, W.F.; HOEG, J.M. 1998. Superovulation of rabbits with $\mathrm{FSH}$ alters in vivo development of vitrified morulae. Theriogenology, 50:1081-1092.

KENNELLY, J.J.; FOOTE, R.H. 1965. Superovulatory response of pre- and postpubertal rabbits to commercially available gonadotropins. Journal of Reproduction and Fertility, 9:177-188.

KILLIAN, G.J.; CHAPMAN, D.A.; ROGOWSKI ,L.A. 1993. Fertility-associated proteins in Holstein bull seminal plasma. Biology of Reproduction, 49 (6):1202-1207.

LAVARA, R.; MOCÉ, E.; LAVARA, F.; VIUDES DE CASTRO, M.P.; VICENTE, J.S. 2005. Do parameters of seminal quality correlate with the results of on-farm inseminations in rabbits? Theriogenology, 64: 130-1141.

LAVARA, R.; BASELGA, M.; VICENTE, J.S. 2011. Does storage time in LN2 influence survival and pregnancy outcome of vitrified rabbit embryos? Theriogenology, 76: 652-657.

LÓPEZ-GATIUS, F.; SANCHES, G.; SANCHO, M.; YAÑIZ, Y.; SANTOLARIA, P.; GUTIERREZ, R.; NUÑEZ, M.; SOLER, C. 2005. Effect of 
solid storage at $15^{\circ} \mathrm{C}$ on the subsequent motility and fertility of rabbit semen. Theriogenology, 64: 252-260.

LÓPEZ-BÉJAR, M.; LÓPEZ-GATIUS, F. 2002. Nonequilibrium cryopreservation of rabbit embryos using a modified (sealed) open pulled straw procedure. Theriogenology, 58: 1541-1552.

MAXWELL, W.M.C.; EVANS, G.; MORTIMER, S.T.; GILLAN, L.; GELLATLY, E.S.; MCPHIE, C.A. 1999. Normal fertility in ewes after cervical insemination with frozen-thawed spermatozoa supplemented with seminal plasma. Reproduction and Fertility Development, 11: 123-126.

MEHAISEN, G.M.; VIUDES-DE-CASTRO, M.P.; VICENTE, J.S.; LAVARA, R. 2006. In vitro and in vivo viability of vitrified and nonvitrified embryos derived from eCG and FSH treatment in rabbit does. Theriogenology, 65: 1279-1291.

MOCÉ, E.; VICENTE, J.S. 2009. Rabbit sperm cryopreservation: a review. Animal Reproduction Science, 110(1-2): 1-24.

MOURVAKI, E.; CARDINALI, R.; DAL BOSCO, A.; CASTELLINI, C. 2010. In vitro antioxidant activity of the prostatic secretory granules in rabbit semen after exposure to organic peroxides. Reproductive Biology and Endocrinology, 8:16.

NIZZA, A.; DI MEO, C.; TARANTO, S. 2003. Effect of collection rhythms and season on rabbit semen production. Reproduction in Domestic Animals, 38: 436-439.

PASCUAL, J.J.; GARCÍA, C.; MARTÍNEZ, E.; MOCÉ, E.; VICENTE, J.S. 2004. Rearing management of rabbit males selected by high growth rate: the effect of diet and season on semen characteristics. Reproduction Nutrition Development, 44: 49-63.

QUINTELA, L.; PEÑA, A.; VEGA, M.; GULLÓN, J.; PRIETO, C.; BARRIO, M.; BECERRA, J.; MASEDA, F.; HERRADÓN, P. 2004. Ovulation induction in rabbit does submitted to artificial insemination by adding buserelin to the seminal dose. Reproduction Nutrition Development, 44: 79-88.

QUINTELA, L.; PEÑA, A.; VEGA, M.; GULLÓN, J.; PRIETO, C.; BARRIO, M.; BECERRA, J.; HERRADÓN, P.G. 2009. Reproductive performance of rabbit does artificially inseminated via intravaginal administration of [des-Gly 10, D-Ala6]-LHRH Ethylamide as ovulation inductor. Reproduction in Domestic Animals, 44: 829-833.

RENARD, J.P.; CARNIER, V.; PARVEX, R. 1982. Production et congélation de l'embryon de lapin. 3es Journées de la Recherche Cunicole en France, Comunication n 18.

ROCA, J.; MARTÍNEZ, S.; VÁZQUEZ, J.M.; LUCAS, X.; PARRILLA, I.; MARTÍNEZ, E.A. 2000. Viability and fertility of rabbit spermatozoa diluted in Tris-buffer extenders and stored at $15^{\circ} \mathrm{C}$. Animal Reproduction Science 64: 103-112.

SAFAA, H.M.; VICENTE, J.S.; LAVARA, R.; VIUDES DE CASTRO, M.P. 2008. Semen evaluation of two selected lines of rabbit bucks. World Rabbit Science, 16:141-148.

THEAU-CLÉMENT, M. 2000. Advances in biostimulation methods applied to rabbit reproduction. In Proceeding of the $7 \mathrm{th}$ World Rabbit Congress, Valencia, Spain. World Rabbit Science, 8 (1): 61-79.

SALVETTI, P.; THEAU-CLEMENT, M.; JOLY, T. 2007. Effect of the luteinizing hormone on embryo production in superovulated rabbit does. Theriogenology, 67:1185-1193.

SMORAG, Z.; GAJDA, B.; WIECZOREK, B.; JURA, J. 1989. Stage-dependent viability of vitrified rabbit embryos. Theriogenology, 31: 1227-1231.

THEAU-CLÉMENT, M.; ESPARBIÉ, J.; BOLETA, G. 1995. Effects of artificial photoperiods on sexual behaviour and sperm output in the rabbit. Animal Science, 60:143-149.

THEAU-CLÉMENT, M. 2007. Preparation of the rabbit doe to insemination: a review. World Rabbit Science, 15: 61-80.

VICENTE, J.S.; GARCIA-XIMÉNEZ, F. 1994. Osmotic and cryoprotective effects of a mixture of dimethyl sulfoxide and ethylene glycol on rabbit morulae. Theriogenology, 42(7):1205-1215.

VICENTE, J.S.; VIUDES-DE-CASTRO, M.P.; GARCIA, M.L. 1999. In vivo survival rate of rabbit morulae after vitrification in a medium without serum protein. Reproduction Nutrition Development, 39: 657-662. 
VICENTE, J.S.; LAVARA, R.; LAVARA, F.; MARCOJIMÉNEZ, F.; VIUDES-DE-CASTRO, M.P. 2008. Rabbit reproductive performance after insemination with buserilin acetate extender. Livestock Science, 115: 153-157.

VICENTE, J.S.; LAVARA, R.; MARCO-JIMÉNEZ, F.; VIUDES-DE-CASTRO, M.P. 2011. Detrimental effect on availability of buserelin acetate administered in seminal doses in rabbits. Theriogenology. 76: 1120-1125.

VIUDES DE CASTRO, M.P.; VICENTE, J.S. 1996. A $S$ imple method for freezing rabbit semen with successful results on fertility and prolificity. Animal Reproduction Science, 44: 195-201.

VIUDES DE CASTRO, M.P.; VICENTE, J.S. 1997. Effect of sperm amount on the fertility and prolificity rates of meat rabbits. Animal Reproduction Science, 46 (3-4): 313-319.
VIUDES DE CASTRO, M.P.; LAVARA, R.; MARCOJIMÉNEZ, F.; CORTELL, C.; VICENTE,J.S. 2007. Ovulation induced by mucosa vaginal absorption of buserelin and triptorelin in rabbit. Theriogenology, 68:1031-1036.

VIUDES DE CASTRO, M.P.; CORTELL, C.; MOCÉ, E.; MARCO-JIMÉNEZ, F.; JOLY, T.; VICENTE, J.S. 2009. Effect of recombinant gonadotrophins on embryo development in superovulated rabbit does and immune response following repeated treatments. Theriogenology, 72: 655-662.

YOUSEF, M.I. 2005. Reproductive performance, blood testosterone, lipid peroxidation and seminal plasma biochemistry of rabbits as affected by feeding Acacia saligna under subtropical conditions. Food and Chemical Toxicology, 43: 333-339. 


\section{ALGUNOS CONCEPTOS SOBRE LA NUTRICIÓN DEL CONEJO PARA CARNE}

\section{INTRODUCCIÓN}

El comportamiento y la fisiología alimentaria del conejo, son algunas de las características más 'extraordinarias' de esta especie a los fines de su sobrevivencia y adaptabilidad a las diversas condiciones climáticasambientales, pero también a los fines de una correcta comprensión de las condiciones óptimas de su crianza.

Teniendo en cuenta que desde el punto de vista económico el objetivo último de una explotación cunícola es la conversión del alimento (vegetal) en carne, resulta esencial lograr el equilibrio entre el costo del alimento y su impacto sobre la ganancia de peso y peso final. De hecho, el alimento más nutritivo no será necesariamente el más eficiente, ya que ello dependerá de su costo. En la producción de carne de conejo, como en otras especies animales, los costos de alimentación representan la mayor parte de los costos de producción y dependiendo principalmente de la inversión, asciende al $70 \%$ de los costos totales.

Un segundo elemento, por ahora con mayor interés en la comunidad europea y sobre todo en las zonas con alta densidad de producción animal, es la protección del medio ambiente ya que en algunos países el estiércol no es más considerado como un fertilizante, sino como un contaminador del medio. La producción de amoníaco agrícola es, en parte, responsable de los problemas de acidificación y los metales pesados están vinculados con la disminución de la calidad del agua superficial y el agua potable. La alimentación animal debe minimizar la eliminación de estos residuos al medio; en los conejos, los programas de alimentación por fases pueden manipular en gran medida la utilización del nitrógeno y fósforo dietario.
Por otro lado, no debe olvidarse el rol de la dieta animal sobre algunos parámetros de importancia para la salud humana como ser el aumento de la adiposidad de la carcasa al utilizar grasa u aceite como fuente energética alternativa y la alteración de la composición acídica de los lípidos musculares en función del origen de los lípidos de la dieta. Para analizar todos estos aspectos de la alimentación práctica, se deben tener en cuenta los conocimientos existentes sobre las particularidades digestivas y las necesidades nutricionales del conejo para luego adaptarlos a luz de la realidad local.

\section{CECOTROFIA Y COMPORTAMIENTO ALIMENTARIO}

El conejo es una especie dotada de una notable capacidad de adaptación a las diferentes situaciones alimenticias; cuenta con un aparto digestivo que permite la ingestión de elevadas cantidades de alimentos y un tránsito rápido de los mismos. Es un herbívoro seleccionador de alimentos 'concentrados' en el cual el alimento sólido ingerido sufre primero una digestión enzimática y sucesivamente es reciclado en una digestión fermentativa, similar a la de los rumiantes. En un medio natural, el conejo tiende a elegir pequeños fragmentos de hierbas, hojas, brotes y granos siendo los 'bigotes' (pelos con funciones táctiles-sensoriales) y su labio superior móvil los que permiten la localización y aprehensión del alimento para ser introducido en la cavidad oral. El bajo peristaltismo intestinal, hace necesario ingerir raciones con nivel adecuado de fibra, para evitar trastornos intestinales.

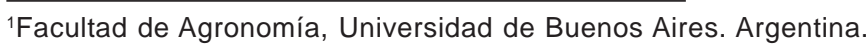


El doble proceso digestivo en el cual la ingesta normal de alimento es seguida por la cecotrofia (producción de pequeñas bolas blandas cubiertas con una membrana mucosa delgada), hace al conejo (a los Lagomorfos en general) completamente diferente a otros herbívoros. De hecho, si el contenido del ciego entra al colon en las primeras horas de la mañana, sufre pocos cambios, adquiere forma redondeada debido a las contracciones de la pared y es recubierta por el moco producido por las paredes del colon. Este material liberado en forma de racimos se conoce como heces blandas o cecotrofos. Si el contenido de la digesta entra en otro momento del día, la actividad del colon proximal es diferente, dando lugar a la separación de partículas y formación de heces duras a partir del material sólido $(>3 \mathrm{~mm}$ de largo). El reciclado digestivo le permite 'fabricarse' alrededor del $30 \%$ de su requerimiento alimenticio-energético; sin embargo, la dimensión de los distintos compartimientos del aparato digestivo y los elevados requerimientos metabólicos del conejo, determinan la necesidad de utilización de alimentos concentrados, indispensables para asegurar un correcto aporte de energía, proteína y fibra.

El ciego actúa como una cuba de fermentación donde llegan los alimentos que ya han sufrido la digestión enzimática y el proceso de absorción en el intestino delgado, ofreciendo a la masa microbiana un sustrato con pocos elementos solubles. Su principal fuente nutritiva son las paredes celulares de los vegetales (digestión del 10-13\% de la fibra contenida en la materias primas tradicionales y hasta un $50 \%$ para material poco lignificado). La actividad fermentativa del ciego da lugar a la producción de ácidos grasos volátiles (AGV) con predominio del ácido acético sobre el propiónico, como consecuencia de la prevalencia del contenido celulolítico del material a fermentar respecto al amiláceo. Los elementos degradables liberados (principalmente AGV) son rápidamente absorbidos por la mucosa intestinal, atraviesan la pared del tubo digestivo, y pasan a la sangre suponiendo un aporte regular de energía para el animal (Carabaño et al., 1997). El ciego de los conejos reúne condiciones ade- cuadas (elevado tamaño, pH estable, anaerobiosis, entrada regular de nutrientes) para ser asiento de una flora microbiana densa (del orden de 1010 bacterias/g) y estable (de Blas et al., 1999).

El volumen del ciego varía en función del proceso en acto. Durante la cecotrofía, el contenido del ciego (partículas alimentarias, bacterias y restos de secreciones digestivas del intestino delgado) pasa a través del colon sin cambios importantes (absorción de agua y elementos minerales) y da lugar a la formación de 'heces blandas'; durante las primeras horas del día, la pared del colon segrega una mucosidad que cubre este material, que se presenta en forma de racimos alargados. Cuando el proceso de cecotrofía no está en acto, la digesta sufre diferentes destinos en la unidad funcional íleo-ciegocolon proximal, evidenciándose una separación neta de partículas en el ciego. Con contracciones alternas (movimientos antiperistálticos), el material evacuado en el colon tiende a volver hacia el otro extremo y es introducido en el ciego, a través de la válvula íleo-cecal; el material grueso (partículas de $>300 \mathrm{~mm}$ ) va directamente al colon proximal (excreción rectal en forma de heces duras ) por lo que se retiene sólo la fracción líquida que contiene los productos solubles y las partículas más finas $(<1 \mathrm{~mm})$ para ser fermentados en el ciego (Jilge, 1980; Björnhag, 1981). La media de tiempo de retención ciego-rectal de la digesta varía de 7 a 16 horas (Leng et al., 1977; Uden et al., 1982; Gidenne et al., 1991; Gidenne y Pérez, 1993, 1994; Bellier, 1994; Gidenne 1994; Gidenne y Jehl, 1996). Teniendo en cuenta las fracciones recicladas, desde una a cuatro veces y en función de la naturaleza de los alimentos, el tránsito digestivo del conejo dura entre 15 a 30 horas aproximadamente.

Las heces duras son evacuadas en la fosa debajo de las jaulas, mientras que los cecotrofos son recuperados por el animal en el momento que salen del ano. La práctica de la cecotrofia tiene un interés nutricional importante aportando alrededor del 15-25 \% de las proteínas ingeridas diariamente (Gidenne y Lebas, 1987, tomado de Rosell Pujol, 2000) y la totalidad de las vitaminas B y C (Lebas, 1989, tomado de Rosell Pujol, 
2000). Aproximadamente un $12-24 \%$ del nitrógeno total ingerido está representado por el nitrógeno bacteriano (García et al., 1995; Gidenne y Jehl, 1996).

El conejo ingiere cerca de $2 / 3$ partes de los alimentos durante el período de tiempo entre la puesta y la salida del sol (comportamiento crepuscular); el número de aprehensiones del alimento es muy alta (aproximadamente 30-40 comidas pequeñas al día). Después de la salida del sol, el conejo cesa de comer y practica la cecotrofía, es decir, la ingestión de las heces blandas o cecotrofos, que se toman directamente del ano y se ingieren luego de insalivarlas, sin ser masticadas (Manning et al., 1994). La ingestión de los cecotrofos (2 a 3 h/día) se produce bajo control hormonal de la glándula suprarrenal y, en el caso de estrés o perturbación, no se produce, con repercusiones negativas en el aspecto nutricional (Proto, 1980). La cantidad de agua ingerida en forma de agua potable y/o agua contenida en los alimentos, es aproximadamente el doble de la materia seca ingerida.

\section{EL APARATO DIGESTIVO}

La longitud del tracto intestinal del conejo es de más de 3,5 m y se caracteriza por la importante presencia de los dos grandes compartimientos: estómago y ciego, donde se concentra alrededor del $80 \%$ del contenido. El alimento se mueve progresivamente a lo largo del tubo intestinal, impulsada por las contracciones coordinadas de las paredes (movimientos peristálticos) y completa todo el tránsito oro-anal en aproximadamente $15-30$ horas (Lebas, 1979) dependiendo de la naturaleza física de las partículas ingeridas (tamaño de partícula) y de la diferente naturaleza de los componentes estructurados (cantidad y calidad de la fibra cruda). El alimento ingerido sufre una digestión enzimática en el estómago e intestino similar a la que ocurre en el resto de los monogástricos y una digestión fermentativa en el ciego.

La continua secreción de saliva asegura, ya en la cavidad oral, un primer ablandamiento e inicio de la digestión a cargo de las enzimas presentes en la saliva (amilasa y lipasa). La comida se mastica a fondo y rápidamente (incluso 120 movimientos de masticación por minuto) con la ayuda de movimientos linguales, lo que favorece la trituración final. Después de la masticación, el bolo alimenticio entra en el estómago, caracterizado por un esfínter bien desarrollado, que no permite la regurgitación ni el vómito.

Las glándulas incluidas en la pared del estómago secretan ácido hidroclorhídrico, pepsina y algunos iones como $\mathrm{Ca}++, \mathrm{K}+$, $\mathrm{Mg}++$ y $\mathrm{Na}++$. En el estómago las partículas alimentarias son atacadas por el jugo gástrico rico en 'mucina' y en enzimas gástricas (pepsina, renina, lipasa, etc.); allí permanecen algunas horas (3-6 aproximadamente). La fuerte acidificación (pH 1-2) provoca la solubilización de numerosas sustancias, además del inicio de la hidrólisis de las proteínas, por acción de la pepsina.

El tracto intestinal del conejo se subdivide en: intestino delgado (duodeno, yeyuno e íleon); ciego (incluyendo el apéndice del ciego); colon (dividido en colon proximal segmentado y colon distal) y recto. El pH del intestino delgado es ligeramente básico en la parte superior $(7,2-7,5)$ y más ácido hacia el final del ileon $(6,2-6,5)$ Desde su entrada en el intestino, la digesta se diluye (8-10\% MS) por el flujo de bilis, por las primeras secreciones intestinales y finalmente, por acción del jugo pancreático (tripsina, quimiotripsina, diastasa, maltasa, lipasa, etc.). Mediante estas enzimas, los elementos fácilmente degradables se liberan, atraviesan la pared del intestino y son distribuidos por la sangre hacia las diversas células del organismo. Las partículas sin degradar, después de una permanencia media de $1,5 \mathrm{~h}$ en el intestino delgado, entran al ciego para proseguir con una digestión de tipo fermentativa. El ciego constituye el segmento más largo del tracto ( $40 \%$ del contenido digestivo total) y contiene $100-120 \mathrm{~g}$ de una mezcla uniforme de consistencia pastosa (21$24 \% \mathrm{MS}$ ). El pH del ciego varía alrededor de 6 y depende del patrón de alimentación y la actividad microbiana.

Bajo el efecto de las contracciones, las fracciones individuales del alimento (líquida y sólida) recorren el tracto digestivo con di- 
ferentes velocidades. Los líquidos, que dejan el estómago más rápidamente que los sólidos, permanecen por más tiempo en el ciego; en última instancia, los líquidos se mueven más lentamente a lo largo de todo el tracto intestinal. Paralelamente, en los sólidos, las partículas gruesas se eliminan con las heces duras más rápidamente que las partículas finas, que quedan retenidas en el ciego hasta su eliminación como heces blandas. Los cecotrofos, una vez ingeridos, siguen el mismo tránsito de los alimentos, permaneciendo 4-6 h en el estómago; pocos minutos en el duodeno, 10-20 min en el yeyuno, 30-60 min en el íleon; 6-9 h en el ciego; $1-2 \mathrm{~h}$ en el colon proximal y 1-1,5 h en el colon distal (Lebas, 1979).

La considerable complejidad de la fisiología digestiva del conejo, vinculado a la cecotrofía, al tránsito diferenciado en las distintas secciones y el ritmo de las ondas peristálticas y antiperistálticas, se complica aún más por la presencia de la microflora digestiva presente en el tracto ciego-colon. La flora microbiana es relativamente simple desde el punto de vista de la composición (principalmente bacterias Gram +) pudiendo distinguirse bacterias con actividad celulolítica, pectinolítica, ureolítica, proteolítica y amilolítica.

Los microorganismos actúan sobre el alimento no digerido en la primera digestión enzimática por lo que este material se somete a una segunda digestión 'fermentativa'. Esta microflora intestinal es la que permite al conejo utilizar la energía contenida en las plantas; dicho proceso está relacionado con la calidad y la cantidad de celulosa y la fibra cruda presente en los alimentos, cuya fermentación determina la formación de AGV, que además de garantizar un nivel relativo de acidez en el ciego, también se utilizan como una fuente de energía (Proto, 1980). Además de los AGV, la fermentación cecal produce amoníaco $\left(\mathrm{NH}_{3}\right)$ a partir de la fermentación de aminoácidos y gases (hidrógeno, metano). La flora es escasa entre el nacimiento y las dos semanas de edad predominando las bacterias provenientes de la madre; el ciego trabaja poco con la dieta láctea. Mientras que a las dos semanas de edad la flora anaerobia amilolítica ya está presente, la colonización de la flora celulolítica comienza aproximadamente a las tres semanas de edad, junto al consumo de alimento y tiende a estabilizarse en la $5^{\text {ta }} 7^{\mathrm{ma}}$ semanas, aunque la producción de AGV continúa aumentando (Padhila, 1995; Padhila et al., 1995, 1996). La flora definitiva se estabiliza alrededor de las ocho semanas de edad y esta es una de las causas por las que el animal es susceptible a trastornos digestivos durante este período. El desarrollo cecal (paredes y contenidos), lento desde el nacimiento hasta 10 días de edad, es paralelo a la ingestión de alimentos sólidos (hasta $5 \%$ de peso vivo). El conejo se diferencia de otras especies por el perfil de AGV específico que, en orden de importancia incluyen: ácido acético (C2, 60-80\% AGVtotales), butírico (C4, 8-20 \% AGVtotal) y ácido propiónico (C3, 3-10\% AGVtotal). La actividad fermentativa es más alta durante la excreción de heces duras y mínima (<25\% del máximo) durante el cecotrofia (Gidenne, 1986; Bellier et al., 1995), coincidiendo con la máxima absorción y el metabolismo de los AGVs (Vernay et al., 1984; Vernay, 1986, 1989). Pocas horas de ayuno inducen una rápida disminución de la producción de AGV de ciego y el cambio de la relación C3/C4 (Gidenne y Bellier, 1992).

En resumen, el conejo se caracteriza por un comportamiento alimentario que le permite 'reciclar' a través de una digestión fermentativa a los alimentos no digeridos en la primera digestión enzimática. Tal comportamiento, sin embargo, complica la fisiología digestiva y hace al animal de criadero, más frágil y susceptible a enfermedades entéricas. Resulta imprescindible entonces hacer hincapié en la importancia de las materias primas que componen los alimentos y las recomendaciones relacionadas con la composición química y la formulación de los alimentos.

\section{COMPONENTES QUÍMICOS DE LA DIETA}

\section{Fibra}

Dada la naturaleza herbívora del conejo, las fibras de origen vegetal constituyen una 
parte importante de su alimentación; sin embargo, la capacidad del conejo de digerir la fibra es muy baja. La fibra juega un papel fundamental en el mantenimiento de tránsito digestivo, estimulando la motilidad intestinal, y en el equilibrio de la flora cecal, favoreciendo el desarrollo de las bacterias productoras de AGV.

Un aporte de fibra adecuado (entorno al $33 \%$ de FND, y $16-19 \%$ de FDA), evita retenciones de digesta en el ciego que pueden dar lugar a disbiosis bacterianas y a una aparición mayor de problemas digestivos. Sin embargo, para caracterizar correctamente las necesidades de fibra en conejos es necesario tener en cuenta, no sólo el aporte total, sino también las características químicas y físicas de la fibra que se introduce en la dieta.

Desde el punto de vista químico, los principales constituyentes de las fibras son, ordenados de menor a mayor digestibilidad la lignina, celulosa, hemicelulosa y pectinas, cuyas proporciones varían considerablemente entre las materias primas.

\section{Lignina}

Muy poco digerible por las bacterias intestinales. Es el componente fibroso que actúa como sustancia de lastre por excelencia. La cáscara de semilla de girasol, el orujo de uva, el tallo de alfalfa y la paja de cereales son ricos en fibra lignificada. Un exceso de lignina o celulosa en el alimento puede elevar el peristaltismo intestinal y generar diarreas y/o disminución severa del tiempo de permanencia de los nutrientes generando un cuadro de subnutrición.

\section{Celulosa}

La celulosa es un componente fibroso susceptible de ser digerido en mayor medida por parte de las bacterias del ciego; junto con la lignina, son los componentes responsables de la disminución de la incidencia de patología digestiva. Las fuentes de celulosa para la fabricación de alimentos balanceados son la alfalfa, paja de trigo, salvados y cascarillas de cereales.

\section{Hemicelulosa}

La fracción hemicelulosa es mucho más digerible por las bacterias del ciego, produciendo AGV, responsables de bajar el pH. Las principales fuentes de hemicelulosa son los forrajes, salvado de trigo, de maíz, de oleaginosas, legumbres y cascarillas.

\section{Pectinas}

Las pectinas son el componente de pared celular más digerible dentro de las fibras, ya que la flora cecal las puede degradar hasta un $75 \%$, generando AGV. Las principales fuentes de pectinas son las pulpas de frutas, la alfalfa y soja.

Los cambios en términos de producción de AGV, amoníaco y pH como respuesta a la menor ingesta de fibra son escasos, sin embargo, se verifican cambios importantes en la proporción molar de AGV (menos butirato; Bellier y Gidenne, 1996; Gidenne et al., 1998). Se puede suponer que la cantidad de fibra que llega al ciego no representa un factor limitante de la fermentación, probablemente debido al reducido tiempo de retención de la digesta en el ciego, permitiendo sólo la degradación de las fracciones fácilmente digeribles (pectina, hemicelulosa); el tiempo de retención aumenta con la disminución de la ingesta fibrosa compensando así la cantidad reducida de fibra en el ciego (Gidenne, 1994). Muy bajos niveles de fibra (fibra en detergente ácido, FDA < $10 \%$ ) pueden aumentar drásticamente el tiempo de retención aumentando así la eficiencia de la degradación (De Blas et al., 1986; Carabaño et al., 1988; Bellier y Gidenne, 1996). Un aumento de la lignina en la dieta reduce la digestibilidad de la fibra y el tiempo de retención de la digesta (Pérez de Ayala, 1989; Gidenne y Pérez, 1994) mientras que el efecto positivo se relaciona con la sanidad animal (menor mortalidad de los conejos en crecimiento; Pérez et al., 1994). El efecto de la celulosa es menor que la de la lignina en cuanto a la digestibilidad y la velocidad de tránsito (Falcao y Cunha, 1988; Gidenne y Pérez, 1996), pero similar al considerar la reducción de la mortalidad de los conejos (Pérez et al., 1996). Las fibras de alta digestibilidad (he- 
micelulosas, pectinas) se asocian con aumentos en la producción de AGV y valores más bajos de $\mathrm{pH}$ cecal (Peeters et al., 1995; Jehl et al., 1998). La digestibilidad de la FDA, el pH cecal y la producción de AGV son muy dependientes de las propiedades físicas de los alimentos (longitud de las partículas, los tratamientos con $\mathrm{NaOH}$; Lebas, 1988; Gidenne, 1992) y de la fibra de origen (Merino y Carabaño, 1992; García et al., 1996).

En resumen, un mayor contenido en hidratos de carbono de fácil fermentación y un menor grado de lignificación favorecen la digestibilidad de la fibra, la producción de AGV y el crecimiento microbiano en el ciego, pero determinan mayores tiempos de retención a nivel cecal (Carabaño et al., 2004). De hecho, un suministro insuficiente de fibra implica una acumulación de digesta en el ciego, una disminución de la velocidad de renovación del ciego, un descenso del consumo y de los rendimientos productivos, un incremento de la concentración de amoníaco, alcalinización del medio cecal y el desequilibrio en la composición de la flora intestinal, con el consiguiente incremento de la incidencia de problemas digestivos (de Blas et al., 1986; Carabaño et al., 1988; de Blas, 1992). Niveles bajos de FDA alteran las fermentaciones bacterianas del ciego con cambios en el pH, producción de AGV y amoníaco. Cuanto menor es la concentración de AGV, mayor es la concentración de amoníaco y $\mathrm{pH}$, aumentando las posibilidades de proliferación de la Escherichia coli. Por otro lado, un exceso de fibra en las dietas de los conejos supone también un empeoramiento de los parámetros productivos, como ser la disminución de la eficacia energética, el rendimiento de la canal, mayor incidencia de cetosis, etc.

En lo que se refiere a sus propiedades físicas, el aporte de fibra debe caracterizarse por tener un tamaño de partícula equilibrado, una proporción de partículas mayor a $0,3 \mathrm{~mm}$ del $20 \%$ para evitar retenciones de digesta en el ciego y el $80 \%$ restante de un tamaño pequeño $(<0,3 \mathrm{~mm})$ para asegurar una entrada de fibra al ciego y favorecer al crecimiento microbiano. Otro factor de suma importancia lo constituye el tamaño de la fi- bra: un molido fino ( $<1 \mathrm{~mm}$ de diámentro) puede provocar disturbios en la motilidad del tracto intestinal, especialmente si la fibra está poco lignificada mientras que una molienda muy gruesa ( $>7 \mathrm{~mm}$ de diámetro) hace difícil la compactación del alimento y disminuye la calidad del pellet.

\section{Almidón}

El almidón es una fuente energética muy importante en el alimento del conejo y a partir del mismo se obtienen las calorías necesarias para la actividad, los procesos metabólicos, la generación de calor, la acumulación de reservas y el crecimiento, etc. Las variaciones en la ingestión de almidón están asociadas normalmente a variaciones mayores en la ingestión de fibras (cantidad y tipo de fibra), por este motivo es difícil delimitar los efectos que tiene el almidón por si mismo sobre la digestión. Las fuentes principales de almidón son los cereales (maíz, cebada, avena, trigo, etc).

En animales adultos, el almidón no degradado que alcanza el ciego es fermentado rápidamente por la flora amilolítica Se ha demostrado que si las dietas son equilibradas, especialmente en términos de la relación proteína/energía, un nivel de almidón ligeramente superior al recomendado (hasta $21 \%$ ), no parece ser responsable de los problemas entéricos (Xiccato et al., 1998).

Se ha demostrado que los animales jóvenes no producen suficiente amilasa para digerir todo el almidón que proviene de una dieta rica en cereales. El almidón no digerido que entra al ciego será degradado por las bacterias cecales hasta glucosa; la elevación de la glucosa estimula el desarrollo del Clostridium spiroforme productor de toxina iota que desencadenará un cuadro de enterotoxemia (Cheeke y Patton, 1980; Borriello y Carman, 1983).

Una mención especial merece la diversa digestibilidad de las fuentes amiláceas; el almidón del maíz y del sorgo es menos digerible que aquel proveniente del trigo, avena o cebada y por lo tanto, se desaconseja la inclusión de estas dos especies en la primera etapa de cría del animal. La molienda grosera de los granos menos digeribles en 
la categoría destete incrementa la probabilidad de generar desórdenes intestinales. La relación entre la ingestión de almidón y la aparición de problemas digestivos es diferente según sea la edad de los animales.

\section{Proteína}

A partir de las proteínas dietarias se obtienen los aminoácidos que son utilizados para construir las proteínas estructurales del organismo y para la síntesis de las proteínas funcionales como las enzimas, los anticuerpos, las proteínas transportadoras y algunas hormonas. Los efectos de un aporte proteico deficitario son el retraso del crecimiento, debilidad y disminución de las defensas orgánicas presentando una mayor vulnerabilidad frente a las enfermedades. Las hembras tienen los mayores requerimientos de proteína, tanto para el crecimiento de los fetos y estructuras asociadas a la gestación, como para la producción láctea.

La proteína presente en el ciego (endógena y exógena), se fermenta y se degrada a amoníaco, la principal fuente de las bacterias fijadoras de nitrógeno. La producción media de $\mathrm{NH}_{3}$ es de alrededor de 4-18 mM/l (Merino y Carabaño, 1992) hasta un máximo de 25-30 mol/l (Morisse et al., 1985; Gidenne, 1986). El amoníaco presente en el ciego también resulta de la descomposición de la urea en la sangre que llega a través de las paredes del ciego y es convertido a amoníaco por la flora ureolítica.

Por otra parte si el aporte proteico es excesivo, superior al $18 \%$ de proteína bruta (PB), la incidencia de diarreas es mayor. El aumento de proteínas de la dieta (12-16 \%) determina un aumento en la producción de nitrógeno y eleva el pH cecal $(5,8$ hasta 6,5$)$, favoreciendo la aparición de enfermedades asociadas con el desarrollo de clostridios y, en menor medida, de bacterias coliformes (Fraga et al., 1984). Un exceso de proteínas en el ciego estimula particularmente la proliferación de bacterias proteolíticas, alcalófilas, que utilizan la energía del radical carbonado de los aminoácidos tras desaminarlos y que, consecuentemente, forman amoníaco. El amoníaco puede pasar al torrente san- guíneo y se producen graves consecuencias sobre todo cuando ocurren trastornos hepáticos o renales (Rosell Pujol, 2000). Además, el aumento de la excreción de nitrógeno y sus compuestos aumentan el riesgo de problemas respiratorios por la mayor presencia de amoníaco ambiental y aumenta la contaminación de los efluentes con nitratos. Un modo de mejorar el balance proteico del alimento, cubriendo las necesidades del animal, consiste en aportar los aminoácidos de mayor requerimiento (lisina, cistina y metionina) en forma de suplemento industrial.

El nivel de proteína digestible del alimento debe estar en equilibrio con la energía digestible (relación PD/ED), ya que si los niveles energéticos son inferiores, el organismo utilizará la fuente proteica para obtener energía con producción de residuos nitrogenados, mientras que si la proteína digestible se encuentra por debajo de los requerimientos, se observará retraso en el crecimiento o disminución de la eficiencia de utilización del alimento.

Las principales fuentes de proteína de los alimentos para conejo son las harinas de soja, girasol, leguminosas y alfalfa.

\section{Lípidos o grasas}

Las grasas constituyen una variedad de sustancias con distintas funciones en el organismo, desde los lípidos de las membranas celulares, hormonas esteroides (estrógenos, progesterona, testosterona, corticosteroides), vitaminas liposolubles (vitaminas A, D, E y K), fosfolípidos, colesterol, sales biliares y triglicéridos, estos últimos con la importante función de reserva.

En el alimento, las grasas, denominadas también 'lípidos' (cuantificables a través del extracto etéreo), provienen mayoritariamente de las oleaginosas y los cereales (aceites) y constituyen junto con los almidones y la fibra digestible, la fuente energética. La proporción de lípidos en el balanceado va del 2 al $4 \%$ según el tipo de alimento pero suele considerarse cantidades mayores cuando hay que cubrir algún déficit energético; este aumento no trae consecuencias perjudiciales en los aspectos sanitarios pero disminu- 
ye la dureza del pellet, aumenta el índice de rotura y el polvillo en la tolva así como la susceptibilidad al enranciamiento.

Los ácidos grasos insaturados no digeridos en el intestino delgado, se hidrogenan y luego son saturados por la flora bacteriana en el ciego. La bibliografía sobre el efecto de la adición de grasa en la fermentación cecal es muy limitada. La grasa vegetal parece aumentar la digestibilidad de la fibra, especialmente en los alimentos con bajo contenido de energía (Santomá et al., 1987; Fekete et al., 1989). La adición de $4 \%$ de grasa aumenta la digestibilidad de la fibra y reduce la digestibilidad aparente de la materia orgánica y la energía (Falcao y Cunha et al., 1996, 1998; Xiccato , 1998 ) .

\section{VITAMINAS Y MINERALES}

Es poco frecuente que aparezcan problemas relacionados con la carencia de estos nutrientes debido a que se adicionan al alimento balanceado correctores, vitaminas, oligoelementos y suplementos minerales (carbonato cálcico, fosfato bicálcico, sal, etc). Además, la cecotrofia es una fuente de vitaminas hidrosolubles (complejo B) y vitamina $\mathrm{K}$, sintetizadas por los microorganismos del ciego (Rosell Pujol, 2000).

\section{Minerales}

Constituidos en dos grandes grupos, los macrominerales como Calcio, Fósforo, Sodio, Potasio, Cloro, Azufre, y Magnesio y los microminerales como Hierro, Cobre, Zinc, Yodo, Manganeso, Selenio, Cobalto, Molibdeno y Fluor.

El Calcio y el Fósforo tienen especial importancia en el alimento para las madres en lactancia y en gestación, ya que estas invierten gran parte de estos minerales en la producción de leche y el desarrollo de los fetos. Cuando la orina de conejo deja depósitos blanquecinos en el piso está indicando la eliminación de calcio, posiblemente en exceso. El exceso de Fósforo en la dieta también será eliminado por los animales, pero como en el caso del Nitrógeno, el Fósforo es un contaminante ambiental.
Los macrominerales en el alimento provienen de cereales, forrajes y salvados y por la incorporación de sal (cloruro de Sodio) conchilla, carbonato y fosfato de Calcio. Los microminerales, cuyas concentraciones son especialmente pequeñas, se incorporan como núcleo mineral pre-formulado.

\section{Vitaminas}

Las vitaminas son sustancias indispensables para el metabolismo y el crecimiento de los animales. Existen dos grupos: Ias hidrosolubles (grupo B y Vitamina C) y las liposolubles ( $A, D, E$ y $K$ ). Las vitaminas del grupo $B$ y la vitamina $K$ son sintetizadas por la flora del ciego y se incorporan principalmente mediante la cecotrofia. El uso de antibióticos altera la flora del ciego y por lo tanto puede interferir con la producción de vitaminas. La vitamina B 12 o cianocobalamina tiene en su composición Cobalto; si este no estuviera presente en la dieta la síntesis de dicha vitamina no será factible. Las vitaminas liposolubles Ilegan al alimento a partir de los cereales y oleaginosas y están asociadas a los aceites, pero para evitar que el aporte sea insuficiente, en la fabricación de los alimentos balanceados se incorporan como núcleo vitamínico.

Las vitaminas liposolubles (A, D,E,K) pueden ser almacenadas en el organismo y en dosis elevadas presentan problemas de toxicidad. La carencia de vitamina A presenta signos como degeneración de los epitelios, trastornos nerviosos, fallas reproductivas y retraso del crecimiento. El exceso de vitamina A (más de 190.000 UI/ kgPV) puede generar cuadros de intoxicación con abortos, reabsorción embrionaria e hidrocefalia en gazapos. Si la vitamina $D$ se encuentra en exceso es posible que se altere la absorción y el metabolismo del calcio, produciéndose la calcificación en tejidos blandos, como arterias (aorta, miocárdicas) y riñones (Rosell Pujol, 2000). La vitamina $E$ es un antioxidante biológico y como tal preserva a los lípidos de las membranas celulares de la peroxidación. Debe tenerse la precaución de incrementar el contenido de la vitamina $E$ en el alimento cuando éste incluye grasas insaturadas. 


\section{ENERGÍA}

Los requerimientos energéticos son cubiertos por el alimento y provienen de sus componentes. El total de la energía presente en el alimento se denomina energía bruta, parte de esta energía no es aprovechada por el animal y se elimina con las heces. La fracción de energía absorbida por el intestino de denomina energía digerible; parte de esta fracción es utilizada en la formación de la orina y procesos digestivos, restando la energía metabolizable; posteriormente al gasto energético asociado a la ineficiencia de los procesos metabólicos y de síntesis, resta la energía neta. La energía neta se utiliza para las funciones de mantenimiento, producción de calor, movimiento, etc. y para las funciones de producción, crecimiento, gestación y lactancia.

\section{ADITIVOS NO ALIMENTICIOS}

Los aditivos incluyen los estimulantes del crecimiento, coccidiostáticos, conservantes (antioxidantes, antimicóticos), enzimas, aromatizantes, oligosacáridos, probióticos, buffers, sustancias adhesivas, etc. Si bien el uso más común es utilizar antibióticos en dosis bajas como 'promotores del crecimiento', buscando mantener selectivamente una flora conveniente durante el engorde, hoy esta práctica ha quedado reducida al uso de coccidiostatos. El coccidio (principalmente Eimeria magna) es un parásito habitual del conejo que en etapas tempranas puede producir diarreas por lo que es recomendable mantenerlo bajo control, y es más sencillo hacerlo a través del alimento que en el agua de bebida. No tiene sentido administrarlo a las madres pues ya están adecuadamente inmunizadas y transmiten dicha inmunidad a los gazapos al menos por los primeros 20 días. Si se utilizara un alimento peridestete podría también incluir coccidiostato cubriendo por lo tanto todo el período en que el conejo está expuesto a desarrollar coccidiosis clínica.

Los probióticos son sustancias de origen biológico cuya función es regular la flora in- testinal. En la medida que estén debidamente probados y su costo sea accesible son un complemento interesante, aunque hasta ahora las experiencias no han sido concluyentes. También pueden incorporarse sustancias que favorezcan la acidificación del contenido intestinal, ya que se ha comprobado que esta circunstancia colabora en el desarrollo de una flora conveniente, lo que puede también lograrse acidificando el agua de bebida.

\section{ALIMENTOS OFRECIDOS}

La cría intensiva del conejo debe ser sostenida por una alimentación adecuada, diferente en función del estado fisiológico del animal. El conejo no es más exigente que otros animales en tema de alimentación; pretende sin embargo, una buena calidad de materias primas y un correcto equilibrio entre energía, proteína y fibra. Se debe evitar el uso de materias primas de escasa calidad y el cambio brusco en la composición y equilibrio de la dieta, a lo que el conejo resulta extremadamente sensible. La estimación de los requerimientos alimenticios debe tener en cuenta tres objetivos que resultan muchas veces contradictorios entre ellos: mantener el regular funcionamiento del aparato digestivo, asegurar la eficiencia óptima del alimento y obtener un producto de calidad y costo adecuado.

De acuerdo a su edad y estado fisiológico, el conejo en el criadero industrial presenta diferentes requerimientos nutricionales que es necesario conocer para hacer los cálculos de consumo. Las características esenciales del alimento según la edad o el estado biológico del conejo son:

* Madres en producción: alimento rico en proteínas (17,5 a $18 \%)$ y calorías (2500 a $2600 \mathrm{Kcal} / \mathrm{kg}$ ) con especial énfasis en ciertos aminoácidos tales como la metionina y la lisina y en el calcio.

* Gazapos (15-45 días): alimento rico en fibras no digeribles y pobre en almidón, moderado contenido de energía y proteína, rico en aminoácidos, y adecuado nivel de macroelementos. 
* Engorde (45 días a la finalización), padres, madres en espera y reproductores en recría: alimento con tenores medios de proteínas (15,5 a $16 \%)$ y calorías (2500 y $2400 \mathrm{KCal} / \mathrm{kg}$, respectivamente)

Estos requerimientos por estado fisiológico sugieren la conveniencia de contar con tres tipos de alimentos, uno para cada etapa. Sin embargo, en la práctica se observan otras alternativas:

* Un alimento único, habitualmente llamado mixto, que tiene valores medios. Simplifica la tarea pero trae una merma en los resultados, esencialmente menor productividad de las madres por acumulación de carencias nutricionales. Sólo es aceptable en criaderos muy pequeños o que por otras razones (planteles de baja performance, problemas sanitarios no resueltos, etc.) no están en condiciones de alcanzar altos niveles de productividad.

* Dos alimentos, uno formulado según las necesidades de las madres en producción y otro para el engorde. De hecho es el esquema más utilizado en todo el mundo. La formulación de madres es consumida por las conejas de reposición, las conejas en gestación, las conejas en lactancia y los machos.

* Tres alimentos, incluyendo un alimento «peridestete» basado en el hecho que el gazapo no ha completado aún el desarrollo de su aparato digestivo y, entre otras cosas, no tiene suficientes enzimas para digerir el almidón ni una flora bacteriana estable. Por ello su dieta debería incluir cantidades mínimas de almidón (baja inclusión de maíz) y mayor proporción de celulosa y hemicelulosa a expensas de la lignina.

Los inconvenientes de esta práctica son el uso de tres alimentos y el cambio de dieta a la madre durante su suministro, Ilevándola a ciertas carencias que deberá compensar en el breve período que resta hasta la siguiente parición, siendo su mayor ventaja la mejora del peso de la camada y la menor mortalidad de ese período. Durante este período (20 días a destete) se suministrará 'alimento de formulación para madres' si prio- rizamos el estado nutricional de las conejas o 'alimento destete' si priorizamos el estado sanitario de los gazapos. Si el destete es temprano (28 a 30 días) conviene suministrar el alimento para destete porque se evitan los riesgos sanitarios asociados a la sobrecarga de almidón y proteína en el ciego de los gazapos sin afectar en demasía a la madre que recupera rápidamente estado corporal al volver a suministrar el alimento de lactación en el post destete de los gazapos. En explotaciones intensivas con alta productividad, será por lo tanto una estrategia recomendable en la medida que se pueda formular un alimento de esas características.

Por otra parte, al aumentar la temperatura ambiente el consumo de alimento disminuye y para lograr que el conejo consuma los nutrientes en cantidad suficiente para cubrir sus requerimientos, los alimentos de verano deberán poseer mayor concentración energética.

\section{ALIMENTACIÓN Y PATOLOGÍAS DIGESTIVAS}

En los jóvenes conejos el consumo de alimento seco se hace significativo cuando los animales son capaces de llegar fácilmente al comedero y bebedero (17-20 días de edad). En condiciones normales de criadero, el consumo promedia los $25-30 \mathrm{~g} / \mathrm{d}$ desde los 16 a 25 días de edad y aumenta otros $25 \mathrm{~g}$ hasta los 35 días (Fortun-Lamothe y Gidenne, 2002). En este período de 25 a 35 días el consumo de alimento sólido supera el de leche y da comienzo la cecotrofía (2228 días; Orengo y Gidenne, 2006). Desde el destete (4-5 semanas), el consumo diario se incrementa correlativamente con el aumento del peso metabólico, hasta los cinco meses de edad.

En el conejo prevalece un mecanismo de regulación química del apetito, o sea, regula su ingesta energética en base a la concentración energética del alimento. Dado que el conejo es un monogástrico herbívoro, el principal componente en sangre responsable de la regulación del apetito, si bien no está del todo comprobado, sería el nivel de glucosa. 
Los animales consumen diariamente la cantidad de energía digestible (ED) que coincide con sus necesidades y por lo general, un aumento en el nivel de energía de la dieta, determina una disminución en el consumo de materia seca manteniendo así, sin cambios, la cantidad de ED ingerida. Este mecanismo de regulación del consumo de energía comienza luego del destete, después de un período de adaptación a la alimentación de 2 a 5 días. Según Partridge et al. (1989), hay un límite a la posibilidad de ajuste del consumo de energía: por debajo de 2150$2270 \mathrm{kcalED} / \mathrm{kg}$, el ajuste es difícil y hay riesgo de bloqueo cecal. En este caso, el nivel excesivamente alto de componentes fibrosos, determina una congestión del tracto digestivo y el consumo se detiene. Cualquiera que sea el nivel de energía de la dieta por debajo de este umbral mínimo, la cantidad de comida consumida diariamente es constante y la ingestión de la ED solo aumenta con el aumento de la concentración de la energía de la dieta. En las dietas con más energía, la ingestión es proporcional al peso metabólico del animal en el intervalo de 2270 a $2750 \mathrm{kcalED} / \mathrm{kg}$, el conejo disminuye el consumo de alimentos mientras que la ingestión de energía permanece constante (alrededor de 2150 a $2390 \mathrm{kcal} / \mathrm{d} / \mathrm{kg}$ peso metabólico). Cuando el nivel de energía es más alto (aceites y/o grasas añadidos), la regulación química no es muy eficiente y el mayor contenido de energía de la dieta conduce a un aumento en el consumo de energía, mejora el rendimiento y los parámetros productivos.

Para cada concentración energética del alimento existe un tenor proteico óptimo. De Blas et al. (1981), estudiando la relación entre la proteína digestible (PD) y la energía digestible, el aumento de peso, el consumo de ED y la mortalidad, encontraron una relación PD/ED óptima igual a 10,2 g/MJ. Con respecto al requerimiento de proteínas, si los aminoácidos lisina, metionina y treonina están presentes en cantidades y proporciones apropiadas a las necesidades, el 15,5\% de PB sería suficiente para obtener el máximo rendimiento de producción. Las necesidades de proteínas, por supuesto, dependen de la edad y disminuyen desde el destete al engorde (Maertens et al., 1997).

El antagonismo entre la eficiencia de la producción y la salud animal es uno de los principales problemas de la alimentación en crecimiento y engorde. El tipo de dieta y el equilibrio entre los nutrientes inciden en la aparición de problemas entéricos y sobre la productividad global del animal. Los principales síntomas digestivos asociados con el tracto ciego-colon son la diarrea y el bloqueo cecal.

Según Morisse (1982) y Lelkes (1987) el correcto equilibrio fisiológico-digestivo del conejo está garantizado por el equilibrio existente, a nivel intestinal, de tres importante factores: motilidad, microflora y $\mathrm{pH}$, que a su vez están influenciados por muchos otros factores. Cualquier desequilibrio en uno de los tres factores desencadena un proceso fisiopatológico que a menudo está acompañado por infecciones microbianas intestinales. Los trastornos digestivos post- destete que perturban la correcta digestión de los alimentos se caracterizan por la abolición de la cecotrofía, diarrea y/o estreñimiento; síndrome de 'la enteritis mucoide'/ enterocolitis, la pérdida de agua y electrolitos, los desequilibrios metabólicos, etc.

Cuanto mayor es la proteína y el almidón que llegan al ciego sin ser digeridos, mayores son las posibilidades de problemas intestinales, especialmente en los gazapos próximos al destete con raciones pobres en fibra, muy lignificadas o demasiado molidas. Con las dietas bajas en contenido de fibra aumenta la actividad antiperistáltica del coIon proximal, debido a la alta proporción de partículas finas y, en consecuencia, aumenta el tiempo de retención de la digesta y la actividad fermentativa de los ciegos se verá afectada negativamente. En este caso, hay una menor producción de AGV (48 mmoles / I vs $58 \mathrm{mmol} /$ I) con inversión de la relación de C3/C4, mayor producción de NH3 (8,3 vs $5,6 \mathrm{mmol} / \mathrm{I})$ y la elevación del pH $(6,73$ vs $6,45)$ (Bellier, 1994). El efecto favorable de fibra no digerible se basa principalmente en el control de la motilidad y la tasa de tránsito intestinal (Cheeke, 1987; Lebas, 1989 ). 
Como ya se mencionó, debido a que el conejo reduce la ingestión a medida que aumenta el contenido de energía de la dieta (autoregulación), la cantidad de almidón ingerida sigue siendo similar en las dietas de alto o bajo contenido fibroso, mientras que disminuye la ingestión de fibra. Por esta razón, en el caso de los conejos de engorde, el almidón no es la causa principal de la aparición de los trastornos entéricos (Lebas, 1989; Parígi Bini et al.,1990; Bellier y Gidenne, 1996). En conejos jóvenes, el destete trae aparejado una situación de stress considerable con cambios drásticos en la composición del alimento, sin que el aparato digestivo del gazapo se encuentre completamente desarrollado; la flora amilolítica es incompleta y por lo tanto la llegada de la alta cantidad de almidón a los ciegos (dieta rica en cereales) sería responsable de los problemas digestivos. De hecho, la amilasa pancreática es activa a los 15 días de edad, pero sólo alcanza su máxima actividad a los 90 días (Lebas et al., 1977; Doÿana et al., 1998). La sustitución de almidón con fibra de alta digestibilidad como fuente de energía (con la misma FDA), afecta positivamente a la salud animal, probablemente debido al efecto barrera de la flora fibrolítica cecal contra las especies patógenas y la oferta más baja de glucosa en el intestino ciego (Jehl y Gidenne, 1996). Un exceso de fibra sin embargo, no es deseable ya que afecta negativamente a la concentración de energía de la dieta y porque se asocia a menudo con una alta proporción de proteína/energía (aumento de la producción de amoníaco por la flora proteolítica por desaminación de la proteína usada como fuente de energía; De Blas et al., 1981; Lebas, 1989).

Un exceso proteico se traduce en una mayor concentración de amoníaco en el ciego con un aumento del pH e incremento de problemas entéricos. En la formulación práctica se debe usar una doble restricción proteica: un máximo para evitar las patologías entéricas y un mínimo para evitar disminuciones en el crecimiento y la productividad. Estudios realizados sobre este tema permiten diferenciar dos niveles de proteína requeridos durante el crecimiento de los animales: un mayor nivel en el período posdestete respecto al período de engorde, dónde reducciones en el aporte proteico permiten obtener un alimento menos costoso y causante de menores problemas patológicos. Dado el interés en satisfacer los requerimientos proteicos del conejo y el estrecho margen de variación que se puede permitir en el nivel proteico del alimento, no puede de ningún modo utilizarse el dato de proteína expresado en 'proteína bruta' o aminoácidos totales. Conceptos cómo proteína digestible, aminoácidos disponibles y proteína ideal deberían constituir parte de los análisis normales realizados por las plantas de alimentos balanceados.

En conclusión, las fórmulas y los programas de alimentación deben tener en cuenta que los requerimientos de los animales varían en función del estado fisiológico y productivo. Parece claro que los principales factores que deben tenerse en cuenta en la formulación de dietas para conejos en crecimiento es la relación proteína/energía, el porcentaje de fibra no digerible, el almidón y la FDA, éste último considerado un predictor relativamente robusto de digestibilidad de la dieta (Jehl et al., 1998). Los márgenes de seguridad deben ser superiores en sujetos sensibles como los gazapos al destete cuando la mortalidad representa la principal preocupación del criador. Un elevado nivel proteico y de almidón es tolerable en las conejas adultas visto que son menos susceptibles a sufrir problemas digestivos y dados los altos requerimientos nutritivos para sostener la lactancia y la preñez en forma simultánea. En teoría, si las dimensiones del criadero lo permiten, deberían formularse tres tipos de alimento: 'alimento para madres', de alta energía y alto nivel de aminoácidos, moderado contenido de macroelementos y fibra; 'alimento para conejos al destete', moderado contenido de energía y proteína, rico en aminoácidos, muy rico en fibra y adecuado nivel de macroelementos y 'alimento para engorde' alto contenido en energía y moderado contenido de aminoácidos y macroelementos, rico en fibra. La empresa fabricante también deberá tener en cuenta la existencia de otros tipos de alimentos balanceados como son los 'alimento para ciclo único', para pequeños criaderos intensi- 
vos y alimentos específicos para conejos de piel, pelo y machos.

\section{DIGESTIÓN Y SISTEMA INMUNITARIO}

Como explican Gidenne y García (2006), el tracto digestivo tiene dos funciones: la digestión de los nutrientes y la protección contra microorganismos patógenos. Estas dos funciones maduran gradualmente a partir del nacimiento, influenciadas por la edad, la dieta, el crecimiento animal y la interacción entre microorganismos, y se estabilizan entre las ocho y diez semanas de edad. Para cumplir con estas dos funciones, la mucosa está compuesta por el epitelio digestivo, el tejido linfoide asociado y el mucus que recubre el epitelio.

La anatomía del tracto digestivo se completa a las 9 semanas de edad, a excepción del apéndice del ciego que crece hasta las 11 semanas. Durante las primeras semanas de vida, la morfología del epitelio intestinal sufre profundos cambios; las vellosidades intestinales al inicio estrechas y alargadas (forma de 'dedo') se ensanchan (forma de 'lengua'). La maduración histológica de la mucosa intestinal es incompleta hasta los 20 días de edad y sigue un gradiente próximo-distal; la mucosa de la pared del ciego y colon sufre cambios a partir de los 16 días con la aparición de las crestas y cuando comienza la actividad fermentativa a partir de la flora establecida. Las modificaciones estructurales que ocurren durante la fase de maduración determinan un aumento importante en la superficie de intercambio. El desarrollo del sistema enzimático de los animales depende principalmente de factores ontogénicos pero puede ser influenciado por factores externos como ser la edad de destete y el tipo de alimentación; por el contrario, el desarrollo de la flora microbiana depende de los nutrientes que entren al ciego y consecuentemente, de la digestibilidad de la dieta.

Son muchos los factores que aseguran la acción defensiva de la mucosa intestinal contra los patógenos, los que pertenecen al sistema inmune y los no-inmunológicos como ser los movimientos peristálticos, la renovación permanente del epitelio digestivo, el mucus que contiene sustancias bacteriolíticas o bacteriostáticas (lactoferrin, lactoperoxidasa y lisozima) y la competencia entre la flora estable y los patógenos. Cuando estos mecanismos no inmunológicos no logran eliminar al agente patógeno, se activa el sistema inmunológico del sistema linfoide asociado a la mucosa intestinal.

La organización del sistema linfático en el conejo es similar al de otros mamíferos pero presenta dos estructuras adicionales, el sacculus rotondus, ubicado en la unión ileo-cecal y el apéndice del ciego. La primer respuesta inmune (innata), no específica, es la primer línea de defensa contra los patógenos y está presente en todo el tracto gastrointestinal; la respuesta adaptativa o adquirida en cambio, dirigida a agentes externos determinados, actúa a través de específicos sitios de inducción (identificación del agente y activación de células que comienzan una reacción contra los antígenos) y sitios efectores (eliminación del agente indeseado; Drouet-Viart y Fortun-Lamothe, 2002). Los sitios de inducción contienen células linfoides organizadas en folículos linfoideos como los parches de Peyer; los conejos tienen de 2 a 10 de estos parches a lo largo del intestino delgado. Tanto el apéndice del ciego como el sacculus rotondus tienen cientos de folículos abovedados cuya organización es similar a la de los parches de Peyer (Mage, 1998) siendo la función de los tres, la eliminación de las macromoléculas y microorganismos del lumen del intestino a las células linfoides.

\section{PRESENTACIÓN}

El alimento debe ofrecerse al conejo en forma sólida y seca ya que al roer, no ingiere partículas pequeñas ni polvo; en la práctica esto equivale al pelleteado. Respecto al tamaño del pellet, después del trabajo publicado en 1996 por el equipo de la Universidad de Pádova, se determinó que el tamaño ideal es de $4,5 \mathrm{~mm}$ de diámetro por $10 \mathrm{~mm}$ de largo aunque es normal encontrar pellets de menor diámetro $(3,5 \mathrm{~mm})$; en cambio hay consenso respecto que el conejo no ingiere 
pellets más largos, cortándolos y despreciando lo que sobra. El otro aspecto esencial es la dureza. Un pellet blando se deshace y no es ingerido por lo que representa una pérdida; por el contrario un pellet muy duro no resulta apetecible para el conejo y se verifica menos frecuencia de ingestas. Otro punto importante es la presencia de polvo. Este puede provenir de defectos de fabricación tales como un pelleteado defectuoso (por escasa o errónea utilización de aglutinantes o en el prensado) o ser fruto de una dureza inadecuada que permite que el pellet se deshaga durante el manipuleo y transporte. La presencia de polvo tiene dos consecuencias nefastas: el polvo se pierde generando pérdidas económicas, e irrita las vías respiratorias del conejo iniciando la secuencia coriza - neumonía - pasteurelosis.

Incluso bien almacenado, el alimento tiene una vida útil breve, que difícilmente exceda los 30 a 40 días, ya que aumenta la probabilidad de humedecerse con el consecuente desarrollo de hongos. Si bien la única forma precisa de determinar contaminación ya sea de microorganismos o toxinas es a través de los respectivos análisis, su costo lo hace inviable en la práctica diaria. Una forma sencilla de descartar problemas groseros es observar el aspecto general: color (sin manchas en la superficie del pellet sospechosas de colonias de microorganismos); dureza (un pellet humedecido es más blando, se quiebra fácil y/o se hace polvo), olor (sin olores rancios ni putrefactos), sabor (por masticación, sin sabores a húmedo o amargos).

Cabe recordar que los fabricantes pueden modificar los ingredientes o el tamaño de las partículas por diferencias en la molienda sin alterar los valores declarados en la etiqueta, ya que aunque dichos valores respondan a las exigencias oficiales no ofrecen la totalidad de la información necesaria.

La preparación de los alimentos es un proceso importante y delicado ya que un alimento sano y que satisfaga los requerimientos de cada tipo de animal, mejora sensiblemente la productividad y la calidad de carne producida por el criadero. La filosofía de una industria productora de alimentos balanceados debe prever que una importante parte del esfuerzo empresarial sea dedicado a la investigación: no se puede mejorar cualitativamente el producto ofrecido sin una constante actualización tecnológica. Los resultados de las investigaciones en el sector de la nutrición del conejo deberían probarse 'a campo' en experiencias controladas por la propia empresa con el fin de establecer, desde el punto de vista nutricional, la formulación óptima del producto.

\section{INGREDIENTES EN LA ALIMENTACIÓN PRÁCTICA}

Los alimentos para conejos pueden formularse a partir de pocos ingredientes cuyas proporciones buscan cumplir con los requerimientos propios de cada estado fisiológico. Cuando algún aminoácido u oligoelemento queda sin cubrir, es mejor suplementar el alimento con dichos elementos obtenidos de la industria y no complicar la fórmula con otros ingredientes que pueden generar desbalances. Resulta esencial mantener la formulación a lo largo de cada período de crecimiento o desarrollo.

La fuente de calorías más económica en Sudamérica es el maíz; si bien algunos de sus componentes son cuestionables para utilización en conejos, su bajo costo lo vuelve inevitable. El trigo (así como la avena, la cebada y el centeno) tienen ventajas sobre el maíz en cunicultura, y son los cereales usados en Europa; por su mayor costo, su uso es más restringido. Como complemento calórico a los hidratos de carbono, se utilizan grasas que pueden provenir del girasol o de la soja. Esto soluciona también el aporte de una variedad de ácidos grasos aunque no debe olvidarse que los lípidos de la dieta inciden en gran parte sobre la composición lipídica de las grasas corporales del conejo a venta. A bajos niveles de inclusión, la digestibilidad de los lípidos es casi $100 \%$; la adición de grasa muestra tasas de crecimiento comparables pero mayor eficiencia alimenticia debido a la mayor ingesta de energía (Maertens, 1998). En las madres, las dietas enriquecidas en grasas favorecen la ingesta de energía adicional que se utiliza principalmente para la producción de leche (Xiccato, 1996, Fortun-Lamothe, 1997). 
Otro componente básico para el conejo es la proteína y los cereales son relativamente pobres en ellas. Por eso es necesario suplementar la formulación con proteínas que normalmente provienen de la soja o girasol. Los requerimientos de aminoácidos (AA) de los conejos destetados disminuyen con el aumento de la edad (Maertens et al., 1997), por lo que recomendaciones dietéticas de AA conjuntas para la fase de crecimiento y terminación subestiman probablemente las necesidades de AA de conejos jóvenes (tres a siete semanas), pero los sobrestiman en la fase de engorde (ocho a once semanas de edad). Un programa de alimentación que contemple al menos el alimento de post destete y el de engorde separadamente, proporcionaría dietas más adaptadas a los requerimientos de las diferentes edades, que resulta en una producción más eficiente. Sin embargo, se carece de datos relativos a la digestibilidad cierta de todos los AA; la cecotrofía en el conejo complica aún más una evaluación correcta como se realizó en cerdos $y$ aves de corral.

El otro elemento crítico en el conejo es el aporte de fibras. No todas las fibras son iguales, por lo que el balance entre fibras que se digieren tal como la celulosa y otras que no tal como la lignina debe ser cuidado. Casi todos los ingredientes mencionados tienen cierta cantidad de fibras, pero en proporción insuficiente. El adecuado balanceo se logra con agregado de ingredientes ricos en fibras, y por su disponibilidad y precio se combinan los salvados, esencialmente afrechillo de trigo, y la alfalfa.

Los insumos mencionados tienen todos los principios nutritivos en diferentes proporciones por lo que la formulación definitiva requiere un análisis donde la mayor o menor proporción de cada insumo irá en función del aporte de cada uno de los principios nutritivos más sus características constitucionales distintivas.

Aparte de los ingredientes básicos, es necesario suplementar con ciertos elementos que o bien no están presentes en dichos insumos o lo están en cantidades insuficientes. Estos aditivos suelen llamarse 'premix' o núcleos vitamínico - minerales, más otras sustancias, tales como ciertos aminoácidos.
Dentro de ese núcleo o dosificado por separado, se incluyen el calcio, el fósforo, la sal (cloruro de sodio) y otros. Lógicamente la base de un buen alimento es una adecuada formulación y la utilización de ingredientes de primera calidad y un núcleo correcto es casi igual de importante para satisfacer las necesidades de un plantel de buen rendimiento.

\section{Conversión}

El índice de conversión se define como el cociente entre el alimento consumido durante cierto período de tiempo y el aumento de peso experimentado en dicho tiempo, o sea cuanto alimento hace falta para que el animal gane 1 kilogramo de peso. Carece de unidad ya que divide kilos por kilos.

La conversión depende de muchos factores: la capacidad propia de la especie para incorporar tejido a partir del alimento, la capacidad propia del individuo, el alimento, las condiciones ambientales, el estado de salud, etc. Debemos tender al menor índice de conversión posible pues el mercado no pagará la ineficiencia de producción.

Como especie, el conejo tiene una conversión bastante variable y a través de la selección se han visto valores que van desde 1,8/2 al destete hasta tres sobre la finalización (2500 kg de peso). La media durante este período (35-75 días), se sitúa entre 2,7 a 2,8. Esto significa que un conejo destetado con 700 gramos consumirá como mínimo $5 \mathrm{~kg}$ de alimento seco hasta alcanzar su peso de venta. Sin embargo, conejos no seleccionados pueden tener valores muy superiores incluso en razas comerciales.

Cuando las condiciones no son óptimas, el conejo consumirá más alimento sin aumentar de peso proporcionalmente. El hacinamiento, las altas temperaturas, las corrientes de aire, los ruidos, y otras alteraciones ambientales afectarán la conversión, siendo la de mayor impacto el estado de salud; un proceso agudo tal como una diarrea significa alimento desperdiciado, así como procesos crónicos muchas veces desapercibidos. El alimento juega un rol importante en el índice de conversión: una dieta pobre en proteínas y energía, excesiva en fibras u otros 
componentes no digeribles, lleva al animal a comer más para cubrir sus requerimientos aumentando el índice de conversión. Este es el defecto más común en los alimentos económicos hechos con exceso de ingredientes de bajo costo (afrechos, forrajes, restos de otras producciones, etc).

La conversión global es un índice que resulta de dividir todo el consumo de alimento del criadero a lo largo de un período, por los kilos de conejo producido. Este índice contempla el alimento que consumen los reproductores, los animales muertos, la reposición, etc., y por lo tanto es una medida de la eficiencia global de la explotación. Comparándola contra la relación entre el costo del alimento y el precio del conejo, tendremos una idea clara del margen bruto que habitualmente se llama margen alimentario, ya que el resto de los componentes del costo suelen ser más o menos fijos. Como referencia, la conversión global en los establecimientos europeos oscila hoy alrededor de cuatro aunque hay algunos que han llegado a valores tan bajos como 3,5.

\section{Mejora de la eficiencia de la alimentación}

\section{Por posibilidades genéticas}

Existen diferentes posibilidades para reducir el índice de conversión alimentaria. La eficiencia de utilización de un alimento para su conversión en carne depende en gran medida del potencial genético. Recién a partir de la década del'90 comienzan a utilizarse líneas paternas terminales especializadas en aumentar la ganancia diaria de peso y mejorar la eficiencia de la alimentación. El gran potencial de tales líneas ha sido demostrada por Blasco et al. (1996) y Rochambeau et al. (1996).

\section{A través de la nutrición}

Existen muchos factores nutricionales que interfieren en la utilización de los minerales dietarios por parte de los animales, principalmente el nitrógeno y el fósforo. Debe evitarse alimentar a los animales por encima de sus necesidades así como suminis- trar dietas desequilibradas, que conducen a eliminar mas residuos en el medio ambiente. Cuanto mejor se ajusten las fórmulas a los requerimientos reales de cada fase de producción, habrá una mayor adaptación del alimento a los requerimientos y por tanto una menor excreción de minerales.

Ya en la década del '90, Maertens demostró que en general, las dietas para conejos contienen en promedio un exceso de proteína. Una dilución del contenido de proteínas de la dieta desde 17,1 hasta $15,7 \%$ (período 32-74 días de edad) resultó en una disminución del $11 \%$ de la excreción de nitrógeno con los mismos resultados zootécnicos si los AA limitantes lisina, azufrados y treonina estaban cubiertos (Maertens et al., 1997); por debajo del $15,7 \%$ de proteína dietaria se obtuvieron menores performances zootécnicas durante las primeras semanas después del destete. Debido a la interacción significativa entre la dieta y la edad de los conejos, se demostró una respuesta dependiente de la edad con contenido de proteína y aminoácidos de la dieta; los conejos jóvenes necesitan mayor contenido de proteína (y AA) en la dieta que en su etapa final. Maertens y Luzi, (1997) ensayaron la 'alimentación por fases', a fin de determinar los requerimientos reales de los animales en sus diversas estados fisiológicos, con el fin de reducir la excreción de Nitrógeno. En las distintas combinaciones de contenido de proteína de la alimentación por fases ensayada obtuvieron una reducción de la ganancia de peso de un 2,3 hasta un $6,1 \%$, pero la disminución observada en la excreción de $\mathrm{Ni}$ trógeno fue del 26,8 al 45,0 \%. Estos resultados ilustraron claramente que puede conseguirse una reducción muy grande de la excreción de nitrógeno si la dieta se corresponde con los requisitos a una edad determinada.

Respecto al fósforo $(P)$, las necesidades de los conejos son bajas y la cantidad suministrada por las materias primas alimentarias supera las necesidades tanto para el engorde como para las hembras (Lebas y Jouglar, 1990); un contenido de $\mathrm{P}$ de $4,8 \mathrm{~g} / \mathrm{kg}$ es suficiente para obtener un rendimiento máximo y para asegurar la resistencia de los huesos (Lebas et al., 1998). Sin 
embargo, la reducción de la excreción de $\mathrm{P}$ no es realizable en condiciones prácticas ya que para obtener un nivel de $P$ en la dieta de $5 \mathrm{~g} / \mathrm{kg}$ no se pueden utilizar varias materias primas ricas en $\mathrm{P}$ como ser los granos y sus subproductos.

En un criadero comercial, aproximadamente las $2 / 3$ partes del alimento es consumida por los conejos en engorde y un 25$30 \%$ en la maternidad. Durante las 6 semanas del período de engorde, el $65 \%$ de la alimentación se consume en la segunda mitad de dicho período. Estos datos se refieren a un criadero con ritmo reproductivo de 42 días entre partos, la edad al destete de 30 días y los conejos se venden a la edad de 72 días $(2,4 \mathrm{~kg})$. Por lo tanto, la utilización de dietas de terminación adaptadas (densidad de energía) contribuye en gran medida a mejorar la eficiencia de la alimentación del criadero; esta relación inversa entre el contenido de energía y la conversión alimenticia también se verifica en las dietas concentradas.

\section{Mediante la reducción de la mortalidad}

La tasa de conversión de alimento se ve fuertemente afectada por la tasa de mortalidad ya que no sólo se pierde todo el alimento consumido por estos conejos, sino que también reducen la eficiencia de la madre. Uno de los factores dietéticos vinculados con la tasa de mortalidad en el período de engorde es el efecto de la lignina en la dieta sobre la velocidad de paso y su efecto protector contra la diarrea (Gidenne y Pérez, 1994; Pérez et al., 1994); la tasa de mortalidad debida a trastornos digestivos está estrechamente relacionada $\left(r^{2}=0,99\right)$ con el nivel de la lignina (LDA: Mortalidad (\%) = 15,8 a 1,08 LDA (\%)). Gidenne et al. (1998) demostraron que dietas con el mismo nivel de almidón y LDA, pero una relación lignina / celulosa muy divergentes mostraron una respuesta clara entre velocidad de tránsito y riesgo de problemas entéricos por lo que los requisitos de fibra en engorde se expresarían mejor como un nivel mínimo de LDA en la dieta (> $5 \%$ ) que como fibra bruta o FDA.
Por otro lado, la sensibilidad de los conejos jóvenes a altos niveles dietéticos de almidón ha sido profusamente demostrada (Lebas y Maitre, 1989; Blas et al., 1994; Peeters et al., 1993; Maertens, 1995); algunos resultados indicarían que una alta capacidad buffer de la dieta conduce a un aumento de los niveles sanguíneos amoníaco y urea (Briens et al., 1998). Sin embargo, cuando los conejos están contaminados con agentes altamente patógenos, la mortalidad se produce incluso con una dieta considerada como 'segura' (ej. Enterocolitis) y la mortalidad se muestra bastante independiente de la dieta utilizada.

\section{Intervalo entre partos}

En criaderos con animales y dietas adecuadas, se puede lograr una conversión alimenticia (sin mortalidad) menor a 3 durante el periodo de engorde. Sin embargo, para obtener una conversión alimenticia global favorable de todo el criadero, no sólo debe considerarse el consumo de alimento sino que también resulta importante la producción de conejos destetados. El uso intensivo de hembras, con intervalos cortos entre las camadas, restringe la cantidad relativa de alimento consumido por la población de 'reproducción'; consecuentemente, el incremento de animales destetados/hembra/año deriva en una eficiencia alimenticia mejorada.

\section{BIBLIOGRAFÍA}

BELLIER, R. 1994. Contrôle nutritionel de l'activité fermentaire caecal chez le lapin. Thèse de Doctorat. Ecole Nationale Supérieure Agronomique, Inst. National polytechnique de Toulouse, 117p.

BELLIER, R.; GIDENNE, T. 1996. Consequences of reduced fiber intake on digestion, rate of passage and caecal microbial activity in the young rabbit. British Journal and Nutrition, 75: 353-363.

BELLIER, R.; GIDENNE, T.; VERNAY, M.; COLIN, M. 1995. In vivo study of circadian variations of the caecal fermentation pattern in post weaned and adult rabbits. Journal of Animal Science, 73: 128-135. 
BJÖRNHAG, G. 1981. The retrograde transport of fluid in the proximal colon of rabbits. Swedish. Journal of Agricultural Reserch, 11: 63-69.

BLAS, E.; CERVERA, C.; FERNANDEZCARMONA, J. 1994. Effect of two diets with varied starch and fibre levels on the performances of 4-7 week old rabbits. World Rabbit Science, 2: 117-121.

BLASCO, A.; PILES, M.; RODRIGUEZ ,E. PLA, M. 1996. The effect of selection for growth rate on the live weight growth curve in rabbits. En: Proceedings 6th World Rabbit Congress, July 9-12, Toulouse (France), Vol 2: 245-248.

BORIELLO, S.P.; CARMAN, J.R. 1983. Cit. da PATTON, N.M. 1983. Research review. Journal of Applied Rabbit Research, 6: 61.

BRIENS, C.; COLTURATO, P.; FLORIN, H.; MAIANI, A.; ROSELL, J.M.; ROY, P.; STEPHAN, S.; TERREROS, E. 1998. Influence du pouvoir tampon de l'aliment sur les performances zootechniques, la mortalité et les paramètres sanguins chez le lapin en engraissement. In : Proc. 7èmes Journ. Rech. Cunicole Fr. Lyon: INRA-ITAVI, 187-190.

CARABAÑO, R.; MOTTA-FERREIRA, W.; DE BLAS, C.; FRAGA, M.J. 1997. Substitution of sugarbeet pulp for alfalfa hay in diets for growing rabbits. Animal Feed Science and Technology, 65: 249-256.

CARABAÑO, R.; FRAGA, M.J.; SANTOMA', G; DE BLAS, J.C. 1988. Effect of diet on composition of cecal contents and on excretion and composition of soft and hard feces. Journal of Animal Science, 66: 901

CASSEN, R.G. 1977. Muscle biochemistry: the importance of miofiber type. Food Technology, 31: 76-83.

CHEEKE, P.R. 1987. Rabbit feeding and nutrition. Florida: Academic Press Orlando.

CHEEKE, P.R.; PATTON, N.M. 1980. Carbohydrate overload of the hindgut. A probable cause of enteritis. Journal of Applied Rabbit Research, 3 (3): 20-23.

DE BLAS, J.C. 1992. The roles of fiber in rabbit nutrition. Vth World Rabbit Congress, Corvalis. Vol. B, 1329-1343.
DE BLAS, J.C.; PEREZ, E.; FRAGA, M.J.; RODRIGUEZ, M.J.; GALVEZ, J.F. 1981. Effect of diet on feed intake and growth of rabbits from weaning to slaughter at different ages and weights. Journal of Animal Science, 52: 1225-1232.

DE BLAS, J.C.; SANTOMA, G.; CARABAÑO, R.; FRAGA, M.J. 1986. Fiber and starch level in fattening rabbit diets. Journal of Animal Science, 63: 1897-1904.

DE BLAS, C.; GARCÍA, J.; CARABAÑO, R. 1999. Role of fiber in rabbit diets. A review. Annales De Zootechnie, 48: 3-13

DOJANÅ, N.; COSTACHE, M.; DINISCHIOTU, A. 1998. The activity of some digestive enzymes in domestic rabbits before and after weaning. Animal Science, 66: 501-507.

DROUET-VIART, F.; FORTUN-LAMOTHE, L. 2002. Review: the organization and functioning of the immune system: particular features of the rabbit. World Rabbit Science, 10: 15-24.

FALCÄO E CUNHA, L. 1988. Os constitutentes do parede celular no processo digestivo de coelho. Thèse de docteur en agronomie. Inst. Sup.Agronomia. Univ. Tecnica Lisbona, 359p.

FALCÄO E CUNHA, L.; BENGALA FREIRE, J.P.; GONÇALVES, A. 1996. Effect of fat and fiber nature on performances, digestibility, nitrogen balance and digestive organs in growing rabbits. VI World Rabbit Congress, Toulouse. Vol. 1, 157-162.

FALCÄO E CUNHA, L.; FERREIRA, P.; BENGALA FREIRE, J.P. 1998. Etude de l'effet de l'interaction fibres $x$ lipides dans l'alimentation du lapin: croissance, digestibilité et paramètres fermentaires. 7 émes Journ. Rech. Cunicole Fr., Lyon. 155-158.

FEKETE, S.; HULLAR I.; FEBEL, H. 1989. Rabbit digestion and blood composition after fat or oil addition to the feed. Journal of Applied Rabbit Research, 12: 233-238.

FORTUN-LAMOTHE, L. 1997. Effects of dietary fat on reproductive performance of rabbit does: a review. World Rabbit Science, 5: 33-38.

FORTHUN-LAMOTTE, L.; GIDENNE, T. 2000. The effect of suckled litter on intake behavior, performance and health status of young 
and reproducing rabbits. Annales de Zootechnie, 49: 517-529.

FRAGA, M.J.; BARRENO, C.; CARABAÑO, R.; MENDEZ, J.; DE BLAS, J.C. 1984. Efecto de los niveles de fibra y proteína del pienso sobre la velocidad de crecimiento y los parámetros digestivos de los conejos. Anales del Instituto Nacional de Investigaciones Agrarias, 29: 91.

GARCIA J.; CARABAÑO R.; PEREZ L.; DE BLAS J.C. 1996. Effect of type of fiber on neutral detergent fiber digestion and caecal traits in rabbits. Proc. VI World Rabbit Congress Vol.1, 175-180.

GARCIA, J.; DE BLAS, J.C.; CARABAÑO, R.; GARCIA, P. 1995. Effect of type of lucerne hay on caecal fermentation and nitrogen contribution through caecotrophy in rabbits. Reproduction Nutrition Development, 35 : 267-275.

GIDENNE, T. 1986. Evolution nycthémérale des produits de la fermentation bactérienne dans le tube digestif du lapin en croissance. Relations avec la teneur en lignines de la ration. Annales de Zootechnie, 35 : 121-136

GIDENNE, T. 1992. Effect of fibre level, particle size and adaptation period on digestibility and rate of pasage as measured at the ileum and in the faeces in the adult rabbits. British Journal of Nutrition, 67 : 133-146.

GIDENNE, T. 1994. Effets d'une rèduction de la teneur en fibres alimentaires sur le transit digestif du lapin. Comparaison et validation de mòdeles d'ajustement des cinétiques d'excrétion fécale des marqueurs. Reproduction Nutrition Development, 34 : 295-306.

GIDENNE ,T.; BELLIER, R.1992. Etude in vivo de l'activité fermentaire caecal chez le lapin. Mise au point et validation d'un nouvelle technique de canulation caecale. Reproduction Nutrition Development, 32: 365-376.

GIDENNE T.; GARCíA, J. 2006. Nutritional and feeding strategies improving the digestibility health of the young rabbit. 4.3 of Chapter 4 in 'Recent advances in rabbit science'. Edited by L. Maertens and P. Coudert. ILVO.

GIDENNE, T.; JEHL, N. 1996. Replacement of starch by digestible fiber in the feed for the growing rabbit. 1)Consequences on digestibility and on rate of passage. Animal Feed Science and Technology, citt. in Gidenne T. 1996.

GIDENNE, T.; PEREZ , J.M. 1993. Effect of dietary starch origin on digestion in the rabbit. 2. Starch hydrolysis in the small intestine, cell wall degradation and rate of passage measurements. Animal Feed Science and Technology, 42: 249-257.

GIDENNE, T.; PEREZ, J.M. 1994. Apports de lignines et alimentation du lapin en croissance. I. Conséquences sur la digestion et le transit. Annales de Zootechnie, 43 : 313-322.

GIDENNE, T.; BELLIER, R.; VAN EYS, J. 1998. Effect of the dietary fiber origin on the digestion and on the caecal fermentation pattern of the growing rabbit. Animal Science, 66: 509-517.

GIDENNE, T.; CARRE, B.; SEGURA, M.; LAPANOUSE, A.; GOMEZ, J. 1991. Fiber digestion and rate of passage in the rabbit: effect of particle size and level of lucerne meal. Animal Feed Science and Technology, 32: 215-221.

GIDENNE T.; MADEC O.; ARVEUX P. 1998. Effects de la nature de la lignocellulose sur la digestion et les performances zootechniques du lapin en croissance. In : Proc. 7èmes Journ. Rech. Cunicole Fr., Lyon. Ed. INRA-ITAVI: 151-154.

GIDENNE T.; PEREZ J.M. 1994. Apports de lignines et alimentation du lapin en croissance. I. Conséquences sur la digestion et le transit. Annales de Zootechnie, 43 : 313-322.

GIDENNE T.; PEREZ J.M. 1996. Apports de cellulose dans l'alimentation du lapin en croissance. I. Conséquences sur la digestion et le transit. Annales de Zootechnie, 45 : 289-298.

JEHL N.; GIDENNE T. 1996. Replacement of starch by digestible fibre in the feed for the growing rabbit. 2) Consequences on microbial activity in the caecum and on incidence on digestive disorders. Animal Feed Science and Technology, citt. in Gidenne T. 1996.

JEHL N.; GIDENNE T.; LE ROUX J.F. 1998. Emploi de rations à forte proportion de fibres digestibles: effets sur la digestion et le transit du lapin en croissance. 7émes Journ. Rech. Cunicole Fr., Lyon. 137-140. 
JILGE, B. 1980. Selective cumulation of smallsize marker particles during hard faeces excretion. Proc. II World Rabbit Sci. Assoc.Congress, Barcelona. WRSA ed., 1.

LEBAS, F. 1979. La fisiologia della digestione nel coniglio. Selezione Veterinaria , XX (2): 129

LEBAS, F. 1988. Feed evaluation and nutritional requirements 3.2. Rabbits. Livestock Production Science, 19 : 289-298.

LEBAS, F. 1989. Besoins nutritionnels des lapins. Cuni-Sciences, $5: 1-27$.

LEBAS, F.; MAITRE I., 1989. Alimentation de présevrage. Etude d'un aliment riche en énergie et pauvre en protéines. Résultats de 2 essais. Cuniculture, 16 : 135-140.

LEBAS, F.; CORRING, T.; COURTOT, D. 1977. Equipement enzymatique du pancréas exocrine chez le lapin, mise en place et évolution de la naissance au sevrage. Relation avec la composition du régime alimentaire. Annales de Biologie Animale, Biochimie et Biophysique, 11 : 399-413.

LELKES, L. 1987. A review of rabbit enteric diseases: a new perspective. Journal of Applied. Rabbits Research, 10: 55-61.

LENG, E.; CLAUSS, W.; HÖRNICKE, H. 1977. Colon passage time in rabbits in relation to the formation of caecotrophes. Zentralblatt für Veterinärmedizin Reihe A, 24: 324-332. doi: 10.1111/j.14390442.1977.tb01581.x

MAERTENS, L. 1995. Effect of dietary technological treatments on the performances of rabbits before and after weaning. Proc. 7th Hungarian Rabbit Production day, Kaposvar 24 May, 1-11.

MAERTENS, L. 1998. Grasas en la nutrición de conejos. (Fats in the nutrition of rabbits). Proc. 1st AB-WRSA Rabbit Conference, September 10-11, Montecillo (Mexico), N1-N16.

MAERTENS, L.; LUZI, F. 1997. Reduction of Nexcretion of growing rabbits using phase feeding. 10. Arbeitstagung über Haltung und Krankheiten der Kaninchen, Pelztiere und Heimtiere. Celle 14-15 Mai 1995. Ed. Deutsche Vet. Med. Gesellschaft e.V., Giessen, 136- 142.

MAERTENS, L.; LUZI, F.; DE GROOTE, G. 1997. Effect of dietary protein and amino acids on the performance, carcass composition and $\mathrm{N}$-excretion of growing rabbits. Annales de Zootechnie, 46: 255-268.

MAGE, R. 1998. Immunology of lagomorphs. In Handbook of vertebrate immunology. Gabriel P., Pastoret P. P., Bazin H., Goaverts A. Eda. Academic Press limited. P. 673.

MANNING, P.J.; RINGLER, D.H.; NEWCOMER, C.E. 1994. The Biology of the Laboratory Rabbit. New York: Academic Press.

MERINO, J.M.; CARABAÑO, R. 1992. Effect of type of fiber on ileal and faecal digestibility. Proc. Vth World Rabbit Congress, Corvalis. Vol. B, 931-937.

MORISSE, J.P. 1982 Taille des particules de l'aliment utilié chez le lapin. Hypothèses de relation nutrition-pathologie digestive. Revue de Médicine Véterinaire, 133 : 635-642.

MORISSE, J.P.; BOILLETOT, E.; MAURICE, R. 1985. Alimentation et modifications du milieu intestinal chez le lapin (AGV, $\mathrm{NH} 3, \mathrm{pH}$, flore). Rec. Méd. Vét. 161(5): 443-449.

ORENGO, J.; GIDENNE, T. 2007. Feeding behavior and caecotrophy in the young rabbit before weaning: an approach by analysing the digestive contents. Applied Animal Behaviour Science, 102 : 106-118.

PADILHA, M.T.S. 1995. Etude des relations entre la microflora et l'activité fermentaire caecale chez le laperau, pendant le période péri-sevrage. Thèse de doctorat. Univ. F.Rabelais, Tours, 160p.

PADILHA, M.T.S.; LICOIS, D.; GIDENNE, T.; CARRABE, B.; COUDERT, C.; LEBAS, F. 1996. Relationships between microflora and caecal fermentation in rabbit before and after weaning. Reproduction Nutrition and Development, 35: 375-386

PARIGI-BINI, R.; XICCATO, G.; CINETTO, M. 1990. Influenza del contenuto di amido alimentare sulla produttività, sulla digeribilità e sulla composizione corporea di conigli in accrescimento. Zootecnica e Nutrizione Animale, 16 (4): 271-282.

PARTRIDGE, G.G.; GARTHWAITE, P.H.; FINDLAY, M. 1989. Protein and energy retention by growing rabbits offered diets with increasing proportions of fiber. Journal of Agricultural Science, 112: 171-178. 
PEETERS, J.E.; ORSENIGO, R.; MAERTENS, L.; GALAZZI, D.; COLIN, M. 1993. Influence of two iso-energetic diets (starch vs fat) on experimental colibacillosis (EPEC) and iota-enterotoxaemia in early weaned rabbits. World Rabbit Science, 1: 53-66.

PEETERS, J.E.; MAERTENS, L.; ORSENIGO, R.; COLIN, M. 1995. Influence of dietary beet pulp on caecal VFA, experimental colibacillosis and iota-enterotoxaemia in rabbits. Animal Feed Science and Technology, 51: 123-139.

PEREZ, J.M.; GIDENNE, T.; LEBAS, F.;CAUDRON, I.; ARVEUX, P.; BOURDILLON, A.; DUPERRAY, J.; MESSAGER, B. 1994. Apports de lignines et alimentation du lapin en croissance. II. Conséquences sur les performances et la mortalité. Annales de Zootechnie, 43 : 323-332.

PEREZ, J.M.; GIDENNE, T.; BOUVAREL, I.; CAUDRON, I.; ARVEUX, P.; BOURDILLON, A.; BRIENS, C.; LE NAUR, J.; MESSAGER, B.; MIRABITO, L. 1996. Apportes de cellulose dans l'alimentation du lapin en croissance. II Conséquences sur les performances et la mortalité. Annales de Zootechnie, citt. in Gidenne T. 1996.

PEREZ DE AYALA, P.M. 1989. Utilizacion de distintos tipos de fibra por los conejos en cebo. Tesis Doctoral. Madrid: Univ. Politecnica ETSIA, 115p.

PROTO, V. 1980. Alimentazione del coniglio da carne. Rivista di Coniglicoltura, 7: 17-32.

ROCHAMBEAU, DE H.; OUHAYOUN, J.; CAVAILLE, D.; LACOSTE, J.L.; LERICHE, J.L.; PONCEAU, J.; RETAILLEAU, B. 1996. Comparison of ten commercial strains of terminal bucks: 1. Growth and feed efficiency. Proc.6th World Rabbit Congress, July 9-12, Toulouse (France), Vol 3, 241-245.

ROSELL PUJOL, J.M. 2000. Enfermedades del conejo. Madrid: Mundi Prensa, 605 p.
SANTOMA, G.; DE BLAS, J.C.; CARABAÑO, R.M.; FRAGA, M.J. 1987. The effect of different fats and their inclusion level in diets for growing rabbits. Animal Production, 45: 291-300.

UDEN, P.; ROUNSAVILLE, T.R.; WIGANS, G.R.; VAN SOEST, P.J. 1982. The measurement of liquid and solid digesta retention in rumiants equines and rabbits given timothy hay (Phleum pratense). British Journal of Nutrition, $48: 329-339$.

VERNAY, M. 1986. Incidence de la caecotrophie sur la production, l'absorption et l'utilisation des acides organiques chez le Iapin. Reproduction Nutrition and Development, 26: 1137-1149.

VERNAY, M. 1989. Incidence of the circadian rhythm of the excretion pattern on acetate absorption and metabolism in the rabbit hind-gut. Reproduction Nutrition and Development, 29: 185-196.

VERNAY, M.; MARTY, J.; MOATTI, J.P. 1984. Absorption of electrolytes and volatile fatty acids in the hind-gut of the rabbit. Circadian rhythm of hind-gut electrolytes and plasma aldosterone. British Journal of Nutrition, 52: 419-428.

XICCATO, G. 1996. Nutrition of lactating does. Proc. 6th World Rabbit Congress, July 9-12, Toulouse (France), Vol 1, 29-50.

XICCATO, G. 1998. Effect of feeding on meat quality in rabbits. Proc. VIII Jornada de Cunicultura, Barcelona (Expoaviga) October 29: 25-39.

XICCATO, G.; COSSU, M.E.; TROCINO, A.; QUEAQUE, P.I. 1998. Influence du rapport almidon/fibre et de l'addition de graise en post-sevrage sur la digestion, les performances zootechniques et la qualité bouchère du lapin. En: Proceedings 7èmes Journ. Rech. Cunicole. Paris, 159-162. 


\section{UTILIZACIÓN DE FORRAJES FRESCOS EN LA DIETA DE LOS CONEJOS}

Gustavo Capra $^{1}$

Los forrajes frescos constituyen una interesante alternativa de sustitución del alimento balanceado, en particular en las condiciones de Uruguay, donde diversos cultivos forrajeros son producidos en forma eficiente y a un costo relativo muy bajo. Desde el inicio de la actividad de investigación en cunicultura, la Unidad Experimental de Cunicultura de INIA ha generado amplia información sobre la utilización de diferentes especies forrajeras en la alimentación de los conejos para carne.

El empleo de forrajes frescos como sustituto parcial de los concentrados es una estrategia difundida desde los inicios de la cunicultura comercial en Uruguay. Esta modalidad de alimentación para todas las categorías del criadero era un componente clave de la tecnología recomendada en la década del 80, cuando la empresa Proinco llevara adelante un importante emprendimiento de producción de carne de conejo con orientación exportadora. En esos años dicha empresa impulsó un acuerdo con la Federación de Sociedades de Fomento Rural del Noreste de Canelones, que implicaba la combinación de la producción de heno de alfalfa con la cría de conejos.

Sin embargo, con el correr del tiempo, esta estrategia nutricional fue progresivamente sustituida por una alimentación basada exclusivamente en raciones balanceadas comerciales. Una investigación destinada a caracterizar los sistemas de producción cunícola en el país, realizada a fines de la década del 90, establecía que el $73 \%$ de los cunicultores utilizaban en la alimentación de sus animales exclusivamente balanceado comercial y solo el $27 \%$ combinaba el alimento balanceado con forrajes frescos (Pérez y Velázquez, 1998). En un estudio más reciente se verificó el uso de forrajes frescos por un $20 \%$ de los productores consultados (Amoza et al., 2008).
Los argumentos manejados por los cunicultores para discontinuar la utilización de forrajes frescos en la alimentación de conejos en crecimiento-engorde incluían, en su momento, la evolución favorable del precio de la ración comercial, la mayor demanda de mano de obra para cortar y distribuir el forraje, la prolongación del período de engorde y supuestos efectos indeseables sobre el color de la grasa y la carne con la utilización de forrajes.

La alimentación de los conejos basada en raciones balanceadas determina resultados productivos satisfactorios, pero la ocurrencia periódica de variaciones muy bruscas en la relación del precio del conejo y el precio del alimento determina que el cunicultor uruguayo afronte episodios en que la rentabilidad de su operación es nula o negativa. La posibilidad de utilizar forraje fresco producido en el predio, como sustituto parcial del alimento balanceado comercial es, para las condiciones de Uruguay, una estrategia válida de alimentación de conejos para carne, que procura reducir costos de producción y atenuar la incidencia de variaciones fuera de control en el precio del insumo que tiene mayor peso en la estructura de costos

El conejo es un animal herbívoro que acepta con avidez los forrajes frescos, en particular aquellos poco fibrosos. Es muy selectivo y tiende a consumir las partes más tiernas, rechazando las partes vegetales sazonadas y fibrosas; elige primero las hojas y tallos más suculentos.

La alfalfa, una leguminosa forrajera mundialmente reconocida por su productividad $y$ alto valor nutritivo, que le han permitido ganar la fama de ser «la reina de las forrajeras», ha demostrado ser un excelente sustituto parcial, obteniéndose resultados menos satisfactorios con gramíneas como avena o sorgo forrajero. Un forraje fresco que demos-

\footnotetext{
${ }^{1}$ Instituto Nacional de Investigación Agropecuaria. Uruguay.
} 
tró excelentes resultados en la alimentación de conejos en crecimiento y terminación fue la guía de boniato, aunque tiene la desventaja de que su oferta se reduce a un pequeño período del año.

La bibliografía internacional ofrece abundante información referida al empleo de alfalfa deshidratada y heno de alfalfa, utilizados tanto como componentes de las raciones balanceadas o como sustituto o complemento de una ración balanceada. Lebas y Gidenne (2000) destacan atributos nutricionales de este ingrediente, tales como que el contenido de energía aportada puede ser calculado en base a su contenido en Fibra Bruta y que no muestra variaciones en función de su nivel de incorporación en la dieta. También señalan que la digestibilidad de la proteína de la alfalfa parece ser moderada, del orden del $60 \%$.

En sucesivos experimentos de suministro de alfalfa a voluntad a conejos en crecimiento-terminación se han logrado ahorros de ración del orden del 11 a $35 \%$, con ligera o nula afectación de los parámetros de desempeño productivo y de calidad de canal con importancia económica, mientras que en conejas en lactación se han obtenido niveles de sustitución del orden del $15 \%$, sin consecuencias negativas sobre la condición corporal de la coneja y el tamaño y el peso de la camada (Blumetto y Capra, 1998 a y b).

Se presentan a continuación los resultados de algunos de los experimentos lleva- dos a cabo en la Unidad Experimental de Cunicultura de INIA Las Brujas.

\section{SUPLEMENTACIÓN CON ALFALFA FRESCA A CONEJAS EN LACTACIÓN}

En el año 1997 se realizó un experimento destinado a evaluar la performance productiva de conejas en lactación bajo dos estrategias de alimentación. Se utilizaron 24 conejas primerizas cruza Californiano $x$ Neozelandés, cuyas camadas fueron igualadas a un número de 8 gazapos mediante transferencias. Se asignaron al azar las conejas a dos tratamientos: un grupo testigo $(T)$ alimentado exclusivamente con ración comercial pelleteada a voluntad y un grupo (S) que recibía 500 gramos diarios de alfalfa fresca además de la ración comercial a voluntad.

Los parámetros evaluados fueron el consumo de concentrado por parte de la coneja y su camada, el peso de la coneja y el tamaño y peso de la camada.

No se verificaron diferencias significativas en tamaño y peso de la camada ni en el peso de las conejas a lo largo del período de lactación de 28 días; las conejas de ambos tratamientos mantuvieron el mismo peso con que iniciaron la lactancia. En el Cuadro 1 se presentan los resultados relativos al consumo de ración balanceada.

Cuadro 1. Consumo semanal y acumulado final de concentrado por coneja para ambos tratamientos (gramos).

\begin{tabular}{|l|c|c|c|c|c|}
\hline Tratamiento & Semana 1 & Semana 2 & Semana 3 & Semana 4 & $\begin{array}{c}\text { Total } \\
\text { lactancia }\end{array}$ \\
\hline T. Ración a voluntad & $2193 \mathrm{~A}$ & $2297 \mathrm{~A}$ & $2509 \mathrm{~A}$ & $3773 \mathrm{~A}$ & $10773 \mathrm{~A}$ \\
\hline $\begin{array}{l}\text { S. Ración a voluntad } \\
\text { + alfalfa fresca }\end{array}$ & $1693 \mathrm{~B}$ & $1758 \mathrm{~B}$ & $2103 \mathrm{~B}$ & $3480 \mathrm{~A}$ & $9035 \mathrm{~B}$ \\
\hline $\begin{array}{l}\text { Diferencia de consumo } \\
\text { entre tratamientos }\end{array}$ & 500 & 539 & 406 & 293 & 1738 \\
\hline $\begin{array}{l}\text { Reducción del consumo } \\
\text { respecto al testigo \% }\end{array}$ & 22,8 & 23,8 & 16,2 & 7,8 & 16 \\
\hline
\end{tabular}

Nota: Los valores en la misma columna acompañados por letras similares no presentan diferencias estadísticamente significativas. 
El ahorro relativo de ración por la suplementación con alfalfa para el total del período fue de un $16 \%$. Como puede apreciarse en el cuadro anterior, dicho ahorro de concentrado fue decreciendo en la segunda mitad de la lactación. Esta reducción en la capacidad de sustitución de la alfalfa en parte puede ser explicada por el aumento del consumo de ración por parte de los gazapos y en parte por el incremento en los requerimientos energéticos de la coneja a medida que progresa la lactación. Debe tenerse en cuenta que la oferta de alfalfa se mantuvo constante en $\mathbf{5 0 0}$ gramos diarios durante todo el período.

El consumo de alimento por parte de la coneja aumenta en forma progresiva, en concordancia con la evolución de la producción de leche (Lebas, 1986). En la cuarta semana de lactación el consumo total de ración se incrementa sensiblemente por tomar importancia el consumo de sólidos por parte de los gazapos; esto determina que el ahorro de ración en términos relativos decaiga sustancialmente al no poder discriminar la proporción de alimento consumido por la coneja y por la camada.

\section{SUPLEMENTACIÓN CON FORRAJES FRESCOS A CONEJOS EN CRECIMIENTO: SUDAN GRASS, AVENA Y «GUÍAS" DE BONIATO}

En los primeros pasos dados en la Unidad Experimental de Cunicultura de INIA para evaluar la posibilidad de sustituir parcialmente las raciones balanceadas por forrajes fres- cos, se realizaron ensayos con distintas especies.

En agosto de 1996 se efectuó un experimento utilizando avena fresca como suplemento de la ración balanceada comercial en conejos en crecimiento-terminación (Blumetto y Capra, 1997). Se utilizaron 48 gazapos de 42 días de edad, con un peso inicial de $1180 \mathrm{~g}$, que se asignaron al azar a dos tratamientos: T1 alimentados exclusivamente con alimento balanceado comercial a voluntad y T2: alimentados con ración balanceada a voluntad + suministro restringido de avena fresca. La avena fue ofrecida en una cantidad fija de $1000 \mathrm{~g}$ por jaula y por día, fraccionada en dos tomas diarias de $500 \mathrm{~g}$ (de mañana y de tarde). Cada tratamiento constó de tres repeticiones (jaulas) con ocho individuos (cuatro machos y cuatro hembras) en cada una de ellas. Se evaluaron parámetros de comportamiento productivo (consumo de ración balanceada, evolución de peso vivo, eficiencia de conversión del alimento) en forma semanal a lo largo del período de crecimiento que se extendió por cinco semanas. Los resultados se presentan en el Cuadro 2.

La avena no se mostró como un sustituto parcial de la ración balanceada que permitiera un desempeño satisfactorio. No se obtuvo una reducción significativa en el consumo de alimento y determinó una reducción en la ganancia de peso, pese a ser consumida con avidez por los conejos en crecimiento.

En el verano de 1997 se llevó a cabo un ensayo destinado a evaluar la capacidad de sustitución del Sudan grass (Blumetto, 1997a). El ensayo involucró 40 gazapos cruza Neozelandés por Californiano de 35 días

Cuadro 2. Ganancia de peso, consumo de ración e Índice de Conversión para conejos alimentados exclusivamente con ración o con ración + avena.

\begin{tabular}{|l|c|c|c|}
\hline Tratamiento & $\begin{array}{c}\text { Ganancia de } \\
\text { peso en el } \\
\text { período (g) }\end{array}$ & $\begin{array}{c}\text { Consumo de } \\
\text { ración en el } \\
\text { período (g) }\end{array}$ & $\begin{array}{c}\text { Índice de Conversión } \\
\text { para el total del período }\end{array}$ \\
\hline T1 Ración a voluntad & $1353 \mathrm{~b}$ & 4116 & 3,0 \\
\hline $\begin{array}{l}\text { T2 Ración a voluntad } \\
\text { + avena }\end{array}$ & $1253 \mathrm{a}$ & 4043 & 3,2 \\
\hline & $\mathrm{P}=0,0361$ & $\mathrm{P}=0,8799$ & $\mathrm{P}=0,7036$ \\
\hline
\end{tabular}


de edad, con un peso medio inicial de $746 \mathrm{~g}$ Los animales fueron asignados a dos tratamientos alimenticios: T1: ración balanceada comercial a voluntad y T2: ración balanceada a voluntad más Sudan grass restringido. Cada tratamiento involucró cinco repeticiones consistentes en la jaula de $0,34 \mathrm{~m}^{2}$ conteniendo cuatro individuos. El Sudan grass fue suministrado en una cantidad constante de $1,5 \mathrm{~kg} /$ día a lo largo de todo el período de ensayo, dividido en dos ofrecimientos de $750 \mathrm{~g}$, uno por la mañana y el otro por la tarde. El experimento se prolongó por cinco semanas, hasta que los gazapos alcanzaron un peso final de $2,4 \mathrm{~kg}$. Los resultados se presentan en el Cuadro 3.

Si bien se logró una disminución en el consumo voluntario de ración del orden del $8,5 \%$ sin afectar de modo significativo la ganancia de peso, no se logró una mejora estadísticamente significativa en el Índice de Conversión del alimento balanceado.

También en 1997 se llevó a cabo un experimento destinado a evaluar la potencialidad del uso de la parte aérea («guías») del cultivo de boniato (Ipomoea batata) en la alimentación de conejos en crecimiento (Blu- metto, 1997b). Se utilizaron 30 gazapos cruza de 30 días de edad y un peso medio inicial de $433 \mathrm{~g}$, que se distribuyeron al azar en dos tratamientos: T1-alimentados con ración comercial a voluntad y T2- alimentados con ración a voluntad + guías de boniato. Cada tratamiento involucró cinco repeticiones consistentes en la jaula de $0,34 \mathrm{~m}^{2}$ conteniendo tres individuos. Las guías de boniato fueron suministradas en forma restringi$\mathrm{da}$, ofreciendo 1 kilogramo diario a cada jaula, la mitad por la mañana y otro tanto en la tarde. El experimento se extendió por un período total de cuatro semanas. Los resultados obtenidos se presentan en el Cuadro 4.

Las guías de boniato permitieron una reducción significativa del consumo de alimento balanceado del orden del $20 \%$ y una mejora importante en el índice de conversión del balanceado. Si bien los resultados son muy alentadores, la disponibilidad de este residuo de cosecha está acotada a las zonas de cultivo y a un corto período del año. Lebas (1997) destaca las cualidades nutritivas de este alimento y las posibilidades de uso en países tropicales, donde su período de oferta se extiende por un período mucho más amplio que en las condiciones de clima templado prevalecientes en Uruguay.

Cuadro 3. Ganancia de peso, consumo de ración e Índice de Conversión para conejos alimentados exclusivamente con ración o con ración + Sudan grass.

\begin{tabular}{|l|c|c|c|c|}
\hline Tratamiento & $\begin{array}{c}\text { Ganancia de peso } \\
\text { en el período } \mathbf{( g )}\end{array}$ & $\begin{array}{c}\text { Consumo de ración } \\
\text { en el período } \\
\text { (g/animal) }\end{array}$ & $\begin{array}{c}\text { Índice de } \\
\text { Conversión } \\
\text { de la ración }\end{array}$ & $\begin{array}{c}\text { Consumo de } \\
\text { relativo \% }\end{array}$ \\
\hline T1 Ración a voluntad & 1709 & $4144 \mathrm{a}$ & 2,43 & 100 \\
\hline $\begin{array}{l}\text { T2 Ración a voluntad } \\
+ \text { Sudan grass }\end{array}$ & 1615 & $3793 \mathrm{~b}$ & 2,36 & 91,5 \\
\hline & $\mathrm{P}=0,1992$ & $\mathrm{P}=0,0277$ & $\mathrm{P}=0,5502$ & \\
\hline
\end{tabular}

Cuadro 4. Ganancia de peso, consumo de ración e Índice de Conversión para conejos alimentados exclusivamente con ración o con ración + guías de boniato.

\begin{tabular}{|l|c|c|c|c|}
\hline Tratamiento & $\begin{array}{l}\text { Ganancia de peso } \\
\text { en el período }(\mathbf{g})\end{array}$ & $\begin{array}{c}\text { Consumo de ración } \\
\text { en el período } \\
\text { (g/animal) }\end{array}$ & $\begin{array}{c}\text { Índice de } \\
\text { Conversión } \\
\text { de la ración }\end{array}$ & $\begin{array}{c}\text { Consumo de } \\
\text { relativo \% }\end{array}$ \\
\hline T1 Ración a voluntad & 1089 & $2101 \mathrm{~b}$ & $1,93 \mathrm{~b}$ & 100 \\
\hline $\begin{array}{l}\text { T2 Ración a voluntad } \\
\text { + guías de boniato }\end{array}$ & 1062 & $1660 \mathrm{a}$ & $1,56 \mathrm{a}$ & 80,4 \\
\hline & $\mathrm{P}=0,7803$ & $\mathrm{P}=0,0261$ & $\mathrm{P}=0,001$ & \\
\hline
\end{tabular}




\section{SUPLEMENTACIÓN CON}

\section{ALFALFA FRESCA A CONEJOS EN RECRÍA-ENGORDE}

Entre 2008 y 2010 se llevaron a cabo en la Unidad Experimental de Cunicultura de INIA Las Brujas varios experimentos destinados a evaluar el efecto de la suplementación con alfalfa fresca en la etapa de crecimiento y terminación sobre el desempeño productivo y las cualidades de la canal. En esta etapa se retomó una línea de trabajo que había sido priorizada sobre finales de la década del 90 , pero con un enfoque orientado a calidad de producto.

\section{Efecto del tipo genético y el sistema de alimentación sobre el comportamiento productivo y la calidad de la canal en conejos para carne}

En el año 2008 se realizó un ensayo destinado a evaluar el efecto del tipo genético y la suplementación con alfalfa fresca sobre el desempeño productivo y los atributos de la canal. Se compararon tres tipos genéticos: línea Verde pura, cruza simple Rosa x Verde y triple cruza Rosa x (Celeste $x$ Verde), y dos sistemas de alimentación: suministro exclusivo de ración balanceada comercial a voluntad vs. ración a voluntad + alfalfa fresca a voluntad. Se utilizó un diseño factorial $3 \times 2$, que implicó seis tratamientos, cada uno de los cuales contaba con cinco repeticiones (jaulas) con cuatro animales (dos machos y dos hembras). El período experimen- tal se extendió desde una semana después del destete hasta el peso de faena $(2500 \mathrm{~g})$. Se evaluaron la ganancia de peso vivo, el consumo de alimento balanceado, el índice de conversión, la edad a la faena y los atributos de la canal; para la evaluación de parámetros vinculados a calidad de canal, se siguió el protocolo descrito por Blasco y Ouhayoun (1996), ampliado por Pla y Dalle Zotte (2000).

Como era de esperar, hubo diferencias significativas en la ganancia de peso y edad a la faena entre los tipos genéticos que involucraban la línea terminal Rosa y los individuos de la línea Verde pura. Este comportamiento se muestra en la Figura 1.

No hubo diferencias significativas en la ganancia media diaria y edad a la faena entre los dos tratamientos alimenticios; la Figura 2 muestra la evolución del peso vivo de los conejos alimentados exclusivamente con ración y los que recibían alfalfa a voluntad además de la ración también a voluntad.

Se verificaron diferencias significativas en el consumo acumulado de concentrado entre los tratamientos con y sin alfalfa (17469 vs. 21305 gramos por jaula de cuatro individuos, $\mathrm{P}<0,0001)$ y en el valor del Índice de Conversión (2,78 vs. $3,44, \mathrm{P}<0,01)$. El ahorro promedio de ración balanceada por el suministro de alfalfa a voluntad significó un $18 \%$.

No se verificaron diferencias estadísticamente significativas entre los tratamientos alimenticios ni en contenido de grasa disecable de la canal ni en el contenido de grasa intramuscular en el músculo Longissimusdorsi.

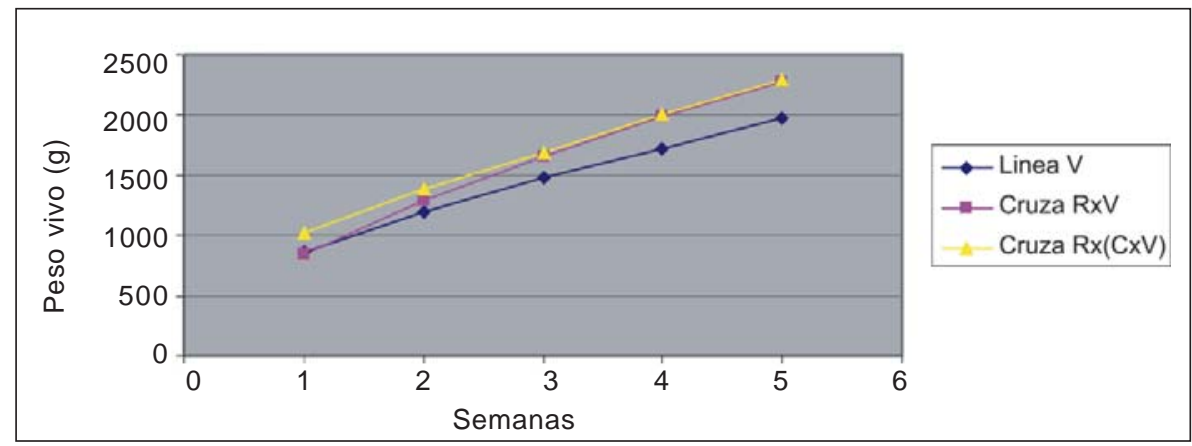

Figura 1. Evolución del peso vivo de los tres tipos genéticos evaluados. 


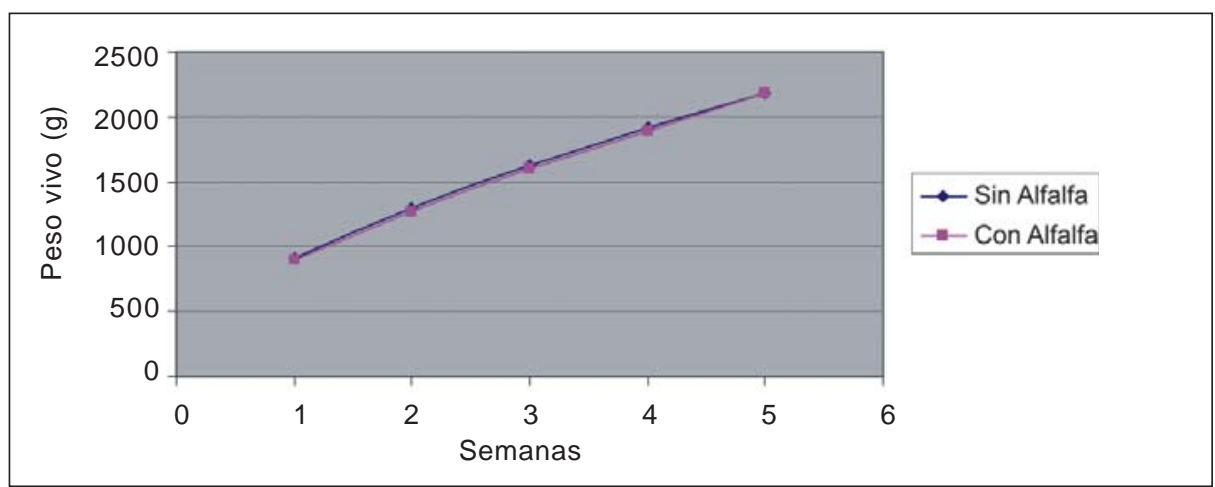

Figura 2. Evolución del peso vivo según tratamiento alimenticio.

Se concluyó que el suministro a voluntad de alfalfa de buena calidad a conejos en crecimiento-terminación determina una importante reducción del consumo voluntario de ración balanceada. Esta sustitución no afecta la velocidad de crecimiento y tampoco determina efectos significativos sobre las características de la canal, en particular sobre la cantidad de grasa de la misma. Se verificó una modificación en la composición de la grasa corporal, tanto la intramuscular como la fácilmente extraíble, compuesta por la grasa perirrenal y dos zonas de deposición lipídica ubicadas en las regiones escapular e inguinal (Figura 3). El efecto de la dieta sobre el perfil lipídico será analizado más en detalle en un capítulo posterior.

\section{Efecto de la alfalfa fresca en la dieta de conejos en crecimiento sobre el comportamiento productivo, las características de la carcasa y la composición de las grasas}

El objetivo de este estudio fue evaluar el efecto del suministro a voluntad de alfalfa fresca a conejos en crecimiento sobre su comportamiento productivo, calidad de canal y composición de las grasas intramuscular y disecable. El trabajo fue presentado en el Congreso de Cunicultura de las Américas realizado en Córdoba (Capra et al., 2010).

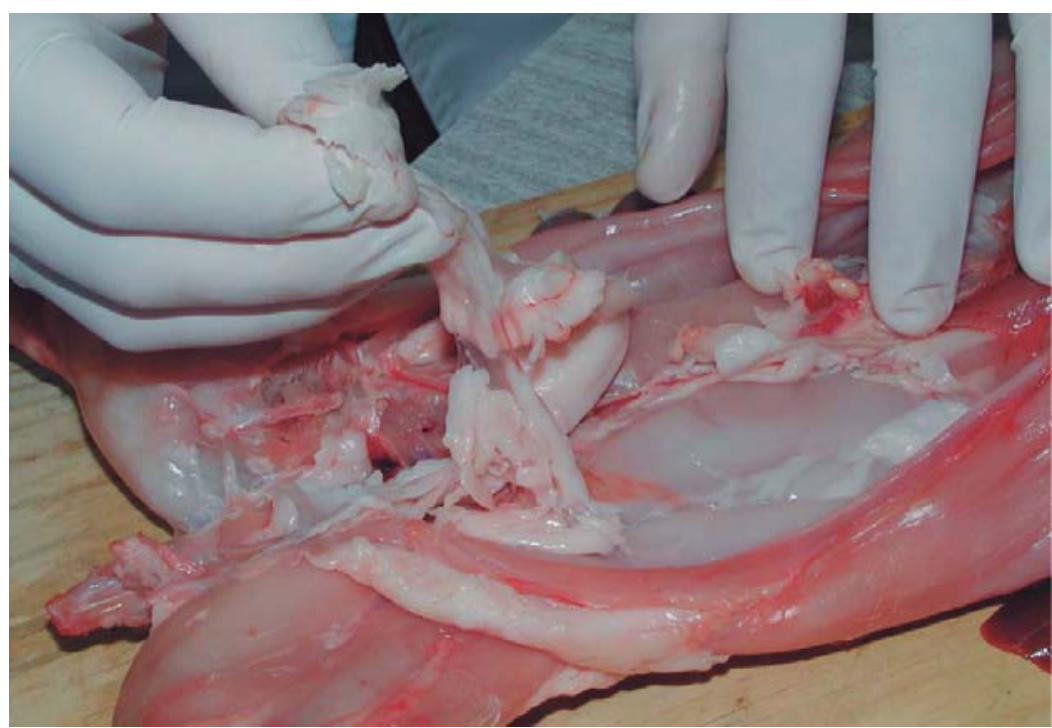

Figura 3. Determinación del contenido de grasa disecable: grasa perirrenal. 
Cuarenta gazapos cruza de las líneas Rosa $\times$ Verde $(R \times V)$ fueron asignados, al momento del destete, a dos tratamientos consistentes en: T1 ración balanceada comercial a voluntad y $T 2$ ración balanceada comercial a voluntad más alfalfa fresca a voluntad.

Cada tratamiento constó de cinco repeticiones (jaulas) con cuatro individuos (dos machos y dos hembras) en cada una de ellas. Se evaluaron parámetros de comportamiento productivo (consumo de ración balanceada, evolución de peso vivo, eficiencia de conversión del alimento) en forma semanal a lo largo del período de crecimiento.

El alimento balanceado comercial utilizado contenía $88,2 \%$ de materia seca, con 20,4 \% de Proteína Cruda, 24 \% Fibra Detergente Ácido, $38 \%$ Fibra Detergente Neutro, $4 \%$ Extracto Etéreo y $7,5 \%$ cenizas, expresados en base seca.

El concentrado se pesaba al momento de incorporarlo al comedero tolva y semanalmente se procedía a pesar el rechazo para obtener por diferencia el consumo semanal por jaula. La alfalfa, procedente de un cultivo de tercer año que al comienzo del ensayo se encontraba en etapa de $10 \%$ de floración, era cortada diariamente y colocada sobre el techo de las jaulas en cantidades que garantizaban que los animales siempre dispusieran del alimento a voluntad (Figura 4). Cada semana se extraían muestras para determinación de Materia Seca, que a lo largo del período de ensayo promedió 19,1\%. Si bien el peso de la alfalfa ofrecida fue registrado diariamente, el consumo real no fue determinado.

Los conejos fueron faenados a medida que llegaban a un peso vivo de $2,5 \mathrm{~kg}$, peso de faena usual en Uruguay, y las canales fueron evaluadas de acuerdo al protocolo descrito por Blasco y Ouhayoun (1996).

El proceso de desosado se realizó a las 24 horas de la faena, tras el enfriado de la canal en cámara a $4{ }^{\circ} \mathrm{C}$. Las muestras de carne (músculo Longissimus lumborum) y grasa disecable destinadas al análisis de perfil lipídico fueron congeladas a $-20^{\circ} \mathrm{C}$ hasta el momento del mismo. La grasa disecable incluyó los depósitos adiposos ubicados a nivel de las regiones perirrenal, escapular e inguinal.

La determinación de la composición de la grasa fue realizada en el Laboratorio de Grasas y Aceites de la Facultad de Química de la Universidad de la República. Para la determinación del porcentaje de grasa intramuscular (GIM) se utilizó el método de Folch, Lees y Sloane (1957) modificado (solventes utilizados: hexano/isopropanol 3:2. La determinación del perfil en ácidos

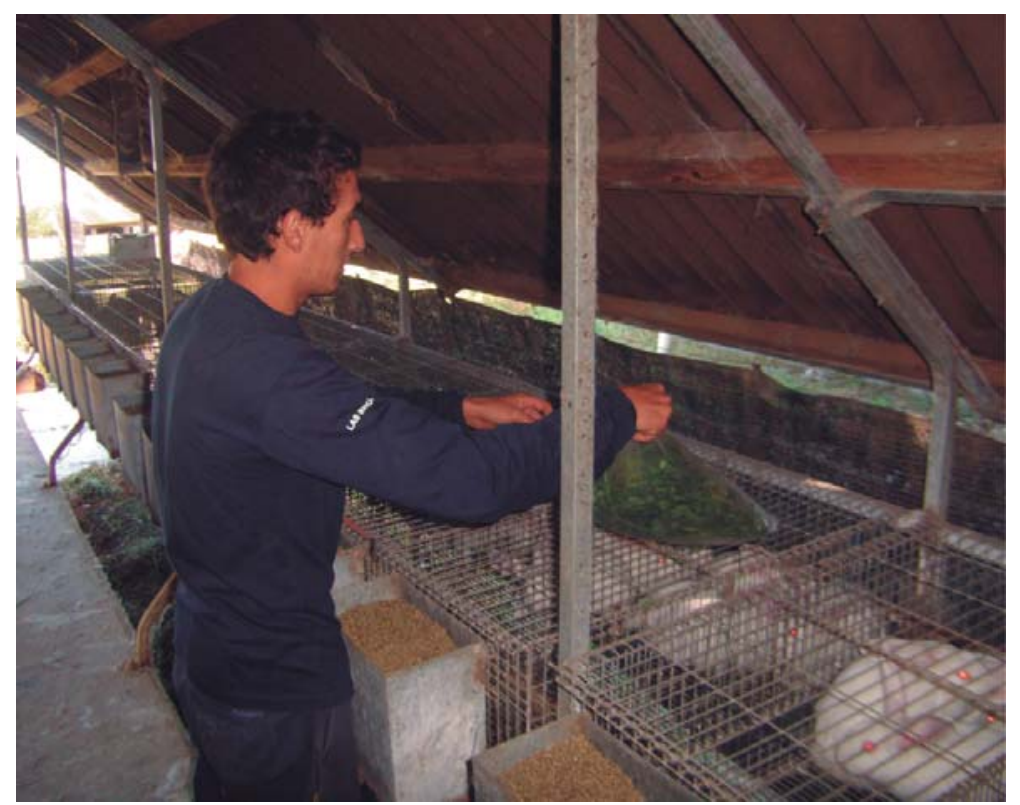

Figura 4. Distribución de alfalfa fresca sobre el techo de las jaulas. 
grasos de la grasa se realizó por cromatografía de gases.

Para el análisis estadístico la unidad experimental fue la jaula de cuatro individuos para el consumo y el índice de conversión, mientras que en el resto de los parámetros evaluados la unidad fue el individuo. Los datos fueron analizados utilizando el procedimiento GLM del SAS (SAS, 2003) con el tratamiento y el sexo incluidos en el modelo como efectos fijos; para parámetros de crecimiento el peso inicial fue incluido como covariable y en parámetros vinculados a las características de la canal se incluyó como covariable a la ganancia media diaria de peso.

En el Cuadro 5 se presentan los resultados relacionados al desempeño productivo en el período de ensayo.
La inclusión de alfalfa a voluntad en la dieta ofrecida a los conejos del tratamiento T2 determinó una reducción significativa en el consumo total de la ración balanceada del orden del 12,6\%. En contrapartida se prolongó la duración del período de engorde en 3,3 días. Estos elementos determinantes de la ecuación económica, junto al costo de la alfalfa y la mano de obra necesaria para el corte y suministro de la misma, deberían ser considerados por el productor para optar por una u otra estrategia de alimentación.

La Figura 5 presenta la evolución semanal del consumo de alimento balanceado en ambos tratamientos.

En este trabajo se pesó diariamente la cantidad de alfalfa ofrecida, pero no se determinó el consumo real. El rechazo era cualitativamente diferente en cuanto los cone-

Cuadro 5. Efecto del tratamiento sobre parámetros de crecimiento.

\begin{tabular}{|l|r|r|c|}
\hline \multicolumn{1}{|c|}{ Variable } & Sin Alfalfa & Con Alfalfa & \\
\hline Peso inicial (g) & $784 \pm 133$ & $813 \pm 135$ & N.S. \\
\hline Peso faena (g) & $2573 \pm 64$ & $2569 \pm 57$ & N.S. \\
\hline $\begin{array}{l}\text { Consumo total ración balanceada } \\
\text { (g/jaula) }\end{array}$ & $24876 \pm 1034$ & $21739 \pm 1281$ & $\mathrm{P}=0,0028$ \\
\hline $\begin{array}{l}\text { Índice de Conversión de la ración } \\
\text { balanceada }\end{array}$ & $3,50 \pm 0,11$ & $3,13 \pm 0,11$ & $\mathrm{P}=0,03$ \\
\hline Edad a la faena (días) & $75,4 \pm 0,9$ & $78,7 \pm 1,0$ & $\mathrm{P}=0,0209$ \\
\hline Ganancia media diaria (g/día) & $42,5 \pm 0,8$ & $40,2 \pm 0,8$ & N.S. \\
\hline
\end{tabular}

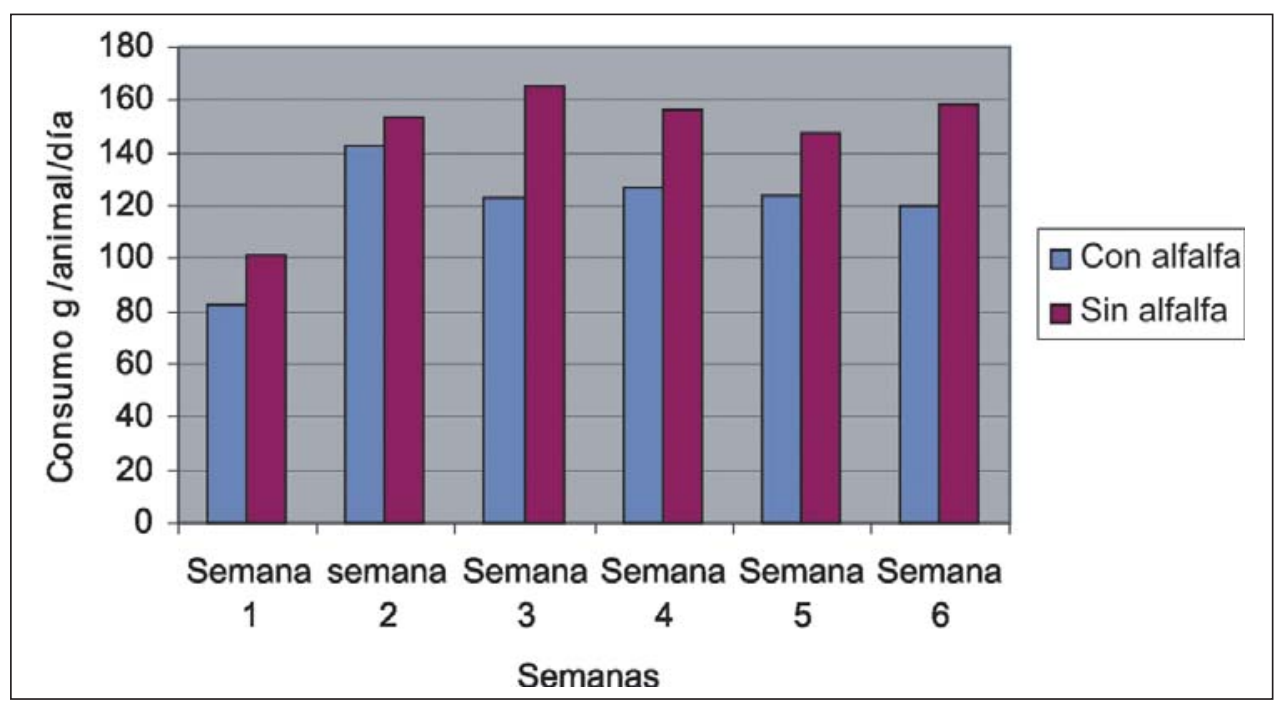

Figura 5. Evolución semanal de consumo de alimento balanceado (gramos/animal/día). 
jos realizaban un consumo selectivo de las hojas y tallos tiernos y no consumían los tallos más gruesos y fibrosos. La oferta de alfalfa a lo largo de todo el período de crecimiento promedió $39,4 \mathrm{k} / \mathrm{j}$ aula de forraje fres$\mathrm{co}$, lo que significa una oferta total de aproximadamente 1,9 k de Materia Seca por conejo.

En la Figura 6 se presenta el Índice de Conversión del alimento balanceado en cada una de las semanas del ensayo para los dos tratamientos.

El Cuadro 6 resume algunos de los parámetros evaluados en relación a las características de la canal.

Los conejos alimentados exclusivamente con ración balanceada presentaron un ren- dimiento significativamente mayor de la carcasa de referencia expresado como porcentaje del peso vivo a la faena. La diferencia de rendimiento puede atribuirse en parte al mayor peso del tracto gastrointestinal Ileno (FGTW) de los animales que recibían la dieta con alfalfa.

Asimismo, se determinaron diferencias significativas a favor del tratamiento sin alfalfa en el peso total de carne en la canal (MW), el rendimiento en carne expresado en porcentaje de la carcasa de referencia (\%MW/RCW) y en la relación carne:hueso $(\mathrm{M} / \mathrm{B})$. No se verificaron diferencias estadísticamente significativas en el contenido de grasa disecable (DFaW) de la canal ni en su

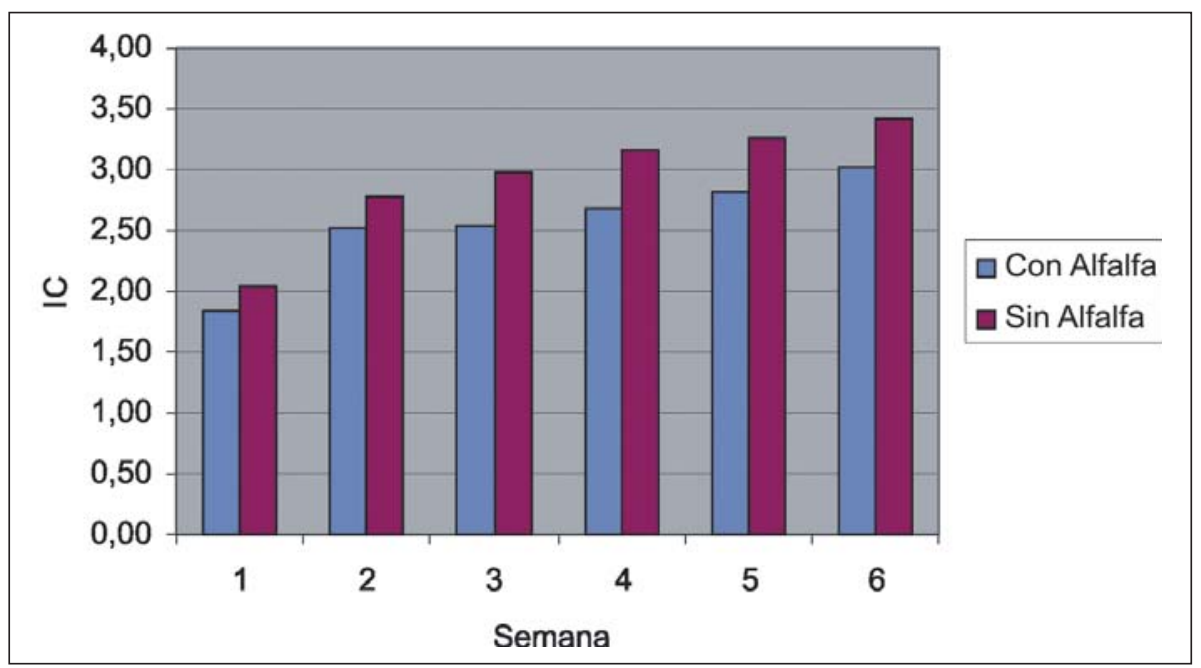

Figura 6. Evolución semanal del Îndice de Conversión acumulado.

Cuadro 6. Efecto de los tratamientos sobre características de la canal.

\begin{tabular}{|l|c|c|c|}
\hline Variable & Sin Alfalfa & Con Alfalfa & \\
\hline$\%$ RCW/LVW & $49,89+0,29$ & $48,65+0,29$ & $\mathrm{P}=0,0041$ \\
\hline FGTW (g) & $450+7$ & $483+7$ & $\mathrm{P}=0,0027$ \\
\hline DFaW (g) & $35+9$ & $31+10$ & N.S. \\
\hline \% DFaW/RCW & $2,72+0,67$ & $2,50+0,77$ & N.S. \\
\hline MW (g) & $965+9$ & $918+9$ & $\mathrm{P}=0,0008$ \\
\hline \%MW/RCW & $75,3+1,8$ & $73,4+2,0$ & $\mathrm{P}=0,0025$ \\
\hline M/B & $3,57+0,07$ & $3,32+0,07$ & $\mathrm{P}=0,0263$ \\
\hline
\end{tabular}

\%RCW/LW- Rendimiento en peso de la Carcasa de Referencia expresado como porcentaje del peso vivo a la faena, FGTW: peso del tracto gastrointestinal Ileno, DFaW: Peso de la Grasa Disecable, \%DFaW/RCW: Porcentaje de la grasa disecable sobre peso de la carcasa de referencia, MW: Peso total de Carne, \%MW/ RCW Rendimiento en carne expresado en porcentaje del peso de la carcasa de referencia. M/B: relación entre el peso total de carne de la canal sobre el peso total de hueso. 
expresión relativa como porcentaje de la carcasa de referencia (\%DFaW/RCW).

Se constató un efecto significativo del sexo sobre el peso del tracto gastrointestinal (481 $\pm 8 \mathrm{~g}$ para las hembras y $451 \pm 6 \mathrm{~g}$ para los machos, $\mathrm{P}=0,0098$ ).

El análisis del contenido de grasa intramuscular del músculo Longissimus dorsi determinó valores medios de 2,51 + 0,55\% para el tratamiento sin alfalfa y $2,32+0,40 \%$ para el que recibió alfalfa, diferencias que no resultaron estadísticamente significativas.

Al igual que en el ensayo descrito previamente, se constató que la inclusión de alfalfa determinaba una modificación significativa en la composición de las grasas intramuscular y disecable.

\section{Calidad de carne de conejos producidos con dos estrategias de alimentación: con y sin alfalfa fresca a voluntad}

El objetivo de este estudio fue ampliar la información sobre el valor nutricional de la carne de conejo producida con dos estrategias de alimentación que coexisten en las condiciones de producción de Uruguay. La estrategia desarrollada en este trabajo es análoga a la descrita en el ensayo anterior, pero se incorporaron determinaciones relativas al aporte de nutrientes de la carne de conejo (minerales, vitaminas y purinas) que podrían resultar modificadas como resultado de la composición de la dieta de los ani- males en crecimiento-terminación (Capra et al., 2013).

Se utilizaron en este caso noventa y seis gazapos de la línea Verde (V), que fueron asignados, una semana después del destete, a dos tratamientos consistentes en: (T1) ración balanceada comercial a voluntad y (T2) ración balanceada comercial a voluntad más alfalfa fresca a voluntad. Cada tratamiento constó de doce jaulas con cuatro individuos en cada una de ella (dos machos y dos hembras) (Figura 7).

El alimento balanceado comercial utilizado contenía $86,8 \%$ de materia seca, con $21,3 \%$ de PC, $27 \%$ FDA, 38\% FDN, 3,6\% EE, $1,9 \%$ de calcio y $1,1 \%$ de fósforo, expresados en base seca.

Se registraba el peso del alimento balanceado suministrado en los días sucesivos y una vez por semana se procedía a pesar el rechazo para obtener por diferencia el consumo semanal por jaula.

La alfalfa, procedente de un cultivo de primer año, que al comienzo del ensayo se encontraba en etapa de inicio de floración, era cortada diariamente y colocada sobre el techo de las jaulas en cantidades que garantizaban que los animales siempre dispusieran del alimento a voluntad. Cada semana se extraían muestras para determinación de Materia Seca, que a lo largo del período de ensayo promedió $20,1 \%$. Si bien el peso de la alfalfa ofrecida fue registrado diariamente, el consumo real no fue determinado.

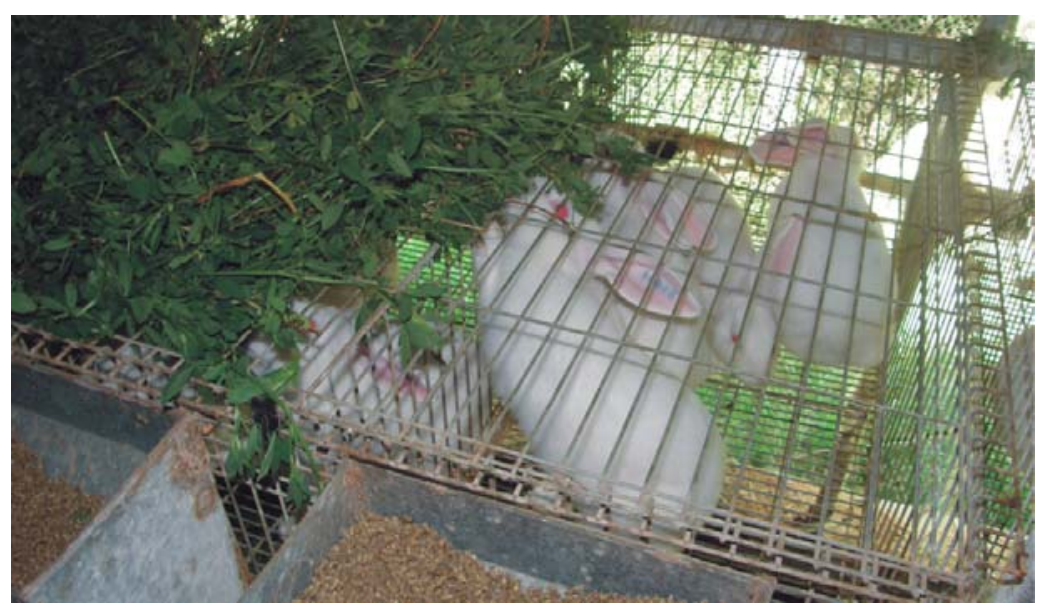

Figura 7. Suministro de alfalfa fresca a voluntad sobre el techo de la jaula. 
Se evaluaron parámetros de comportamiento productivo (consumo de ración balanceada, evolución de peso vivo, eficiencia de conversión del alimento) y los conejos fueron faenados cuando llegaban a un peso vivo de $2500 \mathrm{~g}$. Las canales se evaluaron de acuerdo al protocolo descrito por Blasco y Ouhayoun (1996). Se incorporó la determinación del peso de lo que denominamos Carcasa Uruguaya (UCW), correspondiente a la canal sin cabeza, con hígado y riñones, que es la forma habitual de comercializar el conejo en Uruguay (Figura 8). También se calculó su rendimiento expresado en porcentaje del peso vivo a la faena (\%RUCW/LVW).

El proceso de desosado se llevó a cabo a las 24 horas de la faena, tras el enfriado de la canal en cámara a $4{ }^{\circ} \mathrm{C}$. Se determinó el $\mathrm{pH}$ a las 24 horas en el músculo $L$. dorsi entre la $4^{\mathrm{a}}$ y la $5^{\mathrm{a}}$ vértebra lumbar, utilizando un $\mathrm{pH}$-metro con compensación automática de temperatura.

Se tomaron muestras de músculo y de grasa disecable para determinaciones de contenido de grasa intramuscular (GIM) en el L.dorsi, perfil lipídico de la grasa disecable e intramuscular, aporte de vitamina $\mathrm{E}$, minerales (cinc, hierro, magnesio y sodio) y contenido de purinas. Los resultados relacionados al valor nutricional de la carne serán analizados en otro capítulo.

Para el análisis estadístico del consumo y el índice de conversión, la unidad experimental fue la jaula de cuatro individuos, mientras que en el resto de los parámetros evaluados la unidad fue el individuo. Los datos fueron analizados utilizando el procedimiento GLM del SAS (SAS, 2003) con el tratamiento y el sexo incluidos en el modelo como efectos fijos; para parámetros de crecimiento el peso inicial fue incluido como covariable y en parámetros vinculados a las características de la canal se incluyó como covariable a la ganancia media diaria de peso.

El Cuadro 7 resume los valores medios obtenidos en los parámetros de crecimiento evaluados.

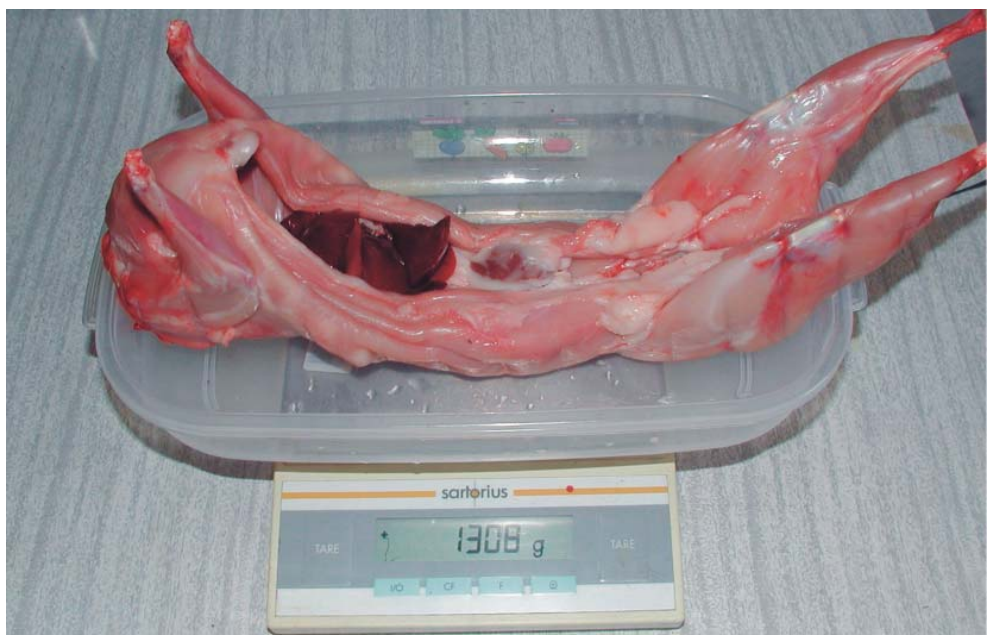

Figura 8. Canal de conejo tal cual se comercializa en Uruguay, sin cabeza, con riñones e hígado.

Cuadro 7. Efecto del tratamiento sobre parámetros de crecimiento (media \pm D.E.).

\begin{tabular}{|l|c|c|c|}
\hline \multicolumn{1}{|c|}{ Variable } & T1 Sin Alfalfa & T2 Con Alfalfa & \\
\hline Peso inicial (g) & $976 \pm 120$ & $952 \pm 93$ & N.S. \\
\hline Peso faena (g) & $2509 \pm 77$ & $2511 \pm 64$ & N.S. \\
\hline Consumo total balanceado (g/jaula) & $23536 \pm 1210$ & $20930 \pm 1960$ & $\mathrm{P}<0,0001$ \\
\hline Índice de Conversión del balanceado & $3,82 \pm 0,32$ & $3,41 \pm 0,24$ & $\mathrm{P}=0,0016$ \\
\hline Edad a la faena (días) & $88,7 \pm 7,1$ & $90,7 \pm 5,9$ & N.S. \\
\hline Ganancia media diaria (g/día) & $34,7 \pm 5,6$ & $32,9 \pm 4,2$ & N.S. \\
\hline
\end{tabular}


La inclusión de alfalfa a voluntad en la dieta ofrecida a los conejos del tratamiento T2 determinó una reducción significativa en el consumo total de balanceado del orden del $11 \%$, sin que se produjera un efecto negativo sobre la velocidad de crecimiento y la edad a la faena. Los resultados son análogos a los obtenidos en el ensayo anteriormente descrito (Capra et al., 2010), con conejos cruza de las líneas Rosa y Verde (RxV), en los que se obtuvo una reducción media del orden del $12,6 \%$ en el consumo de alimento balanceado.

En aquella oportunidad las diferencias entre tratamientos en edad a la faena fueron significativas ( 75,4 vs 78,7 días, para los tratamientos sin alfalfa y con alfalfa respectivamente, $P=0,0209$ ), hecho que no se constató en este caso, presumiblemente como resultado de las diferencias en el tipo genético utilizado. La variabilidad constatada en la edad a la faena en este ensayo es mucho mayor, hecho que podría derivar de que la línea Verde no ha sido objeto de selección por velocidad de crecimiento como sí lo ha sido la línea Rosa.

La Figura 9 presenta la evolución semanal del Índice de Conversión durante el período de ensayo.

El Cuadro 8 resume los resultados obtenidos en la evaluación de las características de la canal.
No se determinaron diferencias estadísticamente significativas para ninguno de los parámetros de calidad de canal evaluados. Estos resultados contrastan con los resultados obtenidos con conejos cruza simple $\mathrm{RxV}$ sometidos a idénticos regímenes alimenticios, en los que se verificaron diferencias significativas a favor de los conejos alimentados exclusivamente con alimento balanceado comercial en rendimiento de la carcasa de referencia, rendimiento porcentual en carne sobre el peso de la carcasa de referencia y relación carne/hueso (Capra et al., 2010).

Los valores obtenidos en contenido de grasa disecable, tanto en términos absolutos como en su expresión relativa al peso de la carcasa de referencia, son muy similares a los logrados en el citado experimento. El contenido de grasa disecable registrado en este ensayo se ubica por debajo de los obtenidos por Pla et al. (1998) para individuos de la línea Verde faenados a pesos inferiores a lo que es habitual en Uruguay. Por el contrario, la relación M/B del cuarto trasero obtenida en este trabajo se ubica por encima de los valores registrados por los mencionados autores (Figura 10).

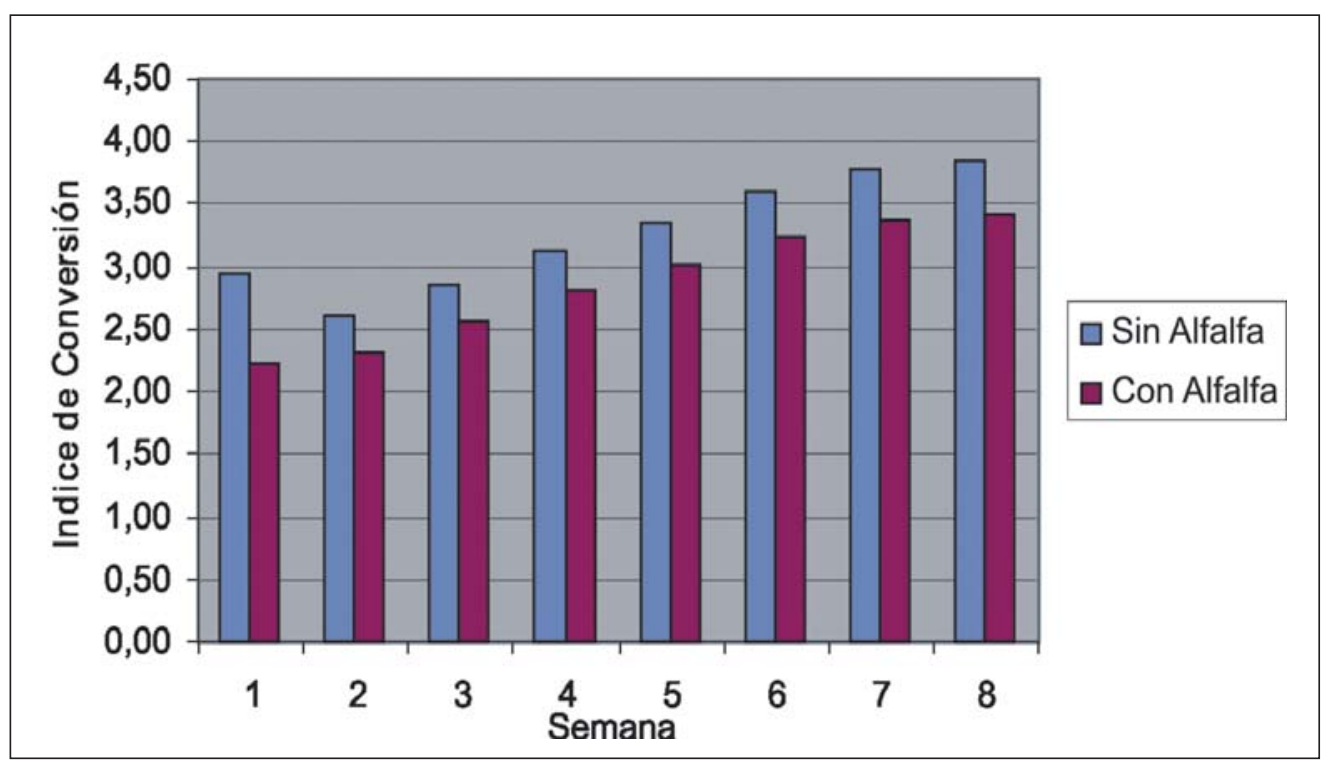

Figura 9. Evolución semanal del Índice de Conversión acumulado de la ración balanceada. 
Cuadro 8. Efecto del tratamiento sobre características de la canal.

\begin{tabular}{|l|c|c|c|}
\hline Variable & Sin Alfalfa & Con Alfalfa & P \\
\hline $\mathrm{pH} 24 \mathrm{~h}$ & $5,57 \pm 0,11$ & $5,59 \pm 0,11$ & N.S. \\
\hline UCW (g) & $1369 \pm 56$ & $1366 \pm 53$ & N.S. \\
\hline$\% R$ UCW/LVW & $54,6 \pm 1,0$ & $54,4 \pm 1,9$ & N.S. \\
\hline RCW (g) & $1265 \pm 52$ & $1264 \pm 54$ & N.S. \\
\hline$\%$ R RCW/LVW & $50,6 \pm 1,4$ & $50,3 \pm 2,1$ & N.S. \\
\hline DFaW (g) & $32,3 \pm 8,1$ & $29,2 \pm 7,1$ & N.S. \\
\hline$\%$ DFaW/RCW & $2,49 \pm 0,68$ & $2,40 \pm 0,57$ & N.S. \\
\hline MW (g) & $968 \pm 54$ & $945 \pm 53$ & N.S. \\
\hline$\% M W / R C W$ & $75,9 \pm 0,9$ & $76,0 \pm 0,9$ & N.S. \\
\hline BW (g) & $264 \pm 9$ & $259 \pm 11$ & N.S. \\
\hline$\%$ BW/RCW & $20,7 \pm 1,0$ & $20,8 \pm 0,8$ & N.S. \\
\hline M/B & $3,63 \pm 0,34$ & $3 ., 65 \pm 0,16$ & N.S. \\
\hline M/B HL & $4,93 \pm 0,43$ & $5,08 \pm 0,35$ & N.S. \\
\hline
\end{tabular}

UCW. Peso de la Carcasa Uruguaya, \%R UCW/LVW: Rendimiento de la Carcasa Uruguaya expresado como porcentaje del peso vivo a la faena; RCW Peso de la Carcasa de Referencia; \%R RCW/LW: Rendimiento en peso de la Carcasa de Referencia expresado como porcentaje del peso vivo a la faena, DFaW: Peso de la Grasa Disecable, \%DFaW/RCW: Porcentaje de la grasa disecable sobre peso de la Carcasa de Referencia, MW: Peso total de Carne, \%MW/RCW Rendimiento en carne expresado en porcentaje del peso de la Carcasa de Referencia. BW: Peso total de Hueso. \%BW/RCW Porcentaje de hueso sobre el peso de la Carcasa de Referencia. M/B: relación entre el peso total de carne sobre el peso total de hueso en la carcasa. M/B HL: relación entre peso de la carne y peso de hueso en la pata trasera.

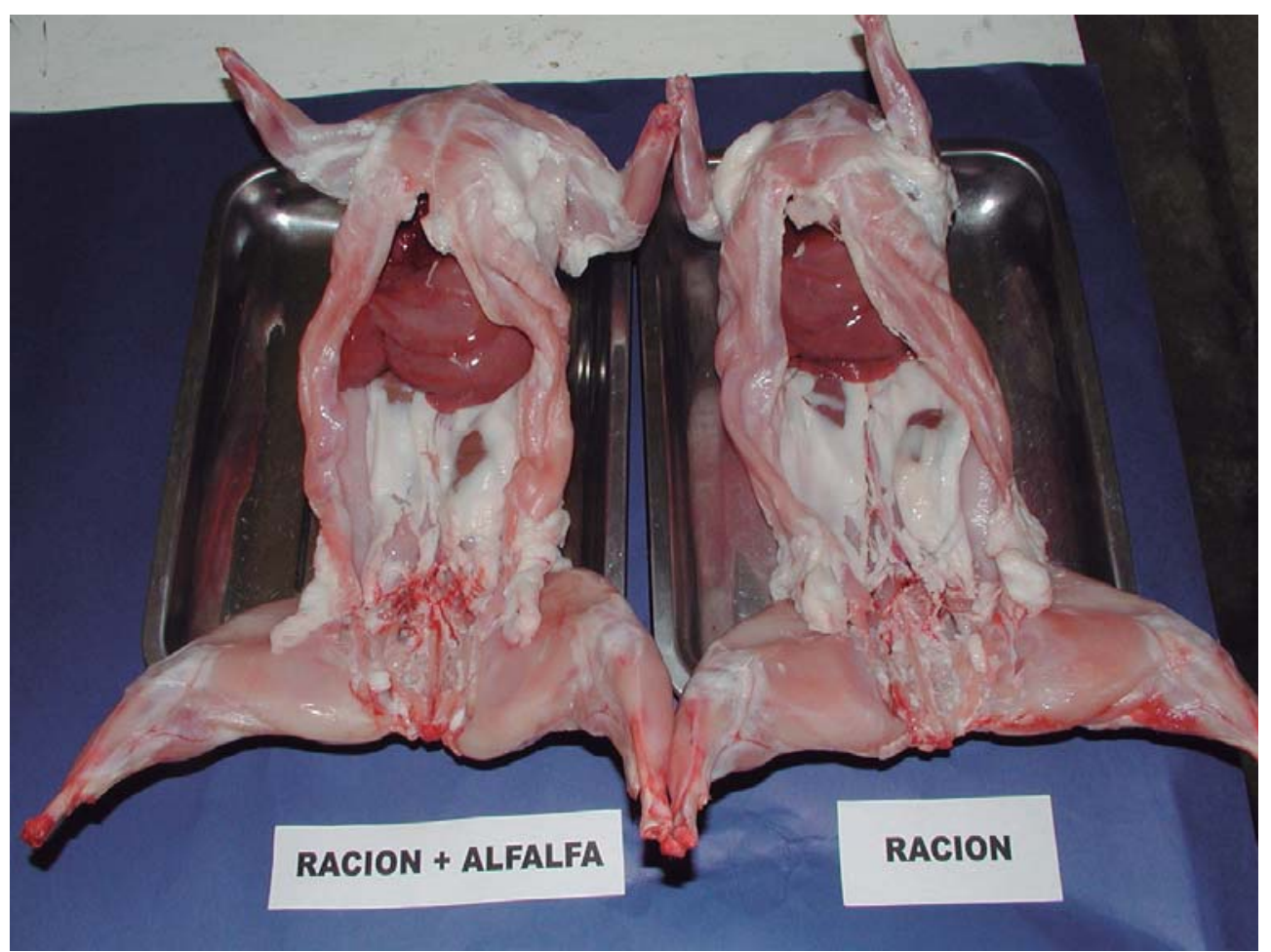

Figura 10. Canales de los conejos sometidos a los dos tratamientos alimenticios descritos. 
El contenido de grasa intramuscular (GIM) en el Longissimus dorsi fue de 1,41 \pm 0,34 vs. $1,39 \pm 0,33 \mathrm{~g} / 100 \mathrm{~g}$ para los tratamientos $\sin y$ con alfalfa respectivamente.

\section{Efecto del régimen de alimentación: suministro de ración a voluntad o en forma restringida}

Entre los cunicultores uruguayos siempre ha habido controversias acerca de la ventaja relativa de ofrecer el alimento a voluntad o en forma restringida a los gazapos en crecimiento-engorde.

Es necesario conceder que hay elementos que justifican posiciones encontradas: a) la información experimental disponible en la bibliografía muestra resultados contradictorios, b) numerosos factores en interacción condicionan los resultados y c) el mejor resultado desde el punto de vista biológico no necesariamente se corresponde con el óptimo económico (Capra et al., 1998a).

Muchos de los trabajos de investigación analizan el efecto de una restricción alimenticia de corta duración aplicada inmediatamente después del destete con el fin de reducir la incidencia de enteropatías. De acuerdo con Oliveira et al. (2012) este tipo de restricción alimenticia puede tener diferente duración (una a tres semanas) y distinta magnitud, lo que condiciona los resultados; sin embargo se ha constatado que la reducción provocada por la restricción en esta etapa se compensa rápidamente al retornar a un régimen alimenticio a voluntad. Gidenne et al. (2009) verificaron una menor mortalidad y morbilidad vinculada a desórdenes digestivos con diferentes niveles de restricción, con muy ligeros efectos sobre la ganancia de peso y los atributos de la canal, pero con una mejora en la eficiencia de conversión del alimento con respecto a los animales alimentados a voluntad.

Con referencia al efecto de una alimentación restringida a lo largo de todo el período de crecimiento, la mayoría de los autores coincide en que una restricción en la cantidad de alimento ofrecida a gazapos en crecimiento tiene por resultado una reducción en la velocidad de crecimiento, por lo que se requiere más tiempo para llegar a un mismo peso de faena (Fekete y Gippert, 1981; Castelló y Gurri, 1992; Lebas, 1997).

Tudela y Lebas (2006) afirman que la restricción alimentaria reduce la velocidad de crecimiento en el orden del 8 a $17 \%$ con un nivel de restricción del $80 \%$ del consumo voluntario, pero mejora significativamente la eficiencia alimenticia. Asimismo, sostienen que con 80-85 \% de restricción no hay efecto sobre la homogeneidad de peso en los animales contenido en cada jaula. Por el contrario, una restricción más severa, del $60 \%$ implica un aumento del $22 \%$ en el desvío estándar del peso vivo final, criterio asumido para evaluar la homogeneidad.

Di Meo et al. (2007) evaluaron el efecto de la alimentación a voluntad y de una restricción del $90 \%$ en conejos en crecimiento entre 35 y 84 días de edad y verificaron que con esta moderada restricción no hubo diferencias en ganancia media diaria (40,0 vs. $39,5 \mathrm{~g} / \mathrm{d}$ para los animales alimentados a voluntad y en forma restringida respectivamente) ni en el peso a la faena 2755 vs 2732 g), pero que el consumo de alimento fue un $11 \%$ menor y que el índice de conversión fue mejor en los animales restringidos en comparación con los alimentados a voluntad (3,40 vs. 3,88 respectivamente, $\mathrm{P}<0,05)$. Los conejos restringidos presentaron una digestibilidad aparente significativamente mayor para Fibra Cruda, NDF y ADF, confirmando una mayor permanencia del alimento en el tracto digestivo.

Por su parte Bergaoui et al. (2008), evaluando el período comprendido entre los 35 y 77 días de edad con restricciones del orden de 85 y $70, \%$, verificaron que los animales alimentados a voluntad presentaron mayor peso corporal a lo largo de todo el período experimental, pero que a las 11 semanas de edad no había diferencias significativas en la ganancia media diaria de peso, en el consumo medio diario de alimento ni en el índice de conversión entre los dos grupos sometidos a restricción y los conejos alimentados a voluntad.

Gidenne et al. (2012b) al comparar el desempeño productivo de conejos alimentados 
a voluntad con el de conejos sometidos a una reducción del consumo del orden del $25 \%$ por un período de cuatro semanas después del destete seguido de alimentación a voluntad por una semana, constataron que los conejos sometidos a restricción presentaron una reducción del $14 \%$ en la ganancia de peso, pero que se mejoró el índice de conversión del período total de engorde en 0,3 unidades.

De acuerdo con Lebas (1997), en lo que respecta al efecto de la restricción sobre la eficiencia de conversión del alimento, la intensidad de la misma es clave en los resultados; una restricción ligera (del orden del 80 a $90 \%$ de la cantidad que consumirían a voluntad) podría determinar una mejora del índice de conversión obtenido en el período de engorde, aunque el tiempo necesario para llegar al peso de faena fuera un poco mayor. De acuerdo con este autor, el problema del suministro restringido radica en la dificultad de implementación práctica, ya que en caso de someter a los gazapos en crecimiento a una restricción más severa, el resultado sería el contrario al esperado, afectando negativamente la eficiencia de conversión del alimento fundamentalmente por la prolongación excesiva del período necesario para alcanzar el peso de faena.

Aunque la restricción alimenticia conduce a una menor velocidad de crecimiento, en contrapartida puede lograrse una mejor eficiencia de conversión del alimento, en particular cuando luego de la restricción se permite a los conejos alimentarse a voluntad, circunstancia en la que se produce un crecimiento compensatorio (Gidenne et al., 2012a).

En países de cunicultura avanzada, donde disponen de equipamiento adecuado, la regulación del consumo puede ser implementada a través del tiempo de acceso al comedero, mecanismo particularmente apropiado para ejecutar en sistemas automáticos de distribución del alimento. Una restricción razonable en el tiempo de acceso al comedero determina una reducción en el consumo de alimento, una disminución de la ganancia media diaria y una mejora en la conversión (Szendro et al., 1989; Tudela y Lebas 2006). Lebas (1997) afirma que el índice de conversión mejora cuando el acceso al comedero se restringe a 9-16 horas por día, en comparación con una alimentación a voluntad; recomienda que la mejor opción es una restricción a 12 horas diarias, preferentemente habilitando el acceso al alimento durante la noche. Esta variante de restricción del consumo por tiempo de acceso al comedero parece más difícil de implementar en las condiciones prevalecientes en los criaderos uruguayos donde predomina el suministro manual en comederos tipo tolva o en bateas. Para nuestras condiciones hemos aportado evidencias de que puede lograrse un efecto análogo al de la restricción alimenticia manejando el número de conejos por jaula, aspecto que desarrollaremos en detalle más adelante.

Existe menos acuerdo con respecto al efecto sobre la calidad de la canal; algunos autores señalan que la restricción provoca una disminución del rendimiento a la faena (Gidenne, 2012a), mientras que otros no constataron efectos sobre la composición de la canal o la calidad de la carne (Osman, 1991; Osman y Tawfit, 1994).

Tümová et al. (2006) evaluaron diferentes estrategias de restricción alimenticia sobre gazapos en crecimiento y concluyeron que la restricción no afectó el rendimiento a la faena pero determinó una reducción en el peso del lomo. La deposición de grasa perirrenal fue detectada en conejos sometidos a restricción a una edad media de 63 días, mientras que en conejos alimentados a voluntad lo fue a los 56 días.

Chodová y Tümová (2013), en una exhaustiva revisión del efecto de restricciones alimenticias de diferente duración e intensidad, concluyeron que la restricción alimenticia afecta el crecimiento y, por tanto, algunos parámetros relevantes de la calidad de canal y de la carne pueden ser afectados concomitantemente. Según estos autores, una fuerte restricción reduce el crecimiento $y$ tiene un efecto negativo sobre el rendimiento a la faena, la proporción de lomo en el total de la canal y en la relación carne:hueso, pero tiene un efecto favorable al reducir el contenido graso de la canal. Una restricción moderada no afecta la composición de la canal, aunque se han descrito un mayor con- 
tenido de agua y menor contenido de lípidos en conejos sometidos a restricción. Asimismo, la restricción alimenticia incrementa la proporción de fibras oxidativas en el músculo y conduce a un mayor valor de $\mathrm{pH}$ último; no se han verificado efectos de la restricción sobre el color de la carne.

Gondret et al. (2000) evaluaron el efecto de una restricción alimenticia en la fase de engorde a partir de las 11 semanas de vida y constataron que la restricción no tuvo efecto sobre el porcentaje medio de diferentes tipos de fibra muscular en los músculos Longissimus lumborum, Biceps femoris y Semimembranosus. La restricción alimenticia determinó una reducción estadísticamente significativa en el contenido total de lípidos y en la actividad enzimática de la enzima málica y de la glucosa- 6 fosfato dehidrogenasa en los tres músculos. La modificación en la concentración de lípidos y actividad enzimática fueron mayores en un músculo oxidativo como el Semimembranosus que en los músculos predominantemente oxidativos, como el Longissimus lumborum o el Bíceps femoris. Estos datos indican que el status nutricional regula la deposición de grasa intramuscular, sin ejercer efecto sobre el tipo de fibra muscular.

Por su parte Dalle Zotte et al. (2004) aplicaron diferentes estrategias de alimentación para evaluar el efecto de una restricción postdestete o durante el período de engorde sobre las características de la fibra del músculo Biceps femoris. Los resultados demostraron que la naturaleza de la restricción alimenticia (70-90 \% vs 90-70 \%) afecta el peso de manera diferencial, obteniéndose un mejor desempeño productivo en el caso de una restricción más severa en la primera etapa post-destete y una alimentación liberal en la fase de engorde. El esquema de racionamiento $70-90 \%$ redujo la proporción de fibras oxidativas a nivel del músculo en estudio.

Desde el punto de vista del comportamiento, la restricción alimenticia no parece generar conductas agresivas de los conejos hacia sus congéneres. En relación al bienestar animal, si bien podría decirse que los conejos sometidos a restricción no disponen de la libertad de saciar su apetito, en contrapartida se valora la mejora en aspectos sanitarios vinculados a desórdenes gastrointestinales, existiendo evidencias de la reducción en la morbilidad y mortalidad en conejos alimentados en forma restringida, en particular durante el período inmediato al destete (Gidenne et al., 2012 a).

Considerando los aportes de la bibliografía, los factores diferenciales a considerar para optar por una u otra estrategia de alimentación pueden resumirse de la siguiente manera:

- Ventajas de la alimentación a voluntad: aprovecha la capacidad de autorregulación del consumo por parte del propio animal, determina una máxima velocidad de crecimiento, lotes más parejos por disminución del efecto de la competencia entre animales, menor requerimiento de mano de obra.

- Ventajas de la alimentación restringida: mejor eficiencia de conversión del alimento, canales con menor contenido graso, menos desperdicio de ración, menor incidencia de desórdenes gastrointestinales.

Con respecto a la disponibilidad de información relacionada al efecto de la restricción de concentrado y el uso simultáneo de forraje a voluntad, la bibliografía internacional aporta mucha información, en particular procedente de países en vías de desarrollo, donde se procura desarrollar una cunicultura de autoconsumo, basada en la maximización del uso de recursos alimenticios producidos en el predio.

Adeyemi y Akanji (2012) describen el efecto de diferentes técnicas de restricción del suministro de concentrados (a voluntad, día por medio o cada tres días) con una estrategia combinada de ofrecimiento de ración y forraje a voluntad; concluyen que la ganancia de peso, el peso corporal final, el consumo total de alimento y la relación consumo de alimento/aumento de peso no mostraron diferencias significativas entre tratamientos. Aunque el consumo de alimento no fue diferente entre los tres tratamientos, el consumo de concentrado, el consumo de forraje, así como el porcentaje de concentrado y forraje en el consumo diario de alimento fueron significativamente influenciados por los 
tratamientos $(P<0,05 \%)$. Tampoco constataron diferencias significativas en rendimiento de la canal y de los diferentes cortes comerciales, ni en el peso de los órganos internos (hígado, riñones, pulmones y corazón). Los autores sugieren la conveniencia de un sistema de alimentación basado en forraje a voluntad y suministro de concentrado cada tercer día.

El trabajo descrito es ilustrativo de las diferentes recomendaciones que pueden surgir en función de las condiciones de producción y de los objetivos productivos en cada país o región. Para las circunstancias de la cunicultura uruguaya, a pesar de sus restricciones e ineficiencias, resulta impensable concebir una producción cunícola basada en estrategias tecnológicas que determinen ganancias de poco más de 12 g/día y conversiones del orden de 6 a 1 como reportan estos autores.

A continuación presentamos algunos resultados de experimentación realizada en la Unidad Experimental de Cunicultura de INIA Las Brujas, que aportan elementos adicionales para la formulación de recomendaciones técnicas.

\section{Efecto del régimen de alimentación: suministro de ración a voluntad o en forma restringida a gazapos en engorde}

Con el fin de evaluar el efecto del régimen de alimentación sobre el desempeño productivo de gazapos en engorde, se llevó a cabo un ensayo en la UEC de INIA Las Brujas en el que se planteó la comparación entre el suministro de ración comercial a voluntad y dos niveles de restricción alimen- ticia (90 y $80 \%$ con respecto al consumo voluntario determinado en ensayos anteriores). Se incluyó además un cuarto tratamiento que consistió en la suplementación con heno de alfalfa a un grupo de gazapos sometidos al nivel más severo de restricción (Capra et al., 1998b). Se utilizaron 80 gazapos cruza Californiano x Neozelandés, con 51 días de edad y un peso vivo promedio inicial de 1415 $\mathrm{g}$, que se distribuyeron al azar en grupos de cinco animales por jaula, asignándose cuatro jaulas a cada uno de los siguientes tratamientos:

\section{T1: Alimentación a voluntad}

T2: Restricción a un nivel teórico del $90 \%$ del consumo voluntario

T3: Restricción a un nivel teórico del $80 \%$ del consumo voluntario

T4: Restricción al 80\% más heno de alfalfa a voluntad

El período de ensayo se extendió entre el 10 de julio y el 14 de agosto de 1997. En el tratamiento con suministro de ración a voluntad se llenaba la tolva una vez por semana, registrándose la cantidad de alimento ofrecido y rechazado, para obtener por diferencia el consumo. En los tratamientos con suministro restringido de ración se estableció una escala con la cantidad de alimento a ofrecer diariamente, en base a un promedio de los consumos históricos registrados en la UEC con suministro a voluntad. De este modo, el ofrecimiento diario de ración balanceada comercial se ajustó a la escala presentada en el Cuadro 9.

La inclusión de un tratamiento basado en la suplementación con heno de alfalfa se enmarcó en la línea de trabajo orientada a sustituir parte del balanceado comercial por forraje producido en el predio. La carencia de forraje fresco derivada de la época del año

Cuadro 9. Suministro diario de ración en los diferentes tratamientos en cada semana del ensayo (g/animal/día).

\begin{tabular}{|l|c|c|c|c|}
\hline Tratamiento & Semana 1 & Semana 2 & Semana 3 & Semana 4 \\
\hline T1 consumo voluntario teórico & 126 & 150 & 150 & 150 \\
\hline T2 (90 \% restricción) & 115 & 135 & 135 & 135 \\
\hline T3 y T4 (80 \% restricción) & 100 & 120 & 120 & 120 \\
\hline
\end{tabular}


determinó la elección de heno de alfalfa de buena calidad, también obtenido en el establecimiento.

El tratamiento con suplementación de heno de alfalfa (T4) recibió una asignación liberal de este forraje en dos ofrecimientos diarios; se procuró que la cantidad asignada superara el consumo voluntario, aunque no se determinó el consumo real.

Cada semana los gazapos fueron pesados individualmente y se determinó el consumo de alimento por jaula, calculándose el índice de conversión resultante de la relación entre el alimento balanceado consumido expresado en base fresca y el aumento de peso registrado por jaula.

A los efectos del análisis estadístico, la unidad experimental para ganancia de peso fue cada conejo individual, mientras que para el consumo y el índice de conversión fue la jaula con cinco individuos. Los resultados obtenidos en este ensayo se presentan en el Cuadro 10.

Los resultados ratifican la dificultad de lograr en la práctica un buen ajuste de la escala de restricción alimenticia. En este caso, el consumo real de los gazapos con ración a voluntad (T1) resultó inferior a las previsiones basadas en el consumo voluntario de lotes anteriores. En el período en que se desarrolló este ensayo se registraron temperaturas anormalmente altas para la época del año, con valores de máximas próximos a los $30^{\circ} \mathrm{C}$ durante toda una semana, lo que provocó una caída general en el consumo de todos los tratamientos. Los conejos sometidos al nivel de restricción más ligero (T2) tuvieron un consumo total de ración significativamente mayor que el grupo manejado a «tolva llena». Es lógico inferir que el suministro diario de ración determinó una estimulación al consumo espontáneo. Otro aspecto que consideramos tuvo relevancia para limitar el consumo de T1 fue la pobre firmeza del pellet de la ración comercial, que tendía a desagregarse rápidamente y determinaba la acumulación de polvillo en el comedero. El agregado diario de ración en los otros tratamientos mitigaba la ocurrencia de esta imperfección en la forma física del alimento.

Si tomamos como valor 100 el consumo total de alimento balanceado del tratamiento T2, los consumos relativos de los otros tratamientos serían 85,90 y $83 \%$, para T1, T3 y $\mathrm{T} 4$ respectivamente.

Comparando los dos tratamientos sometidos al nivel de restricción más drástico (T3 y T4), se constató que el suministro a voluntad de heno de alfalfa determinó una reducción significativa en el consumo de balanceado del orden del 7,6\%.

En cuanto al Índice de Conversión de la ración, se verificaron diferencias significativas entre los tratamientos T2 y T4 (4,25 vs. $3,18)$. El efecto de la suplementación con heno de alfalfa a un ofrecimiento restringido de ración balanceada, resultó en una disminución del consumo voluntario de concentrado y una tendencia a mejorar la ganancia de peso, que redundó en una mejor eficiencia de conversión de la ración en comparación con regímenes alimenticios menos restrictivos.

Cuadro 10. Consumo de ración, aumento de peso en el período, ganancia media diaria e índice de conversión para los cuatro tratamientos.

\begin{tabular}{|l|c|c|c|c|}
\hline \multicolumn{1}{|c|}{ Tratamiento } & $\begin{array}{c}\text { Consumo de } \\
\text { ración total } \\
\text { g/animal }\end{array}$ & $\begin{array}{c}\text { Aumento de peso } \\
\text { en el período de } \\
\text { ensayo g/animal }\end{array}$ & $\begin{array}{c}\text { Ganancia media } \\
\text { diaria } \\
\text { g/animal/día }\end{array}$ & $\begin{array}{c}\text { Índice de } \\
\text { Conversión } \\
\text { del alimento } \\
\text { balanceado }\end{array}$ \\
\hline T1 ad libitum & $3703 \mathrm{bc}$ & $1018 \mathrm{a}$ & $36,4 \mathrm{a}$ & $3,68 \mathrm{ab}$ \\
\hline T2 Restricción 90 \% & $4335 \mathrm{a}$ & $1031 \mathrm{a}$ & $36,8 \mathrm{a}$ & $4,25 \mathrm{a}$ \\
\hline T3 Restricción 80\% & $3925 \mathrm{~b}$ & $1073 \mathrm{a}$ & $38,3 \mathrm{a}$ & $3,67 \mathrm{ab}$ \\
\hline $\begin{array}{l}\text { T4 Restricción 80 \% } \\
\text { + heno de alfalfa }\end{array}$ & $3625 \mathrm{c}$ & $1143 \mathrm{a}$ & $40,8 \mathrm{a}$ & $3,18 \mathrm{~b}$ \\
\hline
\end{tabular}

Nota: Los valores en la misma columna acompañados por letras similares no presentan diferencias estadísticamente significativas $(P<0,05)$. 
Este ensayo resultó altamente ilustrativo de las dificultades para implementar una escala de racionamiento efectiva, en función de la influencia de factores externos tales como la calidad del alimento y la temperatura ambiente.

Otro aspecto verificado en este trabajo, que puede tener implicancias prácticas, es que el suministro frecuente de alimento a los gazapos en crecimiento-engorde estimula su apetito.

Los resultados, si bien no son concluyentes, sugieren que una restricción moderada en la cantidad de alimento ofrecido puede mejorar la eficiencia de conversión del alimento sin afectar la velocidad de crecimiento.

Al momento de realización del ensayo, la relación de precios entre el alimento balanceado comercial y el heno de alfalfa no justificaba su utilización para obtener una leve reducción en el consumo de concentrado de menos del $8 \%$.

\section{Utilización del heno de alfalfa como sustituto parcial de raciones balanceadas}

El ensayo descrito precedentemente fue la primera evaluación del efecto del uso de heno de alfalfa con el objetivo de lograr una economía en el uso de alimento balanceado comercial. Un ensayo ejecutado en la UEC de INIA Las Brujas más de doce años después tuvo por objetivo evaluar el uso de heno de alfalfa a voluntad, comparado con un testigo alimentado en base a ración en forma exclusiva y con dos tratamientos en los que se suministró alfalfa fresca a voluntad simul- táneamente con ración comercial a voluntad y en forma restringida.

El ensayo tuvo lugar entre octubre y diciembre de 2010, utilizándose 80 gazapos de la línea Verde pura que, en la semana siguiente al destete, fueron asignados al azar a los siguientes tratamientos:

T1: alimentación exclusivamente en base a ración comercial a voluntad

T2: ración balanceada a voluntad + heno de alfalfa a voluntad

T3: ración balanceada a voluntad + alfalfa fresca a voluntad

T4:ración balanceada restringida al $70 \%$ + alfalfa fresca a voluntad

Cada tratamiento constó de cinco repeticiones (jaulas) con cuatro individuos (dos machos y dos hembras) en cada una de ellas. Se evaluaron parámetros de desempeño productivo (consumo de ración balanceada, ganancia de peso y eficiencia de conversión del alimento) en forma semanal a lo largo del período de crecimiento.

El peso vivo promedio al inicio del ensayo fue de 852 gramos y los animales fueron sometidos a los tratamientos descritos hasta llegar a un peso de faena individual de $2500 \mathrm{~g}$, siendo las canales evaluadas de acuerdo al protocolo descrito por Blasco y Ouhayoun (1996).

No se verificaron diferencias estadísticamente significativas en la edad a la faena (85.5, 84.6, 84.8 y 84.8 días para T1 a T4 respectivamente) ni en la ganancia media diaria (30.8, 29.5, 29.6 y 31.9 g/día para T1 a T4). Sí se constataron diferencias estadísticamente significativas en el consumo total de ración y en el índice de conversión (Cuadro 11).

Cuadro 11. Consumo de alimento por animal en el período total de ensayo e Índice de Conversión de la ración balanceada.

\begin{tabular}{|l|c|c|}
\hline \multicolumn{1}{|c|}{ Tratamiento } & $\begin{array}{c}\text { Consumo de ración } \\
\text { en el período de } \\
\text { ensayo g/animal }\end{array}$ & $\begin{array}{c}\text { Indice de conversión } \\
\text { del alimento } \\
\text { balanceado }\end{array}$ \\
\hline T1 ración a voluntad & $6302 \mathrm{c}$ & $3,82 \mathrm{c}$ \\
\hline T2 ración y heno a voluntad & $5404 \mathrm{~b}$ & $3,40 \mathrm{~b}$ \\
\hline T3 ración y alfalfa a voluntad & $4248 \mathrm{a}$ & $2,69 \mathrm{a}$ \\
\hline T4 ración restringida y alfalfa a voluntad & $3935 \mathrm{a}$ & $2,41 \mathrm{a}$ \\
\hline
\end{tabular}




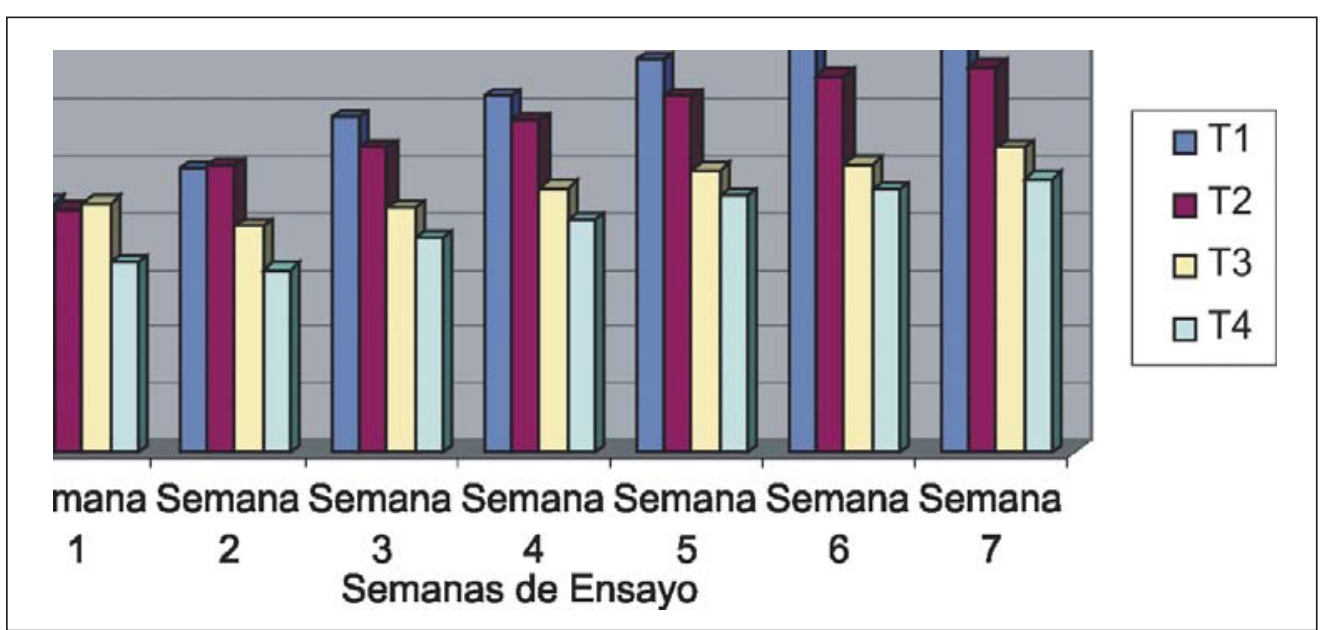

Figura 11. Evolución del Índice de Conversión de la ración balanceada en cada una de las semanas del período en ensayo.

Si tomamos como base 100 el consumo del tratamiento $\mathrm{T} 1$ alimentado exclusivamente con ración balanceada, el consumo relativo de los otros tratamientos fue de 86, 67 y $62 \%$ para T2, T3 y T4 respectivamente.

La Figura 11 representa gráficamente la evolución del Índice de Conversión del alimento balanceado en cada una de las semanas del ensayo.

Esta representación gráfica destaca que en las dos primeras semanas hubo muy poca diferencia en la conversión de los tratamientos que recibían ración a voluntad, debida a la casi nula diferencia en consumo. El acostumbramiento al forraje hizo que progresivamente fuera aumentando el nivel de sustitución, mejorando entonces la eficiencia de conversión del concentrado. También puede apreciarse que el acostumbramiento al consumo de niveles proporcionalmente importantes de heno llevó más tiempo que al forraje fresco, seguramente por la mejor palatabilidad de este último.

No se constataron diferencia estadísticamente significativas en ninguno de los parámetros evaluados para calidad de canal, aunque al igual que en otros trabajos anteriores los conejos recibiendo ración balanceada en forma exclusiva tendían a presentar valores de grasa disecable (perirrenal, inguinal y escapular) ligeramente superiores a los de los animales que recibían forraje suplementario, mientras que los conejos alimentados con forraje mostraban una tendencia a que fuera menor el rendimiento a la faena, asociado a un mayor peso del tracto gastrointestinal.

Los resultados de este trabajo muestran que las estrategias destinadas a sustituir parcialmente la ración balanceada por voluminosos de menos costo permitieron, en estas condiciones, ahorros de ración del orden del $15 \%$ (heno) a $35 \%$ (alfalfa fresca). Nuevamente se constató que la estrategia alimenticia no determinó efectos negativos sobre el desempeño productivo y tampoco hubo afectación significativa en los parámetros de calidad de canal evaluados.

En función de la escasa diferencia en los resultados obtenidos con el tratamiento T3 (con ración a voluntad) y el T4 (ración restringida), parece más seguro mantener la recomendación de ofrecer la ración a voluntad cuando se complementa con alfalfa fresca de buena calidad y a voluntad. Aunque en este caso no se constató que el lote restringido presentara mayor heterogeneidad en su desempeño productivo, debe tenerse en cuenta que el número de animales alojados por jaula era inferior al utilizado en la producción comercial y no tenemos seguridades de que al aumentar la competencia se puedan mantener performances tan parejas.

El heno de alfalfa se presenta nuevamente como una opción económicamente menos ventajosa que el forraje fresco, aunque puede cubrir períodos de escasa disponibilidad de alfalfa fresca si su costo lo justifica. 


\section{CONCLUSIONES}

La utilización de forrajes frescos como sustitutos parciales de las raciones balanceadas comerciales en la producción de conejos para carne es una estrategia alimenticia digna de ser tenida en cuenta en las condiciones productivas de Uruguay, particularmente apropiada a las circunstancias de criaderos de pequeña escala y donde el rubro cunícola está asociado a actividades agrícolas. Su empleo es una decisión económica, dependiente de la relación de precios entre la ración balanceada comercial y el forraje.

La escala del criadero es un factor de importancia para la aplicabilidad de esta estrategia, ya que la mano de obra requerida para el corte y distribución del forraje puede limitar su adopción en criaderos de mayor volumen.

La calidad nutritiva del forraje es muy importante; la alfalfa fresca ha demostrado resultar un eficiente sustituto del concentrado, obteniéndose ahorros importantes de ración, con ligera o nula afectación de los parámetros determinantes del desempeño productivo y de la calidad de canal. En sucesivos ensayos a lo largo del tiempo se han logrado niveles de sustitución comprendidos entre el 10 y el $35 \%$.

Se dispone de evidencias de buenos resultados con tréboles y otras leguminosas, así como con achicoria. Otros forrajes frescos, como avena o sorgo forrajero, mostraron en nuestras condiciones una eficiencia menor a la de la alfalfa. Las guías de boniato, pese a ser un alimento disponible en un corto período del año, demostraron una interesante capacidad sustitutiva del alimento concentrado. La bibliografía internacional muestra una enorme variedad de forrajes evaluados como alimentos alternativos, en particular en países donde las raciones balanceadas son caras o en los casos en que los cunicultores dispongan de limitados recursos financieros para afrontar la adquisición de insumos.

Para las condiciones de nuestro país los forrajes frescos se presentan como una alternativa económicamente más viable que los forrajes henificados. El heno de alfalfa, que permite sustituciones del 8 a $15 \%$ del concentrado, es una opción menos ventajosa, aunque su empleo puede ser considerado para cubrir períodos de escasa disponibilidad de alfalfa fresca si su costo lo permite.

El forraje debe cortarse y suministrarse en el día; no hemos verificado ventajas de dejarlo marchitar antes de ofrecerlo a los conejos. Desde el punto de vista práctico puede resultar conveniente cortar día por medio y conservar el forraje en un lugar fresco y sombreado hasta el momento de suministrarlo a los animales.

Resulta muy conveniente disponer el forraje sobre el techo de la jaula o en rastrillos forrajeros ubicados sobre el frente de la misma; algunas firmas fabricantes de jaulas de Europa, han diseñado jaulas para la producción en pequeña escala que disponen de un espacio especial para el suministro de forraje fresco sobre el lateral, entre una y otra jaula. No se debe disponer el forraje sobre el piso de la jaula porque el pisoteo y la mezcla con las deyecciones determinan un mayor desperdicio.

El conejo consume con avidez forrajes frescos, aunque su comportamiento alimenticio es muy selectivo: en general consume hojas y tallos tiernos y descarta los tallos muy endurecidos o lignificados. Se debe tratar de ajustar la cantidad ofrecida a la capacidad de consumo de los conejos para minimizar el desperdicio. Al iniciar el suministro de forraje se debe ir aumentando gradualmente la cantidad ofrecida, ya que hay un período de acostumbramiento en que el consumo es reducido. En gazapos recién destetados en la primera semana de ofrecimiento de forraje se observa un consumo gradualmente creciente, que se consolida en la segunda semana.

Si bien es posible lograr mayores niveles de sustitución de concentrados por forraje ofreciendo la ración en forma restringida, es muy difícil establecer una escala de racionamiento adecuada. En caso que la restricción aplicada sea excesiva puede verificarse un prolongamiento excesivo del período de engorde que a su vez determine una menor eficiencia de conversión del alimento. En estos casos también puede producirse un 
efecto de la competencia entre los conejos de una jaula que conlleve a una mayor heterogeneidad en los lotes y mayor dispersión en el tiempo necesario para llegar al peso de faena. Estas consideraciones sugieren la conveniencia de ofrecer el forraje fresco y la ración balanceada a voluntad en gazapos en crecimiento-engorde.

Esta misma estrategia alimenticia puede ser aplicada en conejas en lactación, lográndose niveles satisfactorios de sustitución sin afectar la condición corporal de la hembra ni el tamaño y peso de la camada.

Probablemente la única categoría en que puede resultar recomendable ofrecer forraje a voluntad y ración en forma restringida son los reproductores machos, especialmente cuando tienen tendencia genética a aumentar de peso en forma excesiva y si están sometidos a una baja intensidad de trabajo o a una utilización esporádica, en función del tipo de organización en bandas en el manejo reproductivo del criadero.

\section{BIBLIOGRAFÍA}

ADEYEMI, O.A.; AKANJI, A.O. 2012. Restricted concentrate with ad libitum forage feeding: effects on performance and carcass yield of growing rabbits. Revista Científica UDO Agrícola, 12 (3): 668-674.

AMOZA, C.; LUSARDO, R.; OLIVER, L. 2008. La explotación de la cunicultura y su fomento en el Uruguay. Montevideo: Facultad de Ciencias Económicas y Administración. Universidad de la República, 170 p.

BERGAOUI, R.; KAMMOUN, M.; OUERDIANE, K. 2008. Effects of feed restriction on the performance and carcass of growing rabbits. In: 9th World Rabbit Congress, Verona. Proceedings Verona: WRSA, 2008. p.547-550.

BLASCO, A.; OUHAYOUN, J. 1996. Harmonization of criteria and terminology in rabbit meat research. Revised proposal. World Rabbit Science, 4: 93-99.

BLUMETTO, O. 1997a. Utilización de Sudan grass fresco en la suplementación de conejos en crecimiento. En: Jornada de Divulgación en Cunicultura. Canelones: INIA. (Serie Actividades de Difusión, 142).
BLUMETTO, O. 1997b. Utilización de parte aérea (guías) de boniato en la suplementación de conejos en crecimiento. En: Jornada de Divulgación en Cunicultura. Canelones: INIA. (Serie Actividades de Difusión, 142).

BLUMETTO, O.; CAPRA, G. 1997. Utilización de avena fresca en la alimentación de conejos en crecimiento. In: Jornada de Divulgación en Cunicultura. Canelones: INIA. (Serie Actividades de Difusión, 142).

BLUMETTO, O.; CAPRA, G. 1998a. Utilización estratégica de forrajes en la alimentación de conejos. Montevideo: INIA. (Serie Hojas de Divulgación, 68).

BLUMETTO, O.; CAPRA, G. 1998b. Suplementación con alfalfa fresca a conejas en lactación. Montevideo: INIA. (Serie Hojas de Divulgación, 69).

CAPRA, G; BLUMETTO, O.; SEVERAC, N. 1998a. Estrategias de alimentación en conejos en crecimiento. INIA. (Hoja de Divulgación, 72).

CAPRA, G.; BLUMETTO, O.; SEVERAC, N. 1998b. Efecto del régimen de alimentación: suministro de ración a voluntad o en forma restringida a gazapos en engorde. INIA. (Hoja de Divulgación, 73).

CAPRA, G.; GROMPONE, M.A.; URRUZOLA, N.; PARDO, M.J.; MARTÍNEZ, R.; FRADILETTI, F.; COZZANO, S.; REPISO, L.; MÁRQUEZ, R. 2010. Effect of fresh alfalfa in the diet of growing rabbits on growth performance, carcass characteristics and fat composition. IV Congreso Cunicultura de las Américas 2010, Córdoba, Argentina.

CAPRA, G.; MARTÍNEZ, R.; FRADILETTI, F.; COZZANO, S.; REPISO, L.; MÁRQUEZ, R.; IBÁÑEZ, F. 2013. Meat quality of rabbits reared with two different feeding strategies: with or without fresh alfalfa ad libitum. World Rabbit Science, 21(1): 23-32.

CASTELLÓ, J.A.; GURRI, A. 1992. Effects of energy levels in the feed and the feeding program on performances of growing rabbits. Journal of Applied Rabbit Research, 15 (B): 958-964.

CHODOVÁ, D.; TUMOVÁ, E. 2013. The effect of feed restriction on meat quality of broiler rabbits: a review. Scientia Agriculturae Bohemica, 44 (1): 55-62. 
DALLE ZOTTE, A.; REMIGNON, H.; OUHAYOUN, J. 2004. Effect of feed restriction during post-weaning growth on fiber characteristics of Biceps femoris muscle in the rabbit. Proceedings $8^{\text {th }}$ World Rabbit Congress, September 7-10, Puebla, Mexico.

DI MEO, C.; BOVERA, F.; MARONO, S.; VELLA, N.; NIZZA, A. 2007. Effect of feed restriction on performance and feed digestibility in rabbits. Italian Journal of Animal Science, 6(1s). Proceedings of the 17th ASPA Congress, Alghero, May 29-June 1, 2007.

FEKETE, S.; GIPPERT, T. 1981: Studies on the effect of different restricted rations in broiler rabbit production.Magyar Állatorvosok Lapja, 36(7): 484-488.

FOLCH, J.; LEES, M.; SLOANE, G. 1957. A simple method for the isolation and purification of total lipids from animal tissues. Journal of Biology and Chemistry, 226: 497-509.

GIDENNE, T.; COMBES, S.; FEUGIER, A.; JEHL, N.; ARVEUX, P.; BOISOT, P.; BRIENS, C.; CORRENT, E. ; FORTUNE, H. ; MONTESSUY, S. ; VERDELHAN, S. 2009. Feed restriction strategy in the growing rabbit. 2. Impact on digestive health, growth and carcass characteristics. Animal, 3(4): 509-515.

GIDENNE, T.; COMBES, S.; FORTUN-LAMOTH, L. 2012a. Feed intake limitation strategies for the growing rabbit : effect on feeding behaviour, welfare, performance, digestive physiology and health : a review. Animal 6(9): 1407-1419.

GIDENNE, T.; COMBES, S.; BRIENS, C.; DUPERRAY, J. ; MEVEL, L.; REBOURS, G.; ALAUN, J.M.; WEISSMAN, D.; COMBE, Y. ; TRAVEL, A. 2012b. Intake limitation strategy and dietary protein concentration: effect on rabbit growth performance and health from a large-scale study in a French network of experimental units (GEC). World Rabbit Science Association Proceedings 10th World Rabbit Congress - September 3 6, 2012- Sharm El- Sheikh -Egypt, 597-601.

GONDRET, F.; LEBAS, F.; BONNEAU, M. 2000. Restricted feed intake during fattening reduces intramuscular lipid deposition without modifying muscle fiber characteristics in rabbits. Journal of Nutrition, 130 (2): 228-233.
LEBAS, F.; COUDERT, P.; ROCHEMBEAU, H.; THEBAULT, R.G. 1997. The rabbit: husbandry, health and production. (FAO Animal Production and Health Series, 21).

LEBAS, F.; GIDENNE, T. 2000. Recent research advances in rabbit nutrition. Ningbo (China) 22-23 December 2000. 17p.

OLIVEIRA, M.C.; PEREIRA DA SILVA, R.; SOUSA ARAUJO, L.; RODRIGUES DA SILVA, V.; APARECIDO BENTO, E.; MONTES DA SILVA, D. 2012. Effect of feed restriction on performance of growing rabbits. Revista Brasileira de Zootecnia, 41(6).

OSMAN, A.M.A. 1991. Effect of reducing feeding time on the growth performance, carcass traits and meat quality of growing rabbits. Archiv für Geflügelkunde, 55 (5): 196-200.

OSMAN, A.M.A.; TAWFIT, E.S. 1994. The effect of duration of severe feed restriction on growth performance, carcass traits and meat quality of growing rabbits. Der Tropenlandwirt fur die Landwirtschaft in den Tropen und Subtropen, 95: 5-16

PÉREZ, M.; VELÁZQUEZ, D. 1998. Evaluación de la mortalidad perinatal de los gazapos y sus posibles causas. Diagnóstico a nivel nacional. Montevideo: Facultad de Agronomía, Universidad de la República, 30 p.

PLA, M.; GUERRERO, L.; GUARDIA, D.; OLIVER, M.A.; BLASCO, A. 1998. Carcass characteristics and meat quality of rabbits lines selected for different objectives: I. Between lines comparison. Livestock Production Science, 54: 115-123.

PLA, M.; DALLE ZOTTE, A. 2000. Harmonisation of criteria and methods used in rabbit meat research. In Proc.: 7th World Rabbit Congress 2000. Valencia, Spain. World Rabbit Science, 8 (Suppl 1): 539-545.

PLA, M.; FERNÁNDEZ CARMONA, J.; BLAS, E. CERVERA, C. 1994. Growth and some carcass traits of adult rabbits under high ambient temperature. World Rabbit Science, 2(4): 147-151.

SAS. 2003. SAS version 9.1.3. SAS. USA: Institute Cary.

SZENDRO, Z., SZABO, S. and HULLAR, I. 1988. Effect of reduction of eating time on production of growing rabbits. Proceedings 4th World Rabbit Congress, Budapest, 3, 104-114. 
TOMOVÁ, E.; ZITA, L.; STOLC, L. 2006. Carcass quality in restricted and ad libitum fed rabbits. Czech Journal of Animal Science, 51 (5): 214-219.
TUDELA, F.; LEBAS, F. 2006. Modalités du rationnement des lapins en engraissement. Effets du mode de distribution de la ration quotidienne sur la vitesse de croissance, le comportement alimentaire et l'homogenité des poids. Cuniculture Magazine, 33: 21-27. 


\section{EFECTO DEL NÚMERO DE CONEJOS POR JAULA SOBRE EL DESEMPEÑO PRODUCTIVO EN LAFASE DE CRECIMIENTO Y TERMINACIÓN}

Gustavo Capra ${ }^{1}$

Las condiciones de alojamiento de los conejos en la fase de crecimiento y terminación han sido objeto de numerosos estudios, que han demostrado su influencia sobre el desempeño productivo, las características de la canal y las cualidades de la carne. La multiplicidad de condiciones ambientales, modalidades de cría (en jaulas o en piso), diferente peso de faena, así como las dimensiones y el diseño de los alojamientos, justifica la diversidad de resultados. Otro factor a considerar es que se ha demostrado la influencia del tamaño de grupo (número de conejos en crecimiento por alojamiento) y de la densidad, expresada en número de animales o en kilos de conejo por unidad de superficie.

Combes y Lebas (2003) señalan que las investigaciones sobre el efecto de la densidad animal apuntaban en un primer momento a optimizar el desempeño productivo (ganancia de peso, consumo de alimento y eficiencia de conversión) y asegurar mejores condiciones sanitarias para los conejos. A partir de la segunda mitad de la década del 80 comenzaron a incorporarse criterios vinculados a la calidad de la canal, tales como la presentación de la misma y su estado de engrasamiento. Poco a poco los criterios de calidad de producto fueron evolucionando en función de las demandas de los consumidores y así se introdujeron parámetros vinculados a las cualidades higiénica, nutricional y sensorial de la carne, que obligaron a modificar las recomendaciones sobre las condiciones de alojamiento de los conejos. Más recientemente, la creciente preocupación por el bienestar de los animales de producción en los países europeos determinó una profundización de las investigaciones y la aplicación de sus resultados a la confección de normas regulatorias de las condiciones de cría de conejos para carne. Los mencionados autores describen la evolución de los sistemas de alojamiento y compilan los resultados de 43 trabajos de investigación publicados entre 1980 y 2003; en los mismos la superficie de suelo asignada por animal varía entre $0,11 \mathrm{~m}^{2}$ en jaulas de tipo biplaza a más de $20 \mathrm{~m}^{2}$ para crianza en parque. El número de conejos por alojamiento varía entre 1 en jaulas individuales a más de 200 para la cría en parques. Las densidades estudiadas varían entre 2,2 y 32,4 conejos por $\mathrm{m}^{2}$ y entre 5,4 a $62,8 \mathrm{~kg}$ de peso vivo por $\mathrm{m}^{2}$ al final del engorde. Esta exhaustiva revisión pone de relieve la incidencia de las condiciones de alojamiento, donde se combinan factores ambientales (temperatura, humedad relativa ambiente, concentración de diferentes gases), el tamaño de grupo, la asignación de espacio por animal o por kilo de peso vivo, el tipo de piso, las dimensiones de la jaula, el espacio de comedero disponible y el sistema de crianza, sobre el desempeño productivo, las cualidades de la canal y la carne, el comportamiento de los conejos y el resultado económico obtenido.

Morisse y Maurice (1997) evaluaron la influencia de la densidad animal y el tamaño de grupo sobre el comportamiento de conejos en engorde en condiciones de producción intensiva, para lo cual alojaron conejos destetados a los 30 días, en jaulas de 0,77 $x$ 0,51, en lotes de 6, 7, 8 y 9 animales por jaula, con densidades de 15,3, 17,8, 20,4 y

${ }^{1}$ Instituto Nacional de Investigación Agropecuaria. INIA Uruguay. 
23 conejos por $\mathrm{m}^{2}$. El comportamiento de los conejos fue registrado mediante videocámaras en 96 secuencias de un minuto cada 15 minutos a lo largo de dos períodos de 24 horas a las 6 y 10 semanas de edad.

Los comportamientos observados se clasificaron en seis diferentes grupos: de mantenimiento, confort, social y demarcatorio, exploratorio, locomotriz y estereotípico. En las condiciones del experimento, a las seis semanas de edad no detectaron diferencias entre tratamientos en el patrón de comportamiento. A las 10 semanas de edad las interacciones sociales se vieron reducidas para los tamaños de grupo de más de 6 animales, mientras que tendían a incrementar las conductas dirigidas hacia el cuerpo del propio animal o hacia su entorno, con una ligera reducción del comportamiento locomotriz. Los autores sugieren que el bienestar de los animales podría ser mayor si el tamaño de grupo no excediera de 6 para una jaula de dimensiones standard, correspondiente a una densidad de $40 \mathrm{~kg} / \mathrm{m}^{2}$ a las 10 semanas de edad.

Andrea et al. (2004) compararon dotaciones de dos a seis conejos en jaulas de $0,36 \mathrm{~m}^{2}$, equivalentes a densidades comprendidas entre 4,76 y 14,28 conejos $/ \mathrm{m}^{2}$, concluyendo que el aumento de la población influyó negativamente sobre el desempeño de los conejos; la densidad de tres conejos alojados por jaula $\left(7,14\right.$ conejos $\left./ \mathrm{m}^{2}\right)$ resultó la más adecuada para evitar la competencia y promover una mayor ganancia de peso.

En un estudio realizado en Islas Canarias por Camacho et al. (2005), utilizando jaulas de $0,408 \mathrm{~m}^{2}$ con 5 a 8 conejos por jaula, las mejores ganancias de peso fueron logradas con una densidad de 17 conejos $/ \mathrm{m}^{2}$ en otoño-invierno (siete conejos por jaula) y de 12,2 conejos $/ \mathrm{m}^{2}$ para primaveraverano ( 5 conejos por jaula). Los autores destacan que las variaciones en las condiciones de temperatura justifican la utilización de densidades diferentes en las distintas estaciones del año.

Villalobos et al. (2008), compararon cuatro densidades comprendidas entre 6 y 24 conejos por $\mathrm{m}^{2}$, en jaulas de $0,5 \mathrm{~m}^{2}$, bajo stress térmico en las cálidas condiciones de producción prevalecientes en Venezuela, re- comendando que es conveniente evitar densidades superiores a 18 conejos o $34 \mathrm{~kg}$ por $\mathrm{m}^{2}$.

El tipo de piso en interacción con la densidad fue el objeto de estudio de una investigación de Princz et al. (2008), quienes asignaron gazapos de cinco semanas de edad a diferentes tratamientos basados en la aplicación de paja sobre el piso de alambre de la jaula en distintos momentos del ciclo de engorde, con densidades de 8,12 y 16 conejos por $\mathrm{m}^{2}$. Concluyeron que la densidad no afectó el desempeño productivo y que la adición de paja en distintos momentos del engorde ejercía un ligero efecto sobre la ganancia de peso, el consumo de alimento y la relación de conversión del alimento; sugieren que la cría sobre piso de alambre en la fase de recría y la posterior provisión de piso de paja durante el período de engorde podría ser una estrategia adecuada para obtener buen desempeño y prevenir la incidencia de coccidiosis.

También Trocino et al. (2008) evaluaron el efecto del tipo de piso y la densidad sobre el desempeño productivo, condición sanitaria, cualidades de la canal, calidad de carne y comportamiento de conejos en crecimiento. Utilizaron dos densidades, determinadas por alojar 6 gazapos en jaulas de $78 x$ $64 \mathrm{~cm}$ o de $58 \times 64 \mathrm{~cm}$, correspondientes a 12,1 y 16,2 animales $/ \mathrm{m}^{2}$ respectivamente, combinadas con cuatro tipos de piso (slats de acero o de plástico, enrejillado de alambre y cama de paja sobre enrejillado de alambre). La densidad no afectó el desempeño durante el crecimiento, las cualidades de la canal ni la reactividad de los conejos.

Por su parte, Onbasilar y Onbasilar (2007) evaluaron el efecto del número de conejos por jaula y el sexo sobre el desempeño productivo y algunos parámetros indicativos de condiciones de estrés sobre conejos en crecimiento. Al momento del destete, a los 35 días de edad, un total de 90 gazapos, mitad de cada sexo, fueron asignados a tratamientos consistentes en uno, tres y cinco individuos por jaula, determinando diferentes asignaciones de espacio de piso por animal (4200, 1400 y $840 \mathrm{~cm}^{2}$ respectivamente). Los parámetros en estudio fueron ganancia de peso corporal total, consumo de alimento y 
relación de conversión, como indicadores de desempeño productivo, y nivel de corticosterona en plasma y contenido sérico de glucosa, colesterol y triglicéridos, como indicadores de stress. El grupo con cinco individuos por jaula presentó valores significativamente menores de ganancia de peso, consumo de alimento y eficiencia de conversión del alimento; también presentaron mayores niveles de corticosterona en plasma y glucosa sérica. Los niveles séricos de colesterol y triglicéridos no fueron afectados por la densidad. El efecto del sexo solo fue verificado en el nivel de corticosterona; los machos presentaron niveles significativamente mayores que las hembras.

Villagrá et al. (2012) destacan la necesidad de determinar las necesidades de los conejos desde el punto de vista del comportamiento en relación a su bienestar, de manera de poder definir las condiciones apropiadas de alojamiento, aunque las necesidades pueden variar en función de la edad, ritmo circadiano, estación del año, genética y otros factores. Por lo tanto el punto a dilucidar es aún más restrictivo; es necesario determinar los requerimientos en relación al comportamiento de las diferentes categorías: gazapos en crecimiento, madres y machos reproductores.

Paci et al. (2013), en un estudio dirigido a evaluar el efecto de la densidad y el tamaño de grupo por jaula sobre el desempeño productivo y las cualidades de la canal y de la carne en una población de conejos de bajo crecimiento criados al aire libre, verificaron que las densidades más altas determinaron mayor incidencia de lesiones, menor ganancia diaria y un $\mathrm{pH}$ último mayor. En las condiciones de sus experimentos, la combinación de densidad y tamaño de grupo que determinó los mejores resultados productivos y de calidad de canal fueron cinco conejos $/ \mathrm{m}^{2}$, con cuatro conejos por jaula.

Otro aspecto vinculado al tamaño de grupo y la densidad de conejos por unidad de superficie mencionada en la bibliografía se relaciona con la disponibilidad de espacio de comedero. Camacho et al. (2005) sostienen que el disponer de una amplia superficie de acceso al alimento reduce la competencia y favorece el buen desempeño productivo.
En tal sentido, Orova et al. (2008) evaluaron en dos experimentos la libre elección de los conejos entre jaulas con distinta longitud de comedero y el efecto del largo del comedero sobre el crecimiento de los animales. En el primer experimento 24 conejos eran alojados en un bloque de cuatro jaulas, conectadas entre sí con puertas de vaivén, que diferían en el largo del comedero (10, 20,30 y $40 \mathrm{~cm}$ ). Una vez por semana, mediante el registro de 24 horas en cámara de video infrarroja, se determinó el número de gazapos presentes en cada jaula en un período de 30 minutos. Una vez por semana se determinó el consumo de alimento en los diferentes comederos a que tenían acceso los conejos. Aunque la elección de las jaulas con los distintos tamaños de comedero fue significativamente diferente en cada semana, solo se verificó una pequeña diferencia en la elección en el total del período experimental: 22, 25, 26 y $27 \%$ de los conejos permanecieron en las jaulas correspondientes a los cuatro largos de comedero evaluados. El consumo de alimento se distribuyó de modo proporcional al largo del comedero, correspondiendo el 12.6, 17.9, 24.9 y 44,6 \% del total a las jaulas provistas con comederos de 10, 20, 30 y $40 \mathrm{~cm}$ respectivamente. En el segundo experimento se asignaron lotes de 13 conejos a alojamientos de $0,96 \mathrm{~m}^{2}$ de superficie de suelo con diferente longitud de comedero $(10,20,30$ y $40 \mathrm{~cm})$. El peso vivo final, el consumo total de alimento y el índice de conversión del alimento no difirieron significativamente entre alojamientos con diferente largo de comedero. Los autores concluyeron que los diferentes espacios de comedero utilizados en el experimento eran adecuados desde el punto de vista del crecimiento y bienestar de los conejos.

De acuerdo con Szendro y Dalla Zotte (2011), en base a una exhaustiva revisión de la literatura relacionada con las condiciones de alojamiento de los conejos en crecimiento, cuando el tamaño de grupo se encuentra por encima de un máximo de cuatro a cinco conejos por jaula, las desventajas derivadas de un mayor riesgo sanitario y mayores niveles de agresión y de lesiones, superan a las posibles ventajas. Sostienen que varios estudios sugieren que la densidad 
óptima es de 16 a 18 conejos $/ \mathrm{m}^{2}$, con una carga final de 40 a $45 \mathrm{~kg} / \mathrm{m}^{2}$. Esta recomendación es coincidente con las de Combes y Lebas (2003), que sostienen que el incremento de la densidad, más allá de los 18-20 conejos por metro cuadrado o de 40-45 kg de peso vivo $/ \mathrm{m}^{2}$, deteriora ligeramente el desempeño en el crecimiento sin afectar la calidad de la canal ni de la carne, aunque aumenta los riesgos sanitarios. Estos autores señalan que en la producción comercial intensiva de Francia se emplean densidades comprendidas entre 20 y 22 conejos $/ \mathrm{m}^{2}$, para un peso de faena similar al de nuestro país.

Las perspectivas de cambio de la normativa europea referida a las condiciones de cría de los animales de producción, en base a consideraciones referidas al bienestar animal, alentaron estudios sobre el efecto de la reducción de la densidad de conejos por jaula sobre los resultados económicos.

En España, Muguerza et al. (2008) compararon resultados físicos y económicos obtenidos con densidades comprendidas entre 7 y 11 conejos por jaula, para el peso de sacrificio que demanda el mercado español $(2,1-2,2 \mathrm{~kg})$. El peso vivo final y la ganancia media diaria fueron significativamente mejores al disminuir el número de conejos por jaula, mientras que se verificó una reducción significativa en el consumo total de ración consumida por cada conejo para llegar al peso final. El índice de conversión del alimento no mostró diferencias estadísticamente significativas. Desde el punto de vista de los resultados económicos, la reducción de la densidad en la fase de crecimiento determinó una importante reducción en el margen bruto y el margen neto. Al pasar de una dotación de 10 conejos por jaula (equivalente a $52,5 \mathrm{~kg} / \mathrm{m}^{2}$ ) a 7 conejos por jaula $\left(36,75 \mathrm{~kg} / \mathrm{m}^{2}\right)$ se constató una reducción en el margen neto del orden del $50 \%$.

Por su parte Verspecht et al. (2011), en Bélgica, evaluaron los resultados económicos utilizando el método de los presupuestos parciales en base a coeficientes técnicos de granjas comerciales y a los resultados físicos obtenidos en un experimento que comparó siete densidades comprendidas entre 5 y 20 conejos por $\mathrm{m}^{2}$, resultantes de la asignación de ocho gazapos a jaulas de diferentes dimensiones. En el experimento, el aumento en la densidad no afectó significativamente la ganancia de peso, pero redujo significativamente el consumo de alimento, determinando una mejora de la eficiencia de conversión con el aumento de la densidad. La reducción en la densidad en la fase de crecimiento-engorde determinó una fuerte caída en el margen bruto obtenido por madre y por año, que se torna negativo, para las condiciones de producción belgas del año del estudio, a partir de una densidad igual o menor a 10 gazapos $/ \mathrm{m}^{2}$.

\section{APORTES DE LA INVESTIGACIÓN EN LA UNIDAD EXPERIMENTAL DE CUNICULTURA DE INIA}

Los estudios vinculados al efecto del número de conejos por jaula integraron la agenda de investigación de la UEC en las primeras etapas de funcionamiento. Se habían incorporado en ese entonces jaulas importadas de España, que diferían en su diseño y dimensiones de los alojamientos de hormigón al aire libre que eran predominantes en el país, así como de las jaulas de alambre galvanizado de fabricación nacional.

El costo de las jaulas representa un alto componente de la inversión inicial del cunicultor y su amortización constituye un factor relevante en la estructura de costos de la producción de conejos para carne. Un estudio económico, realizado a mediados de los 90 por técnicos del Plan Agropecuario, destacaba el peso relativo de la amortización de jaulas y equipamiento, que se ubicaba como el tercer factor en orden de importancia, con un $6 \%$ del costo de producción (Bonilla y Rodríguez, com. pers.).

Por las razones expuestas y procurando minimizar la incidencia de este factor en la estructura general de costos, se apuntó a aumentar al máximo el número de conejos producidos por jaula, procurando establecer la carga óptima para la fase de crecimientoterminación, con la que se lograría el mejor compromiso entre la productividad biológica y la eficiencia económica. 
La evaluación fue realizada en una batería de jaulas dispuestas en un solo piso (tipo «flat-deck»); las dimensiones de cada jaula son $0,85 \mathrm{~m}$ de largo por 0,40 de ancho, lo que determina una superficie de piso de $0,34 \mathrm{~m}^{2}$. Cada jaula cuenta además con un bebedero automático tipo cazoleta y un comedero tolva con capacidad para $3 \mathrm{~kg}$ de alimento balanceado, que presenta un frente de $0,27 \mathrm{~m}$ para el acceso de los conejos al alimento.

\section{Experimento 1}

El experimento se llevó a cabo entre el 9 y el 30 de mayo de 1996. Se utilizaron 150 gazapos de 32 días de edad, con un peso medio inicial de 821 gramos. Los animales se distribuyeron al azar en cinco tratamientos con tres repeticiones cada uno. Los tratamientos consistieron en alojar 6, 8,10, 12 y 14 conejos por jaula. Todos recibieron alimentación a voluntad y semanalmente se registró el peso vivo individual y el consumo de alimento por jaula. El período de ensayo se extendió tres semanas, en lo que sería la fase de recría de los gazapos en crecimiento. Los resultados obtenidos se presentan en el Cuadro 1.

Con el aumento del número de gazapos por jaula se verifica una reducción en el consumo, que no es acompañada por una reducción proporcional en la ganancia de peso vivo, lo que tiene por consecuencia una mejora en el índice de conversión. El resultado más relevante es la sustancial elevación en el peso vivo ganado por jaula a medida que se aumenta el tamaño de grupo.

\section{Experimento 2}

Este experimento fue complementario del anterior, utilizándose 90 gazapos de 54 días de edad con un peso medio inicial de 1693 gramos. El mismo se llevó a cabo en junio de 1996. Los gazapos fueron asignados al azar a cinco tratamientos, con tres repeticiones, consistentes 4, 5, 6, 7 y 8 conejos por jaula.

El período de ensayo se extendió tres semanas, en lo que sería la fase de terminación del período de crecimiento. Los resultados se presentan en el Caudro 2.

Dentro del rango utilizado en el presente experimento, el número de conejos por jaula no afecta significativamente la ganancia de peso, el consumo de alimento ni la eficiencia de conversión del alimento. El aumento en el tamaño de grupo determina un incremento significativo en el peso vivo ganado por jaula.

La densidad más alta utilizada en este experimento (ocho gazapos por jaula), que corresponde a 23,5 conejos por $\mathrm{m}^{2}$, equivale a una carga final de $57,9 \mathrm{~kg} / \mathrm{m}^{2}$, mucho más alta que la considerada óptima por Szendro y Dalle Zotte (2011) de 16 a 18 conejos $/ \mathrm{m}^{2}$, con un peso vivo total final de 40 a $45 \mathrm{~kg} / \mathrm{m}^{2}$.

Cuadro 1. Desempeño productivo de gazapos en recría sometidos a diferentes tamaños de grupo por jaula.

\begin{tabular}{|c|c|c|c|c|c|}
\hline $\begin{array}{l}\text { Número de } \\
\text { animales } \\
\text { por jaula }\end{array}$ & $\begin{array}{l}\text { Número de } \\
\text { animales } \\
\text { por } \mathbf{m}^{2}\end{array}$ & $\begin{array}{l}\text { Ganancia de } \\
\text { Peso Vivo } \\
\text { promedio por } \\
\text { gazapo para } \\
\text { el período (g) }\end{array}$ & $\begin{array}{l}\text { Consumo medio } \\
\text { de ración por } \\
\text { gazapo para } \\
\text { todo el período } \\
\mathbf{( g )}\end{array}$ & $\begin{array}{l}\text { Índice de } \\
\text { Conversión } \\
\text { acumulado } \\
\text { en todo el } \\
\text { período de } \\
\text { ensayo }\end{array}$ & $\begin{array}{l}\text { Peso Vivo } \\
\text { ganado por } \\
\text { jaula en todo } \\
\text { el período (g) }\end{array}$ \\
\hline 6 & 19,6 & $844 \mathrm{~A}$ & $2501 \mathrm{~A}$ & $3,16 \mathrm{~A}$ & $4686 \mathrm{C}$ \\
\hline 8 & 23,5 & $940 \mathrm{~A}$ & $2309 \mathrm{AB}$ & $2,56 \mathrm{~B}$ & $6153 \mathrm{BC}$ \\
\hline 10 & 29,4 & $855 \mathrm{~A}$ & $2060 \mathrm{BC}$ & $2,47 \mathrm{~B}$ & $8019 \mathrm{~B}$ \\
\hline 12 & 35,3 & $834 \mathrm{~A}$ & $1955 \mathrm{BC}$ & $2,40 \mathrm{~B}$ & $11284 \mathrm{~A}$ \\
\hline 14 & 41,2 & $781 \mathrm{~A}$ & $1775 \mathrm{C}$ & $2,35 \mathrm{~B}$ & $11811 \mathrm{~A}$ \\
\hline
\end{tabular}

Valores en la misma columna seguidos de letras iguales no difieren estadísticamente entre sí $(P<0,05)$. 
Cuadro 2. Desempeño productivo de gazapos en terminación sometidos a diferentes tamaños de grupo por jaula.

\begin{tabular}{|c|c|c|c|c|c|}
\hline $\begin{array}{l}\text { Número de } \\
\text { conejos } \\
\text { por jaula }\end{array}$ & $\begin{array}{l}\text { Número de } \\
\text { animales } \\
\text { por } \mathbf{m}^{2}\end{array}$ & $\begin{array}{l}\text { Ganancia de } \\
\text { Peso Vivo } \\
\text { promedio por } \\
\text { gazapo para } \\
\text { el período } \mathbf{( g )}\end{array}$ & $\begin{array}{l}\text { Consumo medio } \\
\text { de ración por } \\
\text { gazapo para } \\
\text { todo el período } \\
\mathbf{( g )}\end{array}$ & $\begin{array}{l}\text { Índice de } \\
\text { Conversión } \\
\text { acumulado } \\
\text { en todo el } \\
\text { período de } \\
\text { ensayo }\end{array}$ & $\begin{array}{l}\text { Peso Vivo } \\
\text { ganado por } \\
\text { jaula en todo } \\
\text { el período (g) }\end{array}$ \\
\hline 4 & 11,8 & $805 \mathrm{~A}$ & $3814 \mathrm{~A}$ & $4,61 \mathrm{~A}$ & $3221 \mathrm{C}$ \\
\hline 5 & 14,7 & $890 \mathrm{~A}$ & $3890 \mathrm{~A}$ & $4,37 \mathrm{~A}$ & $4450 \mathrm{BC}$ \\
\hline 6 & 19,6 & $900 \mathrm{~A}$ & $3816 \mathrm{~A}$ & $3,97 \mathrm{~A}$ & $5400 \mathrm{AB}$ \\
\hline 7 & 20,6 & $897 \mathrm{~A}$ & $3584 \mathrm{~A}$ & $3,88 \mathrm{~A}$ & $6281 \mathrm{~A}$ \\
\hline 8 & 23,5 & $769 \mathrm{~A}$ & $3430 \mathrm{~A}$ & $4,30 \mathrm{~A}$ & $6152 \mathrm{~A}$ \\
\hline
\end{tabular}

Valores en la misma columna seguidos de letras iguales no difieren estadísticamente entre sí $(P<0,05)$.

\section{Experimento 3}

Entre el 6 de enero y el 17 de febrero de 1997 se llevó a cabo un experimento destinado a evaluar el efecto del número de gazapos alojados por jaula en la fase de terminación en las condiciones imperantes en verano. Se utilizaron 84 gazapos de 48 días de edad con un peso inicial promedio de $1247 \mathrm{~g}$. Los gazapos fueron asignados al azar a cuatro tratamientos consistentes en alojar 4, 6, 8 y 10 animales por jaula, disponiendo cada tratamiento de tres repeticiones. Los conejos recibieron ración balanceada comercial a voluntad durante todo el período, realizándose control de peso individual y del consumo por jaula cada semana. El ensayo se extendió durante seis semanas, entre los 48 y 90 días de edad de los gazapos, dándose por concluido cuando los primeros conejos alcanzaron el peso de faena de $2500 \mathrm{~g}$. Los resultados se presentan en el Cuadro 3.
Para todos los tratamientos se verificó un bajo nivel de consumo de alimento y una baja ganancia media diaria de peso, presumiblemente provocada por las altas temperaturas registradas durante el período de ensayo. El desempeño productivo de los gazapos mostró gran paridad en los tres tratamientos con densidades más bajas, mientras que se verificó una depresión en la ganancia de peso del tratamiento correspondiente a los 10 gazapos por jaula. Este último tratamiento presenta la mayor ganancia de peso por jaula, aunque la reducción en la velocidad de crecimiento estaría determinando una prolongación acentuada del período de engorde. Los resultados sugieren que es posible trabajar con densidades altas aún en el período estival, aunque el pobre desempeño productivo obtenido con las cuatro densidades evaluadas plantea la necesidad de realizar ajustes en las condiciones ambientales y en la nutrición de los conejos en condiciones de alta temperatura.

Cuadro 3. Desempeño productivo de gazapos en terminación sometidos a diferentes tamaños de grupo por jaula.

\begin{tabular}{|c|c|c|c|c|c|}
\hline $\begin{array}{l}\text { Número de } \\
\text { conejos } \\
\text { por jaula }\end{array}$ & $\begin{array}{l}\text { Número de } \\
\text { animales } \\
\text { por } \mathbf{m}^{2}\end{array}$ & $\begin{array}{l}\text { Ganancia de } \\
\text { Peso Vivo } \\
\text { promedio por } \\
\text { gazapo para } \\
\text { el período (g) }\end{array}$ & $\begin{array}{l}\text { Consumo medio } \\
\text { de ración por } \\
\text { gazapo para } \\
\text { todo el período } \\
\text { (g) }\end{array}$ & $\begin{array}{l}\text { Índice de } \\
\text { Conversión } \\
\text { acumulado } \\
\text { en todo el } \\
\text { período de } \\
\text { ensayo }\end{array}$ & $\begin{array}{l}\text { Peso Vivo } \\
\text { ganado por } \\
\text { jaula en todo } \\
\text { el período (g) }\end{array}$ \\
\hline 4 & 11,8 & $1106 \mathrm{~A}$ & $3264 \mathrm{~A}$ & $2,95 \mathrm{~A}$ & $4424 \mathrm{C}$ \\
\hline 6 & 19,6 & $1090 \mathrm{~A}$ & $3224 \mathrm{~A}$ & $2,97 \mathrm{~A}$ & $6338 \mathrm{~B}$ \\
\hline 8 & 23,5 & $1003 \mathrm{AB}$ & $2960 \mathrm{AB}$ & $2,98 \mathrm{~A}$ & $8022 \mathrm{~A}$ \\
\hline 10 & 29,4 & $833 \mathrm{~B}$ & $2664 \mathrm{~A}$ & $3,20 \mathrm{~A}$ & $8333 \mathrm{~A}$ \\
\hline
\end{tabular}

Valores en la misma columna seguidos de letras iguales no difieren estadísticamente entre sí $(P<0,05)$. 


\section{CONCLUSIONES Y RECOMENDACIONES}

En base a la información procedente de la bibliografía de la época y de los resultados de los experimentos descritos precedentemente, en la Unidad Experimental de $\mathrm{Cu}$ nicultura de INIA se adoptó un sistema de manejo del número de conejos por jaula dividiendo el período de crecimiento en dos fases. La primera fase, o etapa de recría se inicia al destete (32 días de edad) y se extiende por tres semanas, hasta que los gazapos pesan aproximadamente $1,5 \mathrm{~kg}$ de peso vivo. En esa etapa se agrupan 12 conejos por jaula, lo que implica una densidad de 35,3 gazapos por $\mathrm{m}^{2}$.

En la segunda fase, que denominamos etapa de engorde o terminación, se subdividen los grupos y se asignan 6 conejos a cada jaula, determinando una densidad de 19,6 conejos $/ \mathrm{m}^{2}$ y una carga final de aproximadamente $49 \mathrm{~kg}$, considerando un peso de faena de $2500 \mathrm{~g}$.

Esta densidad resultó muy adecuada a las condiciones de que se disponía en la UEC $y$ al manejo general del criadero, donde el plantel estaba organizado en bandas semanales con un intervalo medio entre partos de 42 días (servicio a los 11 días post-parto). Con este esquema, cada semana se producen partos en una sexta parte del plantel de madres y se desteta otro tanto. La organización del trabajo también consideraba un día a la semana para el cambio de fase de los conejos en recría, separando en dos grupos los lotes que ingresaban a la fase de terminación. El proceso se completaba con el envío a faena de un lote de conejos que llegaba al peso de faena cada semana.

Esta forma de organización global del criadero permitía ajustar las tareas a una rutina que establecía actividades diferentes para cada día de la semana. Además se hacía un uso muy eficiente de las jaulas destinadas a gazapos en crecimiento-engorde, con una alta productividad en kilos logrados por jaula.

El sistema permitía liberar las jaulas de los conejos que llegaban al peso final y realizar una limpieza y desinfección de las mismas antes del ingreso de un nuevo lote de conejos. Si bien no era un sistema «all in-all out» perfecto, ya que no se vaciaba el local completo sino un grupo de jaulas, permitía ingresar a los gazapos recién destetados a una jaula limpia.

Consideramos que las precauciones en las medidas higiénico-sanitarias adoptadas como una rutina de manejo y la baja presión de enfermedades en las condiciones de un país como Uruguay que presenta un status sanitario privilegiado en comparación con países de cunicultura desarrollada, permitieron trabajar con densidades más altas que las recomendadas en la bibliografía.

Las altas densidades utilizadas en la fase de crecimiento permitieron a los gazapos recién destetados sobrellevar esa etapa crítica prácticamente sin bajas y con mínima afectación del crecimiento. Algunos años más tarde de la adopción de esta alta densidad en el post-destete los aportes de la investigación confirmaban los beneficios de esta estrategia, al mejorar la capacidad de sobrellevar condiciones ambientales adversas (bajas temperaturas) o por las necesidades propias de la especie de interactuar con sus compañeros de camada o congéneres de la misma edad (Camacho et al., 2005; Onbasilar y Onbasilar, 2007)

Los objetivos productivos de la UEC, donde se producían conejos de diferentes líneas para reproducción, generaba ciertas dificultades a la marcha del sistema teórico propuesto, ya que la duración del ciclo era diferente entre las líneas maternas Verde y Amarilla (90 días para alcanzar el peso de $2500 \mathrm{~g}$ ) y la línea paterna terminal Rosa (75 días para llegar al mismo peso). De todas formas, con algunos ajustes inherentes a esta peculiaridad, el esquema definido funcionó adecuadamente durante toda la trayectoria de la UEC. Podemos apuntar que la principal dificultad radicó en la necesidad de que los machos de las líneas maternas fueran faenados puntualmente al llegar al peso de faena, cosa que no siempre se logró debido a los vaivenes de la demanda por conejos. La precocidad sexual de los machos de estas líneas inducía a que se mostraran muy agresivos entre sí, provocando lesiones de entidad que desmerecían la calidad del producto final o que incluso obligaban al sacrifi- 
cio de conejos severamente lastimados. Esto no ocurría con los machos de la línea Rosa ni con conejos resultantes de la cruza con esta línea terminal, de modo que el problema solo afectaba a nuestros núcleos de selección y no a los productores comerciales que manejaban los cruzamientos recomendados.

Tampoco se presentaron problemas en el manejo de las hembras de las líneas maternas, hasta el momento de su venta como reproductores, a un peso comprendido entre los 2-2,5 kg.

Nuestras recomendaciones para los productores comerciales de conejos con respecto a la densidad óptima siempre fueron muy cautelosas, ya que la enorme mayoría de ellos utilizaba jaulas diferentes a las que habíamos importado desde España. Si bien algunos fabricantes de jaulas locales introdujeron mejoras de diseño basadas en el modelo español y que también se produjo una limitada difusión de jaulas fabricadas en Argentina, con características similares a las procedentes del viejo continente, la enorme mayoría de los cunicultores uruguayos empleaban para la etapa de crecimiento y terminación las antiguas jaulas de hormigón al aire libre o jaulas nacionales de alambre galvanizado con graves defectos de diseño. Un problema habitual era que las dimensiones de los comederos no mantenían una adecuada relación con el número de conejos que podía albergar cada jaula en función del espacio de piso disponible.

Recomendamos utilizar densidades altas en el post-destete y la subdivisión de los grupos a un tamaño adecuado antes de llegar a un estado de desarrollo que resultara restrictivo, seguramente en el entorno de $1,5 \mathrm{~kg}$ de peso vivo. Sugerimos que cada productor evaluara para sus condiciones la densidad más apropiada, buscando los mejores resultados desde el punto de vista del desempeño productivo (máxima eficiencia de conversión, velocidad de crecimiento razonable sin prolongaciones excesivas del ciclo de engorde) y de la eficiencia de uso de las jaulas (máxima producción de kilos ganados por jaula), sin arriesgar al uso de densidades excesivas que comprometieran el estado sanitario, performance y bienestar de los animales. También recomendamos tener en cuenta la conveniencia de utilizar densidades más bajas en la estación estival.

\section{BIBLIOGRAFÍA}

ANDREA, M.V.; de CARVALHO, G.J.L., NUNES, S.C.; COSTA, C.N.; BARBOSA, R.P. 2004. Densidade populacional no desempenho productivo de coelhos. Archives de Zootecnia, 53: 391-394.

CAMACHO, A.; MATA, J.; BERMEJO, L.A.; PAZ, C. 2005. Respuesta del crecimiento en conejos según densidad animal. Online version. http://www.engormix.com/ MA-cunicultura/articulos/respuestacrecimiento-conejos Consultado $13 / 01 / 2014$

CAPRA, G.; BLUMETTO, O. 1997. Estudio de la performance de conejos en crecimientoterminación sometidos a diferentes densidades de alojamiento. En: Jornada de Divulgación de Cunicultura. Canelones: INIA. (Serie Actividades de Difusión, 142).

COMBES, S.; LEBAS, F. 2003. Les modes de logement du lapin en engraissement: influence sur les qualités des carcasses et des viandes. 10èmes Journées de la Recherche Cunicole, 19-20 nov. 2003, Paris.

MORISSE, J.P. ; MAURICE, R. 1997. Influence of stocking density or group size on behaviour of fattening rabbits kept under intensive conditions. Applied Animal Behaviour Science, 54: 351-357.

MUGUERZA, M.A.; GARCÍA, I.; EGUINOA, P. 2008. Efecto de la densidad de conejos sobre los resultados técnicoeconómicos. Navarra Agraria, nov-dic: 33-38.

ONBASILAR, E.E.; ONBASILAR, I. 2007. Effect of cage density and sex on growth, food utilization and some stress parameters of young rabbits. Scandinavian Journal of Laboratory Animal Science, 34 (3): 1-7.

OROVA, Z.; MATICS, Z., BIRÓ-NEMETH, E.; GERENCSER, Z.; NAGY, I.; SZENDRO, Z. 2008. Examination of feeder size for growing rabbits. In: Proceedings of the 9th World Rabbit Congress, Verona (Italy) June 10-13, 2008. p. 351. 
PACI, G.; PREZIUSO, G.; D'AGATA, M.; RUSSO, C.; DALLE ZOTTE, A. 2013. Effect of stocking density and group size on growth performance, carcass traits and meat quality of outdoor-reared rabbits. Meat Science, 93 (2): 162-166.

PRINCZ, Z.; NAGY, I.; RADNAI, I.; GERENCSER, Z.; SZENDRO, Z. 2008. Effect of the floor type and stocking density on the productive performance of growing rabbits. In: Proceedings of the 9th World Rabbit Congress, Verona (Italy) June 1013, 2008. p.353.

SZENDRO, Z., DALLE ZOTTE, A. 2011. Effect of housing conditions on production and behaviour of growing meat rabbits: A review. Livestock Science, 137: 296-303.

SZENDRO, Z.; PRINCZ; Z.; ROMVARI, R.; LOCSMANDI, L.; SZABÓ, A.; BÁZAR, G.; RADNAI, I.; BIRÓ-NEMETH, E.; MATICS, Z.; NAGY, I. 2009. Effect of group size and stocking density on productive, carcass, meat quality and aggression traits of growing rabbits. World Rabbit Science 17: 153-162.
TROCINO, A.; XICATO, G.; MAJOLINI, D.; FRAGKIADAKIS, M. 2008. Effect of cage floor and stocking density on growth performance and welfare of grouphoused rabbits. In: Proceedings of the 9th World Rabbit Congress, Verona (Italy) June 10-13, 2008. p. 1251-1255.

VERSPECHT, A.; MAERTENS, L.; TUYTTENS, F.; VAN HUYLENBROECK, G.; VERBEKE, W. 2011. Economic impact of decreasing stocking densities in broiler rabbit production based on Belgian farm data. World Rabbit Science, 19: 123-132.

VILLAGRÁ, A.; OLIVAS, I.; ESTELLÉS, F.; BLAS, E.; RODRÍGUEZ, T.; ROSEL, J.; PASCUAL, J.J. 2012. How far may rabbit cage's space recommendations reach: the gap between science and regulations. In: Proceedings 10 th World Rabbit Congress - September 3 - 6, 2012Sharm El- Sheikh -Egypt, p.1057-1061.

VILLALOBOS, O.; GUILLÉN, O.; GARCíA, J. 2008. Effect of cage density on growth and caracass performance of fattening rabbits under tropical heat stress conditions. World Rabbit Science, 16: 89-97. 


\section{VALOR NUTRITIVO DE LA CARNE DE CONEJO Y SU POTENCIAL COMO ALIMENTO FUNCIONAL}

\section{INTRODUCCIÓN}

El uso generalizado del conejo como animal de interés zootécnico, se debe principalmente a su comportamiento respecto a los alimentos (fisiología básica caracterizada por la «cecotrofia» y no «competitiva» con el hombre) y por ser fuente de proteínas de alto valor nutritivo. El aspecto dual de la carne de conejo como alimento humano radica en que constituye una fuente 'económica' de proteínas de origen animal, destinada a integrar una dieta deficiente en hogares rurales de países en vías de desarrollo, mientras que en los países con elevado producto nacional bruto, aporta carne magra y con potencial valor nutracéutico, acompañando los nuevos objetivos nutricionales de los consumidores actuales. Con el aumento del estándar de vida, se observa una tendencia creciente a consumir carne más magra, siendo el 'nivel de colesterol' y el contenido de ácidos grasos poliinsaturados (AGPI) otros determinantes importantes en la conducta de los consumidores.

Además del alto contenido de proteínas y aminoácidos esenciales, posee altas concentraciones de calcio, fósforo, potasio y ácidos grasos poliinsaturados, moderado contenido en sodio, bajo contenido en grasas y grasas saturadas y bajo porcentaje relativo de colágeno, lo que influye favorablemente sobre el sistema inmunológico, la digestibilidad y proporciona a la carne de conejo un alto valor nutricional. Por lo antedicho, la carne de conejo resulta ideal para los niños, deportistas, personas con problemas cardiovasculares y obesidad, personas mayores que sufren de acidez estomacal e indigestión y constituye una herramienta para la prevención de las enfermedades metabólicas y enfermedades cardiovasculares. Además de todas estas cualidades nutricionales la carne resulta versátil y se puede preparar en diversas formas, ya que el sabor es suave y no presenta 'tipicidad' si proviene de criadero y es faenado a peso comercial.

\section{CALIDAD DE CARNE DE CONEJO}

\section{Generalidades}

La carne de conejo en la canal presenta coloración rosácea tendiendo al rojizo a medida que pierde humedad, aroma característico a las carnes frescas, muy baja acidez y actividad del agua (aw) comprendida en el rango 0,98-0,999.

En la porción de carne magra, el contenido de agua y proteínas es bastante constante $(73,0 \pm 2,3 \mathrm{~g}$ de agua y $21,5 \pm 1,4 \mathrm{~g}$ de proteínas por $100 \mathrm{~g}$ de carne) al igual que el contenido mineral (en torno al 1,2- 1,3 g/100 $\mathrm{g}$ de carne); a pesar del bajo contenido en hierro $(1,3$ y $1,1 \mathrm{~g} / 100 \mathrm{~g}$ para muslo y lomo, (Parigi Bini et al., 1992), similar al de otras carnes 'blancas', contribuye a cubrir parte del requerimiento diario. La carne de conejo se caracteriza también por un bajo contenido de zinc $(0,55 \mathrm{mg} / 100 \mathrm{~g}$ promedio de canal, Lombardi-Boccia et al., 2005, y 1,1 mg/ $100 \mathrm{~g}$ en muslo, Hermida et al., 2006) y sodio (37 mg/100 g de lomo y 49,5 mg/100 g de muslo), es rica en fósforo (234 y $222 \mathrm{mg} / 100$ $\mathrm{g}$ para muslo y lomo), mientras que los niveles de selenio varían de acuerdo a la suplemen- 
tación de selenio en la dieta, con valores de 9,3 hasta $15,0 \mu \mathrm{g} / 100 \mathrm{~g}$ en las dietas suplementadas (Parigi Bini et al., 1992, Hermida et al., 2006).

Los contenidos de vitaminas varían en función a la composición del alimento o por nivel de suplementación. En promedio, el consumo de $100 \mathrm{~g}$ de carne de conejo aporta alrededor del $8 \%$ de los requerimientos diarios de riboflavina (vitamina B2), $12 \%$ de ácido pantoténico (vitamina B5), el $21 \%$ de piridoxina (vitamina B6), el $77 \%$ de niacina (vitamina B3) y tres veces las recomendaciones diarias (RDI) de vitamina B12 (Hernández y Dalle Zotte, 2010).

El contenido de lípidos depende en gran medida de la porción de carne considerada y de los diferentes factores de producción, especialmente la alimentación (Dalle Zotte, 2002). El corte de carne más magra en la canal de conejo es el lomo (contenido promedio de lípidos de 1,8 g/100 g de carne), mientras que el muslo muestra un contenido en lípidos mayor pero bastante contenido (en promedio $3,4 \mathrm{~g} / 100 \mathrm{~g}$ ). El valor energético de la carne de conejo es moderado-alto (1500 $\mathrm{Kcal} / 100 \mathrm{~g}$ de carne comestible, promedio de carcasa) porque depende sobre todo de su alto contenido de proteína, que representa el $80 \%$ del valor energético. En comparación a las carnes de otras especies animales, la de conejo tiene menor contenido de colesterol $(47,0$ y $61,2 \mathrm{mg} / 100 \mathrm{~g}$, de lomo y muslo respectivamente).

En cuanto a composición de la grasa, los ácidos grasos insaturados (AGI) representan alrededor del $60 \%$ del total de ácidos grasos (AG), y la cantidad de AGPI, que representan el 27-33\% del total de los AG, es mayor que la encontrada en otras carnes, incluidas las de las aves de corral (Wood et al., 2008). El ácido linoleico (18:2 n-6) representa en la carne de conejo el $22 \pm 4,7 \%$ del total de los AG; la incorporación de éste ácido en el tejido adiposo y músculo en relación a la cantidad presente en la dieta es mayor que la de otro AG. La presencia de ácido linolénico (18:3 n-3) en la grasa del conejo es importante $(3,3 \pm 1,5 \%$ del total de $A G$ ) debido a la presencia de alfalfa en la dieta, materia prima rica en dicho ácido graso. Dentro de los AGPI de cadena larga
(>20C), el lomo contiene $0,17 \pm 0,13 \%$ y el muslo $0,06 \pm 0,02 \%$ de $A G$ totales de ácido eicosapentaenoico (EPA, 20:5 n-3); el ácido docosahexaenoico (DHA, 22:6n-3) contenido en carne de conejo es más alto que la de EPA y representa el $0,37 \pm 0,34 \%$ de $A G$ total en el lomo y $0,17 \pm 0,27 \%$ de AG totales en la pata trasera. La relación n-6/n-3 es mayor a la recomendada desde el punto nutricional (n-6/n-3: 5,1 y 10 para el lomo y muslo vs n-6/n-3: < 5; Wood et al., 2008).

Finalmente, la carne de conejo contiene altos niveles de aminoácidos esenciales siendo rica en lisina $(2,12 \mathrm{~g} / 100 \mathrm{~g})$, aminoácidos azufrados $(1,10 \mathrm{~g} / 100 \mathrm{~g})$, treonina $(2,01$ $\mathrm{g} / 100 \mathrm{~g})$, valina $(1,19 \mathrm{~g} / 100 \mathrm{~g})$, isoleucina $(1,15 \mathrm{~g} / 100 \mathrm{~g})$, leucina $(1,73 \mathrm{~g} / 100 \mathrm{~g})$ y fenilalanina (1,04 g/100 g) (Hernández y Dalle Zotte, 2010). Este contenido aminoacídico elevado y su fácil digestibilidad (proteínas del tejido conectivo digestibles) confiere a la carne de conejo proteínas de alto valor biológico. Por otra parte, la carne de conejo no contiene ácido úrico y tiene bajo contenido de purina (Combes y Dalle Zotte, 2005; Hernández, 2007).

\section{Efecto del tipo genético sobre la calidad de carne}

El peso final adulto del conejo tiene gran influencia sobre la tasa de crecimiento, la precocidad y la composición corporal, sin embargo, los conejos utilizados comercialmente para producción de carne pesan entre cuatro y cinco kilos finales y se faenan a las 11-13 semanas de edad por lo que las diferencias en calidad de carne son poco importantes aún entre líneas seleccionadas en aspectos de producción de carne. Los programas de selección en machos se centraron sobre tasas rápidas de crecimiento usando líneas terminales de gran tamaño para mejorar la eficiencia alimenticia y acortar el tiempo de crianza. Si estos conejos se sacrificaran a pesos comerciales ligeros (9 semanas), se obtiene un animal menos maduro, de menor rendimiento de la canal (principalmente debido a la mayor proporción del aparato digestivo) y menor calidad de la canal (principalmente por la modificación de la deposición de grasa). 
Un estudio del desempeño productivo y las cualidades de la canal de las líneas genéticas originarias de la Universidad Politécnica de Valencia, realizado en INIA Las Brujas, evaluó las líneas Verde (V) y Rosa (R) puras y la cruza $\mathrm{RxV}$ faenadas a un peso constante de $2,5 \mathrm{~kg}$, peso de faena habitual en Uruguay. La línea terminal Rosa, seleccionada por velocidad de crecimiento, con relación a la línea materna Verde, seleccionada por tamaño de camada al destete, presentó mayor peso del tracto gastrointestinal lleno (633 vs 402g), menor rendimiento de la canal de referencia ( 42,8 vs $52,3 \%)$, menor contenido total de grasa disecable (25 vs $72 \mathrm{~g}$ ) y menor relación Carne:Hueso (2,50 vs 2,91). La cruza RxV presentó valores intermedios a las dos líneas puras en estos parámetros evaluados (Capra, sin publicar).

La selección por rápido crecimiento favorece en general, un metabolismo energético glucolítico en el tejido muscular en detrimento de la calidad de la carne, afectando la terneza (por menor capacidad de retención de agua y $\mathrm{pH}$ final), sabor y jugosidad, por la falta de lípidos intramusculares. Dichos efectos negativos podrían reducirse aumentando el tamaño de la carcasa comercial o incluyendo en los programas de selección, parámetros de calidad de canal o carne (Dalle Zotte, 2002).

La eficiencia de utilización del alimento para la producción de carne depende en gran medida del potencial genético; a partir de la década del '90 comenzaron a utilizarse líneas paternas terminales especializadas para aumentar la ganancia diaria de peso y para reducir el índice de conversión del alimento (Blasco et al., 1996; Rochambeau et al., 1996). La selección por ganancia de peso permite aumentar el peso corporal a lo largo de la curva de crecimiento; el peso a la edad de sacrificio y la velocidad de crecimiento están fuertemente asociadas con un coeficiente de correlación genética de 0,75 a 0,98 (Hernández y Gondret, 2006).

Algunos autores encontraron también una correlación genética positiva entre peso a edad fija y adiposidad en la carcasa (Larzul et al., 2005) o relación músculo/hueso de 0,70-0,85 (Lukefarh et al., 2006). Otros caracteres en cambio, tienen baja o nula here- dabilidad como ser el pH (correlación nula entre peso a 63 días y pH del lomo) y parámetros colorimétricos de la carcasa (Larzul et al., 2005), mientras que la correlación entre performance de crecimiento y contenido de mioglobina muscular es débilmente negativa (-0.09 a 0,25). Por el momento, en conejos no habría evidencias de la existencia de genes principales que influencien la calidad de la carcasa y de la carne (ver Hernández y Gondret, 2006).

Faenados a igual edad, los animales seleccionados muestran igual rendimiento a faena, igual o menor contenido graso e igual o mayor relación carne/hueso que los no seleccionados. Si bien la selección por velocidad de crecimiento aumenta el metabolismo glucolítico muscular y consecuentemente un menor valor de $\mathrm{pH}$ final en la carne, no hay evidencias de animales seleccionados con el defecto PSE (pale-soft and exudative). Respecto a los parámetros colorimétricos, la luminosidad de los cortes resulta similar entre animales seleccionados y no seleccionados pero la respuesta en los parámetros de $a^{*}$ (índice del rojo) y b* (índice del amarillo) resulta variable. La capacidad de retención de agua en carne fresca es inferior para los animales seleccionados por velocidad de crecimiento pero no suficiente para influenciar las pérdidas por cocción, que resultan similares (Piles et al., 2000). Los animales seleccionados y no seleccionados muestran características histológicas similares (número y tamaño de fibras) y mayor dureza instrumental pero similar terneza sensorial, determinada por un panel de evaluadores entrenados. Desde el punto de vista sensorial, la selección por velocidad de crecimiento parece tener implicancias negativas con menor nota aromática anisada y mayor flavor a hígado (Hernández et al., 2005).

La selección por velocidad de crecimiento afectaría la composición en AG aumentando la presencia de ácido mirístico y palmítico en detrimento del ácido linolénico y araquidónico en animales seleccionados (Ramírez et al., 2005), sin diferencias en la actividad de las enzimas lipolíticas (Ariño et al., 2003). Ramírez et al. (2005) compararon animales contemporáneos: un grupo control 
y uno seleccionado por la tasa de crecimiento durante 14 generaciones, evaluando la composición de ácidos grasos de la carne de muslo y de la grasa perirrenal. La selección modificó los porcentajes de ácidos grasos tanto en la carne y como en la grasa perirrenal, pero los índices relacionados con la salud humana fueron sólo ligeramente modificadas por la selección siendo el cambio más alto, un $10 \%$ de reducción en la relación AGPI/AGS. Los autores concluyeron que la selección por la tasa de crecimiento no dañaría la calidad de la carne y la grasa comestible desde el punto de vista de la salud humana.

Finalmente, los animales seleccionados por velocidad de crecimiento tendrían aproximadamente el mismo grado de madurez que los animales no seleccionados cuando se los faena a igual edad (Blasco et al., 2003); si se quiere comparar el efecto de la selección entre líneas, debe hacerse con animales faenados a igual edad.

En INIA Las Brujas se realizó un estudio comparativo de las cualidades de la canal de conejos correspondientes a la línea materna Verde, a la cruza simple entre la línea terminal Rosa y la Verde, y a la triple cruza obtenida a partir de machos Rosa con hembras cruza de las líneas maternas Celeste y Verde, faenando a una edad fija de 77 días. Los cruzamientos que incluían a la línea terminal Rosa presentaron una mayor velocidad de crecimiento que la línea Verde pura, lo que determinó que a igual edad de faena se lograra un peso aproximadamente $10 \%$ mayor en los individuos cruza. Se verificaron diferencias estadísticamente significativas en los parámetros de calidad de canal que implicaban determinaciones de peso (peso de la canal de referencia, peso total de carne en la canal) pero no se constataron diferencias significativas en el rendimiento de la canal de referencia ni en las relaciones Carne:Hueso para la canal total o para cada uno de los cortes tecnológicos en que se fraccionó la misma (Capra y Fregossi, 2007).

\section{Pesoledad de faena y Calidad de Carne}

El peso corporal del animal aumenta con la edad por lo que se hace difícil atribuir un efecto que dependa tan sólo del peso o de la edad del conejo. Los diferentes componentes del cuerpo desarrollan a velocidades diferentes (alometría del crecimiento) y salvo el tejido adiposo y la piel, el coeficiente alométrico de los otros órganos y tejidos disminuyen con la edad. Debido a los cambios de los coeficientes alométricos, el rendimiento de la canal aumenta hasta 91-98 días de edad; a mayor edad de faena, se reducen las pérdidas de refrigeración y mejora la carnosidad de la canal. La mayor edad al sacrificio permite un mejor aprovechamiento del potencial de crecimiento, pero el aumento del contenido de grasa de la canal y del índice de conversión alimenticia, reduce el interés económico de criar conejos más allá de una determinada edad, dependiendo de la precocidad de la línea utilizada.

La calidad global de la carne aumenta a medida que aumenta el crecimiento ya que aumenta su contenido en lípidos en detrimento del contenido de agua, y presenta un sabor y olor más desarrollado (Dalle Zotte, 2002). Por el contrario, algunas de las propiedades físico-químicas de carne podrían empeorar con la edad, como ser el aumento del metabolismo de la energía glucolítica mientras disminuye el nivel de mioglobina y el $\mathrm{pH}$ final, correlacionado con la reducción de la capacidad de retención de agua (CRA) en la carne cruda.

La faena de animales de igual edad pero distinto peso tiene efecto sobre la grasa separable y el contenido lipídico del músculo, mayor en animales más pesados, sin diferencias significativas en otros parámetros de calidad de carcasa y carne.

Al comparar los conejos sacrificados al mismo peso, pero en diferentes edades, la calidad de la canal depende de la velocidad de crecimiento y el peso vivo final. Los conejos que alcanzan el peso de faena prefijado (2,3 a 2,5 kg) a menor edad (62 vs 80 días), presentan mejor desempeño productivo pero menor calidad de canal (rendimiento y carnosidad) indicando que los animales caracterizados por un crecimiento más rápido poseen un inadecuado grado de madurez. Aunque las propiedades sensoriales de la carne no se vieron afectados por la tasa de crecimiento, la bibliografía sobre el tema 
sugiere que cuando se usan conejos de crecimiento rápido, éstos tienen que ser sacrificados a mayor edad (Dalle Zotte, 2002).

Capra y Fregossi (2007) señalan que las evidencias sugieren la necesidad de ajustar el peso de faena óptimo para cada tipo genético, ya que al faenar animales seleccionados por velocidad de crecimiento al mismo peso habitual que individuos no seleccionados, se acorta el ciclo de engorde, pero se pierde rendimiento y aumenta la proporción de hueso en la canal.

Respecto a la calidad de carne, existe similitud para varios parámetros cualitativos en conejos con distinta tasa de crecimiento y faenados a igual peso. Gondret et al. (2005) no encontraron diferencias en el pH del lomo, CRA y pérdidas de cocción en líneas seleccionadas por diferencia de peso a 63 días y faenados a igual peso.

\section{Alimentación y Calidad de Carne}

La alimentación del conejo asume un importante rol en la salud humana a través de su papel en la obtención de una carne que cumpla con los estándares de los consumidores actuales y futuros; de todos los parámetros productivos, la alimentación es el que tiene mayor impacto en la calidad de la carne resultante. Por su condición de monogástrico, la manipulación de la dieta constituye un método muy eficaz en el aumento de los niveles de AG esenciales, ácido eicosapentaenoico (EPA), ác. docosahexanoico (DHA), conjugados del ácido linoleico (CLA) y AG de cadena ramificada así como de vitamina E y selenio en la carne de conejo. La alimentación puede también influir en cierta medida en el contenido de colesterol así que, considerando las posibles consecuencias de la ingesta de colesterol para la salud humana, la alimentación debería tener en cuenta estrategias para contener o minimizar el contenido de colesterol en la carne de conejo; el suplemento dietario con aceite de pescado y con AG insaturados esenciales, reducen significativamente el nivel de colesterol total en la carne (Xiccato y Trocino 2003).

Debido a las necesidades de fibra, las dietas de conejos se caracterizan por un contenido medio en términos de energía dis- ponible. Sin embargo, los conejos pueden digerir las grasas, los aceites o alimentos ricos en grasas de una manera comparable a otros animales monogástricos, por lo que los lípidos constituyen una alternativa para aumentar el contenido de energía alimentaria. A bajos niveles de inclusión, la digestibilidad de los lípidos dietarios es casi $100 \%$, mantiene la tasa de crecimiento, favorece la eficiencia alimenticia y manipula en gran medida los lípidos depositados (Cobos et al., 1993; Cavani et al., 1996; Dalle Zotte, 2002). Bajo condiciones de alimentación prácticos, la adición de grasa es limitada debido a problemas tecnológicos; la durabilidad de los pellets se reduce significativamente por encima del 2-3\% de adición de grasa.

En la revisión bibliográfica de Dalle Zotte (2002) y Dalle Zotte y Szendrõ (2011), Hernández y Gondret (2006) y Hernández y Dalle Zotte (2010) entre otras, se citan las investigaciones llevadas a cabo para incrementar el contenido de AG n-3 en la carne a través de la suplementación dietaria con aceite vegetal, con materias primas ricas en AGPI n-3 como lino, chía y colza (canola) y con fuentes de origen marino. Se mencionan también los estudios que evidencian la capacidad de conejo para sintetizar AGPI de cadena larga (EPA y DHA) a partir del precursor dietético linolénico, que conduce a un aumento del contenido en AGPI n-3 de la carne y una reducción de la relación de n-6/ n-3 pero un empeoramiento de la estabilidad oxidativa. El aumento de la insaturación de los lípidos de depósito puede ser controlado por la adición de antioxidantes a la dieta como ser la suplementación supranutricional de alfa-tocoferol acetato, recomendándose $200 \mathrm{mg} / \mathrm{kg}$ (Dal Bosco et al., 2004). Un dato muy interesante respecto al tiempo de suplementación dietaria indica que el perfil de AG de los músculos puede ser modificado suplementando sólo durante dos-tres semanas; la administración tardía de las dietas enriquecidas a conejos en engorde sería suficiente para aumentar el contenido de AGPI en la carne, reduciendo los costos, en comparación con un tratamiento más largo (Dalle Zotte y Szendrõ, 2011).

La estrategia más directa para aumentar los AG de cadena larga tal como EPA, DPA 
y DHA en las carnes de conejo se basa en el uso dietético de harina o aceite de pescado o productos de origen marino (harina o aceite de algas, mariscos etc,) en los cuales se encuentran pre formados; sin embargo la bibliografía muestra algunos problemas relacionados con la alta oxidación de los lípidos en los alimentos, el crecimiento de los conejos y la vida útil de las carnes (Navarrete et al., 2007). La inclusión de $1,8 \%$ de aceite de pescado a la dieta de conejos en engorde influencia la calidad sensorial de la carne (menor intensidad de flavor característico y aparición significativa de off flavores), asociados a la mayor oxidación lipídica (Lamanna et al., 2013 a, b).

La contribución diferencial de las fuentes lipídicas de la dieta de conejos sobre el perfil de los ácidos grasos de la carne, la relación n-6/n-3 y la presencia de AGPI de cadena larga fue objeto de numerosos estudios a partir de la difusión del conocimiento sobre la relación entre la grasa consumida y la salud humana. Un estudio muy completo al respecto fue el realizado en la década del '90 por Bernardini et al. (1999), en su estudio sobre las vías metabólicas de los ácidos grasos de la dieta en diferentes tejidos (hígado, grasa perirrenal y músculo longissimus lumborum) en el que se utilizaron cuatro dietas semi-purificadas con distinta relación n-6/n-3 a base de girasol, girasol y lino, lino y aceite de pescado. El hígado mostró el papel más importante en la síntesis de ácidos grasos y resultó el tejido con mayor contenido de AG de cadena larga (> 20C). El girasol determinó un aumento en los AGMI y los n-6 mostrando un claro antagonismo frente a los AG n-3 mientras que la dieta de pescado determinó el mayor enriquecimiento de los n-3. Los autores encontraron que el ácido alfa-linolénico se convierte de manera eficiente en AG n-3 de cadena larga principalmente cuando la relación n-3/n-6 es alta. El músculo mostró la misma tendencia pero de una forma menos consistente mientras que el tejido adiposo reflejó más estrechamente la composición de los ácidos grasos de la dieta. Los resultados de éste trabajo preliminar mostraron la posibilidad de modificar el perfil de ácidos grasos de la car- ne de conejo por medio de una dieta y que la relación de los AG n-3 y n-6 de la dieta es crucial en la regulación de la presencia relativa de los AG de cadena larga en los productos cárnicos.

La producción sobre pasturas y la producción orgánica son métodos alternativos para mejorar el contenido de AG n-3 y $\alpha$-tocoferol en carne de conejo y son vistas como una opción más saludable por los consumidores. La inclusión de forrajes en la dieta como fuentes de ácidos grasos n-3, en animales criados en forma tradicional o al aire libre, fue objeto de estudios recientes como modo de contribuir a modificar favorablemente las cualidades nutricionales de la carne a menor costo (Combes y Cauquil, 2006; Forrester-Anderson et al., 2006; Webb y O'Neill, 2008; Capra et al., 2013).

En línea con los trabajos realizados con alfalfa en INIA Las Brujas, Uruguay, Cossu et al. (2006) evaluaron la influencia de la incorporación de radicheta ${ }^{1}$ (Cichorium intyibum L.) al balanceado comercial (35 a $80 \mathrm{~d}$ de edad), sobre la calidad de carne de conejo. Los animales fueron criados bajo sistema colonia 'open air' y la radicheta se suministró premarchitada en pasteras adaptadas a tal fin. La inclusión de radicheta determinó un mayor porcentaje de fibras rojas $(\beta R)$ en el lomo, relacionadas con una mejor calidad de carne, mientras que en el muslo, la inclusión de radicheta determinó un mayor porcentaje de AGS (mayor contenido de ácidos palmítico y esteárico), y menor porcentaje de AGPI por menor contenido de ácido linoleico, a pesar de la mayor presencia de linolénico, lo que derivó en una menor relación n-6/n-3 para los animales suplementados.

Debido a la existencia de diferencias productivas, citadas en la bibliografía de origen europeo, y con el objetivo de hacer un aporte al conocimiento de las cualidades de la carne de conejo obtenido en condiciones productivas orgánicas, Cossu et al. (2012) evaIuaron la calidad de carne resultante de conejos criados a corral a piso, alimentados con granos y forrajes orgánicos, comparada con la calidad de carne de conejos derivados de un sistema de crianza comercial; to-

\footnotetext{
${ }^{1}$ Nota del Editor: en Uruguay esta forrajera es denominada comúnmente «achicoria».
} 
dos los animales se faenaron a peso comercial $(2,400 \mathrm{~kg})$. No se encontraron diferencias a nivel del contenido de grasa intramuscular ni en la dureza instrumental, indicando que la superficie disponible para el movimiento animal y la edad de faena, no afectan la terneza de la carne de los conejos criados a piso. El perfil lipídico mostró mayor porcentaje de AGS en el sistema orgánico debido al mayor porcentaje de los ácidos palmítico y esteárico. Si bien no hubo diferencias en el contenido total de AGI, la carne de los conejos criados en el sistema comercial presentó mayor nivel de ácido linoleico (C18:2) y menores niveles de ácido linolénico (C18:3) y ácidos conjugados del ácido linoleico (CLA). Los resultados mostraron que la carne de conejos orgánicos resultó igualmente tierna, más oscura que la carne de conejos comerciales y presentó mayor contenido de AGS y AG n-3 lo que derivó en carnes con una relación n6/n3 más beneficiosa para la salud humana.

\section{Tecnología de envasado. Tipos de envasado de carne de conejo}

Los cambios en el estilo de vida, especialmente en los países industrializados, limitan el tiempo dedicado a la preparación de los alimentos a nivel hogar, perjudicando la difusión de la carne de conejo, tradicionalmente presentado como carcasa entera o en porciones. En los últimos años se registró un aumento del procesamiento de la canal del conejo para facilitar tanto su preparación y cocción como la elaboración de productos derivados. Las nuevas tendencias en el consumo muestran asimismo un mayor interés por los productos frescos y «naturales» (poco o sin contenido de aditivos), que conserven sus propiedades nutritivas y organolépticas tras el procesado. En respuesta a estos nuevos hábitos, la industria agroalimentaria ha implementado nuevas tecnologías de conservación que aumentan la vida útil, garantizando la calidad higiénica y minimizando los cambios en los productos alimenticios.

Las propiedades sensoriales de la carne son cruciales para la elección del consumidor al momento de la compra. Las variables cualitativas más importantes son el aspecto (color y consistencia de la carne cruda), textura (terneza y jugosidad) y flavor (olor y sabor). La carne de conejo cambia la 'apariencia' con el tiempo de almacenamiento: puede ser más oscura y seca o húmeda de acuerdo con el sistema de envasado. En general, el consumidor asocia frescura y calidad con un buen color de la carne magra, por lo que las condiciones de almacenamiento deben ser tenidos en cuenta y evaluar los diversos métodos de envasado disponibles que no alteren la apariencia de la carne fresca pero estos sistemas de conservación no han sido estudiados en profundidad para la carne de conejo (Berruga et al., 2005). La elevada actividad de agua y el alto contenido en nutrientes de la carne de conejo y los productos cárnicos derivados los convierte en alimentos perecederos, al igual que el resto de las carnes. La contaminación microbiana superficial, que puede extenderse al resto del producto durante su procesado, la oxidación lipídica que origina sabores y olores desagradables así como la deshidratación y las alteraciones de los pigmentos responsables del color serían los fenómenos más importantes implicados en su deterioro.

Dentro de las tecnologías de envasado que tienen el objetivo mantener la calidad sensorial de productos y prolongar su vida comercial, el uso de películas de distinta permeabilidad al oxígeno, el vacío y la atmósfera protectora, pueden ser utilizados para la carne o productos derivados de carne de conejo. El envasado en atmósfera protectora implica la eliminación del aire contenido en el envase seguida o no de la inyección de un gas o mezcla de gases seleccionado de acuerdo a las propiedades del alimento; el envase ejerce de barrera y aísla, en mayor o menor grado, dicho ambiente de la atmósfera externa. Se habla del envasado bajo Vacío, cuando se evacúa el aire del interior del recipiente, de Atmósfera Controlada, cuando se inyecta un gas/ mezcla de gases tras la eliminación del aire y se somete a un control constante durante el periodo de almacenamiento y Atmósfera Modificada, cuando se extrae el aire del envase y se introduce una atmósfera 
creada artificialmente cuya composición no puede controlarse a lo largo del tiempo.

La elección de una determinada tecnología de envasado resulta condicionada por el tipo de carne. Para carnes con $\mathrm{pH}$ alto (pavo, cordero, conejo) sería recomendable el empleo de atmósferas modificadas que contengan dióxido de carbono (>20 \%) por su acción antimicrobiana mientras que para carnes rojas, se requiere una alta proporción de oxígeno en el empaquetado para el mantenimiento del color, pero combinado con proporciones variables de dióxido de carbono. Los principales microorganismos implicados en el deterioro de los canales de conejo, con valores de $\mathrm{pH}$ superiores a los de otras carnes rojas, son pseudomonas y en menor grado las levaduras y $B$. thermosphacta; las carcasas se estropean y desarrollan olores putrefactos más rápidamente que otras carnes (Rodríguez-Calleja et al., 2005). Para los elaborados cárnicos se recomienda el envasado al vacío o en atmósfera modificada para preservarlos del deterioro microbiano y oxidativo. La bibliografía (Iglesias et al., 2006) recomienda para productos cárnicos envasados en atmósfera modificada: carne fresca: $65-80 \%$ de $\mathrm{O}_{2} / 20-35 \% \mathrm{CO}_{2}$ y resto $\mathrm{N}_{2}$ a $0-4{ }^{\circ} \mathrm{C}$ y una vida útil de $6-8$ días; productos avícolas: $20-70 \%$ de $\mathrm{O}_{2} / 30-50 \% \mathrm{CO}_{2}$ y resto $\mathrm{N}_{2}$ a $0-4{ }^{\circ} \mathrm{C}$ hasta dos semanas de vida útil, no haciendo ninguna especificación para la carne de conejos o productos derivados.

El envasado al vacío reduce la oxidación de lípidos en la carne de conejo y extiende su vida útil a temperaturas de enfriamiento (Fernández-Esplá y O’Neill, 1993); sin embargo se verifica un oscurecimiento de la carne por lo que este tipo de envasado resultaría conveniente cuando la retención del color rojo no sea importante. La atmósfera modificada permite la mezcla de oxígeno para prolongar la retención del color y de dióxido de carbono para inhibir el crecimiento bacteriano. Gariepy et al. (1986) compararon el efecto de los envases a vacío con el de atmósfera modificada (nitrógeno y dióxido de carbono) en la carne de conejo; después de 50 días de almacenamiento refrigerado, el envasado en atmósfera controlada determinó menor pH y crecimiento bacteriano, pero redujo la CRA y la carne resultó más brillante y más dura.

Según el Código Alimentario Argentino para carnes bovinas, el límite de vida útil en refrigeración corresponde a un contenido de nitrógeno básico volátil (NBV) de $30 \mathrm{mgN} /$ $100 \mathrm{~g}$ carne, un contenido de substancias reactivas al ácido tiobarbitúrico (TBARS) de 0,6 mg malonaldehído / $\mathrm{kg}$ carne, recuento de coliformes totales de $300 \mathrm{ufc} / \mathrm{g}$ y recuento de lactobacilos de $106 \mathrm{ufc/g}$. En base a estos parámetros Londoño Orjuela et al. (2011) no encontraron diferencias cualitativas entre las películas usadas para envasado al vacío (permeabilidad al 02: 6-14 y 150 $\mathrm{cm}^{3} / \mathrm{m}^{2}$ día atm) a distintas temperaturas de refrigeración $\left(0\right.$ y $\left.4{ }^{\circ} \mathrm{C}\right)$ de lomos y muslos por 0, 7, 14 y 21 días de almacenamiento, pero encontraron mejor respuesta (menor velocidad de producción de NBV, menor oxidación de lípidos y la preservación de las características de color), en las muestras conservadas a $0^{\circ} \mathrm{C}$. Los tiempos de vida útil de carne de conejo envasada al vacío serían de 3 días a $4^{\circ} \mathrm{C}$ y de 6 días a $0^{\circ} \mathrm{C}$. Los mismos autores, en una experiencia de congelación rápida $\left(-18^{\circ} \mathrm{C}\right.$ x 60, 90 o 120 días) de cortes de lomo envasados con la película de mayor permeabilidad al oxígeno y descongelados a dos velocidades (rápida:1.52 h-1 y lenta: 0.4 h-1) mostraron que la descongelación rápida, resultó más desfavorable en características como color, formación de TBARS, aumento de la dureza y exudado.

La refrigeración $\left(0\right.$ y $\left.5{ }^{\circ} \mathrm{C} \pm 1\right)$ de hamburguesas elaboradas con carne de lomo y muslo de conejo envasadas al vacío (bolsas de 60 micrones de espesor) o con atmósfera modificada ( $30 \% \mathrm{CO}_{2}-70 \% \mathrm{~N}_{2}$ ) hasta 28 días no mostró diferencias en los parámetros cualitativos de las hamburguesas entre envases, características que de off-olores durante el consumo; Cossu et al., 2010). Un trabajo similar, pero envasando los cortes lomo y muslo tampoco mostró diferencias entre sistemas de envasado hasta 28 días si fueron influenciados por el tiempo, la temperatura y el origen de la carne (hamburguesas de lomo menos luminosas, menos rojas, con menor oxidación lipídica y exudación durante la cocción y menor presencia pero si efectos 
del tiempo y temperatura de conservación. A mayor tiempo y mayor temperatura, mayor color global, exudación, intensidad de olor y off olores; la oxidación lipídica fue contenida pero el off olor alcanzó los 5,5 puntos en escala de 10 en las muestras de muslo (Lamanna et al., 2010a).

La influencia del sistema de producción (orgánico o comercial) y del envasado (con o sin vacío) sobre la calidad de hamburguesas elaboradas con carne de toda la carcasa de conejo fue evaluada sobre hamburguesas refrigeradas $\left(4^{\circ} \mathrm{C} \pm 1\right)$ durante 12 días. La oxidación lipídica fue mayor en la carne derivada del sistema comercial y aumentó con el tiempo de conservación mostrando valores bajos y constantes para las hamburguesas de producción orgánica. Las hamburguesas 'orgánicas' se diferenciaron por su mayor valor nutritivo (<n6/n3 e índice trombogénico cercano a 1) y menor intensidad del olor en crudo con el tiempo de conservación. Respecto al envasado, el vacío determinó menor olor a rancio y mayor flavor a conejo pero acompañado de mayor gusto a hígado (Cossu et al., 2009).

Finalmente, y con el objetivo de introducir la carne de conejo en el mercado de las carnes procesadas, Cossu et al. (2012) compararon la calidad y aceptabilidad de hamburguesas de conejo y de pollo refrigeradas $\left(4{ }^{\circ} \mathrm{C} \pm 1\right)$ envasadas al vacío o con atmósfera modificada (30\% $\mathrm{CO}_{2}-70 \% \mathrm{~N}_{2}$ ) hasta 12 días. El sistema de envasado y los días de conservación influenciaron la aceptabilidad de las hamburguesas de ambas carnes; el off-olor/flavor fue muy limitado hasta los nueve días de conservación tanto en vacío como en atmósfera modificada pero el vacío mostró mayor grado de aceptación en general. La preferencia de los consumidores por flavor fue 3 días de conservación - envasadas en atmósfera modificada, para las hamburguesas de conejo y 3 días de conservaciónenvasadas bajo vacío, para las de pollo.

El almacenamiento congelado extiende aún más la conservabilidad de la carne especialmente a temperaturas internas de $-18{ }^{\circ} \mathrm{C}$ logradas en $2.30 \mathrm{~h}$ en comparación con los métodos de congelación ordinarias a $-12{ }^{\circ} \mathrm{C}$, mostrando mayor preservación de tejidos y mayor CRA. Si se compara con carne fresca, la carne congelada tiene menor capacidad de retención de agua y menor saturación del color, cualquiera que sea la longitud de almacenamiento, ya que el congelamiento en si mismo no detiene las reacciones enzimáticas (principalmente hidrolítica) por lo que el proceso de maduración continúa. El pH permanece estable hasta 3 meses, seguido por un aumento progresivo hasta 15 meses (Dalle Zotte et al., 1998) o a 18 meses (Cabanes-Roiron et al., 1996); el congelado, también empeora algunos parámetros indicadores de la evolución bioquímica de la carne: el valor del índice del ácido tiobarbitúrico ( TBARS), indicador de la oxidación de lípidos y de nitrógeno volátil total (TVN), un indicador de la desaminación de proteínas, que son mayores en las carnes congeladas respecto a las carnes frescas. Algunos estudios indicarían que las variaciones físico-químicas derivadas del congelamiento no afectan significativamente los parámetros sensoriales de la carne cocinada, hasta los 12 meses de almacenamiento. Posteriormente, la estabilidad de los lípidos y proteínas se ve comprometida, con un efecto directo sobre los atributos sensoriales (Dalle Zotte, 2002). Debido a la presencia de antioxidantes naturales aportados por el forraje, la oxidación de la carne de hamburguesas congeladas derivadas de una producción orgánica de conejos, se mantuvo más estable y con valores de TBARS de menor magnitud respecto a la carne de hamburguesas derivadas de una producción comercial. La conservación bajo congelamiento de hamburguesas derivadas de producción orgánica presentan mayor estabilidad oxidativa y de los parámetros colorimétricos, menor olor a conejo pero mayor flavor característico (Lamanna et al., 2010b).

\section{La carne de conejo como alimento funcional}

El alto nivel de bioseguridad alcanzado por la carne de conejo, para la que no se han informado casos de daño o intoxicación, resulta muy interesante desde el punto de vista de la alimentación y la dietética humana. Sin embargo, las cualidades de dicha carne, como ser el alto valor nutricional, su 
baja alergenicidad, bajo contenido en sodio, grasa y colesterol y elevada proporción de AGPI, no son suficientes para orientar la elección masiva de los consumidores, influenciados por mensajes promocionales destinados al consumo de otras carnes. El creciente conocimiento acerca de la relación entre la dieta y la salud ha aumentado la conciencia 'alimentaria' y la demanda de alimentos funcionales. La carne y sus derivados pueden ser considerados como tales desde el momento en que contienen numerosos compuestos con propiedades funcionales. La exhaustiva revisión de Dalle Zotte y Szendrõ (2011) muestra las excelentes propiedades nutricionales y dietéticas de la carne de conejo y las estrategias llevadas a cabo para mejorar el valor 'funcional' de la carne de conejo.

Como los rumiantes, los conejos contienen AG impares y de cadena ramificada (de origen microbiano) en su carne, debido a la cecotrofia. Algunos AG de cadena ramificada tienen la propiedad de inhibir el crecimiento de diversas células cancerosas tanto in vitro como in vivo (Wongtangtintharn et al., 2004) y puede aumentarse su presencia a través de la dieta. Papadomichelakis et al. (2010) suministraron altos niveles de fibra digestible (260 g/kg MS vs control: $180 \mathrm{~g} / \mathrm{kg}$ MS) logrando aumentar el contenido de AGPI en detrimento de los AGMI y un aumento significativo de la cantidad de AG impares y de cadena ramificada en la carne. Por medio de la cecotrofia también puede retenerse CLA en la carne (Gómez-Conde et al., 2006), aunque con dietas tradicionales solo se logran valores bajos, cercanos a $0.07 \mathrm{~g} / 100 \mathrm{~g}$ de AGtot. de cis-9, trans-11 CLA; la suplementación dietaria de CLA sintético permite aumentar su contenido. Un trabajo de Lo Fiego et al. (2005) muestra que una suplementación de $0,0,25$ y $0,50 \%$ de CLA derivó en contenidos de $0.402 .54,7.59 \mathrm{mg} / \mathrm{g}$ de lípidos totales para el cis-9, trans-11 CLA. La suplementación de altas concentraciones de CLA sintético por cortos períodos (tres semanas) parece ser lo más adecuado para la producción de carne de conejo enriquecido con CLA a menor costo (Dalle Zotte y Szendrõ 2011).

La forma más bioactiva de los $A G$ n-3 son EPA y DHA, mientras que el ácido alfa-lino- lénico tiene muy poca actividad biológica desde que su conversión a EPA en los seres humanos es muy baja (17:01) (Decker y Park, 2010); estos dos ingredientes de alimentos funcionales pueden incrementarse fácilmente en la carne de conejo a través del aumento de los mismos en la alimentación. La suplementación dietética con semillas o aceites ricos en AG n-3 incrementa significativamente el contenido de ácidos grasos poliinsaturados y reduce la relación $n-6 / n-3$ en la carne de conejo y podrían ser potencialmente utilizados para obtener carnes funcionales, sólo si se complementa con un alto nivel de antioxidantes. En general, los lípidos totales y el contenido de AG aumentan en la carne cocida a causa de las pérdidas por cocción; los contenidos de AGS y AGMI no cambian significativamente, pero los AGPI generalmente disminuyen a menos que se protejan con antioxidantes.

El principal problema asociado al aumento de contenido de AGPI en la carne es la oxidación de los mismos y la reducción de la vida útil de la carne o productos cárnicos, problema que se agrava cuando se pica la carne, se cuece o se almacena durante mucho tiempo (Lee et al., 2006). Las propiedades antioxidantes de la vitamina $\mathrm{E}$ mejoran la calidad de los nutrientes ya que impiden la oxidación de ácidos grasos y mantienen el color 'fresco', extendiendo la vida útil de la carne. Al igual que otras carnes, la carne de conejo puede enriquecerse con vitamina $\mathrm{E}$ a través de la suplementación dietética de acetato de $\alpha$-tocoferol (Dalle Zotte y Szendrõ, 2011)

El contenido de vitamina $E$ se puede aumentar en más del $50 \%$ respecto al obtenido con una dieta comercial, con suplementos dietéticos de 200mg á-tocoferol acetato/ $\mathrm{kg}$ dieta, logrando mayor capacidad de retención hídrica, mejor preservación del color y estabilidad oxidativa en carne fresca o congelada. La reducción de los procesos de peroxidación y de pérdida de AG n-3 aumenta el valor nutricional de la carne enriquecida con vitamina $\mathrm{E}$, incluso en su presentación como hamburguesa o productos elaborados a base de carne de conejo.

La industria de la carne de conejo aún no está desarrollada suficientemente como para 
valorar las propiedades antioxidantes y antimicrobianas de aceites esenciales y extractos de muchas plantas (orégano, salvia, tomillo, romero, etc), como ocurre en otras carnes. De hecho, estos productos naturales usados como antioxidante dan respuestas variables y debe seguir estudiándose la dosis y el tiempo de suministro adecuado para cada uno. El aceite esencial de orégano ejerce un efecto antioxidante significativo a nivel de $200 \mathrm{mg} / \mathrm{kg}$ y una reducción del número promedio de microbios en las canales. La chía (Salvia hispánica), es muy rica en ácidos grasos omega-3 pero también fuente de antioxidantes; los taninos y la Spirulina platensis (una microalga azul-verde), parecen también ser candidatos potenciales (ver revisión de Dalle Zotte y Szendrõ, 2011).). El alga desecada y molida (10\% de la dieta) resultó efectiva en controlar la oxidación de la carne fresca y congelada por tres meses de conejos alimentados con 1,8\% de aceite de pescado (Lamanna, 2013c). Por lo tanto, la fortificación de la dieta con vitamina $E$, aceites (orégano, chía) o productos naturales tales como algas y microalgas (Spirulina platensis), parecen ser vías prometedoras para mejorar la estabilidad oxidativa de la carne de conejo, además de constituir en sí mismos ingredientes funcionales.

El selenio desempeña un papel importante en la eficiencia del sistema antioxidante y con dietas suplementadas (algas o levaduras selenizadas), el contenido de selenio en la carne de conejo puede aumentar de 24 a 39,5 $\mu \mathrm{g} / 100 \mathrm{~g}$ (Dokoupilova et al., 2007; Marounek et al., 2009). Aunque estos autores no encontraron ningún efecto sobre la estabilidad oxidativa de la carne, $140 \mathrm{~g}$ de carne de conejos alimentados con selenio cubriría la ingesta recomendada de selenio al día para los adultos (55 mg/día, Surai, 2006) y podría ser considerada como una carne funcional.

Aunque la carne de conejo ofrece excelentes propiedades nutricionales y dietéticos per se, su enriquecimiento con compuestos bioactivos a través de la manipulación de la dieta, permitiría obtener carne considerada como funcional. Esta carne proporcionaría a los consumidores mayores niveles de AGPI,
CLA, EPA, DHA, vitamina E y selenio, así como menor relación $n-6 / n-3$, compuestos que desempeñan un papel importante en el control de las enfermedades cardiovasculares y otras enfermedades crónicas con claro beneficio para la salud humana.

\section{BIBLIOGRAFÍA}

ARIÑO B.; HERÁNDEZ P.; BLASCO A. 2003. Efecto de la selección por velocidad de crecimiento sobre la actividad de enzimas proteoliticas y lipolíticasde la carne de conejo. ITEA, 24: 225-228.

BERNARDINI, M.; DAL BOSCO, A.; CASTELLINI, C. 1999 . Effect of dietary $n-3 / n-6$ ratio on fatty acid composition of liver, meat and perirenal fat in Rabbit. Animal Science, 1 (68): 647-654.

BERRUGA, M.I.; VERGARA, H.; LINARES M.B. 2005. Control of microbial growth and rancidity in rabbit carcasses by modified atmosphere packaging. Journal of the Science of Food and Agriculture, 85: 1987-1991.

BLASCO A.; PILES M.; RODRIGUEZ. PLA M. 1996. The effect of selection for growth rate on the live weight growth curve in rabbits. In: Proc.6th World Rabbit Congress, July 9-12, Toulouse (France), Vol 2, 245-248.

BLASCO A.; PILES M.; VARONA L. 2003. A bayesian analysis of the effect of selection for growth rate on growth curves in rabbits. Genetics Selection Evolution, 35 : 21-41.

CABANES-ROIRON A.; OUHAYOUN J.; GILBERT S. 1996. Congélation de la viande de Iapin. Influence de la durèe de conservation sur les propriétés physicochimiques et sensorielles $(3,6,9,12$ e 18 mois Viandes et Prodiuts Carnés, 17 (4), 166-171.

CAPRA, G.; FREgossI, A. 2007. Comportamiento productivo y características de la canal de conejos para carne de líneas sintéticas de alto rendimiento y sus cruzas. IX Encuentro de Nutrición y Producción de Animales Monogástricos. Memorias del Encuentro. Montevideo: Facultad de Agronomía, Universidad de la República, 107. 
CAPRA, G.; GROMPONE, M.A.; URRUZOLA, N.; PARDO, M.J.; MARTÍNEZ, R.; FRADILETTI, F.; COZZANO, S.; REPISO, L.; MÁRQUEZ, R. 2010. Effect of fresh alfalfa in the diet of growing rabbits on growth performance, carcass characteristics and fat composition. IV Congreso Cunicultura de las Américas 2010, Córdoba, Argentina.

CAPRA, G.; MARTÍNEZ, R.; FRADILETTI, F.; COZZANO, S.; REPISO, L.; MÁRQUEZ, R.; IBÁÑEZ, F. 2013. Meat quality of rabbits reared with two different feeding strategies: with or without fresh alfalfa ad libitum. World Rabbit Science, 21(1): 23-32.

CAVANI, C.; ZUCCHI, P.; MINELLI, G.; TOLOMELLI, B.; CABRINI, L.; BERGAMI, R. 1996. Effects of soybeans on growth performance and body fat composition in rabbits. Proc.6th World Rabbit Congress, July 9-12, Toulouse (France), Vol 1, 127-133.

COBOS A.; CAMBRO M.I.; ORDOÑEZ J.A.; DE LA HOZ L. 1993. Effect of fat-enriched diets on rabbit meat fatty acid composition. Journal of the Science of Food and Agriculture, 62 : 83-88.

COMBES, S.; CAUQUIL, L. 2006. Une alimentation riche en luzerne permet d'enrichir la viande des lapins en oméga 3 . Viandes Production Carnés, 25: 31-35.

COMBES, S.; DALLE ZOTTE, A. 2005: La viande de lapin: valeur nutritionnelle et particularités technologiques. In: Proceedings 11èmes Journées de la Recherche Cunicole, pp. 167-180, 2930 November 2005, Paris, France.

COSSU, M.E.; GAUNA, C.; GRAZIOTTI, E.; TACCHINI, F., MARTINO, P., CUMINI, M.L.; LAZZARI, G., BASSO, L. 2006. Calidad de carne de conejo: efectos de la adición de achicoria fresca (Cichorium intyibum I.) en la dieta. Revista Actualización en Nutrición de la Sociedad Argentina de Nutrición, 7 (4): 11-17.

COSSU, M. E.; CERVINI, M. L.; LAMANNA, M. L.; GIARDINA, E. 2012. Traits of meat quality in rabbits in an integrated organic farming system. 10th World Rabbit Congress. 3-6 September. Sharm ElSheikh. Egipto, 755-759.
COSSU, M. E.; LAMANNA, M.L.; CUMINI, M.L.; LAZZARI, G.; VELLO, V. 2010. Effects of packing and ageing on shelf life of rabbit hamburgers. 4to. Congreso de Cunicultura de las Américas. 21 al 24 septiembre. Córdoba. Cd rom

COSSU, M. E.; LAMANNA, M. L.; PICALLO, A. B.; CUMINI, M. L.; GAMBETTI, P.; LAZZARI G. 2012. Physical, chemical and sensory quality in rabbit burgers, refrigerated and stored under different conservation methods.10th World Rabbit Congress. 3-6 september. Sharm El-Sheikh. Egipto. Pg. 887-890.

COSSU, M.E.; PICALLO, A.B.; LAMANNA,M.L.; PEREYRA, A.M.; COSTE, B, BASSO, L. 2009. Effects of packing and ageing on shelf life of rabbit hamburgers from 'organic' and 'commercial' production system. 55th International Congress of Meat Science and Technology, 17-21/09/09, Cophenaguen, Dinamarca. CDRoom. Sección 8. PE8.13.

DAL BOSCO, A.; CASTELLINI, C.; BIANCHI, L.; MUGNAI, C. 2004. Effect of dietary alinolenic acid and vitamin $E$ on the fatty acid composition, storage stability and sensory traits of rabbit meat. Meat Science, 66: 407-413.

DALLE ZOTTE, A. 2002. Perception of rabbit meat quality and major factors influencing the rabbit carcass and meat quality. Livestock Production Science, 75: $11-32$.

DALLE ZOTTE, A.; RIZZI, C.; CHIERICATO, G.M. 1998 - «Un trop long stockage dégrade les caractéristiques qualitatives». Viandes Production Carnés, 19 (3): 1-4.

DALLE ZOTTE, A.; SZENDRÕ, Z. 2011. The role of rabbit meat as functional food. Meat Science, 88(3): 319-33.

DECKER, E.A.; PARK, Y. 2010. Healthier meat products as functional foods. Meat Science, 86: 49-55.

DOKOUPILOVÁ, A.; MAROUNEK, M.; SKØIVANOVÁ, V., BØEZINA, P. 2007. Selenium content in tissues and meat quality in rabbits fed selenium yeast. Czech Journal of Animal Science, 52: 165-169. 
FERNÁNDEZ-ESPLÁ, M.D.; O‘NEILL, E. 1993. Lipid oxidation in rabbit meat under different storage conditions. Journal of Food Science, 58: 1262-1264.

FORRESTER-ANDERSON, I.T.; McNITT, B.J.; WAYC, R.; WAYC, M. 2006. Fatty acid content of pasture-reared fryer rabbit meat Search. Journal of Food Composition and Analysis, 19(6-7): 715-719.

GARIEPY, C.; AMIOT, J.; SIMARD, R.E.; BOUDREAU, A.; RAYMOND, D.P. 1986. Effect of vacuum-packing and storage in nitrogen and carbon dioxide atmospheres on the quality of fresh rabbit: aspects méthodologiques et application a l'étude des effets de l'age et du type génétique. selon des critères sensoriels In: Proceeding of the 7e'mes Journées de la Recherche Cunicole, meat. J. Food Quality 9, 289-309.

GÓMEZ-CONDE, M.S.; MENOYO, D.; CHAMORRO, S.; LÓPEZ-BOTE, C.J.; GARCÍA-REBOLLAR, P.; DE BLAS, J.C. 2006. Conjugated linoleic acid content in cecotrophes, suprarenal and intramuscular fat in rabbits fed commercial diets. World Rabbit Science, 14:95-99.

GONDRET. F.; LARZUL, C.; COMBES, S.; ROCHEMBEAU DE H. 2005. Carcass composition, bone mechanical properties and meat quality traits according to growth rate of rabbits. Journal of Animal Science, 83: 1526-1535.

HERMIDA, M.; GONZALEZ, M.; MIRANDA, M.; RODRÌGUEZ-OTERO, J.L. 2006. Mineral analysis in rabbit meat from Galicia (NW Spain). Meat Science, 73: 635-639.

HERNÁNDEZ, P.; GUERRERO, L.; RAMIREZ, J., MAKAWWI, W.; PLA, M.; ARINO, B.,IBAÑEZ M.; BLASCO A. 2005. A bayesian approach to the effect of selection for growth rate on sensory meat quality in rabbits. Meat Science, 69: 123-127.

HERNÁNDEZ, P.; GONDRET F. 2006. In Rabbit advances in rabbit sciences. Edited by L. Maertens and P. Coudert. ILVO 2006. Chapter 5.1 Rabbit Meat quality, pg 269.

HERNÁNDEZ, P. 2007. Carne de conejo, ideal para dietas bajas en ácido úrico. Revista Científica de Nutrición. $N^{\circ} 8$ septiembre. Boletín de cunicultura, 154: 33-36.
HERNÁNDEZ, P.; DALLE ZOTTE A. 2010. Influence of diet on rabbit meat quality. pp 163-178. In: Nutrition of the rabbit. Edited by $C$. de Blas, Universidad Politécnica, Madrid, J. Wiseman, University of Nottingham, UK.

IGLESIAS E.G.; GAGO CABEZAS L.; FERNÁNDEZ NUEVO J.L. 2006. Tecnologías de envasado en atmósfera protectora. Colección coordinada por: Fundación para el conocimiento madri+d CEIM. Impresión: Elecé Industria Gráfica, Depósito Legal: M-42.918-2006. pgs 130.

LAMANNA, M.L.; COSSU, M.E.; PICALLO, A.; COSTE, B.; PEREYRA A.M.; MONTENEGRO, B.; LAZZARI G. 2010. Hamburguesas de conejo congeladas: efecto del tiempo de conservación y el origen de la carne. 33. Congreso Argentino de Producción Animal. 13-15 octubre, Viedma, p. 29-30.

LAMANNA, M. L.; COSSU, M.E.; GAMBETTI, P.; PICALLO, A.; LAZZARI, G.; GUEVARA, G. 2013a. Calidad de lomos de conejos provenientes de dietas ricas en omega 3. $36^{\circ}$ Congreso Argentino de Producción Animal. 1-4 de octubre, Corrientes. Argentina.

LAMANNA, M.L.; COSSU, M.E.; GAMBETTI, P.; PICALLO, A.; BASSO, L.; LANDA, A. 2013 B. Efecto de la dieta rica en omega 3 sobre la calidad física y sensorial de muslos de conejos. $36^{\circ}$ Congreso Argentino de Producción Animal. 1-4 de octubre, Corrientes. Argentina.

LAMANNA, M.L.; COSSU, M.E.; GAMBETTI, P.; PICALLO, A.; BASSO, L.; LANDA, A. 2013 C. Influencia del uso de algas y vitamina E como antioxidantes en dietas de conejo rica en omega 3. Datos no publicados lamanna@agro.uba.ar

LAMANNA, M.L.; COSSU, M.E.; PICALLO, A.; MERCANTE, C.; CUMINI, M.L.; VELLO, V. 2010. Effect of vacuum or modified atmosphere packaging on rabbit meat quality. $4^{\text {to }}$. Congreso de Cunicultura de las Américas. 21 al 24 septiembre. Córdoba. Cd room

LARZUL, C.; GONDRET, F.; COMBES, S.; ROCHAMBEAU DE H. 2005. Divergent selection on 63-d body weight in the rabbit: response in growth, carcass and muscle traits. Genetics Selection Evolution, 37: 105-122. 
LEE S.; FAUSTMAN C.; DJORDEVICH D.; FARAJI H.; DECKER E.A. 2006. Effect of antioxidants on stabilization of meat product fortified with n-3 fatty acid. Meat Science, 72:18-24.

LO FIEGO D.P.; MACCIONI P.; SANTORO P.; ROSSI R.; PASTORELLI G.; CORINO C. 2005. Influence of conjugated linoleic acid (CLA) on intramuscular fatty acid composition in the rabbit. Italian Journal of Animal Science, 4: 553-555.

LOMBARDI-BOCCIA G.; LANZI S.; AGUZZI A. 2005. Aspects of meat quality: trace elements and B vitamins in raw and cooked meats. Journal of Food Composition and Analysis, 18(1): 39-46.

LUKEFARH, S.D.; ODI, H.B.; ATAKORA, J.K.A. 2006. Mass selection for 70-days body weight in rabbit. Journal of Animal Science, 74: 1481-1489.

LONDOÑO ORJUELA, M.; DELLO STAFFOLO, M.; BERTOLA, N.; BEVILACQUA, A. E. 2011. Vida útil de carne de conejo envasada en película plástica durante el almacenamiento refrigerado y congelado. Recurso electrónico. Consultado el 20/12/2011.

MAROUNEK M.; DOKOUPILOVÁ A.; VOLEK Z., HOZA I. 2009. Quality of meat and selenium content in tissues of rabbits fed diets supplemented with sodium selenite, selenized yeast and selenized algae. World Rabbit Science, 17(4): 207-212.

NAVARRETE, C.; MARTÍNEZ, E.; RÓDENAS, L.; MOYA, V.J.; PASCUAL, J.J.; BLAS, E.; CERVERA, E. 2007. Empleo de destilados de palma y de aceites de pescado en piensos de conejo. In Proceedings of II Congreso Ibérico de Cunicultura,. Vila Real, Portugal, pp.173-181.

PAPADOMICHELAKIS, G; KARAGIANNIDOU, A.; ANASTASOPOULOS, V.; FEGEROS, K. 2010. Effect of high dietary digestible fibre content on the fatty acid composition of two muscles in fattening rabbits. Livestock Science, 129:159-165.

PARIGI BINI, R.; XICCATO, G.; CINETTO, M.; DALLE ZOTTE, A. 1992. Effetto dell'età, del peso di macellazione e del sesso sulla qualità della carcassa e della carne cunicola. Zootecnica e Nutrizione Animale, 18: 173-190.

PILES, M.; BLASCO A.; PLA M. 2000. The effect of selection for growth rate on carcass composition and meat characteristics of rabbit. Meat Science, 54: 347-355.

RAMIREZ, J.A.; DÍAZ, I.; PLA M.; GIL M.; BLASCO, A.; OLIVER M.A. 2005. Fatty acid composition of leg meat and perirenal fat of selected rabbits by growth rate. Food Chemistry, 90 : 251-256.

ROCHAMBEAU DE H.; OUHAYOUN, J.; CAVAILLE, D.; LACOSTE, J.L.; LERICHE, J.L.; PONCEAU, J.; RETAILLEAU, B. 1996. Comparaison of ten commercial strains of terminal bucks: 1. Growth and feed efficiency. Proc.6th World Rabbit Congress, July 9-12, Toulouse (France), Vol 3, 241-245.

RODRÍGUEZ-CALLEJA, J.M.; GARCÍA-LÓPEZ, M.L.; SANTOS, J.A.; OTERO, A. 2005. Development of the aerobic spoilage Xora of chilled rabbit meat. Meat Science, 70: 389-394

SURAI, P.F. 2006. Selenium in nutrition and health. Nottingham: Nottingham University Press, p. 643-808.

WOOD, J.D.; ENSER, M.; FISHER, A.V.; NUTE, G.R.; SHEARD, P.R.; RICHARDSON, R.I.; HUGHES, S.I.; WHITTINGTON, F.M. 2008. Fat deposition, fatty acid composition and meat quality: A review. Meat Science, 78: 343-358.

WONGTANGTINTHARN, S.; OKU, H.; IWASAKI, H.; TODA, T., 2004. Effect of branchedchain fatty acids on fatty acid biosynthesis of human breast cancer cells, Journal of Nutrition and Science Vitaminology, 50: 137-143.

XICCATO, G.; TROCINO, A. 2003. Role of dietary lipid on digestive physiology immune system and growth in rabbits. Cost 848 , Agriculture and Biotechnology, Praga, Czech Republic, 48-57.

WEBB, E.C.; O'NEILL, H.A. 2008. The animal fat paradox and meat quality. Meat Science, 80 (1): 28-36. 


\section{INVESTIGACIONES EN CALIDAD DE CARNE DE CONEJO EN INIA URUGUAY}

Gustavo Capra $^{1}$

\section{INTRODUCCIÓN}

El consumo de carne de conejo en el Uruguay es insignificante, estimándose que en promedio no llega a los 100 gramos por habitante y por año. Varios factores condicionan la baja demanda del consumidor, entre los cuales se menciona el escaso conocimiento sobre las bondades nutritivas de esta carne y sus posibles formas de preparación culinaria.

Si bien existe abundante información acerca del aporte nutritivo de la carne de conejo en la bibliografía internacional, fundamentalmente generada en los países de Europa mediterránea, la existencia de diferencias con nuestros sistemas de producción hacía necesario el aporte de conocimiento específico sobre las cualidades del producto obtenido en las condiciones productivas prevalecientes en el Uruguay.

Por este motivo, las líneas de investigación desarrolladas en INIA Uruguay incluyeron, en una primera instancia, la caracterización nutricional de la carne de conejo obtenida en las condiciones de producción uruguayas $y$, en una segunda fase, la mejora del aporte de nutrientes mediante la manipulación de la dieta.

\section{COMPARACIÓN DEL VALOR NUTRICIONAL CON DOS ESTRATEGIAS DE ALIMENTACIÓN: CON Y SIN ALFALFA FRESCA}

La utilización de forrajes frescos, producidos en el predio, como sustituto parcial de los alimentos comerciales balanceados, ha sido una estrategia tradicionalmente utilizada por los cunicultores uruguayos para re- ducir costos y atenuar la dependencia de insumos con precios sujetos a bruscas variaciones. Las condiciones agroecológicas del país son favorables para la producción de forrajes de buena calidad a bajo costo.

Si bien la investigación nacional había generado información sobre el uso de diversos forrajes frescos en la alimentación de conejos para carne (Blumetto y Capra, 1998a y b), la adopción de esta estrategia nutricional se había visto limitada por prejuicios vinculados a posibles efectos negativos sobre la eficiencia productiva y la calidad del producto. Estudios sobre la tecnología de producción utilizada en el país sugerían que más del $70 \%$ de los productores dependían exclusivamente de alimentos balanceados comerciales y algo menos del 30 \% recurría a la utilización de forrajes en la dieta de los conejos (Pérez y Velázquez, 1998; Amoza et al., 2008).

La información procedente de la bibliografía sugería que la inclusión de forrajes en la dieta podía contribuir a modificar favorablemente las cualidades nutricionales de la carne de conejo. Hernández (2008) cita trabajos de Forrester-Anderson et al. (2006) que sugieren que dietas basadas en forrajes, en conejos criados al aire libre sobre pasturas, determinan incrementos en el contenido de ácidos grasos n-3. Webb y O'Neill (2008) afirman que se logran cambios favorables en la relación n-6/n-3 en carnes de diferentes especies por la inclusión en la dieta de forrajes ricos en ácidos grasos n-3. Por su parte Dalle Zotte (2000) asegura que la composición de los lípidos de la dieta del conejo modifica el perfil lipídico de los tejidos y menciona específicamente a la alfalfa como fuente de C18:3 n-3. Combes y Cauquil (2006) determinaron que niveles crecientes de inclusión de alfalfa deshidratada en la dieta de conejos en crecimiento provocan incremen- 
tos significativos en el contenido de Ácidos Grasos Poliinsaturados (AGPI), particularmente C18:3 n-3, y una mejora de la relación n-6/ $\mathrm{n}-3$ en la grasa intramuscular del pernil.

Partiendo de estos antecedentes, en sucesivos experimentos realizados en INIA Uruguay se evaluó el desempeño productivo, las cualidades de la canal y el valor nutritivo de la carne de conejos obtenidos con las dos estrategias de alimentación más difundidas en el país, una basada exclusivamente en el suministro de alimento balanceado comercial y otra consistente en ofrecer forraje fresco (alfalfa) a voluntad simultáneamente con la ración comercial.

En el primer experimento, cuarenta conejos cruza de las líneas sintéticas Rosa y Verde (RxV) fueron asignados al momento del destete a dos tratamientos consistentes en estrategias alimenticias basadas en un caso (T1) en el suministro exclusivo de alimento balanceado comercial a voluntad y en el otro (T2) en el ofrecimiento de alfalfa fresca a voluntad además del mismo alimento balanceado también a voluntad (Capra et al., 2010).
La metodología del ensayo se describió a partir de la página 90 en adelante.

El análisis del contenido de grasa intramuscular del músculo Longissimus dorsi determinó valores medios de 2,51 $\pm 0,55 \%$ para el tratamiento sin alfalfa y $2,32 \pm 0,40 \%$ para el que recibió alfalfa, diferencias que no resultaron estadísticamente significativas.

En los Cuadros 1 y 2 se presenta la composición media porcentual en ácidos grasos de las grasas intramuscular y disecable para ambos tratamientos.

Por su relevancia desde el punto de vista de la salud del consumidor se analizó el efecto del tratamiento sobre la sumatoria de los ácidos grasos saturados, monoinsaturados y poliinsaturados, el contenido de los dos ácidos grasos poliinsaturados presentes en mayor abundancia (linoleico y linolénico) y la relación entre los n-6 y n-3. Estos resultados se presentan en los Cuadros 3 y 4.

El importante aumento verificado en el contenido de ácido linolénico (C18:3n-3) de la grasa de los conejos alimentados con alfalfa fresca a voluntad concuerda con los re-

Cuadro 1. Perfil lipídico de la grasa intramuscular (\%).

\begin{tabular}{|c|c|c|c|c|c|c|c|c|c|c|c|c|c|c|c|c|}
\hline Tratamiento & $14: 0$ & $\begin{array}{l}14: 1 \\
n-5\end{array}$ & $15: 0$ & $16: 0$ & $\begin{array}{l}16: 1 \\
n-7\end{array}$ & $17: 0$ & $17: 1$ & $18: 0$ & $\begin{array}{l}18: 1 \\
n-9\end{array}$ & $\begin{array}{l}18: 2 c \\
n-6\end{array}$ & $\begin{array}{l}18: 3 \\
n-3\end{array}$ & $\begin{array}{l}20: 1 \\
n-9\end{array}$ & $20: 2$ & $\begin{array}{l}20: 3 \\
n-6\end{array}$ & $\begin{array}{l}20: 4 \\
n-6\end{array}$ & $\begin{array}{l}\% \text { Total } \\
\text { identificados }\end{array}$ \\
\hline Con Alfalfa & 1,7 & & 0,5 & 26,8 & 2,3 & 0,6 & 0,3 & 7,5 & 22,3 & 24,2 & 3,1 & 0,3 & 0,3 & 0,4 & 3,6 & 93,7 \\
\hline Sin Alfalfa & 2,0 & 0,3 & 0,4 & 26,9 & 2,9 & 0,5 & 0,3 & 7,0 & 23,2 & 23,8 & 1,6 & 0,3 & 0,3 & 0,4 & 3,4 & 93,4 \\
\hline
\end{tabular}

Cuadro 2. Perfil lipídico de la grasa disecable (\%).

\begin{tabular}{|c|c|c|c|c|c|c|c|c|c|c|c|c|c|c|}
\hline Tratamiento & $14: 0$ & $\begin{array}{l}14: 1 \\
n-5\end{array}$ & $15: 0$ & $16: 0$ & $\begin{array}{l}16: 1 \\
n-7\end{array}$ & $17: 0$ & $17: 1$ & $18: 0$ & $\begin{array}{l}18: 1 \\
n-9\end{array}$ & $\begin{array}{l}18: 2 c \\
n-6\end{array}$ & $\begin{array}{l}18: 3 \\
n-3\end{array}$ & $\begin{array}{l}20: 1 \\
n-9\end{array}$ & $20: 2$ & $\begin{array}{l}\% \text { Total } \\
\text { identificados }\end{array}$ \\
\hline Con Alfalfa & 2,2 & & 0,5 & 27,3 & 2,2 & 0,6 & 0,3 & 5,2 & 25,8 & 28,3 & 4,2 & 0,4 & 0,3 & 97,2 \\
\hline Sin Alfalfa & 2,4 & & 0,5 & 28,1 & 2,8 & 0,6 & 0,3 & 5,1 & 26,7 & 27,7 & 2,2 & 0,3 & 0,3 & 97,1 \\
\hline
\end{tabular}

Cuadro 3. Efecto de los tratamientos sobre la composición de la grasa intramuscular del músculo Longissimus dorsi (\%).

\begin{tabular}{|l|c|c|c|}
\hline Parámetro & Sin alfalfa & Con alfalfa & \\
\hline C18:2 n-6 & $23,8 \pm 1,5$ & $24,2 \pm 1,8$ & N.S. \\
\hline C18:3 n-3 & $1,6 \pm 0,2$ & $3,1 \pm 0,5$ & $\mathrm{P}<0,0001$ \\
\hline Suma saturados & $37,2 \pm 1,3$ & $37,1 \pm 1,9$ & N.S. \\
\hline Suma monoinsaturados & $26,3 \pm 1,5$ & $24,7 \pm 1,6$ & $\mathrm{P}=0,0254$ \\
\hline Suma poliinsaturados & $29,2 \pm 1,9$ & $31,2 \pm 2,2$ & $\mathrm{P}=0,0384$ \\
\hline Relación $\mathrm{n}-6 / \mathrm{n}-3$ & $17,1 \pm 2,8$ & $9,3 \pm 1,9$ & $\mathrm{P}<0,0001$ \\
\hline
\end{tabular}


Cuadro 4. Efecto de los tratamientos sobre la composición de la grasa disecable (\%).

\begin{tabular}{|l|c|c|c|}
\hline Parámetro & Sin alfalfa & Con alfalfa & \\
\hline C18:2 n-6 & $27,7 \pm 2,4$ & $28,3 \pm 2,8$ & N.S. \\
\hline C18:3 n-3 & $2,2 \pm 0,2$ & $4,2 \pm 0,8$ & $\mathrm{P}<0,0001$ \\
\hline Suma saturados & $36,8 \pm 1,2$ & $35,8 \pm 1,9$ & N.S. \\
\hline Suma monoinsaturados & $30,2 \pm 1,9$ & $28,6 \pm 2,0$ & N.S. \\
\hline Suma poliinsaturados & $30,1 \pm 2,6$ & $32,6 \pm 3,5$ & N.S. \\
\hline Relación $\mathrm{n}-6 / \mathrm{n}-3$ & $12,4 \pm 0,7$ & $6,9 \pm 1,0$ & $\mathrm{P}<0,0001$ \\
\hline
\end{tabular}

sultados obtenidos por Combes y Cauquil (2006) al evaluar el efecto logrado con diferentes niveles de inclusión de alfalfa deshidratada. Sin embargo, a diferencia del citado trabajo, en el presente estudio no se detectaron niveles cuantificables de los ácidos grasos n-3 eicosapentanoico (EPA) y docosahexanoico (DHA).

La magnitud de la modificación del perfil lipídico por influencia de la dieta resultó mayor en la grasa disecable que en la grasa intramuscular. Dalle Zotte (2002) afirma que el perfil lipídico de la grasa disecable parece reflejar más el de los lípidos de la dieta que la grasa intramuscular. Según Pla (2004) la influencia de los ácidos grasos exógenos es más pronunciada en los depósitos lipídicos disecables que en la grasa intramuscular.

En el segundo experimento, noventa y seis conejos de la línea Verde fueron asignados, una semana después del destete, a tratamientos consistentes en las mismas dos estrategias alimenticias: (T1) suministro exclusivo de alimento balanceado comercial a voluntad y (T2) alfalfa fresca a voluntad además del mismo alimento balanceado también a voluntad (Capra et al., 2013).

Por su relevancia desde el punto de vista nutricional, se evaluó el contenido de grasa intramuscular (a nivel del músculo Longissimus dorsi), la composición química de la grasa intramuscular y disecable y el aporte de la carne en hierro, cinc, magnesio, sodio, vitamina $E$ y purinas.

La inclusión de alfalfa a voluntad en la dieta ofrecida a los conejos del tratamiento T2 determinó una reducción significativa en el consumo total de balanceado, del orden del $11 \%$, sin que se produjera un efecto ne- gativo sobre la velocidad de crecimiento y la edad a la faena.

No se constataron diferencias estadísticamente significativas para ninguno de los parámetros evaluados en referencia a las características de calidad de la canal. Los valores obtenidos en contenido de grasa disecable (la grasa fácilmente removible de la canal, compuesta por la grasa perirenal y depósitos situados en la zona escapular e inguinal), tanto en términos absolutos como en su expresión relativa al peso de la canal de referencia, son muy similares a los logrados en experimentos anteriores en nuestras condiciones.

El contenido de grasa intramuscular (GIM) en el músculo Longissimus dorsi fue de $1,41 \pm 0.34$ vs. $1.39 \pm 0.33 \mathrm{~g} / 100 \mathrm{~g}$ de carne, para $\mathrm{T} 1$ y $\mathrm{T} 2$ respectivamente.

Desde el punto de vista de la composición de las grasas, la inclusión de alfalfa a voluntad en la dieta de los conejos en crecimiento determinó un incremento en el contenido de ácidos grasos poliinsaturados y en particular un aumento significativo del ácido linolénico C18:3 n-3, tanto a nivel de la grasa intramuscular como en la grasa disecable (Cuadro 5). Esto determina un mejor equilibrio en la relación n6/n3, considerada un indicador de importancia en la caracterización de los alimentos con relación a la incidencia de enfermedades cardiovasculares.

Al igual que en el primer experimento, la magnitud de la modificación del perfil lipídico por influencia de la dieta resultó mayor en la grasa disecable que en la grasa intramuscular.

Se destaca la verificación en la grasa intramuscular, pero no en la grasa disecable, 
Cuadro 5. Efecto de los tratamientos sobre la composición de la grasa disecable e intramuscular (\%).

\begin{tabular}{|c|c|c|c|c|c|c|}
\hline \multirow[b]{2}{*}{ Acido graso } & \multicolumn{2}{|c|}{ Grasa Intramuscular } & \multirow[b]{2}{*}{$\mathbf{P}$} & \multicolumn{2}{|c|}{ Grasa Disecable } & \multirow[b]{2}{*}{$\mathbf{P}$} \\
\hline & T1 & T2 & & T1 & T2 & \\
\hline C12:0 & $0,07 \pm 0,01$ & $0,07 \pm 0,02$ & N.S. & $0,25 \pm 0,17$ & $0,18 \pm 0,14$ & N.S. \\
\hline C14:0 & $1,88 \pm 0,27$ & $1,58 \pm 0,33$ & $P=0,0391$ & $2,36 \pm 0,35$ & $2,13 \pm 0,26$ & N.S. \\
\hline C16:0 & $28,66 \pm 1,89$ & $28,04 \pm 1,56$ & N.S. & $31,49 \pm 2,86$ & $29,65 \pm 0,71$ & N.S. \\
\hline C18:0 & $8,44 \pm 0,74$ & $8,85 \pm 0,74$ & N.S. & $5,64 \pm 0,72$ & $6,22 \pm 0,56$ & N.S. \\
\hline C16:1cis & $4,13 \pm 1,19$ & $2,95 \pm 0,80$ & $P=0,0181$ & $2,34 \pm 0,54$ & $1,35 \pm 0,32$ & $P=0,0031$ \\
\hline C18:1cis & $27,50 \pm 1,67$ & $24,70 \pm 2,46$ & $P=0,008$ & $27,27 \pm 1,47$ & $25,13 \pm 1,37$ & $P=0,0265$ \\
\hline C18:2 (n-6) & $21,27 \pm 1,84$ & $22,24 \pm 2,63$ & N.S. & $26,58 \pm 3,80$ & $28,70 \pm 2,04$ & N.S. \\
\hline C18:3 (n-3) & $1,82 \pm 0,50$ & $3,28 \pm 0,63$ & $P<0,0001$ & $2,29 \pm 0,45$ & $5,15 \pm 0,68$ & $P<0,0001$ \\
\hline$C 20: 4(n-6)$ & $2,18 \pm 0,97$ & $3,45 \pm 1,47$ & $P=0,0348$ & $0,07 \pm 0,01$ & $0,08 \pm 0,01$ & N.S. \\
\hline C20:5 (n-3) & $0,25 \pm 0,19$ & $0,18 \pm 0,11$ & N.S. & - & - & - \\
\hline C22:5 (n-3) & $0,12 \pm 0,10$ & $0,47 \pm 0,25$ & $P=0,0112$ & - & - & - \\
\hline C22:6 (n-3) & $0,20 \pm 0,12$ & $0,37 \pm 0,34$ & N.S. & - & - & - \\
\hline$\Sigma$ SFA & $40,36 \pm 2,37$ & $39,91 \pm 1,99$ & N.S. & $40,76 \pm 3,12$ & $39,37 \pm 0,81$ & N.S. \\
\hline$\Sigma$ MUFA & $32,10 \pm 2,47$ & $28,30 \pm 2,57$ & $P=0,0035$ & $30,10 \pm 2,10$ & $26,73 \pm 1,58$ & $P=0,0105$ \\
\hline$\Sigma$ PUFA & $27,04 \pm 3,51$ & $31,15 \pm 4,00$ & N.S. & $29,02 \pm 3,91$ & $33,89 \pm 2,04$ & $P=0,0222$ \\
\hline PUFA/SFA & $0,68 \pm 0,12$ & $0,79 \pm 0,13$ & N.S. & $0,72 \pm 0,15$ & $0,86 \pm 0,06$ & N.S. \\
\hline SFA/(MUFA+PUFA) & $0,69 \pm 0,07$ & $0,67 \pm 0,06$ & N.S. & $0,69 \pm 0,09$ & $0,65 \pm 0,02$ & N.S. \\
\hline$\Sigma(n-6)$ & $23,59 \pm 2,79$ & $25,83 \pm 3,55$ & N.S. & $26,77 \pm 3,72$ & $28,74 \pm 2,00$ & N.S. \\
\hline$\Sigma(n-3)$ & $2,81 \pm 0,67$ & $4,55 \pm 0,81$ & $P<0,0001$ & $2,38 \pm 0,48$ & $5,18 \pm 0,71$ & $P<0,0001$ \\
\hline$n-6 / n-3$ & $8,60 \pm 1,21$ & $5,82 \pm 1,19$ & $P<0,0001$ & $11,58 \pm 2,34$ & $5,64 \pm 0,86$ & $P=0,0002$ \\
\hline$n-3 / n-6$ & $0,12 \pm 0,02$ & $0,18 \pm 0,03$ & $P<0,0001$ & $0,09 \pm 0,02$ & $0,18 \pm 0,03$ & $P<0,0001$ \\
\hline $\mathrm{Al}$ & $0,62 \pm 0,07$ & $0,58 \pm 0,06$ & N.S. & $0,70 \pm 0,10$ & $0,63 \pm 0,03$ & N.S. \\
\hline$\pi$ & $0,96 \pm 0,12$ & $0,80 \pm 0,10$ & $P=0,0057$ & $1,12 \pm 0,17$ & $0,88 \pm 0,04$ & $P=0,0065$ \\
\hline $\mathrm{h} / \mathrm{H}$ & $1,95 \pm 0,21$ & $2,02 \pm 0,17$ & N.S. & $1,77 \pm 0,21$ & $1,91 \pm 0,06$ & N.S. \\
\hline
\end{tabular}

Îndice de Aterogenicidad: $\mathrm{Al}=\left[\mathrm{C} 12: 0+\left(4^{*} \mathrm{C} 14: 0\right)+\mathrm{C} 16: 0\right] /[(\Sigma$ PUFA $)+(\Sigma$ MUFA $)]$

Índice de Trombogenicidad: TI $=[C 14: 0+C 16: 0+C 18: 0] /\left[\left(0,5^{\star} \Sigma\right.\right.$ MUFA $\left.)+\left(0,5^{\star} \Sigma n-6\right)+\left(3^{\star} \Sigma n-3\right)+(n-3 / n-6)\right]$ $\mathrm{h} / \mathrm{H}=(\Sigma$ MUFA $+\Sigma \mathrm{PUFA}) /(\mathrm{C} 14: 0+\mathrm{C} 16: 0)$

de tenores medibles de ácidos grasos poliinsaturados de cadena larga del grupo n-3: eicosapentanoico (EPA) C20:5, docosapentanoico (DPA) C22:5 y docosahexanoico (DHA) C22:6. La inclusión de alfalfa en la dieta determinó en un incremento significativo en el nivel de DPA. Podría afirmarse que el nivel de estos ácidos grasos n-3 en la carne de conejo es relativamente bajo y variable. Combes y Cauquil (2006) sostienen que hay variabilidad individual en la capacidad de depositar ácido linolénico en la carne. Se sugiere que un incremento en el aporte de linolénico, precursor de los mencionados ácidos grasos de cadena larga, estimula su biosíntesis por elongación y desaturación del linolénico (Combes y Cauquil, 2006; Tres et al., 2008).
La modificación en la composición de las grasas intramuscular y disecable por inclusión de alfalfa en la dieta tiene un efecto beneficioso en todos los índices utilizados para evaluar el valor nutritivo y el impacto potencial de los alimentos sobre la salud del consumidor. Uno de los indicadores más utilizados, la relación n-6/n-3 presenta diferencias relevantes entre ambos tratamientos. Los Índices de Aterogenicidad y Trombogenicidad propuestos por Ulbricht y Southgate (1991) también exhiben una mejora resultante de la inclusión de alfalfa, especialmente en la grasa disecable. Ambos índices establecen una relación de los contenidos de diferentes ácidos grasos que permitiría predecir el efecto de los alimentos (o las dietas) so- 
bre la incidencia de enfermedades vasculares. En este experimento se verificaron diferencias estadísticamente significativas entre tratamientos en el valor del TI, con efecto positivo de la dieta con alfalfa. Los valores obtenidos en este experimento para el Al son ligeramente más bajos y los de TI ligeramente más altos que los registrados por Lazzaroni et al. (2009), en conejos criados en dos diferentes sistemas de alojamientos.

La relación h/H entre ácidos grasos hipocolesterolémicos e hipercolesterolémicos es otro indicador utilizado para estimar los atributos nutricionales de los alimentos (Herranz et al., 2008): En este experimento no se registraron diferencias estadísticamente significativas para este indicador ni en la grasa intramuscular ni en la disecable

La estrategia alimenticia consistente en la inclusión de alfalfa a voluntad mejoró la calidad de la grasa, principalmente a través de un incremento del contenido de ácido linolénico C18:3 n-3. Esto determina un mejor valor de la relación n-6/n-3, considerado un importante factor en la prevención de enfermedades cardiovasculares (Carrero et al., 2005; Béliveau y Gingras, 2007). De acuerdo con López-Farré y Macaya (2006) el efecto protector de los ácidos grasos del grupo n-3 se basaría en tres mecanismos: efecto antinflamatorio, efecto antitrombótico y acción antiarritmia.
Desde el punto de vista del contenido y la composición de las grasas, la carne de conejo puede ubicarse junto a los llamados alimentos saludables, y contribuir a una nutrición defensiva. A la vez el perfil lipídico de la grasa intramuscular, particularmente el logrado en conejos suplementados con alfalfa, exime a esta carne de los efectos negativos atribuibles a la ingestión de otras de consumo frecuente en Uruguay, ofreciendo efectos positivos para la salud, como un menor contenido de AGS y mayor de AGI.

En el Cuadro 6 se presentan los resultados del efecto de los tratamientos sobre el aporte de algunos minerales seleccionados (sodio, hierro, magnesio y cinc) y vitamina $\mathrm{E}$.

Los valores obtenidos para sodio y magnesio se encuadran dentro de los que provee la bibliografía europea, mientras que el aporte de hierro se encuentra por debajo y el cinc por encima (Dalle Zotte, 2002; Combes y Dalle Zotte, 2005; Gigaud and Le Cren, 2006). Hermida et al. (2006) sostienen que el bajo contenido de sodio y el alto tenor en potasio determinan que la carne de conejo sea particularmente recomendable en dietas para hipertensos. Estos autores también señalan que la carne de conejo provee menos cinc y hierro que las carnes de otras especies.

El contenido de purinas determinado en la carne de conejo de ambos tratamientos se presenta en el Cuadro 7.

Cuadro 6. Efecto de los tratamientos sobre el aporte de minerales y vitamina E.

\begin{tabular}{|l|c|c|c|}
\hline & T1 sin alfalfa & T2 con alfalfa & $\mathbf{P}$ \\
\hline Sodio $\mathrm{mg} / 100 \mathrm{~g}$ & $44,1 \pm 0,49$ & $48,2 \pm 0,30$ & $\mathrm{P}=0,0382$ \\
\hline Hierro $\mathrm{mg} / 100 \mathrm{~g}$ & $0,629 \pm 0,46$ & $0,645 \pm 0,66$ & N.S. \\
\hline Magnesio $\mathrm{mg} / 100 \mathrm{~g}$ & $22,5 \pm 0,17$ & $24,4 \pm 0,16$ & $\mathrm{P}=0,0211$ \\
\hline Cinc $\mathrm{mg} / 100 \mathrm{~g}$ & $1,29 \pm 0,11$ & $1,34 \pm 0,14$ & N.S. \\
\hline Vit. E $\mathrm{mg} \alpha$-tocoferol/100g & $0,267 \pm 0,04$ & $0,309 \pm 0,05$ & N.S. \\
\hline
\end{tabular}

Cuadro 7. Contenido medio de purinas (mg/100 g).

\begin{tabular}{|l|c|c|c|}
\hline & T1 sin alfalfa & T2 con alfalfa & $\mathbf{P}$ \\
\hline Guanina & $20,7 \pm 2,6$ & $19,7 \pm 1,9$ & N.S. \\
\hline Hipoxantina & $82,1 \pm 7,4$ & $80,6 \pm 6,4$ & N.S. \\
\hline Xantina & n.d. & n.d & - \\
\hline Adenina & $23,6 \pm 2,8$ & $21,8 \pm 2,0$ & N.S. \\
\hline
\end{tabular}


Cuadro 8. Resultados de la evaluación sensorial de textura y agrado general.

\begin{tabular}{|l|c|c|}
\hline & Textura & Agrado general \\
\hline T1 sin alfalfa & $6,8 \mathrm{a}$ & $6,9 \mathrm{~b}$ \\
\hline T2 con alfalfa & $6,5 \mathrm{a}$ & $6,6 \mathrm{~b}$ \\
\hline
\end{tabular}

Letras diferentes dentro de una misma columna indican diferencia significativa para ese atributo $(p<0,05)$.

La carne de conejo ha sido promocionada por su bajo contenido en purinas, que la haría especialmente recomendada en dietas para hiperuricémicos (Bixquert y Gil-Borrás, 2005; Hernández, 2008). Sin embargo otras fuentes, como las tablas de composición nutricional de alimentos Souci-FachmannKraut, ubican a la carne de conejo entre los alimentos con un contenido moderado de purinas, comprendido en el rango $95-150 \mathrm{mg}$ ácido úrico/100g.

Brulé et al. (1988) sostienen que las purinas poseen diferente efecto metabólico, habiéndose constatado que el consumo de adenina e hipoxantina modifica los niveles de ácido úrico sérico y urinario, mientras que guanina y xantina no muestran dicho efecto. Estos autores afirman que, si bien existe una amplia variación en el contenido total de purinas en los alimentos, prácticamente todos los productos cárnicos poseen similares valores para la sumatoria de adenina + hipoxantina, en el rango de 100 a $150 \mathrm{mg} / 100 \mathrm{~g}$ de alimento.

La evaluación sensorial dio por resultado que el panel de consumidores, integrado por funcionarios del Laboratorio Tecnológico del Uruguay, fue capaz de diferenciar, con un 95\% de confianza, las muestras procedentes de ambos tratamientos. Sin embargo, la evaluación sensorial de los atributos textura y agrado general de las muestras no mostró diferencias estadísticamente significativas (Cuadro 8).

Estos resultados sugieren que la inclusión de alfalfa fresca imprime una modificación en las cualidades sensoriales de la carne de conejo que permiten al consumidor distinguirla de la procedente de conejos alimentados exclusivamente con alimento balanceado, pero que este efecto no se traduce en una afectación significativa del agrado general de la misma.

\section{CONCLUSIONES}

Estos trabajos confirman algunas de las bondades reconocidas a la carne de conejo, como su bajo contenido en grasa y su elevado aporte en ácidos grasos poliinsaturados, en particular aquellos integrantes del grupo omega-3. Se verificaron algunas diferencias con información procedente de la literatura internacional en las características de la canal y en el aporte de nutrientes, atribuibles a las condiciones de producción, que justifican la conveniencia de disponer de datos nacionales.

Los resultados obtenidos sugieren que la carne de conejo, obtenida en las condiciones de producción prevalecientes en Uruguay, ofrece cualidades nutricionales que le permitirían ocupar un lugar de privilegio en la formulación de recomendaciones alimentarias orientadas a promover salud y reducir riesgo de enfermedades, en un país caracterizado por altos niveles de consumo de carne vacuna, un suministro de energía alimentaria superior a la necesidad promedio y elevada incidencia de sobrepeso y obesidad en la población adulta e infantil.

La inclusión de alfalfa fresca a voluntad en la dieta de conejos en crecimiento debe ser considerada como una alternativa a tener en cuenta en el diseño de la estrategia de alimentación de conejos para carne en crecimiento-terminación. Para las condiciones de producción del Uruguay, la sustitución parcial del alimento balanceado por este forraje fresco significa una reducción relevante en el costo de producción, que no va en detrimento de las características con peso económico de la canal.

Se verificó una modificación favorable en la composición de las grasas por la inclusión de alfalfa fresca, con incremento signi- 
ficativo del contenido de ácido linolénico C18:3 n-3 y del total de ácidos grasos del grupo omega-3, que resulta relevante desde el punto de vista nutricional. Dicho incremento se refleja en una significativa mejora de indicadores del valor nutritivo y del impacto potencial sobre la salud del consumidor, en particular la relación $n-6 / n-3$. Otras modificaciones producidas en el valor nutritivo de la carne de conejo, como el leve incremento en el aporte de sodio y magnesio, o la tendencia a mejorar el aporte de Vitamina E, por su escasa magnitud carecen de relevancia desde el punto de vista nutricional.

El contenido medio de purinas en la carne de conejo verificado en este trabajo se ubica por encima de valores que se citan para promover las cualidades del producto en dietas para hiperuricémicos y lo aproximan a otras carnes, dentro del grupo de alimentos con contenido moderado.

El suministro de alfalfa fresca no determina efectos negativos en textura ni agrado general para el consumidor, aunque sus atributos sensoriales sean percibidos como diferentes a los de la carne de conejos alimentados exclusivamente con alimento balanceado comercial.

\section{MODIFICACIÓN DEL PERFIL LIPÍDICO MEDIANTE EL MANEJO DE LA DIETA}

El efecto de la composición de la dieta sobre el perfil lipídico y el contenido de otros nutrientes de la carne de conejo ha sido confirmado por numerosos autores, lo que ha propiciado la búsqueda de modificaciones en la alimentación que contribuyan a la mejora del aporte nutritivo de la carne de esta especie. Numerosos trabajos de investigación han centrado su objetivo en el manejo de la composición de la dieta para incrementar el contenido de la carne de conejo en ácidos grasos poliinsaturados omega-3, mejorar la relación n-6/n-3 y enriquecer el contenido en compuestos bioactivos, como EPA, DHA, CLA, Vitamina E y Selenio (Oliver et al., 1997; Gigaud and Le Cren, 2006; Maertens et al., 2008; Tres et al., 2008; Kowalska y
Bielanski, 2009; Petracci et al., 2009). Una exhaustiva revision de Dalle Zotte y Szendro (2010) resume las excelentes cualidades nutricionales de la carne de conejo y las posibilidades de mejorar su valor funcional, a través de la manipulación de la dieta, lo que permite incrementar los niveles de ácidos grasos esenciales, EPA, DHA, CLA y ácidos grasos de cadena ramificada.

Como sostiene Hernández (2009), la carne de conejo puede ser una buena manera de aportar compuestos saludables a los consumidores, enfatizando sus posibilidades como «alimento funcional». En esta dirección se orientaron recientes investigaciones en INIA, apuntando al enriquecimiento de la carne de conejo en compuestos bioactivos, en base a la utilización de ingredientes de la dieta disponibles a un costo accesible, que hiciera económicamente viable su empleo para diferenciar y valorizar la carne de esta especie.

Con el fin de evaluar la posibilidad de modificar la composición de las grasas en la carne de conejo como resultado de la inclusión en la dieta de diferentes aceites y semillas de oleaginosas, se llevó a cabo en INIA Las Brujas un experimento que involucró ocho tratamientos (Cuadro 9); 160 conejos de la línea Verde, con un peso medio de $1145 \mathrm{~g}$ y 45 días de edad, fueron distribuidos al azar a los diferentes tratamientos alimenticios, tras un período de una semana de acostumbramiento a una dieta combinada compuesta por ración balanceada comercial a voluntad y alfalfa fresca también a voluntad. Cada tratamiento constó de cinco jaulas con cuatro individuos (dos machos y dos hembras). Los animales permanecieron todo el período de engorde, hasta un peso de faena de $2500 \mathrm{~g}$.

Los ingredientes y composición química del alimento balanceado comercial se presentan en el Cuadro 10.

Las semillas de oleaginosas (colza, chia, lino) fueron molidas y mezcladas con el alimento pelleteado comercial. Los aceites (girasol alto oleico, pescado) fueron mezclados con los pellets de ración. El CLA sintético utilizado en el tratamiento T7 era Tonalin TG 80 de BASF, que contiene, de acuerdo a la infor- 
Cuadro 9. Los tratamientos aplicados se ajustan al siguiente detalle.

T1. Ración comercial a voluntad más alfalfa fresca a voluntad + Vit.E/Se

T2. Ración comercial a voluntad con $8 \%$ de colza $+2 \%$ aceite pescado + alfalfa a voluntad

T3. Ración comercial a voluntad con $8 \%$ de colza + alfalfa a voluntad

T4. Ración comercial a voluntad con $2 \%$ Aceite de Pescado + alfalfa a voluntad

T5. Ración comercial a voluntad con $8 \%$ de colza $+2 \%$ aceite de pescado + CLA sintético $5 \mathrm{~g} / \mathrm{kg}$ de ración + alfalfa a voluntad

T6. Ración comercial a voluntad con $6 \%$ de semilla de lino + alfalfa a voluntad

T7. Ración comercial a voluntad con $2 \%$ de Aceite de Girasol Alto Oleico + alfalfa a voluntad

T8. Ración comercial a voluntad con $6 \%$ de semilla de chia + alfalfa a voluntad

Cuadro 10. Ingredientes y composición química del alimento balanceado comercial.

\begin{tabular}{|l|r|}
\hline Ingredientes & kg \\
\hline Heno de alfalfa & 360 \\
Afrechillo de trigo & 120 \\
Maíz & 111,7 \\
Harina de girasol & 100 \\
Semitín & 80 \\
Harina de soja & 70 \\
Harina de trigo & 70 \\
Avena & 60 \\
Fosfato dicálcico & 13,1 \\
Carbonato de calico & 5,6 \\
Sal & 5,4 \\
Premezcla Vitamínico-mineral VM-602 & 2 \\
Propionato de calico & 1 \\
Zinc bacitracina & 0,5 \\
DL-metionina 99 \% & 0,4 \\
L-Lisina 95 \% & 0,3 \\
& 1000 \\
\hline Composición química & $\%$ \\
\hline Materia Seca & 88,9 \\
Proteina Cruda* & 22,3 \\
FDA* & 27,0 \\
FDN* & 38,0 \\
Extracto al Eter* & 3,3 \\
Calcio* & 1,9 \\
Fosforo* & 1,1 \\
\hline *En base materia seca & \\
\hline
\end{tabular}

*En base materia seca 
mación suministrada por el fabricante, una mezcla 50:50 de dos isómeros (C18:2, c9, t11 y C18:2, t10, c12). Es un producto de uso humano formulado para su utilización en la industria alimentaria o como suplemento dietético. El suministro de CLA sintético al tratamiento T7 comenzó en la cuarta semana de ensayo, en una dosis de $5 \mathrm{~g}$ por $\mathrm{kg}$ de alimento balanceado.

La alfalfa fresca fue cortada a diario y pesada la cantidad suministrada a cada jaula. La ración suministrada se pesó al inicio de la semana, se registraron las cantidades ofrecidas a lo largo de la semana y se pesó el rechazo al fin de la semana, obteniéndo- se el consumo por diferencia entre lo ofrecido y lo rechazado. No se determinó el consumo de alfalfa, registrándose solamente los volúmenes ofrecidos de este forraje.

En el Cuadro 11 se presenta la composición de la fracción lipídica de la alfalfa y las raciones correspondientes a cada uno de los tratamientos aplicados.

Se evaluó el desempeño productivo de los animales (ganancia media diaria, consumo de alimento balanceado, índice de conversión) y al llegar al peso de faena cada canal fue evaluada siguiendo el procedimiento descrito por Blasco y Ouhayoun (1996). Para la determinación de la composición química de

Cuadro 11. Perfil lipídico de los alimentos.

\begin{tabular}{|c|c|c|c|c|c|c|c|c|c|}
\hline 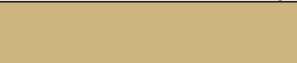 & Alfalfa & T1 & T2 & T3 & $\mathrm{T} 4$ & T5 & T6 & T7 & T8 \\
\hline Ácidos Grasos & $\%$ & $\%$ & $\%$ & $\%$ & $\%$ & $\%$ & $\%$ & $\%$ & $\%$ \\
\hline $14: 0$ & 0,7 & - & 1,7 & 0,2 & 2,1 & 2,2 & - & 0,1 & 0,2 \\
\hline $15: 0$ & 0,2 & - & 0,2 & - & 0,2 & 0,2 & - & - & \\
\hline $15: 1$ & 0,3 & - & 0,2 & - & 0,2 & 0,3 & - & - & \\
\hline $16: 0$ & 16,8 & 12,1 & 12,5 & 12,9 & 15,3 & 14,5 & 11,6 & 7,7 & 14,4 \\
\hline $16: 1$ & 0,2 & - & 2,1 & 0,1 & 2,4 & 2,8 & - & 0,1 & 0,2 \\
\hline $17: 0$ & 0,2 & - & 0,1 & 0,1 & 0,1 & - & - & & 0,1 \\
\hline $17: 1$ & & & 0,1 & - & 0,1 & - & - & & \\
\hline $18: 0$ & 2,5 & 2,6 & 2,3 & 2,4 & 2,6 & 2,6 & 2,3 & 2,6 & 2,8 \\
\hline 18:1 n9c & 1,8 & 26,8 & 38,3 & 27,2 & 27,1 & 27,4 & 23,9 & 61,7 & 27,3 \\
\hline $18: 2 n 6 c$ & 16,3 & 47,0 & 24,7 & 47,8 & 30,7 & 22,7 & 40,3 & 23,6 & 47,3 \\
\hline 20:0 & 0,5 & 0,4 & 0,4 & 0,4 & 0,4 & 0,3 & 0,4 & 0,3 & 0,5 \\
\hline $20: 1$ & & 0,3 & 1,7 & 0,4 & 1,9 & 1,8 & - & 0,2 & 0,3 \\
\hline 21:0 & & & & & & & & & 0,4 \\
\hline $18: 3 n 3$ & 52,0 & 5,9 & 5,2 & 6,3 & 4,0 & 4,8 & 6,5 & 1,6 & 5,6 \\
\hline CLA & & & & & & 4,7 & - & - & - \\
\hline $20: 2$ & & & 0.9 & - & - & - & - & - & \\
\hline $22: 0$ & 0.6 & 0.3 & 0.2 & - & 0.2 & - & - & 0,5 & 0,3 \\
\hline $20: 3$ & & & & & & & & & 0,6 \\
\hline $20: 4$ & 0,8 & & - & - & - & - & - & - & \\
\hline 20.5 & & - & 1,7 & - & 2,2 & 2,2 & - & - & \\
\hline $22: 6$ & & & 3,2 & & 4,5 & 4,1 & - & - & \\
\hline Saturados & 21,5 & 15,4 & 17,4 & 16,0 & 20,9 & 19,8 & 14,3 & 11,2 & 18,7 \\
\hline Monoinsaturados & 2,3 & 27,1 & 42,4 & 27,7 & 31,7 & 32,3 & 23,9 & 62 & 27,8 \\
\hline Poliinsaturados & 70,3 & 52,9 & 35,7 & 54,1 & 41,4 & 33,8 & 46,8 & 25,2 & 52,9 \\
\hline Total identificados & 94,1 & 95,4 & 95,5 & 97,8 & 94,0 & 90,6 & 85,0 & 98,4 & 99,4 \\
\hline
\end{tabular}


la grasa intramuscular se tomaron muestras del músculo Longissimus dorsi de cinco animales al azar de cada tratamiento.

Los Cuadros 12 y 13 muestran resultados del análisis de la composición química de la grasa intramuscular.

Como puede observarse en los cuadros, la composición química de la grasa intramuscular es afectada por el perfil lipídico de la dieta. La adición de CLA sintético en el T5 se refleja en que éste es el único tratamiento donde se verificaron cantidades medibles de los dos isómeros del ácido linoleico (en el cuadro CLA 1 corresponde a C18:2, c9, t11 y CLA 2 al isómero C18:2, t10, c12). Los resultados son análogos a los obtenidos por Lo Fiego et al. (2005) quienes lograron incrementos significativos de CLA en la grasa intramuscular de los conejos a través de la suplementación con niveles de 0,25 y $0,5 \mathrm{mg} / \mathrm{g}$ de un producto comercial conteniendo $65 \%$ de CLA con proporciones iguales de ambos isómeros. Los autores concluyen que la suplementación con CLA influencia significati- vamente la composición de la grasa intramuscular, provocando un incremento en el contenido total de ácidos grasos saturados y una reducción en los monoinsaturados. Estas modificaciones conducen a una mayor relación entre los SFA/UFA y un deterioro en los Índices de Aterogenicidad y Trombogenicidad. Este efecto no fue verificado en nuestra investigación. Cabe consignar que los valores de Al obtenidos por Lo Fiego et al. en los diferentes tratamientos se ubicaron en el rango de 0,53 a 0,61 , mientras que el TI varió entre 0,94 y 1,09. En nuestro experimento los rangos obtenidos se ubican entre 0,48 y 0,61 para el Al y 0,60 a 0,81 para el TI.

La inclusión de aceite de pescado en la dieta de los conejos (T2, T4 y T5) determina un incremento de magnitud relevante en el contenido de EPA, DPA y DHA, mientras que la inclusión de aceites vegetales o semillas de oleaginosas imprime su sello distintivo en la proporción de ácidos grasos saturados, monoinsaturados y poliinsaturados.

Cuadro 12. Contenido de grasa intramuscular y proporciones de ácidos grasos.

\begin{tabular}{|c|c|c|c|c|}
\hline Tratamiento & (\%) grasa intramuscular & MUFA & PUFA & SFA \\
\hline T1 & 1,36 & 29,94 & 32,50 & 37,43 \\
\hline T2 & 1,46 & 31,49 & 29,82 & 35,34 \\
\hline T3 & 1,26 & 30,64 & 33,30 & 35,92 \\
\hline T4 & 1,59 & 29,83 & 30,73 & 36,78 \\
\hline T5 & 1,33 & 28,91 & 30,71 & 35,77 \\
\hline T6 & 1,62 & 28,89 & 34,46 & 36,53 \\
\hline T7 & 1,76 & 34,94 & 31,38 & 33,58 \\
\hline T8 & 1,34 & 27,40 & 36,25 & 36,19 \\
\hline
\end{tabular}

Cuadro 13. Proporciones relativas de algunos ácidos grasos seleccionados y sus relaciones.

\begin{tabular}{|c|c|c|r|r|c|c|c|c|c|}
\hline Tratamiento & PUFA/SFA & $\mathbf{n 6}$ & $\mathbf{n 3}$ & $\mathbf{n 6 / n 3}$ & $\mathbf{C 2 0 : 5} \mathbf{n 3}$ & $\mathbf{C 2 2 : 5} \mathbf{n 3}$ & $\mathbf{C 2 2 : 6} \mathbf{n 3}$ & CLA1 & CLA2 \\
\hline T1 & 0,87 & 27,23 & 5,40 & 5,04 & 0,17 & 0,78 & 0,12 & & \\
\hline T2 & 0,84 & 24,17 & 9,01 & 2,68 & 0,58 & 1,05 & 3,37 & & \\
\hline T3 & 0,93 & 27,82 & 5,61 & 4,96 & 0,22 & 0,81 & 0,13 & & \\
\hline T4 & 0,84 & 24,61 & 8,79 & 2,80 & 0,58 & 0,85 & 2,67 & & \\
\hline T5 & 0,86 & 24,37 & 10,19 & 2,39 & 0,64 & 1,18 & 3,84 & 0,49 & 0,28 \\
\hline T6 & 0,94 & 26,84 & 7,75 & 3,47 & 0,21 & 0,70 & 0,13 & & \\
\hline T7 & 0,93 & 26,64 & 4,84 & 5,51 & 0,14 & 0,51 & 0,10 & & \\
\hline T8 & 1,00 & 26,73 & 9,35 & 2,86 & 0,34 & 1,15 & 0,17 & & \\
\hline
\end{tabular}


La inclusión de semilla de Chia (T8) determinó un incremento importante en el contenido de $n-3$, con un valor de $9,35 \%$, próximo a los obtenidos con el aceite de pescado. Peiretti y Meineri (2008), quienes evaluaron el efecto de la inclusión de semilla de Chia en niveles de 0,10 y $15 \%$, lograron incrementos mucho mayores, con valores de $\mathrm{n}-3$ superiores a $20 \%$ y relaciones $\mathrm{n}-6 / \mathrm{n}-3$ comprendidas entre 1,03 y 1,19. Peiretti (2012) afirma que el efecto de la inclusión de diferentes ingredientes (entre los cuales incluye la semilla de lino, chia y otras) como fuentes de ácidos grasos poliinsaturados fue verificado en varios experimentos que demuestran que la suplementación es efectiva en mejorar el contenido de n-3, reducir la relación n-6/n-3 y reducir el valor de los índices de aterogenicidad y trombogenicidad de la grasa intramuscular y disecable, con el consecuente beneficio sobre las cualidades nutricionales de la carne de conejo.

Todos los tratamientos muestran bajos contenidos de grasa intramuscular, con valores en todos los casos inferiores a $2 \mathrm{~g} / 100 \mathrm{~g}$ de carne, así como satisfactorias relaciones PUFA/SFA (muy por encima del 0,45 recomendado por la OMS) y n-6/n-3 (inferiores al valor de 5 recomendado por dicha organización).

De este modo se confirma la potencialidad de mejorar las cualidades nutricionales de la carne de conejo mediante la manipulación de la dieta, hecho sobre el cual hay numerosas evidencias en la bibliografía internacional.

La forma de modificar el alimento balanceado comercial a través de la mezcla de los pellets con aceite o semillas molidas resultó efectiva, lo que hace que los productores puedan realizar la modificación de la dieta sin necesidad de que los ingredientes se incorporen antes de que se realice el pelleteado. La adopción de estas modificaciones en la dieta estará condicionada por factores económicos y por la posible demanda de los consumidores por carne enriquecida en compuestos bioactivos. Como ya hemos visto, el suministro de alfalfa fresca a voluntad determina un incremento significativo en el contenido de ácidos grasos del grupo omega-3 tanto en la grasa disecable como en la intra- muscular, pero además determina un ahorro de alimento comercial que en sucesivos experimentos ha variado entre el 10 y el $22 \%$. La incorporación de aceites o semillas de oleaginosas implicó en las condiciones de este experimento un incremento del costo del alimento variable según el ingrediente utilizado, con un mínimo de $7 \%$ de aumento del costo en el caso del aceite de pescado y un máximo de $44 \%$ en el caso de la adición de Chia (Salvia hispanica L.), que no se produce en Uruguay, debiéndose recurrir a semilla importada con destino a alimentación humana.

Otro factor determinante de la posible utilización de estos ingredientes es la eventual afectación de las cualidades sensoriales de la carne de conejo. Para evaluar este aspecto se realizó la evaluación sensorial de los atributos sabor, olor, textura y agrado general de muestras de carne de cuatro tratamientos. Se utilizó una escala hedónica estructurada de nueve puntos (1-Me disgusta mucho, 5-Me es indiferente, 9-Me gusta mucho). Las muestras fueron presentadas en cubos de $2 \times 2 \mathrm{~cm}$ envueltos en papel de aluminio codificados con números aleatorios de tres dígitos siguiendo un orden de presentación balanceado para cada participante. Los consumidores contaban con agua sin gas como borrador. La evaluación se realizó en una sala normalizada según ISO 8589:1988 bajo luz artificial blanca y con temperatura controlada (entre 22 y $24^{\circ} \mathrm{C}$ ), con un panel piloto de 42 consumidores ( $43 \%$ de sexo masculino). Para el análisis de resultados se realizó un análisis de varianza para cada atributo y se calculó la diferencia mínima significativa utilizando la prueba LSD de Fisher $(p<0,05)$ con Infostat versión 2008. Los resultados se presentan en el Cuadro 14.

Las muestras correspondientes a los tratamientos sin aceite de pescado (T1 y T3) presentaron calificaciones significativamente mejores que las procedentes de los tratamientos con inclusión de aceite de pescado (T2 y T4). Los valores adjudicados al tratamiento T3 con inclusión de colza, tendieron a ser mejor evaluados en sabor, olor y agrado general que los de nuestro testigo T1, aunque las diferencias no llegaron a ser significativas para ninguno de los parámetros 
Cuadro 14. Resultados de la evaluación sensorial.

\begin{tabular}{|c|c|c|c|c|}
\hline Tratamiento & Sabor & Olor & Textura & Agrado general \\
\hline T3 & $6,8 \mathrm{a}$ & $6,4 \mathrm{a}$ & $6,6 \mathrm{a}$ & $6,8 \mathrm{a}$ \\
\hline $\mathrm{T} 1$ & $6,7 \mathrm{a}$ & $6,0 \mathrm{ab}$ & $6,8 \mathrm{a}$ & $6,6 \mathrm{a}$ \\
\hline $\mathrm{T} 4$ & $5,9 \mathrm{~b}$ & $5,5 \mathrm{~b}$ & $6,6 \mathrm{a}$ & $6,1 \mathrm{ab}$ \\
\hline $\mathrm{T} 2$ & $5,7 \mathrm{~b}$ & $5,4 \mathrm{~b}$ & $6,5 \mathrm{a}$ & $5,8 \mathrm{~b}$ \\
\hline
\end{tabular}

Letras distintas dentro de una misma columna indican diferencias significativas $(P<0,05)$ para ese atributo.

evaluados. Todos los atributos fueron promedialmente valorados con notas positivas, por encima del 5 correspondiente a una valoración de indiferencia, a pesar de que los panelistas disponían mayoritariamente de escasa o nula experiencia previa en el consumo de carne de conejo. Los resultados son similares a los de Kowalska y Bielanski (2009) quienes verificaron que la inclusión de aceite de pescado al $3 \%$ determinaba una significativa reducción en la valoración en intensidad y calidad del aroma y sabor de la carne de conejo, aunque con una mejora en la terneza y jugosidad; en este caso no se verificaron diferencias estadísticamente significativas en agrado general.

Los resultados son auspiciosos en cuanto a la posibilidad de modificar positivamente el perfil lipídico de la grasa intramuscular de la carne de conejo mediante el manejo de la dieta, aunque sugieren la necesidad de ajustar los niveles de inclusión, en particular en el caso del aceite de pescado, para evitar efectos indeseables sobre las propiedades sensoriales.

\section{BIBLIOGRAFÍA}

AMOZA, C.; LUSARDO, R.; OLIVER, L. 2008. La explotación de la cunicultura y su fomento en el Uruguay. Montevideo: Facultad de Ciencias Económicas y Administración. Universidad de la República, 170 p.

BELIVEAU, R.; GINGRAS, D. 2007. Los alimentos contra el cáncer. La prevención del cáncer a través de la alimentación. Buenos Aires: El Ateneo.

BIXQUERT JIMENEZ, M.; GIL-BORRÁS, R. 2005. Propiedades nutricionales y digestibilidad de la carne de conejo. Revista Científica de Nutrición, (1). Recurso electrónico. Disponible en: www.intercun.org. Consultado enero 2012.

BLASCO, A.; OUHAYOUN, J. 1996. Harmonization of criteria and terminology in rabbit meat research. Revised proposal. World Rabbit Science, 4: 93-99.

BLUMETTO, O.; CAPRA, G. 1998a. Utilización estratégica de forrajes en la alimentación de conejos. Montevideo: INIA. (Serie Hojas de Divulgación, 68).

BLUMETTO, O.; CAPRA, G. $1998 \mathrm{~b}$. Suplementación con alfalfa fresca a conejas en lactación. Montevideo: INIA. (Serie Hojas de Divulgación, 69).

BRULÉ, D.; SARWAR, G.; SAVOIE, L. 1988. Purine content of selected Canadian food products. Journal of Food Composition and Analysis, 1: 130-138.

CAPRA, G.; GROMPONE, M.A.; URRUZOLA, N.; PARDO, M.J.; MARTÍNEZ, R.; FRADILETTI, F.; COZZANO, S.; REPISO, L.; MÁRQUEZ, R. 2010. Effect of fresh alfalfa in the diet of growing rabbits on growth performance, carcass characteristics and fat composition. IV Congreso Cunicultura de las Américas 2010, Córdoba, Argentina.

CAPRA, G.; MARTÍNEZ, R.; FRADILETTI, F.; COZZANO, S.; REPISO, L.; MÁRQUEZ, R.; IBÁÑEZ, F. 2013. Meat quality of rabbits reared with two different feeding strategies: with or without fresh alfalfa ad libitum. World Rabbit Science, 21(1): 23-32.

CARRERO, J.J.; MARTIN-BAUTISTA, E.; BARÓ, L.; FONOLLÁ, J.; JIMÉNEZ, J.; BOZA, J.J.; LÓPEZ-HUERTAS, E. 2005. Efectos cardiovasculares de los ácidos grasos omega-3 y alternativas para incrementar su ingesta. Nutrición Hospitalaria, XX: 63-69. 
COMBES, S.; CAUQUIL, L. 2006. Une alimentation riche en luzerne permet d'enrichir la viande des lapins en oméga 3 . Viandes Production Carnés, 25: 31-35.

COMBES, S.; DALLE ZOTTE, A. 2005. Le viande de lapin: valeur nutritionnelle et particularités technologiques. In : Proceedings: 11émes. Journées de la Recherche Cunicole, 29-30 November, 2005. Paris, France, 167-180.

DALLE ZOTTE, A. 2000. Main factors influencing the rabbit carcass and meat quality. In: Proc.: $7^{\text {th }}$ World Rabbit Congress, Valencia, Spain. World Rabbit Science, 8 (Suppl.1): 507-537.

DALLE ZOTTE, A. 2002. Perception of rabbit meat quality and major factors influencing the rabbit carcass and meat quality. Livestock Production Science, 75: 11-32.

DALLE ZOTTE, A.; SZENDRO, Z. 2010. The role of rabbit meat as functional food. In: IV Congreso de Cunicultura de las Américas 2010, Córdoba, Argentina. 30 p.

GIGAUD, V.; LE CREN, D. 2006. Valeur nutritionnelle de la viande de lapin et influence du régime alimentaire sur la composition en acide gras. Recurso electrónico.Disponible en: http:// www.itavi.asso.fr/presentation/station/ lapin.omega3.pdf.Consultado enero 2012.

HERMIDA, M.; GONZÁLEZ, M.; MIRANDA, M.; RODRÍGUEZ-OTERO, J.L. 2006. Mineral analysis in rabbit meat from Galicia (NW Spain). Meat Science, 73 (4): 635-639.

HERNÁNDEZ, P. 2008. Enhancement of nutritional quality and safety in rabbit meat. In Proc.: $9^{\text {th }}$ World Rabbit Congress 2008. Verona, Italy, 12871299. Electronic resource. Available at: http://world-rabbit-science.com/WRSAProceedings/Congress-2008-Verona/ Papers/Q0-Hernandez.pdf. Consultado enero 2012.

HERNÁNDEZ, P. 2009. Carne de conejo como alimento funcional. Cunicultura, 37 (218): 21-24.

HERNÁNDEZ, P.; DALLE ZOTTE, A. 2010. Influence of the Diet on Rabbit Meat Quality. Nutrition of the Rabbit, 2nd edition. C. De Blas/ J. Wiseman (Eds.). UK: CABI, p. 163-178.
HERRANZ, B.; ORDÓÑEZ, J.A.; DE LA HOZ, L.; HIERRO, E.; SOTO, E.; CAMBERO, M.I. 2008. Fatty acid composition of salami from different countries and their nutritional implications. International Journal of Food Sciences and Nutrition, 59(7-8): 607-618.

KOWALSKA, D.; BIELANSKI, P. 2009. Meat quality of rabbits fed a diet supplemented with fish oil and antioxidant. Animal Science Papers and Reports, 27: 139-148.

LAZZARONI, C.; BIAGINI, D., LUSSIANA, C. 2009. Fatty acid composition of meat and perirenal fat in rabbits from two different rearing systems. Meat Science, 83: 135-139.

LO FIEGO, D.P.; MACCHIONI, P.; SANTORO, P.; ROSSI, R.; PASTORELLO, G.; CORINO, C. 2005. Influence of conjugated linoleic acid (CLA) on intramuscular fatty acid composition in rabbit. Italian Journal of Animal Science, 4 (Supp. I.2): 553-555.

LÓPEZ-FARRÉ, A.; MACAYA, C. 2006. Efectos antitrombóticos y antiinflamatorios de los ácidos grasos omega-3. Revista Española de Cardiología, (Supl. 6): 31D37D.

MAERTENS, L.; HUYGHEBAERT, G.; DELEZIE, E. 2008. Fatty acid composition of rabbit meat when fed a linseed based diet during different periods after weaning. In: Proceedings: $9^{\text {th }}$ World Rabbit Congress 2008. Verona, Italy, 13811384. Recurso electrónico. Disponible en: http://world-rabbit-science.com/ WRSA-Proceedings/Congress-2008Verona/Papers/Q-Maertens.pdf. Consultado: enero 2012.

OLIVER, M.A.; GUERRERO, L.; DIAZ, I.; GISPERT, M.; PLA, M.; BLASCO, A. 1997. The effect of fat-enriched diets on the perirenal fat quality and sensory characteristics of meat from rabbits. Meat Science, 47: 95-103.

PEIRETTI, P.G. 2012. Effects of dietary fatty acids on lipid traits in the muscle and perirena fat of growing rabbits fed mixed diets. Animals, 2: 55-67.

PEIRETTI, P.G;; MEINERI, G. 2008. Effects on growth performance, carcass characteristics, and the fat and meat fatty acid profile of rabbits fed diets with chia (Salvia hispanica L.) seed supplements. Meat Science, 80: 1116-1121. 
PÉREZ, M.; VELÁZQUEZ, D. 1998. Evaluación de la mortalidad perinatal de los gazapos y sus posibles causas. Diagnóstico a nivel nacional. Montevideo: Facultad de Agronomía, Universidad de la República, 30 p.

PETRACCI, M.; BIANCHI, M.; CAVANI, C. 2009. Development of rabbit meat products fortified with n-3 Polyunsaturated Fatty Acids. Nutrients, 1: 111-118. Disponible en: http://www.mdpi.com/2072-6643/1/2/ 111/. Consultado enero 2012.

PLA, M.; GUERRERO, L.; GUARDIA, D.; OLIVER, M.A.; BLASCO, A. 1998. Carcass characteristics and meat quality of rabbits lines selected for different objectives: I. Between lines comparison. Livestock Production Science, 54: 115-123.

PLA, M.; DALLE ZOTTE, A. 2000. Harmonisation of criteria and methods used in rabbit meat research. In: Proceeding: $7^{\text {th }}$ World Rabbit Congress, 4-7 July, 2000. Valencia, Spain. Jr. World Rabbit Science, 8 (Suppl.1): 539-545.
PLA, M. 2004. Effects of nutrition and selection on meat quality. In: Proceedings: $8^{\text {th }}$ World Rabbit Congress, 7-10 September, 2004. Puebla, Mexico, 13371348. Available at: http://world-rabbitscience.com/WRSA-Proceedings/ Congress-2004-Puebla/Papers/ Meat\%20Quality/Q0-Pla.pdf. Consultado Enero 2012.

SOUCI-FACHMANN-KRAUT'S FOOD COMPOSITION NUTRITIONAL TABLES, 6TH ED. Available at www.sfk-online.net. Consultado Enero 2012

TRES, A.; BOU, R.; CODONY, R.; GUARDIOLA, F. 2008. Influence of dietary doses of $n-3$ or n-6-rich vegetable fats and -tocopheryl acetate supplementation on raw and cooked rabbit meat composition and oxidative stability. Journal of Agricultural and Food Chemistry, 56: 7243-7253. 


\section{CLIMATIZACIÓN Y CALIDAD AMBIENTAL EN CUNICULTURA}

\section{INTRODUCCIÓN}

La producción cunícola se ha venido intensificando en los últimos años en los principales países productores. Una de las bases de esa intensificación es alojar a los animales en naves en las que se consigue controlar el ambiente interior. Así, uno de los factores de producción más relevantes, y sobre los que el ganadero dispone de un mayor margen de maniobra, es el control ambiental de las naves. Mantener a los animales en unas condiciones óptimas desde el punto de vista del confort ambiental es fundamental, y no únicamente considerando la mejora en factores productivos, sino también atendiendo al bienestar de los animales y a los impactos producidos en el medio ambiente (Villagrá et al., 2004).

Desde el punto de vista de facilitar el confort ambiental de los animales, los parámetros más importantes son la temperatura, la humedad, la velocidad del aire, la concentración de gases (principalmente el amoníaco y el dióxido de carbono) y la carga microbiológica en aire, principalmente asociada a partículas en suspensión.

La temperatura es el factor con un efecto más evidente desde el punto de vista productivo (Marai et al., 2002). En primer lugar, aquellos animales que se encuentren fuera de su temperatura óptima, destinarán parte de la energía consumida en el pienso a termo regularse, reduciendo así su crecimiento y/o su capacidad reproductiva. Así, por ejemplo, los conejos consumirán aproximadamente un $10 \%$ más de pienso a $10^{\circ} \mathrm{C}$ que a $20^{\circ} \mathrm{C}$, aumentando el coste de alimentación, según la revisión realizada por Cervera y Fernandez-Carmona (1998). Por otro lado, la aptitud reproductiva de los ani- males se ve claramente afectada cuando las temperaturas se encuentran fuera de los rangos recomendados, reduciéndose la fertilidad y prolificidad, afectando a la producción de leche y aumentando la mortalidad pre-destete a temperaturas elevadas (Frangiadaki et al., 2003; Marai et al., 2002).

En lo referente al efecto de la humedad sobre los animales, es sabido que la humedad relativa presenta una interacción muy importante con la temperatura ambiental, incrementando la sensación del calor de los animales a altas temperaturas cuando la humedad ambiental aumenta. También se conoce que una elevada humedad favorece la proliferación de microorganismos en el aire, mientras que niveles muy bajos de humedad pueden favorecer la aparición de enfermedades respiratorias y digestivas en el conejo (Villagrá et al., 2004). Finalmente, la velocidad del aire también puede considerarse como un factor clave dentro de la calidad ambiental en la cunicultura, siendo los conejos animales muy sensibles a las corrientes de aire.

La información disponible acerca del resto de factores sobre la producción en cunicultura es escasa. En cualquier caso, se conoce que elevadas concentraciones de amoníaco en la nave conllevan efectos negativos sobre los animales de cebo y las reproductoras, afectando los índices productivos en ambos casos. Las consecuencias de estas altas concentraciones de amoníaco pueden observarse incluso semanas después de producirse (Sahuquillo et al., 2004). Sin embargo, se desconoce con exactitud cómo afecta la acumulación de otros gases y partículas en suspensión a la salud y productividad de los animales. Estos factores, de forma inespecífica, aumentan la incidencia de enfermedades respiratorias.

${ }_{1}^{1}$ Instituto de Ciencia y Tecnología Animal, Universidad Politécnica de Valencia, España. 
Para conseguir unas condiciones óptimas en el interior de la nave, el ganadero dispone de diversas herramientas que se pueden clasificar en: ventilación, aislamiento, calefacción y refrigeración. La ventilación es el factor más importante, dado que es clave para el control de todos los parámetros mencionados anteriormente. La calefacción y refrigeración tienen una implicación directa sobre la regulación de temperaturas, aunque también influyen en la humedad relativa. Finalmente, el aislamiento afectará únicamente al control térmico, lo cual tendrá unas implicaciones clave en las otras tres herramientas (fundamentalmente en la reducción del coste de calefacción y/o refrigeración).

\section{NECESIDADES AMBIENTALES DE LOS ANIMALES}

El primer paso para conseguir una climatización adecuada en las granjas es, obviamente, conocer cuáles son las necesidades de los animales.

En el caso de la temperatura es necesario definir dos conceptos: la temperatura óptima y la temperatura crítica. La temperatura óptima viene determinada por un rango de valores (más o menos estrecho en función del tipo de animal), dentro del cual el animal requiere un esfuerzo mínimo para regular su propia temperatura, optimizando así el uso de los recursos energéticos. Por encima y por debajo de ese rango, parte de la energía consumida en el pienso será destinada a termorregulación, con el consecuente perjuicio productivo. La temperatura crítica es aquella que limita la producción, y normalmente existe una temperatura crítica superior y una inferior. Así pues, si se supera la temperatura crítica superior o no se alcanza la temperatura crítica inferior, los perjuicios productivos y sanitarios resultan inaceptables.

El Cuadro 1 recoge los rangos de temperatura óptimos y críticos para la producción cunícola en función del tipo de animal

Cabe destacar que, a excepción de los gazapos, los problemas aparecen principalmente con temperaturas elevadas, puesto que son animales bastante resistentes al frío y con poca capacidad para disipar el calor.

En lo referente a la humedad relativa, ésta debe encontrarse entre el 60 y $70 \%$ dentro de la nave para optimizar la producción, aunque en momentos puntuales se puede llegar hasta el 55 ó 75 \% (Ferré, 1996).

Las concentraciones de amoníaco deben mantenerse por debajo de las 20-25 ppm como norma general en explotaciones ganaderas (Wathes y Charles, 1994; CIGR, 1992). En cunicultura, a pesar de que existen pocos estudios al respecto, Ferré y Rosell (2000) consideran que la concentración es elevada al superar las $10 \mathrm{ppm}$. Por otro lado, se recomienda de modo general que las concentraciones de dióxido de carbono no superen las 3.000-5.000 ppm en el interior de los alojamientos ganaderos (Wathes y Charles, 1994; CIGR, 1992). Finalmente, las concentraciones máximas deseables de partículas suspendidas en el aire en las explotaciones ganaderas son de $1,7 \mathrm{mg} / \mathrm{m}^{3} \mathrm{y}$ $3,4 \mathrm{mg} / \mathrm{m}^{3}$ para PM 2,5 (partículas con diámetro equivalente inferior a 2,5 micras) y PM10 (partículas con diámetro equivalente inferior a 10 micras), respectivamente (Cambra-López et al., 2008).

Cuadro 1. Rangos de temperatura óptimos y críticos en función del tipo de animal (Ferré, 1996).

\begin{tabular}{|l|c|c|}
\hline Tipo de animal & Temperatura óptima $\left({ }^{\circ} \mathrm{C}\right)$ & Temperatura crítica $\left({ }^{\circ} \mathrm{C}\right)$ \\
\hline Maternidad & $16-20$ & $10-25$ \\
\hline Machos & $14-18$ & $6-24$ \\
\hline Dentro del nidal & $31-33$ & $31-33$ \\
\hline Recién destetados & $19-22$ & $14-26$ \\
\hline Engorde & $19-22$ & $10-30$ \\
\hline Recría & $16-18$ & $8-28$ \\
\hline
\end{tabular}




\section{LA VENTILACIÓN EN GRANJAS CUNÍCOLAS}

Aunque existen muchas variantes, pueden distinguirse dos sistemas bien diferenciados para conseguir el intercambio de aire necesario en las explotaciones cunícolas: la ventilación natural y la ventilación forzada. Cada uno de estos sistemas presenta una serie de ventajas y limitaciones que es necesario conocer. En este apartado se analizan los movimientos de flujo de cada sistema, estableciéndose algunas orientaciones prácticas.

\section{Ventilación natural}

La ventilación natural tiene la ventaja de no requerir consumo eléctrico, siendo por tanto de coste menor que la ventilación forzada. Puede ser adecuada en zonas de climas poco rigurosos, y es la única alternativa en zonas sin acceso al suministro eléctrico. Sin embargo, es más difícil controlar la ventilación, y el uso de paneles refrigerantes es inviable en la práctica.

El movimiento del aire en este tipo de instalaciones está causado por dos fuerzas: la diferencia de presiones que se produce en la nave cuando hay viento en el exterior, y la diferencia de temperaturas entre el interior y el exterior. En el primero de los casos, el movimiento de aire se produce en el eje paralelo al suelo (horizontalmente), y el caudal de ventilación depende directamente de la superficie abierta al paso del aire (número y tamaño de las entradas del aire), así como de la velocidad y dirección del viento. Se trata del sistema más simple y económico, pero las posibilidades de control son escasas debido a la fuerte dependencia de las condiciones ambientales del momento. En el segundo caso, cuando en el interior de la nave la temperatura es superior a la temperatura exterior, se produce un intercambio de aire, que entrará por las aberturas laterales del edificio y saldrá de la nave por la cumbrera. Cuanto mayor sea la diferencia de temperaturas entre el interior y el exterior, la diferencia de cotas entre los puntos de entrada y salida del aire y las superficies abiertas para el intercambio de aire, mayor será el caudal de ventilación. En este caso, un buen diseño de las instalaciones es esencial para conseguir cierto grado de manejo sobre la ventilación.

En general, la opción más habitual consiste en la instalación en la nave de ventanas laterales y un caballete central en cumbrera (Figura 1).

Las ventanas laterales pueden situarse en la parte superior o inferior del alojamiento, mientras que el ancho de la nave no debe ser excesivo para que haya una buena distribución de aire. La Figura 2 muestra la distribución de los flujos de aire en el interior de una explotación de este tipo, tanto en condiciones de calma como con viento lateral. Estos resultados se han obtenido mediante algoritmos de dinámica de fluidos computacional (CFD) usando el programa informático Ansys Fluent. En esa figura se muestran las líneas de corriente de aire, indicando en colores azules las zonas de menor velocidad y en rojo las de mayor velocidad. Como se observa en esta figura, en este tipo de alojamientos el flujo de aire es más intenso en la parte superior de la nave, pro-
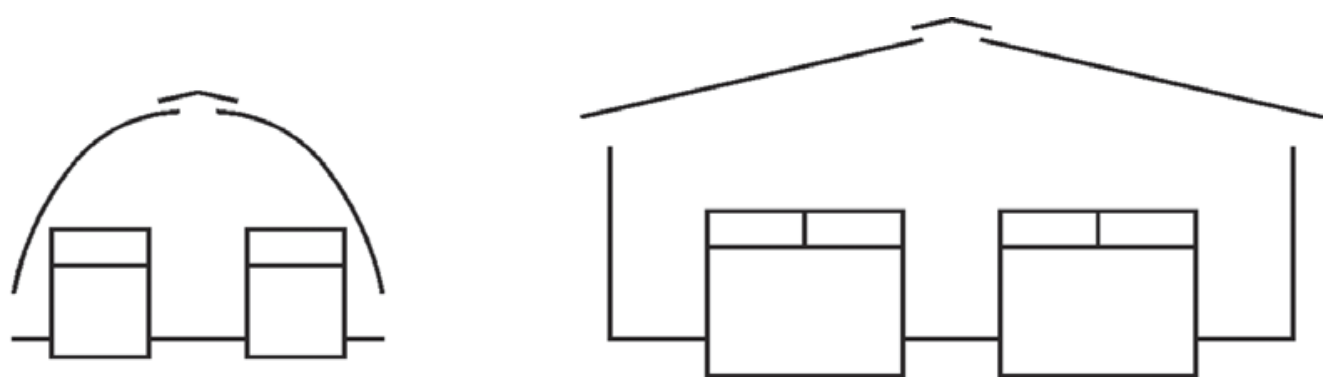

Figura 1. Alojamientos con ventilación natural. 

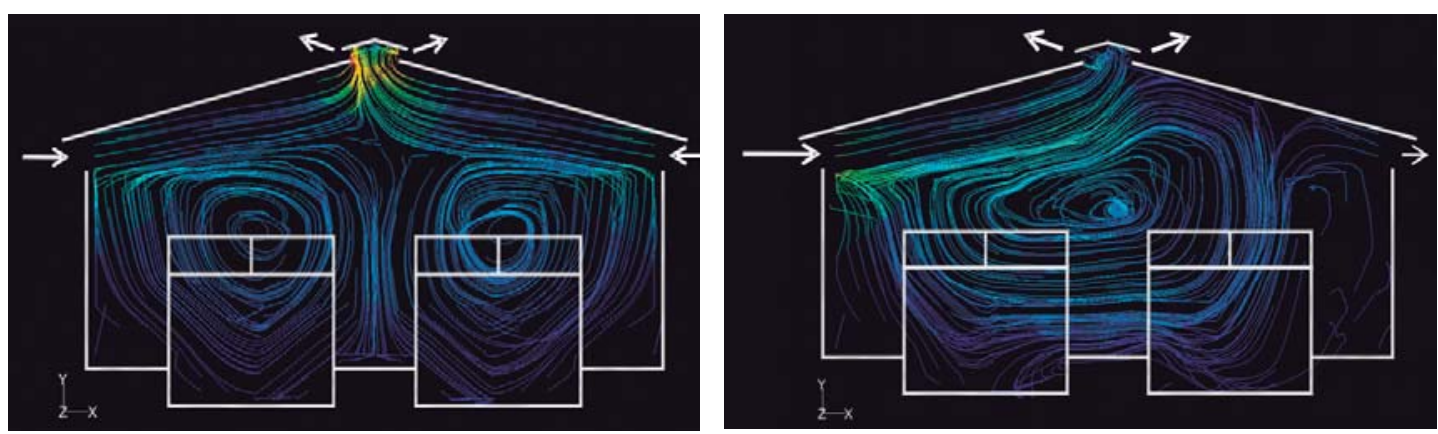

Figura 2. Flujos de ventilación en alojamientos con ventilación natural: en situación de calma (izquierda) y con viento lateral (derecha).

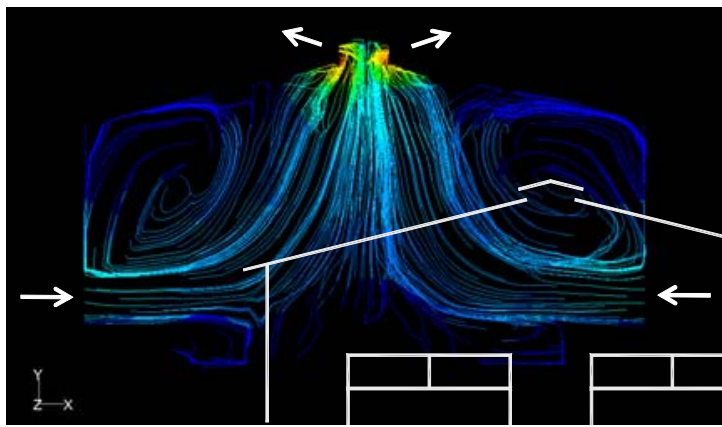

Figura 3. Flujos de ventilación en alojamientos con ventilación natural y ventanas en la parte inferior, en situación de calma.

duciéndose dos remolinos de menor velocidad en la parte inferior. La configuración de las corrientes varía sensiblemente en caso de haber viento lateral.

Una posible variación de este sistema hace referencia a la distinta ubicación de las ventanas. Así, en la Figura 3 se muestran las líneas de flujo correspondientes a la misma granja con las ventanas en la parte inferior de la pared. En este caso, la distribución del flujo cambia y se consigue mayor velocidad y renovación de aire a la altura de los animales.

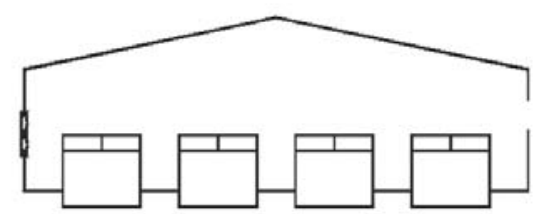

Transversal

\section{Ventilación forzada}

La ventilación forzada o mecánica requiere energía para realizar el intercambio de aire en la explotación, a pesar de este coste energético, es capaz de conseguir un mayor control sobre los parámetros ambientales, especialmente en las condiciones más desfavorables. Si bien la disposición en granjas es muy variada, los principales tipos son los indicados en la Figura 4.

La ventilación transversal fuerza un barrido lateral de aire, en el cual las máximas velocidades se dan en las entradas y salidas. La altura de las ventanas es fundamental en la distribución del flujo en la sala: si las ventanas están en la parte superior de la pared habrá menor velocidad de aire a la altura de los animales, y una distribución del flujo más desigual. Por el contrario, si las ventanas se localizan a la altura del animal, se consigue una mayor velocidad de aire a la altura de estos, con distribución más regular, consiguiéndose un mejor arrastre de los gases producidos en el interior. En cualquier caso, los animales más cercanos a las ventanas de entrada de aire estarán expuestos a mayores velocidades de aire.

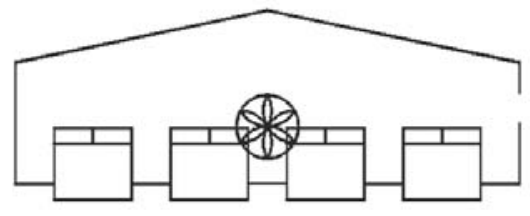

\section{Túnel}

Figura 4. Esquema de los tipos de alojamiento con ventilación forzada. 
La ventilación tipo túnel pretende realizar un barrido de aire en el sentido longitudinal de la nave ganadera. Este tipo de ventilación alcanza su máximo potencial si las ventanas se sitúan en la parte opuesta al ventilador. Con esta disposición se consigue una mayor velocidad media de aire para un mismo caudal de ventilación. Cabe considerar que este sistema puede crear desigualdades muy importantes en las naves en cuanto a la calidad del aire. Así, aquellos animales que se encuentran cerca de los extractores siempre dispondrán de un aire de peor calidad (ya que ha sido arrastrado por toda la nave) que aquellos animales situados cerca de las entradas de aire. Estas desigualdades son más patentes a medida que aumenta la longitud de las naves.

\section{Necesidades de ventilación}

Determinar las necesidades de ventilación (caudal de ventilación, expresado en $\mathrm{m}^{3} / \mathrm{h}$ ) en una explotación ganadera es una tarea compleja dado que el objetivo de la ventilación es múltiple. La ventilación influye simultáneamente en el control de la temperatura, la humedad y las concentraciones de $\mathrm{CO}_{2}$ y $\mathbf{N H}_{3}$. Lamentablemente, la situación en la que un determinado caudal de ventilación satisface simultáneamente las necesidades de los animales en cuanto a estos parámetros se da muy raramente. Por ello, se recomienda establecer cada uno de ellos como criterio de cálculo para seleccionar posteriormente el más restrictivo.

\section{Control de la temperatura}

El cálculo de las necesidades de ventilación para controlar la temperatura en el interior de las naves se fundamenta en los balances de calor sensible en las mismas
(Garcimartin et al., 2007). En dicho balance, las ganancias de calor se consideran términos positivos del balance (incorporan calor), mientras que las pérdidas se consideran negativas. Así, es necesario equilibrar el balance entre pérdidas y ganancias de calor sensible $\left(\Sigma Q_{i}=0\right)$.

La principal fuente de calor en las explotaciones ganaderas son los propios animales $\left(Q_{\text {animales }}\right)$, que en función del número, de su peso y estado fisiológico producirán una determinada cantidad de calor sensible (Cuadro 2).

La transmisión de calor a través de los cerramientos (paredes, puertas, cubierta, suelo, etc.) puede materializarse en una pérdida de calor (cuando la temperatura interior es superior a la exterior) o en una ganancia (en el caso contrario). La magnitud del calor sensible transmitido a través de los cerramientos $\left(Q_{\text {cerramientos }}\right)$ es la suma del calor transmitido a través de cada cerramiento $(i)$. Para cada cerramiento, el calor transmitido se calcula como el producto de tres factores: la diferencia de temperaturas entre el interior y el exterior del cerramiento $(\Delta T$, expresado en grados Kelvin), la superficie del cerramiento $\left(S\right.$, expresada en $\left.\mathrm{m}^{2}\right)$ y el nivel de aislamiento del cerramiento $(U$, expresada en $W$ por $\mathrm{m}^{2}$ y K).

$$
Q_{\text {cerramientos }}=\sum_{i} U_{i} \times S_{i} \times \Delta T_{i}
$$

Por otro lado, la propia ventilación también origina un intercambio de calor con el exterior. La mayor parte de ganaderos consideran que la ventilación ocasiona una pérdida de calor de la explotación, es decir, que la ventilación siempre consigue enfriar la nave. Por ello se suele entender que es deseable ventilar más en verano, mientras que es un problema en invierno, cuando quiere

Cuadro 2. Producción de calor sensible en conejos en función del tipo de animal (CIGR, 2002).

\begin{tabular}{|l|c|c|}
\hline Tipo de animal & Peso medio $(\mathbf{k g})$ & Calor sensible producido (W/animal) \\
\hline Conejas reproductoras & 3,5 & 8,58 \\
\hline Machos & 4 & 9,85 \\
\hline Recría & 2,5 & 6,77 \\
\hline Engorde & 1,5 & 4,37 \\
\hline
\end{tabular}


evitarse la pérdida de calor. Lo cierto es que esta concepción es errónea, ya que la ventilación puede incorporar o extraer calor de la nave según la temperatura exterior sea superior o inferior a la interior. De ese modo en verano, cuando la temperatura en el exterior de la nave es superior a la deseada en el interior, a través de la ventilación, y en ausencia de sistema de refrigeración, se introduce más calor en la propia nave. La cantidad de calor sensible transmitido por la ventilación $\left(Q_{\text {ventilación }}\right)$ es pues función de la diferencia de temperaturas entre el interior y el exterior de la nave ( $\Delta T$, expresada en grados Kelvin), la cantidad de aire intercambiado o caudal de ventilación ( $V$, expresado en $\mathrm{m}^{3} / \mathrm{h}$ ), el calor específico del aire ( $c$, expresado en W por $\mathrm{kg}$ y K) y la densidad del aire $\left(r\right.$, en $\left.\mathrm{kg} / \mathrm{m}^{3}\right)$.

$$
Q_{\text {ventilación }}=\frac{V \times c \times \Delta T}{\rho}
$$

Finalmente, los sistemas de calefacción suponen siempre una ganancia de calor en la granja. Algo equivalente, en sentido contrario, ocurre con la refrigeración, cuyo funcionamiento siempre causa una pérdida de calor al aire interior. Otras fuentes de calor como son la iluminación, los motores de la nave, la radiación solar y los estiércoles, no se suelen considerar para los cálculos en la práctica dada su baja aportación al balance en comparación con las otras fuentes citadas anteriormente.

Así, la cantidad de aire a intercambiar en la nave necesaria para controlar la temperatura, expresado como caudal volumétrico de aire $\left(V_{\text {temperatura }}\right.$ en $\left.\mathrm{m}^{3} / \mathrm{h}\right)$ se calculará como:

$$
V_{\text {temperatura }}=\frac{-\mathrm{Q}_{\text {animales }}-\mathrm{Q}_{\text {cerramientos }}}{c \times \Delta T \times \rho}
$$

\section{Control de la humedad}

De forma similar a la temperatura, el cálculo de las necesidades de ventilación para controlar la humedad en el interior de las naves se fundamenta en los balances de vapor de agua en el interior de las mismas. Así, para conseguir establecer unas condiciones de humedad estable en la nave es necesario equilibrar el balance entre pérdidas y ganancias de agua $\left(\Sigma \mathrm{H}_{\mathrm{i}}=0\right)$. En este caso, el balance es más sencillo: las ganancias de humedad en la nave se producen a través de la producción de vapor de agua de los animales $\left(H_{\text {animales }}\right)$ y su estiércol $\left(H_{\text {estiércol }}\right)$. La producción de humedad de los animales depende de su estado fisiológico y peso (Cuadro 3), mientras que la humedad generada por las deyecciones suele establecerse en un $10 \%$ sobre la producción de humedad de los animales.

Por otro lado, la eliminación natural de la humedad en las naves se produce mediante la ventilación $\left(H_{\text {ventilación }}\right)$. En este caso, sí que es habitual que la humedad (expresada en valor absoluto, w en $\mathrm{g} \mathrm{H}_{2} \mathrm{O} / \mathrm{m}^{3}$ aire) sea mayor en el interior de las naves que en el exterior, por lo que la ventilación siempre conseguirá reducir la humedad del aire interior. La cantidad de humedad eliminada a través de la ventilación se calcula como:

$$
H_{\text {ventilación }}=G \times \Delta w
$$

Así, el caudal de aire necesario para eliminar la humedad producida en la granja $\left(V_{\text {humedad, }}\right.$ en $\left.\mathrm{m}^{3} / \mathrm{h}\right)$ estará en función además de las humedades absolutas del aire en el exterior de la nave y en el interior de la misma:

$$
V_{\text {humedad }}=\frac{-H_{\text {animales }}}{\Delta w} \times v
$$

Cuadro 3. Producción de humedad en conejos (considerando un incremento del $10 \%$ procedente del estiércol) en función del tipo de animal (CIGR, 2002).

\begin{tabular}{|l|c|c|}
\hline Tipo de animal & Peso medio $\mathbf{( k g )}$ & Humedad producida $\left(\mathbf{g ~ H}_{\mathbf{2}}\right.$ Olanimal y hora) \\
\hline Conejas reproductoras & 3,5 & 8,60 \\
\hline Machos & 4 & 9,90 \\
\hline Recría & 2,5 & 6,80 \\
\hline Engorde & 1,5 & 4,40 \\
\hline
\end{tabular}




\section{Control de la concentración de gases}

Finalmente, para eliminar el exceso de gases nocivos $\left(\mathrm{CO}_{2}\right.$ y $\left.\mathrm{NH}_{3}\right)$ en la nave, es necesario determinar un caudal de ventilación apropiado $\left(V_{G A S i}\right.$ en $\left.m^{3} / h\right)$, que será distinto para cada gas $(i)$. Análogamente a los casos anteriores, se debe cumplir un balance de masas en la nave, en el que las cantidades generadas sean eliminadas mediante la ventilación $\left(\Sigma G A S_{i}=0\right)$, de forma que no se superen las concentraciones antes indicadas. La producción de gases en la nave procede únicamente de los animales y sus estiércoles (siempre y cuando no se produzca una combustión en el interior de la nave). Así, a modo de simplificación, podemos considerar una única fuente de gases que serían

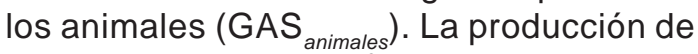
gases en granja es un factor muy variable y que depende de múltiples variables (temperatura, manejo de las deyecciones, alimentación, etc.), además en el caso de la especie cunícola, existe muy poca información científica disponible. A modo orientativo, en el Cuadro 4 se presentan resultados experimentales obtenidos en granjas españolas.

La eliminación de los gases del interior de la granja se realiza exclusivamente a través de la ventilación $\left(G A S_{\text {ventilación }}\right)$. Esta magnitud dependerá de dos factores, la cantidad de aire intercambiado o caudal de aire y la diferencia entre las concentraciones (en $\mathrm{mg} / \mathrm{m}^{3}$ ) de gases en el interior y exterior de la nave $\left(\mathrm{GAS}_{\text {ext }}-\mathrm{GAS}_{\text {int }}\right.$ ). De este modo, la cantidad de un gas $i$ eliminado a través de la ventilación se calcularía como:

$$
G A S_{\text {ventilación }}=V x\left(G A S_{\text {ext }}-G A S_{i n n}\right)
$$

De tal modo que, para calcular el caudal de ventilación necesario para eliminar la producción de gas por parte de los animales, se calculará, para cada uno de los dos gases, utilizando la siguiente ecuación:

$$
V_{G A S i}=\frac{-G A S_{i, \text { animales }}}{G A S_{\text {ext }}-G A S_{i n t}}
$$

De este modo, las necesidades de ventilación en la nave en un momento dado (expresadas en $\mathrm{m}^{3} / \mathrm{h}$ ) corresponderán al mayor de los cuatro valores determinados para cumplir con las cuatro necesidades descritas anteriormente (temperatura, humedad relativa, $\mathrm{CO}_{2}$ y $\mathrm{NH}_{3}$ ).

En condiciones frías, las necesidades de ventilación vendrán determinadas por el control de la humedad o concentración de gases, lo cual conllevará un coste adicional de calefacción. En cualquier caso, éste coste debe ser asumido si se pretende conseguir una calidad ambiental óptima en la nave.

\section{REFRIGERACIÓN Y CALEFACCIÓN}

La refrigeración y la calefacción son herramientas adicionales que permiten mejorar la climatización de los alojamientos. Mientras que la refrigeración resulta fundamental para sobrellevar las épocas más calurosas (los conejos son bastante sensibles al calor), la calefacción permitirá alcanzar las temperaturas requeridas en épocas más frías.

\section{Refrigeración}

Los sistemas de refrigeración utilizados en las granjas se basan en el fundamento de la refrigeración evaporativa, que reduce la temperatura del aire a costa de aumentar su contenido en humedad. La capacidad de enfriamiento del sistema depende de la humedad ambiental de la zona donde se instale el sistema. Cuanto menor es la humedad

Cuadro 4. Producción de gases en conejos (considerando la emisión directa de los animales y su estiércol) en función del tipo de animal (Calvet et al., 2011).

\begin{tabular}{|l|c|c|}
\hline Tipo de animal & $\begin{array}{c}\mathrm{CO}_{2} \text { producido (g/animal } \\
\text { y hora) }\end{array}$ & $\begin{array}{c}\mathbf{N H}_{3} \text { producido } \\
\text { (mg/animal y hora) }\end{array}$ \\
\hline Conejas reproductoras & 11,0 & 55,9 \\
\hline Engorde & 4,2 & 10,1 \\
\hline
\end{tabular}


del aire en el exterior, mayor capacidad de evaporación del agua, y mayor capacidad de enfriamiento. Por el contrario, si el aire exterior está muy húmedo (HR>70 \%), su capacidad de admitir más vapor de agua es baja y el proceso de enfriamiento es poco efectivo. En estas condiciones de elevada humedad los sistemas de refrigeración no son capaces de reducir la temperatura del aire de entrada a la nave más allá de 2 ó $3^{\circ} \mathrm{C}$.

Así pues, es muy importante tener en cuenta las condiciones climatológicas antes de instalar y poner en funcionamiento un sistema de refrigeración basado en la evaporación de agua, puesto que en zonas con elevada humedad relativa muy probablemente resultará ineficaz.

\section{Calefacción}

El uso de la calefacción en cunicultura no está tan extendido, siendo necesario únicamente en climas fríos. Deben evitarse los sistemas de calefacción por combustión en los que los gases de combustión (fundamentalmente el $\mathrm{CO}_{2}$ ) sean expulsados en el interior de la nave. Estos sistemas pueden Ilevar a acumulaciones de gas muy por encima de los límites máximos recomendados.

\section{AISLAMIENTO Y EFICIENCIA ENERGÉTICA}

Un correcto aislamiento de las naves tiene un efecto directo sobre el coste de climatización. Pese a que supone un coste de instalación inicial, los costes de refrigeración y/o calefacción pueden reducirse a menos de la mitad dependiendo de las condiciones ambientales.

A modo de ejemplo, en la Figura 5 se muestra el ahorro que se puede llegar a producir en refrigeración al instalar diferentes aislantes en la nave, en las paredes y en las cubiertas. Se consideran unas condiciones iniciales (sin aislante) en las que las paredes de la nave son de hormigón y la cubierta de fibrocemento. La temperatura exterior es de $30^{\circ} \mathrm{C}$ y la interior de $20^{\circ} \mathrm{C}$.

Se puede observar en la figura como se puede llegar a ahorrar hasta la mitad del coste de refrigeración con un buen aislamiento. También se aprecia como es mucho más efectivo aislar la cubierta del edificio que aislar las paredes.

Por ello, es muy importante tomar las medidas adecuadas en cada caso concreto. Por ejemplo, generalmente se transmite más

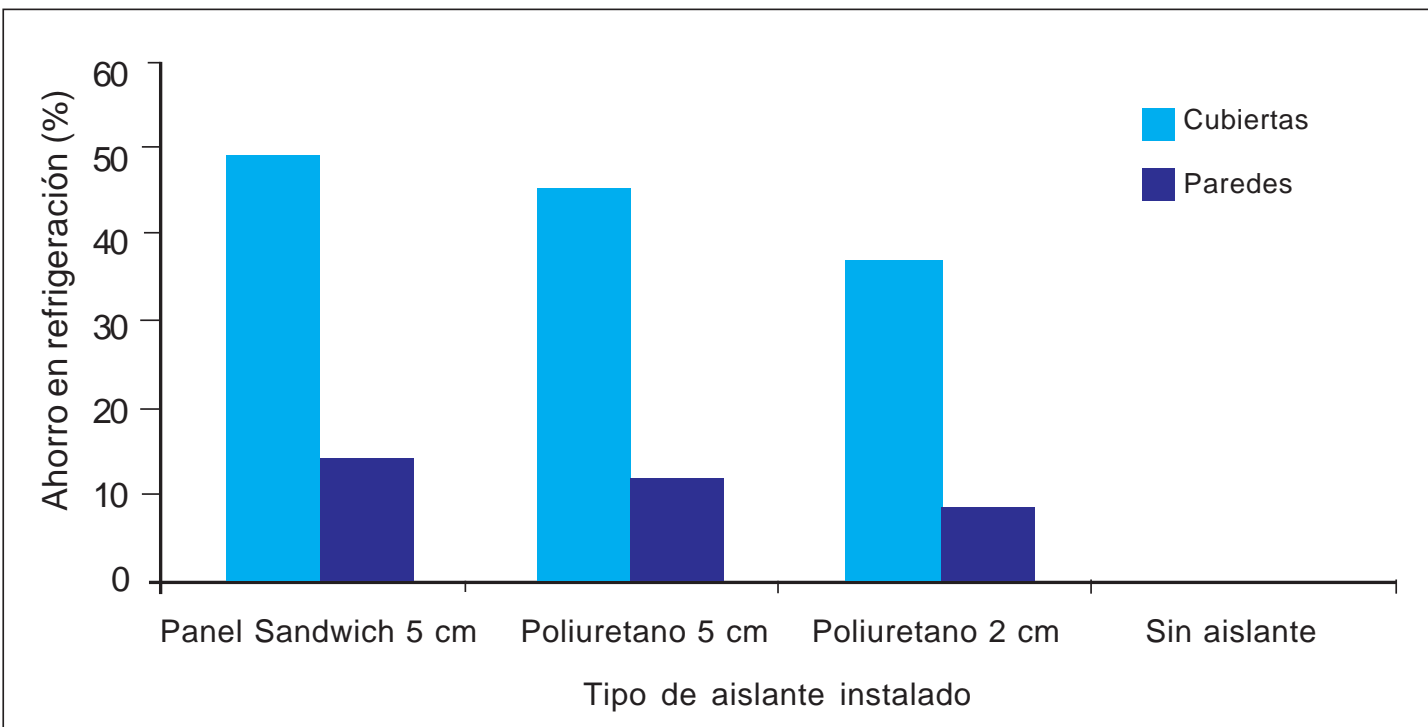

Figura 5. Ahorro esperado en refrigeración en una nave de conejos de cebo al instalar diferentes aislantes en paredes y cubierta. 

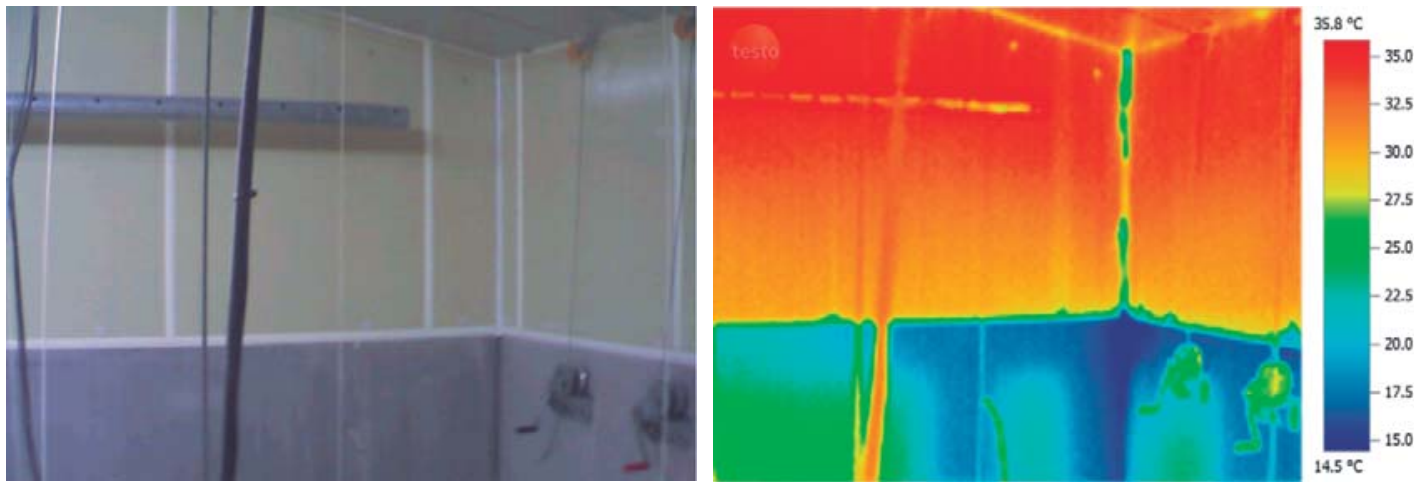

Figura 6. Ejemplo típico de puente térmico en la zona inferior de las paredes de la nave compuesta de hormigón sin aislamiento. El perjuicio para los animales más próximos es evidente ya que están en contacto con una zona fría de la nave.

calor a través de las cubiertas del edificio que a través de las paredes, por lo que resulta en una mejor relación coste/beneficio aislar las cubiertas de las naves. Por otro lado, es fundamental evitar los puentes térmicos en las naves (Figura 6). Los puentes térmicos son zonas o elementos estructurales (puertas, pilares, etc.), donde el aislamiento es deficiente (pese a que el aislamiento general de la nave sea adecuado). Estas zonas crean grandes diferencias en las condiciones de temperatura en sus proximidades, empeorando la producción y bienestar de los animales allí alojados, y reduciendo la eficiencia energética de la climatización.

\section{CONCLUSIONES}

El control ambiental en explotaciones cunícolas es un factor decisivo desde el punto de vista productivo, aunque no siempre se le ha prestado la atención necesaria. Cabría destacar una serie de puntos clave a tener en cuenta en este tema:

- Las necesidades de los conejos en lo referente a la calidad del ambiente se componen de varios factores: temperatura, humedad del aire, velocidad del aire y concentración de contaminantes.

- El correcto dimensionamiento y configuración de los sistemas de ventilación son pilares básicos para alcanzar resultados productivos óptimos.
- Es necesario estudiar con detalle las necesidades de calefacción y refrigeración en las naves, y cerciorarse de que estos sistemas van a aportar las soluciones deseadas.

- El aislamiento de los cerramientos en las naves, fundamentalmente en la cubierta, es una herramienta muy potente desde el punto de vista del ahorro energético.

\section{BIBLIOGRAFÍA}

CALVET, S.; CAMBRA-LOPEZ, M.; ESTELLES, F.; TORRES, A. G. 2011. Characterization of gas emissions from a Mediterranean broiler farm. Poultry Science, 90: 534-542.

CIGR. 1992. Climatization of animal houses. Second Report of the Working Group on Climatization of Animal Houses, Centre for Climatization of Animal Houses, Ghent, Belgium, 1-147.

CIGR. 2002. Climatization of animal houses. Heat and moisture production at animal and house levels. Pedersen, S. y K. Sälvik. Danish Institute of Agricultural Sciences, 1-46. Horsens, Denmark.

GARCIMARTIN, M. A.; OVEJERO, I.; SÁNCHEZ, E.; SÁNCHEZ-GIRON, V. 2007. Application of the sensible heat balance to determine the temperature tolerance of commercial poultry housing. World Poultry Science Journal, 63: 575-584. 
ADELL, E.; CALVET, C.; TORRES, A. G.; CAMBRALÓPEZ, M. 2012. Particulate matter concentrations and emissions in rabbit farms. World Rabbit Science, 20: 1-12.

CERVERA, C.; FERNÁNDEZ CARMONA, J. 1998. Climatic environment. En: De Blas C.I Wiseman J. (Eds). The Nutrition of the Rabbit. CABI Publishing. UK: CAB International, p. 273-295.

FERRÉ, J. S.; ROSELL, J. M. 2000. Alojamiento y Patología. Rosell, J. M. En: Enfermedades del conejo. Tomo I: Generalidades. 1 Capítulo 3. Madrid: Ediciones Mundi-Prensa, p. 167-211.

FRANGIADAKI, E.; GOLIDI, E.; MENEGATOS, E.; LUZI, F. 2003. Comparison of does' performances under high and moderate temperature in a Greek commercial farm. World Rabbit Science, 11: 137-143.
MARAI, I. F. M.; HABEEB, A. A. M.; GAD, A. E. 2002. Rabbits productive, reproductive and physiological performance traits as affected by heat stress: a review. Livestock Production Science, 78: 71-90.

SAHUQUILLO, J.; VILLAGRÁ, A.; BLANES, V.; TORRES, C.; TORRES, A. G. 2004. Effects of ammonia concentration on reproductive performance in rabbits. In: Proceedings AgEng 2004 September, Leuven, Belgium, 698-699.

VILLAGRÁ, A.; BLANES-VIDAL, V.; TORRES, A. G. 2004. Introducción a la climatización de granjas cunícolas. Boletín de Cunicultura, 131: 12-18.

WATHES, C. M.; CHARLES, D. R. 1994. Livestock Housing.1, Wallingford: CAB International, p. 1-428. 


\section{EL BIENESTAR ANIMAL Y SUS BASES ETOLÓGICAS EN LA CUNICULTURA COMERCIAL}

Arantxa Villagrá ${ }^{1}$

\section{INTRODUCCIÓN}

El bienestar de los animales de granja en general y de los conejos en particular, se puede contemplar desde el punto de vista de las cinco Libertades o cinco Necesidades. Así, se puede considerar que el bienestar de un animal será adecuado si:

- Está libre de hambre y sed mediante el acceso a agua y alimento que le permita un desarrollo saludable

- Está libre de incomodidades

- Está libre de dolor, enfermedades o lesiones

- Es libre de expresar sus comportamientos naturales

- Es libre de miedo y estrés

De este modo, con el fin de mantener un adecuado grado de bienestar para los animales, debemos ser capaces de garantizar el cumplimiento de estas Cinco Libertades en las explotaciones cunícolas.

\section{Características biológicas de los conejos}

Los conejos son animales del orden de los Lagomorfos (familia Leporidare). El comportamiento del conejo doméstico es similar al del silvestre, y la posible privación de relaciones sociales en condiciones de confinamiento podría comprometer su bienestar (Trocino y Xiccato, 2006). Así, el olfato es vital tanto en funciones sexuales como sociales y el oído es también importante; las orejas grandes y móviles les sirven para la detección de la proximidad de depredadores (EFSA, 2005). Las orejas participan también en la regulación de la temperatura corporal
(Harkness et al., 2010). En cuanto a la vista, el conejo tiene una visión panorámica aunque no muy precisa (Lebas, 2002).

Los conejos tienen un comportamiento alimentario único en comparación a otras especies. Su alimentación varía en el trascurso del día y aproximadamente el $60 \%$ de su ingestión sólida (con la excepción de los cecotrofos) se produce durante los períodos de oscuridad (Gidenne et al., 2010). También practican la cecotrofia, ingiriendo heces blandas directamente del ano, principalmente durante la mañana. Por otra parte, en cautividad y con dietas secas la disponibilidad de agua es esencial (EFSA, 2005). Aunque el conejo no es un roedor, una de las características esenciales de su comportamiento es roer.

\section{BIENESTAR ANIMAL EN EL CONEJO DOMÉSTICO}

\section{Comportamiento de los conejos}

Para hablar de bienestar en conejos, es importante conocer algunos comportamientos naturales de los conejos silvestres.

Con respecto al repertorio de comportamientos, los conejos en libertad se mueven con saltos, aunque en estado de alerta pueden caminar. También es frecuente el comportamiento de juego en los gazapos, así como el escarbado asociado a la realización de conejeras y a la exploración. Los conejos descansan tumbados sobre el vientre con las patas traseras encogidas o estiradas dependiendo de si se encuentran en estado de alerta o de relajación, respectivamente. También pueden tumbarse lateralmente indi-

${ }^{1}$ Instituto de Ciencia y Tecnología Animal. Universidad Politécnica de Valencia, España. 
cando un grado máximo de relajación. Descansan entre 12 y 18 horas al día y muestran preferencia por descansar en grupo y apoyados en superficies firmes (EFSA, 2005). Otra actividad importante es el aseo del pelaje mediante las patas, los dientes y la lengua. Es de destacar que el acicalamiento hacia sus congéneres favorece la cohesión del grupo (EFSA, 2005). Además los conejos exploran frecuentemente olisqueando, aunque es habitual que interrumpan esta u otra actividad ante estímulos que identifican como amenazas de predación. Ante estas amenazas adoptan posturas de alerta y es frecuente ver a conejos sentados o incluso de pie sobre las patas traseras con las orejas orientadas hacia la fuente del estímulo. Otras pautas asociadas a la presencia de predadores son el «freezing» o paralización, que implica la total inmovilidad del animal en un intento de confundir a su agresor y escapar de él y las patadas para avisar a sus congéneres de la presencia de una amenaza golpeando las paredes de la conejera.

Los conejos silvestres viven en grupos; las jerarquías se establecen claramente mediante interacciones agresivas. El orden jerárquico se mantiene en el tiempo y la agresividad se reduce notablemente a medida que pasa el tiempo (EFSA, 2005). Los grupos están constituidos por 1-4 machos y 1-9 hembras. En general, la tolerancia hacia los jóvenes es alta aunque depende del tamaño de grupo.

En cuanto al comportamiento sexual, el éxito evolutivo de esta especie se basa en «el número» (Pascual, 2010), es decir en época de reproducción los conejos en libertad tratan de tener camadas numerosas y frecuentes. Las atenciones dedicadas a la camada son escasas, reduciéndose a la preparación del nido unos tres días antes del parto y al amamantamiento una vez al día, durante pocos minutos (Fernández-Carmona et al., 2005). La coneja abre el nido a los 18-20 días del parto momento en que los gazapos empiezan a ingerir sólidos, que incluyen heces maternas, comenzando la actividad cecal. A los 24-25 días las conejas abandonan definitivamente a la camada para dedicarse al siguiente parto.

\section{Instalaciones y equipamiento}

Quizás una de las principales preocupaciones cuando se habla de bienestar en cunicultura está relacionada con las instalaciones y el equipamiento de las mismas. La restricción de espacio en el alojamiento cambia los patrones de comportamiento de los conejos que se acaban de explicar (Dixon et al., 2010), les impide realizar algunos comportamientos específicos, reduce la actividad y puede favorecer la aparición de comportamientos anómalos y redirigidos (Hansen y Berthelsen, 2000).

En el sistema productivo actual los conejos son alojados en jaulas de rejilla, aunque en sistemas alternativos se pueden encontrar corrales con cama de paja o algún otro material. En la actualidad existe un debate intenso, fundamentalmente en el seno de la Unión Europea, sobre el mantenimiento de las jaulas tradicionales o la evolución de los sistemas de alojamiento. Esta evolución puede ser tanto a sistemas que mantengan a las conejas alojadas en jaulas individuales o a sistemas de alojamiento en grupo.

Las jaulas individuales actuales pueden ser muy cuestionadas fundamentalmente desde un punto de vista de desarrollo de comportamientos naturales, puesto que el resto de libertades están garantizadas. No obstante, algunos comportamientos naturales como todos aquellos que rodean al parto, también los puede desarrollar la coneja en las jaulas individuales, gracias a la colocación de los nidos. Aún así, el cuestionamiento de las dimensiones de las jaulas es inevitable. Según Trocino y Xiccato (2006), las dimensiones de las jaulas varían entre países tal y como se presenta en el Cuadro 1 , y en la actualidad, no ha sido posible llegar a un acuerdo de cuáles son las mejores dimensiones para las conejas desde un punto de vista de bienestar animal y para el sector cunícola. 
Cuadro1. Resumen de las dimensiones de las jaulas de conejas reproductoras en algunos países europeos.

\begin{tabular}{|c|c|c|c|c|}
\hline $\begin{array}{l}\text { País } \\
\text { Tipo de jaula }\end{array}$ & $\begin{array}{c}\text { Ancho } \\
(\mathrm{cm})\end{array}$ & $\begin{array}{l}\text { Profundo } \\
\text { (cm) }\end{array}$ & $\begin{array}{c}\text { Altura } \\
(\mathrm{cm})\end{array}$ & $\begin{array}{l}\text { Superficie } \\
\text { disponible }\left(\mathrm{cm}^{2}\right)\end{array}$ \\
\hline \multicolumn{5}{|l|}{ Francia/Bélgica } \\
\hline Hembras jóvenes o no preñadas & $26-30$ & $45-50$ & $29-30$ & $1200-1500$ \\
\hline Hembra lactante con camada & 40 & $90-100$ & $29-30$ & $3600-4000$ \\
\hline \multicolumn{5}{|l|}{ Italia/Hungría } \\
\hline Hembras jóvenes o no preñadas & 38 & 43 & 35 & 1600 \\
\hline Hembra lactante con camada & 38 & 95 & 35 & 3600 \\
\hline \multicolumn{5}{|l|}{ España } \\
\hline Hembras jóvenes o no preñadas & 30 & 40 & 33 & 1200 \\
\hline Hembra lactante con camada & 40 & 85 & 33 & 3400 \\
\hline \multicolumn{5}{|l|}{ EFSA } \\
\hline Machos y hembras reproductoras & 38 & $65-75$ & $38-40$ & 3600 \\
\hline
\end{tabular}

NOTA: Dimensiones sin nido.

Los mayores problemas de bienestar derivados de las dimensiones de las jaulas podrían venir derivados de un exceso de tiempo tumbados, de problemas locomotores y de desarrollo esquelético anormal (Trocino y Xiccato, 2006). Pero como se observa en la tabla, no sólo son importantes el largo y el ancho de las jaulas, sino que también es importante la altura, puesto que una altura suficiente puede permitirles desarrollar posturas de alerta o vigilancia, apoyados en sus patas traseras (Hansen y Berthelsen, 2000). En cualquier caso, las jaulas deben tener al menos la altura suficiente para que los conejos puedan sentarse con las orejas erectas.

En cambio, como se ha dicho, se está trabajando también sobre nuevas instalaciones de alojamiento de conejas en grupo, enfocados a mejorar el bienestar de los animales al favorecer comportamientos naturales, pero en este caso pueden aparecer otro tipo de problemas de bienestar. Así, según Szendro et al. (2013), la producción en este tipo de conejas disminuye considerablemente, el estrés derivado de comportamientos agresivos aumenta, y las heridas y la mortalidad de gazapos también. Asimismo, la longevidad de las conejas también se ve reducida. No obstante, estos sistemas están tomando mucha fuerza en países como Bélgica y Holanda, donde los trabajos parecen indicar que productivamente la merma no es significativa y la agresividad se puede reducir manteniendo grupos de hermanas (Rommers y Kemp, 2012).

Aparte de todo lo comentado, en general, una de las principales recomendaciones en todas las especies cuando se habla de bienestar animal es el uso de materiales de enriquecimiento ambiental. El enriquecimiento ambiental puede mejorar la calidad de vida de los animales en cautividad ya que permite que éstos lleven a cabo comportamientos propios de su especie. En el caso de los conejos, el enriquecimiento ambiental puede favorecer el desarrollo de actividades como roer, rascar y refugiarse.

Los principales elementos de enriquecimiento, disponibles y testados, son:

- Espejos: colocados en un lateral de la jaula (Dalle Zotte et al., 2009)

- Refugios (Hubrecht et al., 2011): en animales alojados en grupo y conejas con camada

- Elementos para roer y evitar el sobrecrecimiento de los incisivos; por ejemplo, trozos de madera o juguetes de materiales sintéticos, colgados de las paredes o el techo de la jaula, e incluso forraje (Princz et al., 2007). 


\section{Condiciones ambientales}

Aunque casi siempre se le da mucha importancia a las jaulas, existen otros aspectos de las instalaciones de conejos a los que, en muchos casos, no se les presta tanta atención y que no por ello son menos importantes desde el punto de vista del bienestar de los animales. De hecho, el medio que rodea al animal y sus características son clave para su bienestar. Condiciones ambientales inadecuadas favorecen el estrés y las enfermedades, provocando mermas en el bienestar y la productividad. De este modo hay cuatro puntos clave a controlar en el interior de las explotaciones: la temperatura, la humedad relativa y la velocidad y calidad del aire, que incluye el material particulado en el ambiente y los gases (Blanes et al., 2004).

\section{- Temperatura}

Los conejos son animales sensibles a las altas temperaturas ya que su capacidad de disipación de calor es bastante limitada, por la espesa capa de pelo que poseen y la carencia de glándulas sudoríparas. Cuando la temperatura ambiental es muy alta y se prolonga en el tiempo, el animal es incapaz de controlar su temperatura corporal y se produce una situación de estrés térmico, en la que pueden aparecer problemas sanitarios graves. Por otra parte, el pelo les permite resistir bastante bien las temperaturas frías, aunque si éstas son muy bajas y prolongadas pueden provocar deterioro de la inmunidad y consecuentemente aumento de las enfermedades (especialmente respiratorias) y mayor mortalidad
Así es importante mantener la temperatura ambiental dentro del rango de temperatura óptima mediante sistemas de calefacción y refrigeración para evitar problemas de termorregulación.

El Cuadro 2 recoge los valores óptimos y críticos de temperatura por tipo de animal (Ferré, 1996).

\section{- Humedad}

Dentro de la nave la humedad debe mantenerse entre el 60 y el $70 \%$ (Ferré, 1996). Niveles muy altos (>80 \%) o muy bajos ( $<55$ \%) (Gullón, 2004) deben evitarse sobre todo cuando la temperatura también es inadecuada. Si la temperatura es alta, la humedad relativa alta favorece la proliferación de microorganismos y dificultan la termorregulación, mientras que la humedad relativa baja aumenta los problemas respiratorios y digestivos (Villagrá et al., 2004). Resulta por tanto vital controlar la humedad de manera combinada con la temperatura.

\section{- Velocidad de aire}

Los conejos son animales muy sensibles a las corrientes de aire que pueden ser causa de problemas respiratorios y diarreas inespecíficas en los jóvenes.

\section{- Gases y polvo}

Los gases más importantes a controlar en la explotación son el amoníaco y el dióxido de carbono. Elevadas concentraciones de estos gases provocan problemas sanitarios en los animales, principalmente enfermedades del aparato respiratorio. Pese a la escasez de estudios específicos para esta espe-

Cuadro 2. Valores óptimos y críticos de temperatura ambiental por tipo de animal en explotaciones cunícolas.

\begin{tabular}{|l|c|c|}
\hline Tipo de animal & Temperatura óptima $\left({ }^{\circ} \mathbf{C}\right)$ & Temperatura crítica $\left({ }^{\circ} \mathbf{C}\right)$ \\
\hline Maternidad & $16-20$ & $10-25$ \\
\hline Machos & $14-18$ & $6-24$ \\
\hline Dentro del nidal & $31-33$ & $31-33$ \\
\hline Recién destetados & $19-22$ & $14-26$ \\
\hline En crecimiento & $19-22$ & $10-30$ \\
\hline Recría & $16-18$ & $8-28$ \\
\hline
\end{tabular}


cie, se recomienda no sobrepasar concentraciones de 20 ppm de amoníaco y 3000 ppm de dióxido de carbono en las granjas.

El polvo irrita las mucosas y además favorece la propagación de microorganismos. Existen limitaciones para concentraciones de partículas de diámetro inferior a 2,5 micras y 10 micras, que son 1,7 y $3,4 \mathrm{mg} / \mathrm{m}^{3}$ respectivamente.

\section{- Iluminación}

En los conejos la iluminación afecta a los resultados productivos y al comportamiento, y por lo tanto al bienestar. Fundamentalmente se ven afectados algunos parámetros reproductivos y en cuanto a los comportamentales, son la cecotrofia y los hábitos crepusculares los que más pueden verse alterados (Gutiérrez et al., 2006).

\section{RESUMEN DE OTROS PROBLEMAS DE BIENESTAR DE LOS CONEJOS}

\section{Destete}

El destete en todas las especies constituye una etapa delicada para el bienestar de los gazapos, ya que abandonan definitivamente a la madre y la alimentación láctea, por lo que habrá que intentar minimizar el estrés que supone para ellos. Sin embargo, considerando tanto las connotaciones de bienestar para hembras y gazapos, como las connotaciones de salud peri-destete, es difícil definir una edad al destete recomendada para todas las granjas que asegure una mejora del bienestar. En general, los destetes largos mejoran el bienestar y protección digestiva de los gazapos pero pueden llevar a un excesivo desgaste de la coneja, mermando su bienestar. Por este motivo, si se opta por destetes más allá de los 35 días, no deberían aplicarse a conejas primíparas, y en multíparas deberían de ir acompañadas de un retraso en la fecha de cubrición (al menos a 25 días post parto) y la vigilancia del estado corporal de las conejas. Por otro lado, destetes previos a los 28 días de edad no son recomendables puesto que los gazapos no tendrían asegurada una adecuada adaptación de la alimentación láctea a la sólida.

\section{Pododermatitis}

La pododermatitis en conejos es una enfermedad de la piel que aparece en las patas traseras, y que una vez aparece puede ser colonizada por microorganismos patógenos, complicando la lesión y generando un grave problema de bienestar para la coneja. De hecho, se calcula que es la causante de aproximadamente el $16,5 \%$ de los sacrificios de conejas en explotación en toda Europa (EFSA, 2005). Por tanto, este tipo de lesión debe estar muy controlado en las explotaciones, valorando las patas de los animales cada vez que se manipulen, con el objetivo de tratar la lesión antes de que llegue a estados avanzados. Una forma de valorarla es a través de escalas de valoración como la de Olivas et al. (2013).

\section{BIBLIOGRAFÍA}

BLANES, V.; MANZANO, J.; TORRES, A. 2004. Cálculo de las necesidades de ventilación y ventilación mecánica de las granjas de conejos. Boletín de Cunicultura, 134: 24-40.

DALLE ZOTTE, A.; PRINCZ, Z.; MATICS, Z.; GERENCSOR, Z.; METZGER, S.; SZENDRO, Z. 2009. Rabbit preference for cages and pens with or without mirrors. Applied Animal Behaviour Science, 116 (2-4): 273-278.

DIXON, L.M.; HARDIMAN, J.R.; COOPER, J.J. 2010. The effect of spatial restriction on the behavior of rabbits (Oryctolagus cuniculus). Journal of Veterinary Behavior, 5: 302-308.

EUROPEAN FOOD (EFSA) collectif. 2005. The Impact of the current housing and husbandry systems on the health and welfare of farmed domestic rabbits. Annex to the EFSA Journal, 267: 1-31.

FERNÁNDEZ-CARMONA, J.; SOLAR, A.; PASCUAL, J.J.; BLAS, E., CERVERA, C. 2005. The behaviour of farm rabbits around parturition and during lactantion. World Rabbit Science, 13: 253-277. 
FERRÉ, J. S. 1996. Alojamientos en cunicultura en producciones cunícola y avícolas alternativas 2. Madrid: Mundi-Prensa: Zootecnia. Bases de la Producción Animal, p.79-99.

GUTIERREZ, R.P.; SAHUQUILLO, J.; TORRES A. 2006. La iluminación en las granjas cunícolas (1 $1^{\mathrm{a}}$ parte). Boletín de Cunicultura, 136: 6-10.

HANSEN, L.T.; BERTHELSEN, H. 2000. The effect of environmental enrichment on the behavior of caged rabbits (Oryctolagus cuniculus). Applied Animal Behaviour Science, 68 (2): 163-178.

HARKNESS, J.E.; TURNER, P.V.; VANDE WOUNDE, S.; WHELER, C.L. 2010. Harkness and Wagner's Biology and medicine of rabbits and rodents $5^{\text {th }}$ Edition. Iowa: Blackwell Publishing, p. 23-45.

HUBRECHT, R.; BUCKWELL, A.; CUBITT, S.; HOWARD, B.; JACKSON, A.; POIRIER, G.M. RSPCA. Refining rabbit care. A resource for those working with rabbits in research. Disponible en: http:// w w w. r s p ca.org.uk/s e rvlet/ Satellite?pagename=RSPCA.

GIDENNE, T.; GARCÍA, J.; LEBAS, F.; LICOIS, D. 2010. Nutrition and feeding strategy: interactions with pathology. En: Nutrition of the rabbit. De Blas C.I Wiseman J. (Eds). Wallingford: CAB International, p. 179-199.

GULLÓN, J. 2004. Problemas sanitarios y productivos derivados de la ventilación en granjas cunícolas. COGAL, pp. 5-16.
LEBAS, F. 2002. Biologie du lapin. Disponible en : http://www.cuniculture.info/Docs/ Biologie/biologie-09.htm.

OLIVAS, I.; TORRES, A.G.; VILLAGRÁ, A. 2013. Development of a pododermatits score in breeding does using clustering methods. Animal, 7 (6):1011-1016.

PASCUAL, J.J. 2010. The role of body condition on new feeding and breeding programmes for reproductive rabbit does. En: 22nd Hungarian Conference on Rabbit Production, Kaposvár, Hungría, pp. 11-22.

ROMMERS, J.; KEMP, B. 2012. Effect of group housing of young does during rearing 0 reproduction performance and aggressions: a pilot study. 2012. En: Proceedings of the $10^{\text {th }}$ World Rabbit Congress, 1101-1105. Sharm El Sheik, September, 2012.

SZENDRO, Zs.; MIKO, A.; ODERMATT, M.; GERENCSER, Zs.; RADNAI, I.; DEZSERY, B.; GARAI, É.; NAGY, I.; SZENDRO, K.; MATICS, Zs. 2013. Comparison of performance and welfare of singlecaged and group-housed rabbit does. Animal, 7(3): 463-468.

TROCINO, A.; XICATTO, G. 2006. Animal welfare in reared rabbits: a review with emphasis on housing systems. World Rabbit Science, 14(2): 77-93.

VILLAGRÁ, A.; BLANES, V.; TORRES, A. 2004. Introducción a la climatización de granjas cunícolas. Boletín de Cunicultura, 131: 12-18. 


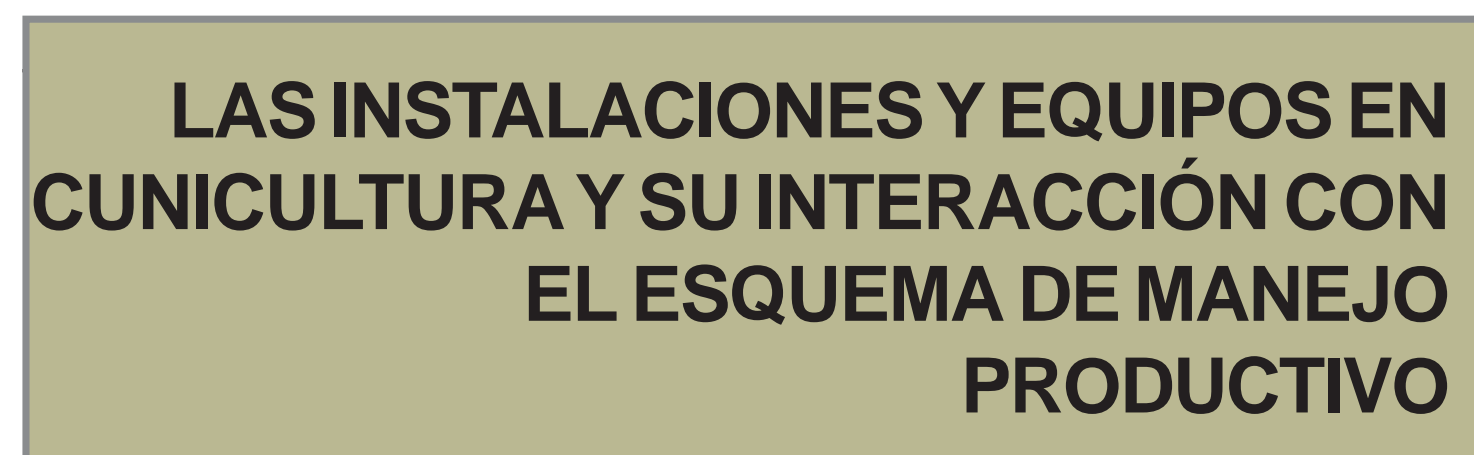

Oscar Blumetto $^{1}$

\section{INTRODUCCIÓN}

La cunicultura es una de las producciones más intensivas en el uso de instalaciones y mano de obra. El presente capítulo repasa los principales equipos de producción y la forma de organización del manejo reproductivo y del engorde. Integra directa o indirectamente toda la información que fue generada a nivel internacional durante mucho tiempo y que ha sido expuesta en los restantes capítulos.

Se trata entonces de recomendaciones sobre la planificación y organización de instalaciones, animales y tareas que hacen a la cotidianeidad de una unidad productiva en cunicultura, basadas especialmente en la experiencia generada en 15 años de manejo de la Unidad Experimental de Cunicultura de INIA (UEC), la granja experimental de la Universidad Politécnica de Valencia y granjas comerciales en Uruguay, Argentina y España. Como grandes temas involucra: Instalaciones y planificación física, manejo reproductivo, manejo del engorde y transporte de animales para faena.

\section{INSTALACIONES}

La cunicultura moderna para producción comercial de carne se realiza en locales techados, naves o galpones con diferentes diseños y tipos de ventilación como se explica en capítulos anteriores. Esto implica la posibilidad de cierto manejo sobre las condiciones atmosféricas internas, la ausencia de precipitación y la necesidad de manejar los efluentes. A su vez, dentro de estas naves, se ubican jaulas que en definitiva serán donde se alojarán los conejos. La utilización de jaulas suspendidas en el aire se ha impuesto en especial por razones sanitarias (Rosell, 2000).

En el capítulo de manejo ambiental, han sido descritos los formatos de naves y las formas de ventilación, por lo cual nos referiremos a los equipos que se ubican dentro de estas naves.

En lo que refiere al manejo, la principal variable que define el tipo de jaulas a emplear, es la categoría productiva de los animales. En este sentido se distingue las categorías reproductivas madres y padrillos, los animales de reposición de reproductores y el engorde.

En términos generales solo los accesorios o en algún caso el tamaño diferencian las jaulas destinadas a cada categoría.

\section{GENERALIDADES}

La mayor parte de las jaulas para producción comercial de conejos a nivel mundial están construidas con alambres de hierro galvanizado. Este material reúne características importantes como resistencia, fácil higienización y dependiendo de los contenidos de zinc y los procesos industriales, resistencia a la corrosión. Algunos componentes pueden ser de chapa galvanizada y cada vez más materiales plásticos (Figura 1).

Las dimensiones habitualmente implican una superficie de 0,3 a $0,4 \mathrm{~m}^{2}$ con relacio- 
nes ancho largo variables según modelo. En los países de mayor producción como Italia y España las superficies de las jaulas son en promedio de 0,36 y $0,34 \mathrm{~m}^{2}$ respectivamente (Xiccato y Trocino, 2005). Camps (2002) propone que el grosor del alambre para el piso de las jaulas debe ser de un mínimo de $2 \mathrm{~mm}$ de diámetro, y tener un espacio entre hileras de alambre de $12 \mathrm{~mm}$, para que pasen bien las cagarrutas, y ofrezcan buen apoyo a las patas del conejo.

\section{JAULAS PARA MADRES}

Las madres se alojan en forma individual. Aunque algunas propuestas modernas basadas en el bienestar animal han recomendado el usos de jaulas colectivas para maternidad, no ha podido ser demostrada una mejora en los resultados productivos (López, 2006) .

Las jaulas de madres no se diferencian en su estructura de las jaulas de engorde, pero poseen accesorios indispensables para ésta categoría. El accesorio principal de este tipo de jaula es el nido. Los nidos son habitualmente de materiales plásticos muy resistentes y flexibles, de fácil lavado y desinfección. Los laterales y frente suelen ser metálicos y en la mayoría de los modelos pueden ser retirados cuando la coneja no tiene gazapos o los gazapos pueden prescindir del abrigo del nido, lo cual ocurre aproximadamente luego de tres semanas del parto. La ubicación puede ser interna (Figura 1.A) o ser colocado en el exterior (Figura 2).

Desde el punto de vista práctico debe disponer de fácil acceso para la revisación periódica de la camada, higienización y agregado de material de cama. El nido dominante en la cunicultura comercial es tipo cuna el cual está provisto de un piso fijo con una rejilla fina y un piso flotante también en forma de rejilla, entre los cuales se coloca un material absorbente (ej: viruta, paja o borra de algodón) en un espesor de 2 a $3 \mathrm{~cm}$. Este «sándwich» actúa en forma similar al gel de

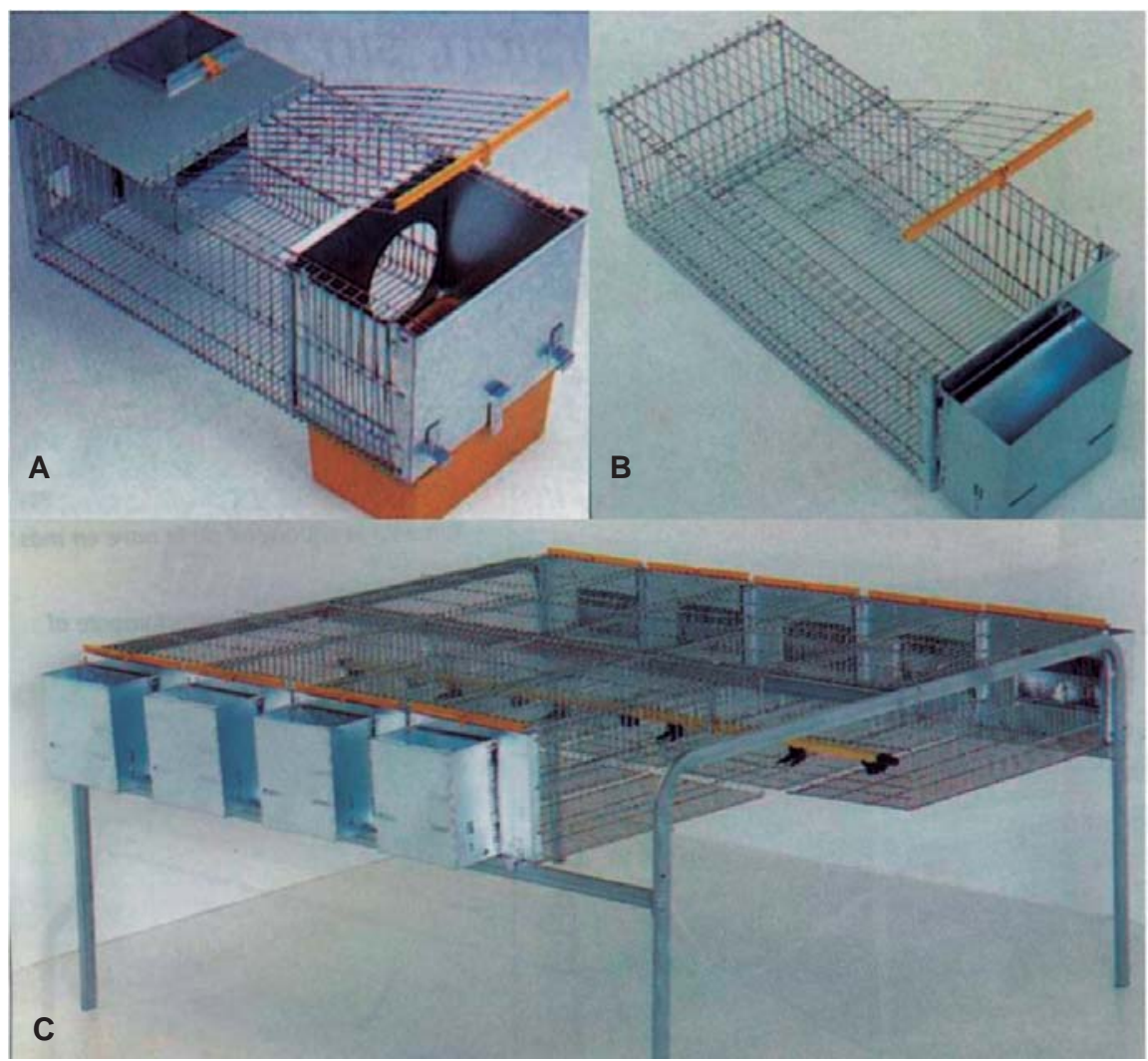

Figura 1. Ejemplos de jaulas para conejos, A: jaula de madres, B: jaula de engorde, C: disposición de jaulas tipo «flat deck». 


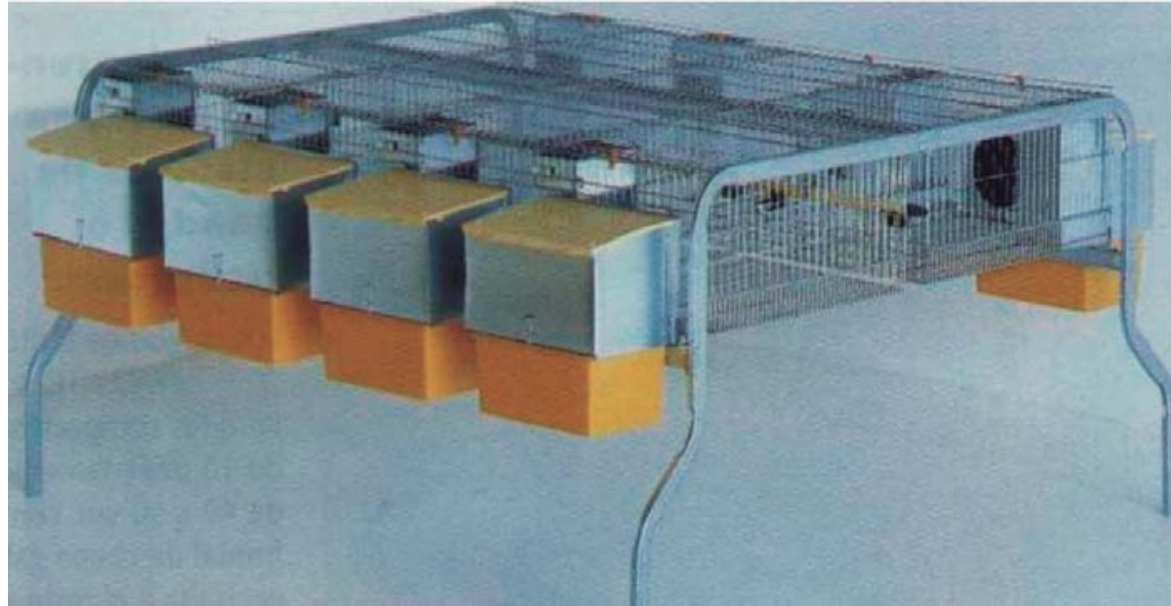

Figura 2. Módulos de ocho jaulas maternales con nido exterior.

un pañal descartable, absorbiendo y dispersando la humedad de la orina de los gazapos e impidiendo la pérdida de temperatura y las corrientes de aire. Sobre ese piso flotante se coloca el material de cama que constituirá el nido junto con el pelo de la coneja, utilizando normalmente los mismos materiales antes mencionados (Figura 3).

Si bien no hay mucha información sobre la influencia de dichos materiales sobre la performance reproductiva, las conejas prefieren la paja en relación a la viruta de madera y también se obtiene una mejor calidad de nido dada la conservación de mayor porcentaje del material original y la disposición de pelo en el nido (Blumetto et al., 2010).

A pesar de que en nuestro país ha sido común el uso de nidos de madera, en la UEC tempranamente se determinaron diferencias significativas como se muestra en la Figura
4, tomado de Blumetto y Capra (1998). Las diferencias a favor de los nidos de plástico son notorias si consideramos los gazapos destetados y principalmente dos razones explicarían las diferencias: la facilidad de limpieza y desinfección del plástico, las propiedades higro-térmicas del sistema sándwich y por último la diferente disposición del nido que en el caso del tipo cuna se coloca por debajo del nivel del piso, mientras que las zapatas se colocan sobre el piso de la jaula.

Otro accesorio importante para reproductores, tanto para hembras como machos, son los reposapatas. Se trata de una pequeña plataforma donde el reproductor puede descansar evitando el daño sobre la almohadilla de pelos de las patas, producido por el piso de alambre de la jaula. Este daño puede causar callos plantares, conocido habitualmente como mal de patas (Camps, 2000).

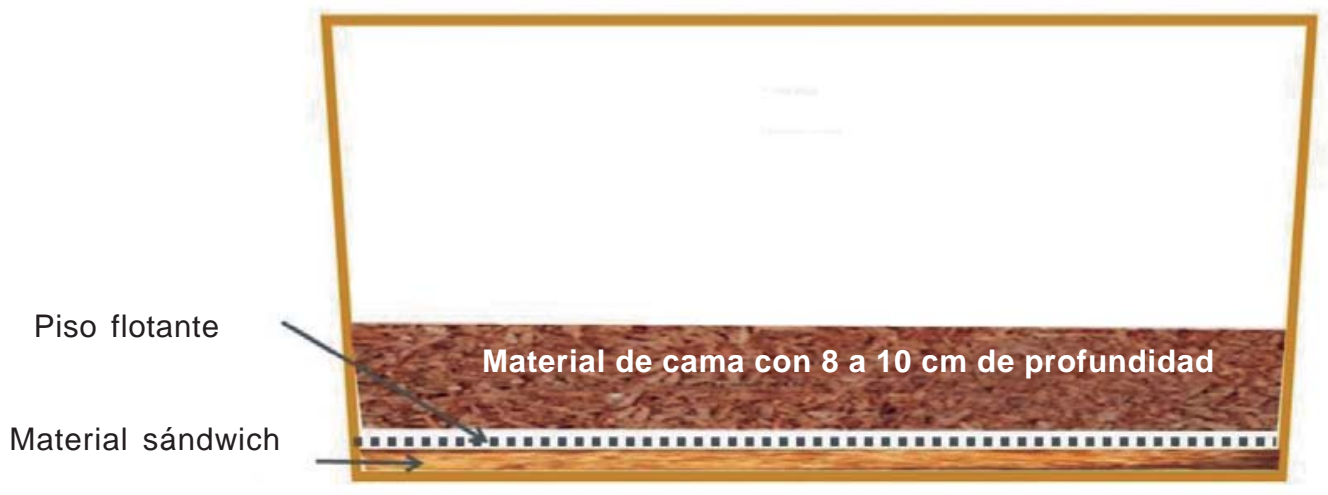

Figura 3. Esquema de un nido cuna-sándwich para jaula maternal. 


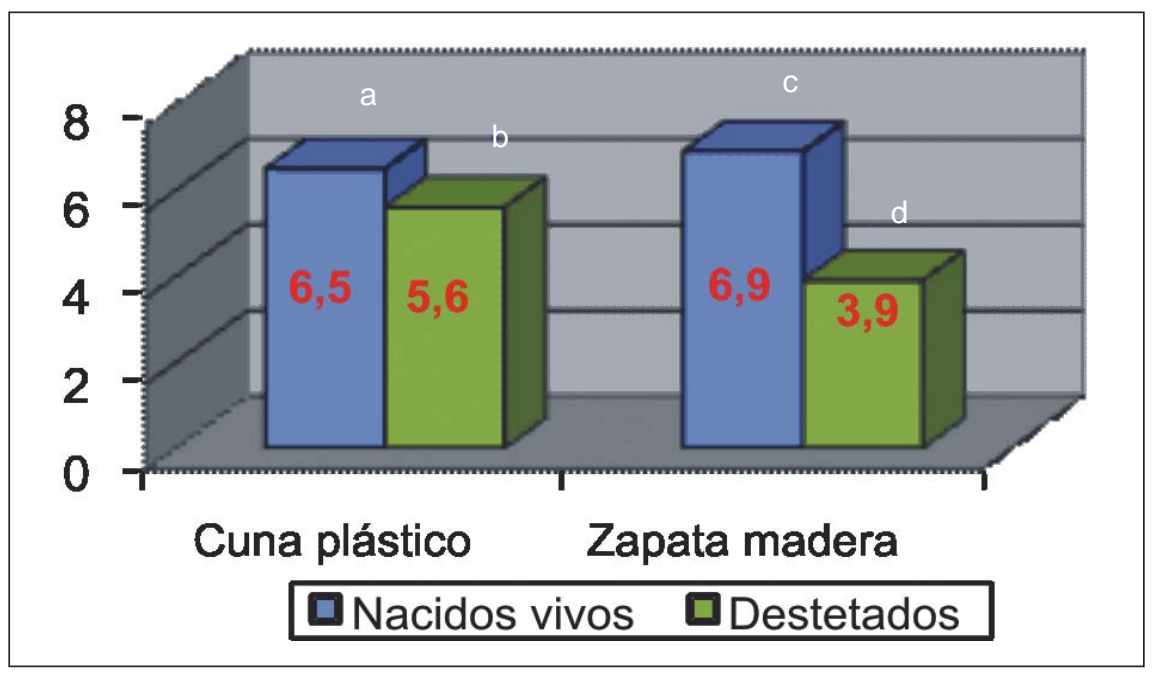

Figura 4 . Número promedio de gazapos nacidos vivos y destetados en dos tipos de nido obtenidos en la UEC durante los años 1997 y 1998.

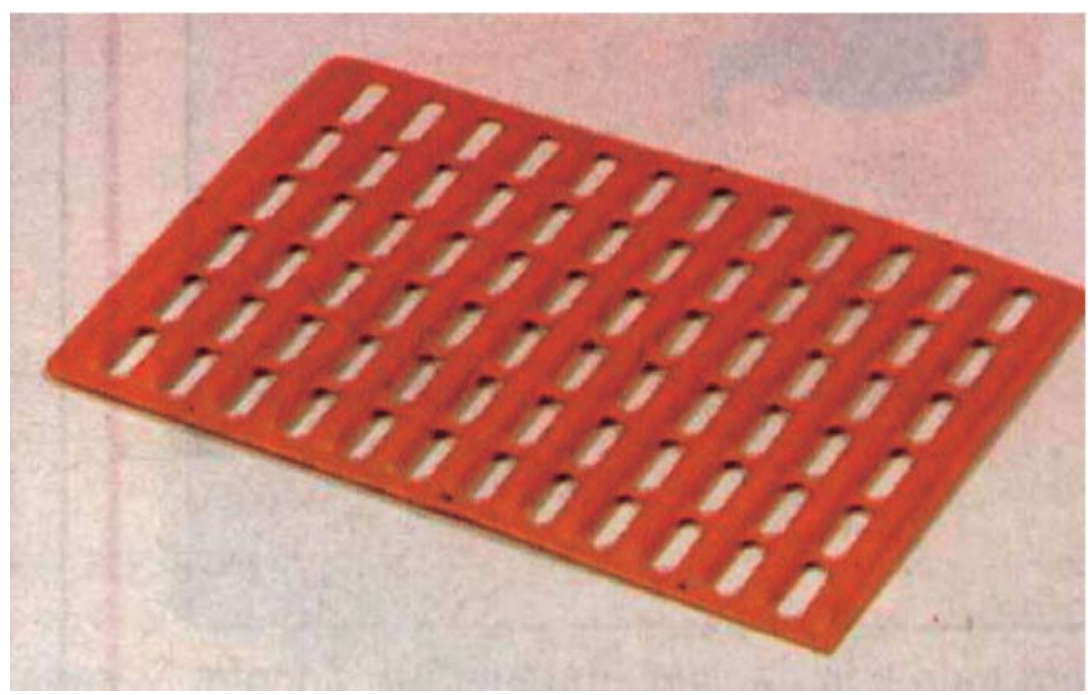

Figura 5 . Modelo de reposapatas plástico.

Estos dispositivos pueden ser de plástico específico (Figura 5) con un cierto calado que permite la caída de deyecciones o una plataforma de madera, cuya dificultad es la higienización.

\section{JAULAS PARA MACHOS}

Las jaulas para machos normalmente poseen las mismas dimensiones y características que las jaulas de madres, a excepción de la necesidad de un nido.
Algunos sistemas de pequeña escala han utilizado jaulas circulares para los machos. La teoría indica que ofrece ventajas a la hora de la monta, ya que la hembra no tiene rincones donde resguardarse y evitar la monta, sin embargo, la coneja receptiva (en celo) no ofrece ninguna resistencia y facilita dicha monta en cualquier tipo de jaula. Además tiene otras dificultades prácticas, por no adaptarse al formato modular de las otras jaulas, ocupando más espacio en el criadero. 


\section{JAULAS DE ENGORDE}

La mayoría de los fabricantes de jaulas utilizan los mismos tipos de jaulas para engorde que las utilizadas para maternidad y machos, con algunos pequeños cambios, como la colocación exterior de los comederos para aumentar el espacio disponible (ver Figura 1). Por tanto se trata en general de una superficie libre de dispositivos con excepción del bebedero que ocupa un espacio menor en algún lateral de la jaula, cuyo suministro de agua es exterior a la misma.

\section{JAULAS DE REPOSICIÓN/ ESPERA}

Existen muchos modelos de jaulas de reposición según el fabricante, pero todas ellas comparten la característica de poseer dimensiones menores que las antes mencionadas, pudiendo ir de 0,08 a $0,25 \mathrm{~m}^{2}$. El objetivo es alojar individualmente animales de reposición, tanto machos como hembras, que serán los futuros reproductores, en el período que va de la finalización del engorde hasta el comienzo de la etapa reproductiva. Con el objetivo del ahorro de espacio dentro del local muchas veces pueden estar ubicadas en baterías de varios niveles.

\section{ORGANIZACIÓN DEL ESQUEMA REPRODUCTIVO}

El esquema de producción de conejos para carne implica la realización de un ciclo completo, es decir la cría o maternidad y la recría-engorde, de donde finalmente se obtiene el producto final. El proceso reproductivo es, por tanto, el que regula los flujos de producción. Este proceso comienza desde la incorporación de un reproductor al plantel hasta que se destetan los gazapos, cuyo número es precisamente lo que determinará la cantidad de gazapos que podremos engordar.

El esquema que desarrollaremos es el adoptado en la UEC y en la mayor parte de los productores comerciales de Europa y América, es la producción en bandas, con un intervalo entre partos teórico (IEP) de 42 días.

El intervalo entre partos recomendado resulta de un equilibrio entre la máxima cantidad de partos que se pueda obtener en un período de tiempo por cada hembra y el período de tiempo necesario para que una madre pueda recuperar su estado corporal entre una y otra lactancia. Para la línea Verde establecer un IEP teórico de 42 días parece como el más conveniente para lograr estos objetivos. Esto implica, si consideramos una gestación promedio de 31 días (Alvariño, 1993) que debemos realizar el servicio al día 11 pos parto; en la práctica es poco probable que el $100 \%$ de las hembras estén receptivas ese día y que todas las hembras servidas logren la preñez, por lo cual el IEP real promedio alcanza para nuestras condiciones valores cercanos a los 50 días. Para permitir un período de recuperación del tejido mamario de la hembra y una alta sobrevivencia de gazapos destetados se realiza el destete a los 33 días de edad, momento en el cual estos objetivos parecen alcanzar un equilibrio óptimo.

Para los sistemas donde se procura obtener la máxima eficiencia reproductiva, un flujo constante de producción y una organización metódica del trabajo rutinario, el esquema recomendable es la utilización de seis bandas a intervalos semanales.

En términos prácticos el esquema en bandas significa tener un lote de conejas pariendo simultáneamente; en el esquema de seis, tendremos una parición por semana, en forma continua. Para lograr bandas uniformes se deben llevar a servicio un número de conejas superior al que queremos definitivamente pariendo. Esto se logra con el servicio de las conejas que se encuentran en el día 11 posparto, más las que servidas 14 días atrás dan negativo en la palpación y otras que no hayan aceptado la monta la semana anterior. En promedio debemos servir entre 20 y $30 \%$ más conejas que el tamaño de la banda deseada. De modo gráfico en la Figura 6 se representa la evolución temporal de una banda. 


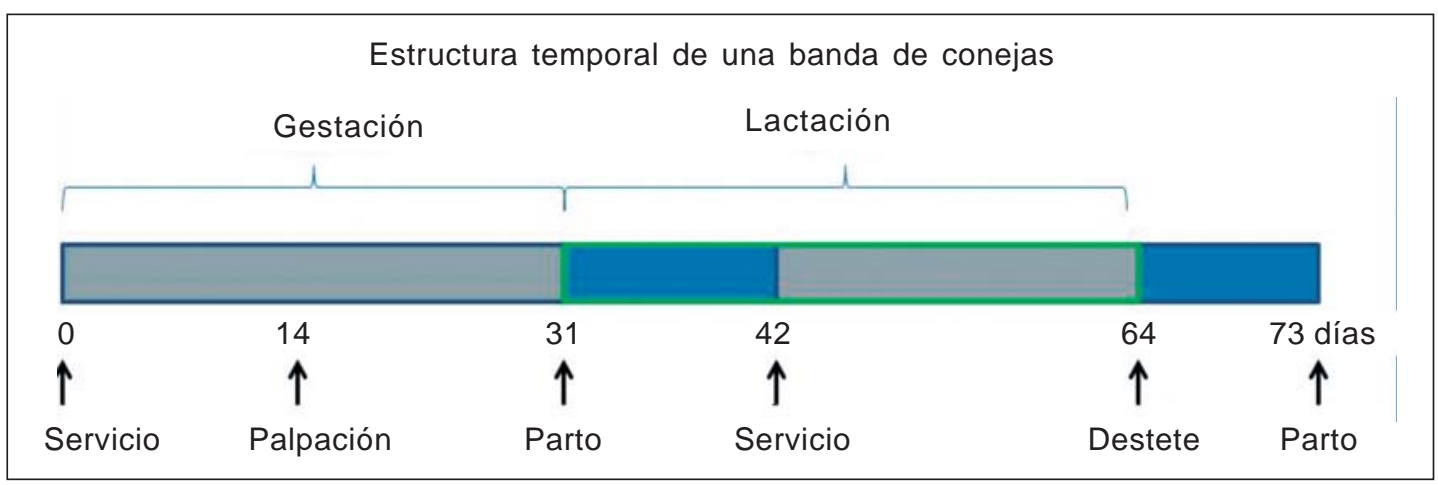

Figura 6. Línea de tiempo para el funcionamiento de una banda.

1 semana

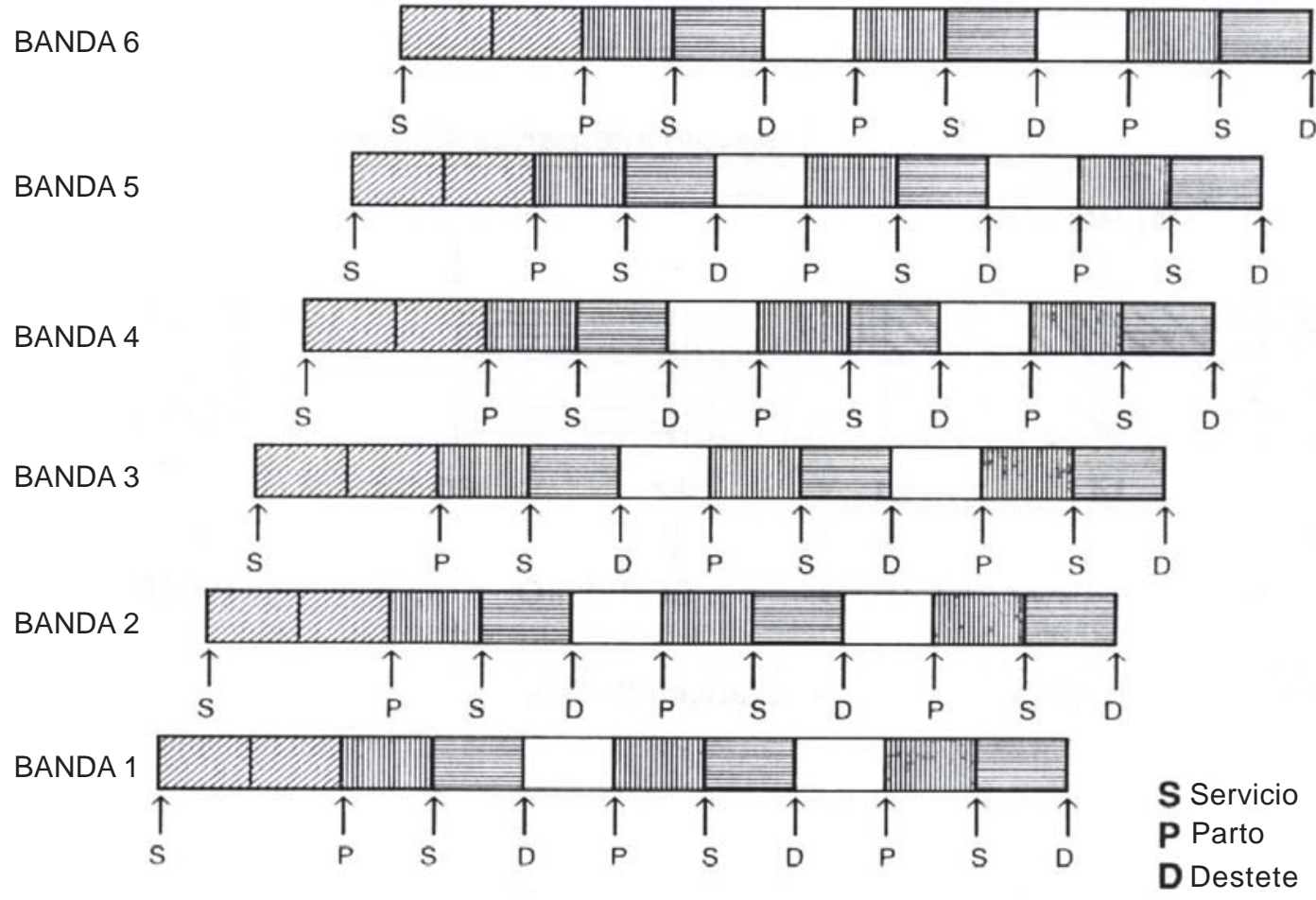

Figura 7. Esquema temporal de funcionamiento de un sistema de producción en seis bandas.

La superposición de los esquemas de cada banda individual nos da como resultado la visualización gráfica de la totalidad del sistema (Figura 7).

Esta metodología de organización permite planificar el trabajo y ajustar las actividades a una rutina bien establecida para cada día de la semana. En la UEC las principales tareas se realizaron de la siguiente manera: Lunes: palpaciones y servicios
Martes: colocación de nidos y destetes

Miércoles: pueden producirse partos adelantados

Jueves: se produce el grueso de los partos Viernes: pueden producirse partos atrasados y se realizan divisiones de los lotes de engorde (ver manejo del engorde)

Para esta estructura organizativa, realizando monta natural, la relación macho hembra del plantel reproductor no debería 
alejarse de 1:10. Esto asegura una fertilidad adecuada y no incrementa costos por el gasto de mantenimiento de un exceso de machos.

En inseminación artificial la relación podría variar de 1:50 a 1:100, dada la dilución que se realiza del semen extraído; sin embargo esta técnica solo es económicamente viable y ventajosa desde el punto de vista práctico con escalas de producción que superen las 100 madres.

La longevidad de los reproductores tiene grandes variaciones individuales, de todos modos al calcular la reposición necesaria, debemos pensar en cifras de $120 \%$ anual aproximadamente para las hembras. Esta cifra resulta de la sustitución total anual del plantel de madres (un año de vida productiva) y un porcentaje extra por reposición de individuos que presenten algún problema durante su vida productiva. En estos casos, siempre hablamos de situaciones promedio, habiendo ocasiones donde algunas madres superen el año de vida productiva y otras deban ser sustituidas antes de ese período. En todos los casos el criterio será productivo, es decir si se detecta baja de productividad, problemas físicos o fisiológicos, problemas sanitarios, mal comportamiento maternal o se produce la muerte.

El caso de los machos es diferente, ya que normalmente alcanzan vidas productivas más largas dado que no sufren el desgaste que provocan las sucesivas lactancias en las hembras. Es común alcanzar un año y medio a dos de trabajo con los machos de la línea Rosa; lo prioritario es cuidar su estado sanitario, en especial la aparición de callos plantares, lo cual se evita con una adecuada higiene y la utilización de reposapatas.

\section{MANEJO DE LA RECRÍA- ENGORDE}

La recría-engorde es el período de tiempo que va desde el destete (33 días de edad en el esquema anteriormente descrito) hasta el momento de la faena. En Uruguay el peso promedio para el sacrificio es de 2,5 $\mathrm{kg}$ en pie, lo cual para el caso de los gazapos híbridos Verde $x$ Rosa se alcanza a los 72 a 75 días de edad.

Si bien esta categoría de animales podría ser caracterizada como una de las menos exigentes, es importante tener en cuenta que es en esta etapa donde se consume el $66 \%$ del total de alimento, que es el más importante de los costos de producción y ocupan la mayor parte de las instalaciones de la granja.

Con motivo de optimizar el uso de instalaciones y maximizar la eficiencia de conversión alimenticia, en la UEC se ha recomendado un sistema que consta de la división del período de engorde en dos etapas. La primera de ellas (E1) va desde el destete hasta la tercera semana de engorde y la segunda (E2) desde ese momento hasta el momento de la faena. Estas recomendaciones están basadas en trabajos de investigación propia sobre densidades de alojamiento realizados con conejos de la razas Neozelandés y Californiano, las cuales fueron ratificadas con los gazapos cruza de las líneas Verde y Rosa, como puede apreciarse en los Cuadros 1 y 2.

Cuadro 1. Ganancia semanal de peso de gazapos desde el destete hasta el final de la tercera semana de engorde (etapa 1).

\begin{tabular}{|c|c|c|c|}
\hline $\mathbf{N}^{\circ}$ gazapos por jaula & Semana 1 & Semana 2 & Semana 3 \\
\hline 6 & $369 \pm 45$ & $318 \pm 42$ & $299 \pm 46$ \\
8 & $369 \pm 44$ & $300 \pm 48$ & $286 \pm 62$ \\
10 & $369 \pm 58$ & $308 \pm 55$ & $291 \pm 48$ \\
12 & $375 \pm 42$ & $297 \pm 50$ & $273 \pm 40$ \\
\hline
\end{tabular}


Cuadro 2. Ganancia semanal de peso de gazapos desde la cuarta hasta el final de la sexta semana de engorde (etapa 2).

\begin{tabular}{|c|c|c|c|}
\hline $\mathbf{N}^{\circ}$ gazapos por jaula & Semana 4 & Semana 5 & Semana 6 \\
\hline 6 & $279 \pm 45$ & $312 \pm 60$ & $235 \pm 64^{\mathrm{a}}$ \\
\hline 8 & $263 \pm 54$ & $288 \pm 54$ & $208 \pm 53^{\text {ab }}$ \\
\hline 10 & $280 \pm 80$ & $290 \pm 66$ & $175 \pm 73^{\mathrm{b}}$ \\
\hline $\mathrm{p}$ & $\mathrm{NS}$ & $\mathrm{NS}$ & 0,05 \\
\hline
\end{tabular}

*Letras similares en la columna significa que no hay diferencias significativas $p=0,05$.

En consecuencia en las primeras tres semanas de engorde se recomiendan densidades de alojamiento de 12 animales por jaula, para los modelos estándar que tienen superficies entre 0.30 y $0,32 \mathrm{~m}^{2}$. Esta densidad debe ser disminuida si no se cuenta con bebederos automáticos y comederos tipo tolva.

En la segunda etapa los lotes de 12 animales son divididos a dos lotes de seis cada uno, densidad a la cual se mantendrán hasta la terminación. De acuerdo a los resultados obtenidos, podrían admitirse densidades un poco mayores, al menos en las primeras semanas de la segunda etapa del engorde, que en la práctica resultaría en mezclar animales que han venido ocupando jaulas diferentes, lo cual podría provocar agresiones entre los gazapos que seguramente repercuten en la tasa de crecimiento.

\section{CÁLCULO DE LAS NECESIDADES DE JAULAS Y EQUIPOS}

En base a lo mencionado en relación a las recomendaciones de manejo de reproductores y engorde es posible calcular las necesidades de jaulas y equipos. A modo de ejemplo, utilizaremos una base de cálculo de una unidad de 100 madres.

Las madres y machos deben alojarse en forma individual, por lo cual si consideramos una relación hembra: macho de 10:1 como recomendable serían necesarias 110 jaulas de reproductores en un manejo tradicional. No obstante el manejo en bandas permite la realización de sobreocupación, esto implica la posibilidad de tener más madres que jaulas de madres.

Esto es posible dado el período que transcurre entre el destete y el siguiente parto de una coneja, permite que sea alojada al menos durante una semana en una jaula de reposición/espera. En resumen ésta medida de trasladar la madre destetada a una jaula de espera hasta tres o cuatro días antes del siguiente parto, liberando una de cada 6 semanas de cada jaula de madre, con lo cual requeríamos 85 jaulas para 100 madres en producción. En la práctica es un manejo que requiere una gran dedicación, por lo que es más común tener jaulas fijas para cada madre.

En cuanto al engorde, nos basaremos en un manejo en seis bandas, los destetes promedio obtenidos en la UEC y un engorde de seis semanas divido en dos fases de tres cada una.

Considerando un sistema en pleno funcionamiento, tendremos destetes todas las semanas de 15 a 17 conejas, con un promedio de 8,5 gazapos destetados por madre, nos daría un máximo de144 gazapos por banda. Esto significaría 12 jaulas para alcanzar una densidad de 12 gazapos por jaula, donde permanecerán tres semanas para luego ser divididos a seis gazapos por jaula, con lo cual necesitaremos 12 jaulas adicionales.

En un manejo en 6 bandas, todas las semanas ocurren destetes y subdivisiones de lotes, por lo tanto en forma regular en una granja se tendrán tres lotes en la primera fase de engorde y tres lotes en la segunda fase. Esto implica en términos numéricos que habrá 36 jaulas en primera fase de engorde y 72 en segunda fase, lo cual totaliza 108 jaulas totales en el engorde. 
También debe preverse las necesidades de jaulas para la reposición tanto de hembras como de machos. Si consideramos que lo habitual sea un $120 \%$ de reposición anual y que entre el final del engorde y el inicio de la reproducción transcurren unos dos meses, requeriremos unas 25 jaulas individuales, que normalmente tienen una superficie de un 25 a $50 \%$ de la jaula de madre. Es posible en el caso de las hembras alojarlas en forma colectiva (dos o tres por jaula de engorde) hasta el inicio de la reproducción. En el caso de hacer sobreocupación, habría que agregar entre 15 y 20 jaulas de espera.

A estos cálculos de necesidades de jaulas habría que agregar un comedero tipo tolva y un bebedero automático por cada jaula, con lo cual necesitaríamos 243 tolvas y un número igual de bebederos.

En el caso de los nidos, éstos pueden ser retirados transcurridos los 21 días de lactancia, deben ser colocados unos tres días antes del parto y ser higienizados con un margen de tiempo de unos tres días, con lo cual sería suficiente con 65 nidos.

Los reposa-patas deben estar disponibles para todos los reproductores adultos, por lo cual serán necesarios 110 unidades.

En resumen para una unidad de 100 madres con manejo convencional se requerirán:

100 jaulas de maternidad

10 jaulas de macho

108 jaulas de engorde

25 jaulas de reposición

243 tolvas

243 bebederos

80 nidos

110 reposa-patas

\section{MANEJO DE EFLUENTES}

\section{Consideraciones generales}

Al utilizarse jaulas para la producción, los animales no entrar en contacto con las deyecciones, pero las mismas deben ser retiradas de las naves de producción para disposición final o procesamiento. Para ello, deben construirse fosas que se ubicaran debajo de las jaulas, donde las heces y orina puedan acumularse por cierto tiempo. En efecto, en jaulas tipo flat deck, los anchos de fosa salvo excepciones, se sitúan entre 1,8 y $2 \mathrm{~m}$, por lo que en esta materia poco diferirán los diferentes proveedores. Los anchos pueden ser superiores (hasta $3 \mathrm{~m}$ ) en alojamiento tipo batería o californiano, cada vez menos frecuentes dadas las dificultades de higiene y ventilación que estos sistemas conllevan. Los aspectos realmente variables en la construcción de fosas son su profundidad, diseño (formas, drenajes, materiales, etc.) y adaptación a diferentes sistemas de limpieza.

Los sistemas existentes para explotaciones industriales, se describen brevemente a continuación, adaptado de Blumetto y Torres (2005).

\section{Sistemas de fosa profunda}

Los sistemas de fosa profunda procuran minimizar el trabajo de limpieza y de retirada de deyecciones; la profundidad de estas fosas es variable ( 1 a $5 \mathrm{~m}$ ), permitiendo la deposición por meses e incluso años.

El sistema prevalece en relativamente pocas granjas europeas, debido principalmente a las dificultades de construcción que implica el desnivel requerido entre la planta de la nave, el fondo de la fosa y el acceso exterior a las mismas. Dicho desnivel es necesario para poder introducir maquinaria (tractor, pala mecánica, etc.) para poder efectuar la retirada de estiércol.

Este tipo de instalaciones nunca ha sido utilizado en Uruguay.

\section{Fosas convencionales}

El diseño más comúnmente utilizado es de escasa profundidad (20 a $80 \mathrm{~cm}$.), al cual puede adaptarse un sistema de limpieza mecanizado. En la Figura 8 se puede apreciar un esquema de este sistema. La frecuencia con la que se retire el estiércol, puede ser desde diaria a bimensual. La mayor frecuencia con la que se realice el procedimiento de limpieza podría parecer en un principio, una práctica de máxima higiene, sin 


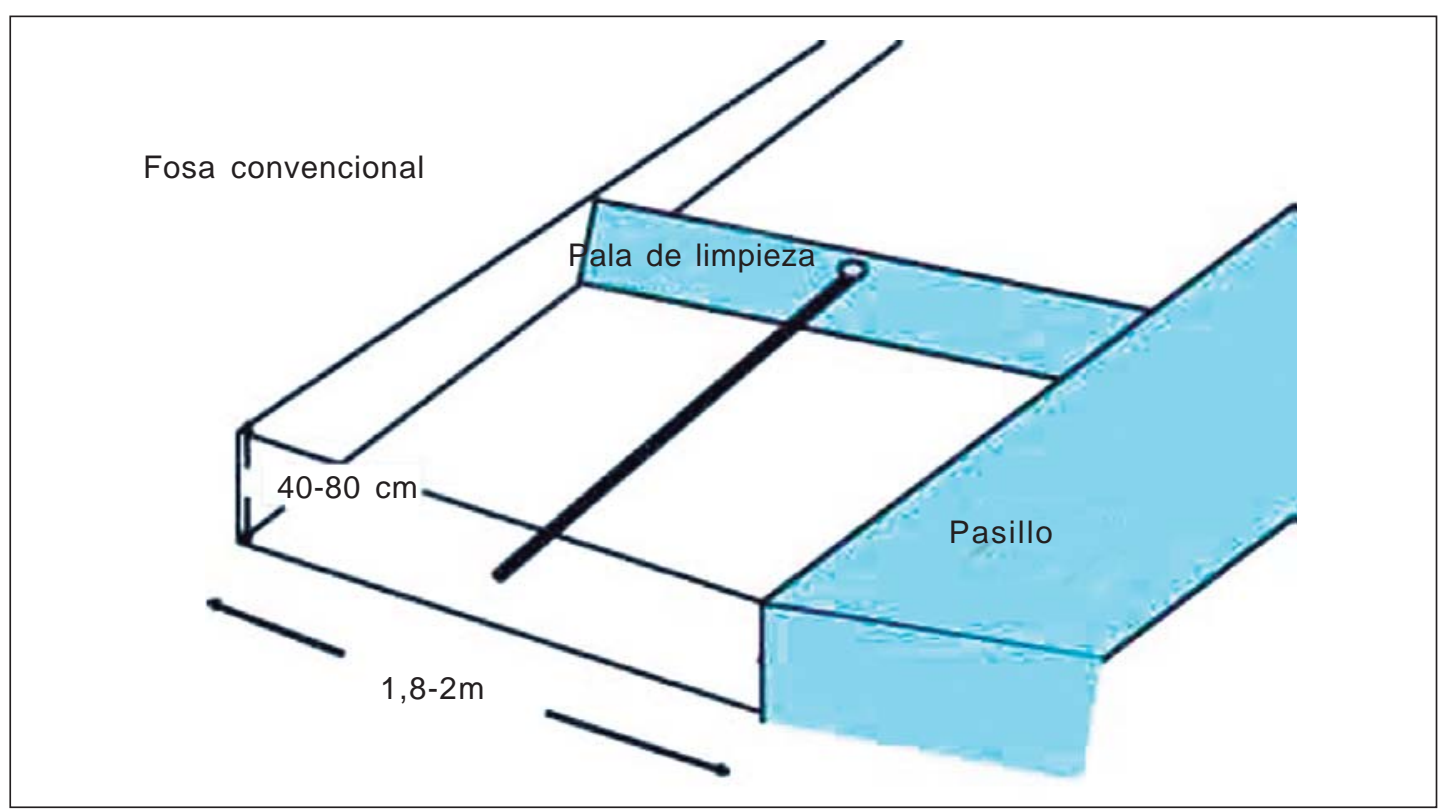

Figura 8. Esquema de una tosa convencıonal y pala para Ia Iımpıeza.

embargo debe tenerse en cuenta que este procedimiento posee varias desventajas. Así, al aumentar la frecuencia de limpieza, se incrementan algunas emisiones a la atmósfera (ej: amoníaco), el tiempo dedicado a dicha tarea, el gasto de energía y el desgaste de equipos. Cuando se permite la acumulación de deyecciones por varios días se reduce en gran medida la producción de algunos gases. En el caso del amoníaco, tiene efectos directos sobre los animales, pudiendo provocar en caso de altas concentraciones problemas sanitarios de tipo respiratorio.

Con la disminución de la frecuencia de limpiezas también se opera en forma menos frecuente los equipos, que en general son eléctricos y por tanto se reduce el gasto energético.

A modo de ejemplo si se compara una hora de limpieza cada tres días, con una limpieza de hora y media cada dos semanas, se reduce de 122 a 36 la cantidad de horas operativas de un equipo. Si se considera que un motor típico de los equipos de limpieza consume entre 1,5 y $2 \mathrm{KW}$ hora, anualmente variaría entre $122-183 \mathrm{KW} / \mathrm{h}$ a $54-72 \mathrm{Kw} . / \mathrm{h}$. lo que implica una reducción del $70 \%$. Las condicionantes que determina el plazo máximo de las retiradas de estiércol son la capa- cidad de la fosa y el tipo de pala. El drenaje de lixiviados se realiza a través de la parte central de la fosa, ya que esta cuenta con una disposición en « $\mathrm{V}$ » con pendiente negativa de 3 a $5 \%$ desde los laterales hacia el centro.

\section{Fosas con piso de grava}

Esta modalidad es una variante de la tradicional, con una modificación en el piso de la fosa, a la cual se le agrega un zócalo en ambos laterales que actuará de tope al descenso de la pala de limpieza. En la parte inferior de la fosa se coloca grava de bajo calibre $(0,5 \mathrm{a} 1 \mathrm{~cm})$ hasta enrasar con los zócalos. Esta capa actuará como drenaje permitiendo una mejor separación de la orina y las heces, lo cual producirá una acumulación de estiércol con menos humedad. La reducción en el contenido de agua de las heces acumuladas, disminuye las emisiones gaseosas y también la humedad ambiente, con el consecuente beneficio para el bienestar y sanidad de los animales. Otra ventaja adicional es la reducción del peso total de las deyecciones al ser retiradas. Al igual que en el caso anterior, en este sistema debe preverse el escurrimiento de los lixiviados para su conducción y almacenamiento. 


\section{Sistemas de extracción de estiércol}

En unidades productivas de pequeña escala, el sistema de retiro más común es el manual, pero con aumentos de la escala, se vuelve necesario un sistema de limpieza mecanizado. El más comúnmente utilizado es el de palas de tracción mecánica, accionadas por un motor eléctrico. Existen variaciones de modelos según el fabricante, pero la base del sistema es una pala metálica que es arrastrada por medio de un cable de acero, por un motor eléctrico dotado de poleas de desmultiplicación que reducen la velocidad de avance y aumentan la potencia. El diseño de las palas puede tener variantes en su forma y también en la posibilidad de ser fijas o portátiles. Las palas fijas permanecen siempre en la fosa en la que fueron colocadas y los cables no se desmontan al finalizar la tarea de limpieza.

Las palas portátiles tienen la posibilidad de ser utilizadas en diferentes fosas, para lo cual su diseño difiere en algo de las anteriores y los cables se desmontan para trasladar el equipo. El largo de la pala debe impedir que la misma gire en el interior de la fosa y su avance se vea impedido por atascamiento. El diseño permite que en el avance frontal arrastren las deyecciones y puedan retroceder sin arrastrar las mismas, condición necesaria para poder ser colocadas en diferentes fosas cuando estas tienen su capacidad colmada. Algunos modelos poseen una pala doble lo que permite arrastrar un eventual rebose de la primera pala.

La potencia de los motores oscila entre 2 y $3 \mathrm{CV}$, en modalidades de alimentación eléctrica monofásica y trifásica. También en este caso los hay fijos, sujetos al piso en la cabecera de la fosa, o portátil el cual está dotado de ruedas y posee un formato de carretilla o carro para poder trasladarlo de un sitio a otro. Este sistema requiere anclajes, que se ubicarán alineados al eje de la fosa, a los cuales se sujetará el aparato. Los equipos modernos poseen la posibilidad de programación para realizar la limpieza por tramos en forma automática, condición necesaria para la operación en fosas con gran acumulación que excederán la capacidad de la pala.
Más recientemente se han incorporado como alternativa, los tapices. Se trata de un sistema que consta de una banda de material plástico montado sobre rodillos, de forma que las deyecciones caen sobre éste y es retirado fuera de la nave por rotación de los rodillos que lo propulsan. El tapiz puede ser perforado para que la orina drene, reduciendo las emisiones y el peso acumulado sobre el mismo.

\section{Almacenamiento}

Una vez retirado de las naves, el estiércol debe ser correctamente gestionado. Las explotaciones deberían disponer de estercolero impermeabilizado, para evitar el riesgo de filtración hacia aguas superficiales o subterráneas. Debe recoger todos los lixiviados de la granja y estar cubierto para evitar arrastres pluviales. Debe tener además capacidad suficiente para almacenar y gestionar adecuadamente.

El almacenamiento es absolutamente necesario porque las deyecciones se producen continuamente y las salidas suelen ser muy temporales, mayoritariamente según las necesidades de los usuarios, normalmente horticultores o fruticultores.

En sistemas con drenaje de orina se debe tener una fosa de recogida profunda en la cual se puede acumular por seis meses (Luzi 2000). Según estos autores la deshidratación y la sedimentación provocan la formación de una costra y el aumento del porcentaje de materia seca, hasta el extremo de no poderse bombear. Hoy existen en el mercado productos que combinan sustancias químicas, bacterias y enzimas que fluidifican estos efluentes.

\section{Tratamientos de las deyecciones de conejos}

No es usual someter a las deyecciones de conejos a tratamiento de algún tipo de reducción de su carga contaminante o de obtención de energía (biogás) como ocurre con otros estiércoles y residuos ganaderos. En efecto, éstos pueden ser utilizadas directamente como enmienda orgánica para suelos agrícolas, tal como se analizará pos- 
teriormente, y generalmente no necesitan más que un cierto periodo de maduración. No obstante, el elevado contenido de agua del estiércol (48-66 \%) puede ser un factor limitante para la manipulación. Luzi et al (2000) señalan que puede aplicarse un tratamiento térmico $\left(130^{\circ} \mathrm{C}\right)$ llevando de $40 \%$ a $90 \%$ el contenido de materia seca con un costo relativamente bajo, $0,1 \mathrm{I}$ de gasoil y $0,03 \mathrm{~kW} / \mathrm{h}$ por $\mathrm{kg}$ de deyecciones. Pero quizás el tratamiento más interesante al que se puede someter es el compostaje para mejorar su capacidad fertilizante. El compostaje es un tratamiento mediante el cual se facilita la degradación microbiológica aeróbica del estiércol. En un lapso de aproximadamente un mes, dependiendo de la temperatura ambiente, el volumen total se reduce por evaporación de agua y la pérdida de $\mathrm{CO}_{2}$ resultado de la utilización del carbono por los microorganismos. El proceso además produce calor, el cual elimina muchos parásitos y eventuales microorganismos patógenos. Luzi et al. (2000) señalan distintos factores y condiciones que afectan la eficacia del proceso:

a) $\mathrm{pH}$ de la mezcla a tratar. Debe estar comprendido entre 6,5 y 8 .

b) Cantidad de materia seca: el óptimo es 35 y el mínimo $30 \%$. El compost (producto final) tiene $25 \%$ de humedad.

c) Porcentaje de materia orgánica: tiene que estar comprendido entre el 50 y $70 \%$.

d) Porosidad de la biomasa: favorece la presencia de oxígeno. El compostaje es lo contrario de la putrefacción anaerobia.

e) Relación adecuada de C/N (carbono/ nitrógeno). Debe ser 25-30. Con valores inferiores hay que añadir paja, viruta o materiales similares.

f) La temperatura se regula en algunos casos inyectando aire en la biomasa.

Tanto la elevación de la temperatura como la aireación pueden ser controladas a través de la remoción del material en forma periódica. El estiércol colocado en pilas es removido diariamente con palas de tractor, rastrillos o aparatos diseñados a esos efectos,
Ios cuales oxigenan aumentando temporalmente la porosidad de la mezcla. El vermicompostaje es una alternativa del proceso en la cual la degradación aerobia es facilitada por la presencia de lombrices. La producción de lombrices es una práctica bastante extendida mediante la cual sobre estiércol de ciertas características se crían lombrices, en general lombriz roja californiana (Eisenia foétida). Estos anélidos procesan el estiércol pasándolo por sus aparatos digestivos donde es atacado por enzimas y microorganismos.

En términos generales esto acelera el proceso, modifica en algo la composición y mejora las características físicas; como producto secundario se obtiene las lombrices que pueden ser utilizadas con varios fines: alimentación animal, carnada para pesca o como pie de cría para otros lombricarios.

\section{Ejemplo de cálculo de la capacidad del estercolero}

Si se considera el dato de producción de deyecciones por plaza y por año de 0,412 m3/plaza/año, propuesto por Flotats (2004), y teniendo en cuenta que la relación de plazas de madres y engorde es bastante estable en sistemas comerciales de producción, se puede calcular fácilmente el volumen total de estiércol que se producirá en una determinada granja cunícola. Así, a modo de ejemplo una unidad productiva de 100 conejas madres tendrá como término medio un total de 300 plazas totales (plz). En consecuencia, la producción anual resultante será: $V\left(\mathrm{~m}^{3} / \mathrm{año}\right)=300 \mathrm{plz} \times 0,412 \mathrm{~m}^{3} / \mathrm{plz} / \mathrm{año}=123,6$ $m^{3} / a \tilde{n}$.

Considerando que se debería asegurar que la capacidad de almacenamiento del estercolero contenga como mínimo la producción de deyecciones de la granja para un periodo de tres meses, el volumen del mismo para este ejemplo debería ser de al menos $370 \mathrm{~m}^{3}$. Por otro lado, teniendo en cuenta que la densidad promedio es de $0,75 \mathrm{Tm} / \mathrm{m}^{3}$ (Flotats, 2004), por lo que hay que prever un transporte para unas 277,5 toneladas de peso. 
En el caso de los sistemas con fosa con piso de grava deberá preverse que el escurrimiento de líquidos debe ser canalizado a un contenedor capaz de retenerlo al menos por un período similar. En este caso, considerando una producción de $80 \mathrm{~L}$. diarios para una unidad de 100 madres (Roca, 1980), en el ejemplo anterior, se producirían 7200 L por trimestre. Las pérdidas de agua en los sistemas de bebederos son dependientes del sistema de los mismos (los chupetes permiten más pérdidas que las cazoletas) pero en ambos se producen pérdidas que en muchos casos pueden superar el volumen de la orina. La separación de los efluentes líquidos no alterará prácticamente el volumen de estiércol pero reducirá su peso de manera sensible.

\section{BIBLIOGRAFÍA}

ALVARIÑO, M. 1993. Control de la reproducción en el conejo. Madrid: Mundi prensa, $137 p$.

BLUMETTO, O.; TORRES, A. 2005. Instalaciones para la gestión de estiércol en Granjas Cunícolas industriales (Segunda Parte). Boletin de Cunicultura, 140: 6-16.

BLUMETTO, O.; OLIVAS, L.; TORRES, A.; VILLAGRÁ, A. 2010. Use of straw and wood shavings as nest material in primiparous does. World Rabbit Science, 18 (4): 237-242.

CAMPS, J. 2000. Comparación científica entre suelos de varilla, o los mismos con «relax®», para el control del «mal de patas». Lagomorpha, 112: 36-38.
CAMPS, J. 2002. Propuestas de máximos y mínimos en jaulas. Disponible en: ddd.uab.cat/pub/jcamps/jcampsapu/ jcampsapu_131.pdf

CAPRA, G.; BLUMETTO, O. 2002. Producción de conejos para carne: situación y perspectivas. En: Jornada de Divulgación en Cunicultura. INIA. Serie Actividades de Difusión No. 298.

FLOTATS, X. 2004. Guia dels trataments de les dejeccions ramaderes. Area de Enginyeria Ambiental. Catalunya: Centro UdL-IRTA.

LEBAS, F.; COUDERT, P.; de ROCHANBEAU, H.; THÉBAULT, R.G. 1996. El Conejo: Cría y patología. FAO-Roma. 227 p.

LÓPEZ, M. 2006. El Bienestar de la especie cunícola. Boletin de Cunicultura, 148: 616.

LUZI, F.; MORENO, R.; ROSELL, J.M. 2000. Bienestar y medio ambiente. En: Enfermedades del conejo: tomo1, Generalidades. Barcelona: MundiPrensa, 605 p.

ROCA, T. 1980. Sistemas de limpieza y manejo de excrementos. En: Curso de Cunicultura. $5^{\mathrm{a}}$ parte: Manejo. Real Escuela Oficial y Superior de Avicultura. Arenys de Mar (Barcelona).

ROSSEL, J.M. 2000. Enfermedades del conejo. Tomo 1: Generalidades. Barcelona: MundiPrensa, 605 p.

TORRES, E. 2003. La gestión de las deyecciones en la explotación cunícola. Boletín de Cunicultura, 125: 6-19.

XICATTO, G.; TROCINO, A. 2005. XXX Symposium de Cunicultura: Bienestar Animal. pp 45-62 Asescu- Valladolid 1920 de mayo de 2005. 
Impreso en Editorial Hemisferio Sur S.R.L.

Buenos Aires 335

Montevideo - Uruguay

Depósito Legal 363-465/14 